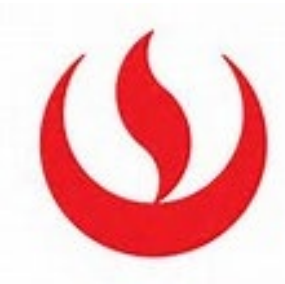

UNIVERSIDAD PERUANA DE CIENCIAS APLICADAS

FACULTAD DE INGENIERÍA

CARRERA DE INGENIERÍA CIVIL

\title{
INTEGRACIÓN SISTÉMICA Y EVALUACIÓN DE HERRAMIENTAS DE LA FILOSOFÍA LEAN CONSTRUCTION: LAST PLANNER SYSTEM Y PULL PLANNING EN LA PLANIFICACIÓN Y CONTROL DE UN TÚNEL DE TRINCHERA CUBIERTA EN EL PERÚ
}

Tesis

para optar el Título Profesional de Ingeniero Civil

AUTOR(ES)

Bach. Gian Pier Guzmán Arana (0000-0002-0188-8203)

Bach. Jean Paul Vela Cieza (0000-0002-8043-4372)

ASESOR:

Ing. Julio Farje Mallqui (0000-0003-3998-8696) 
Laureate International Universities ${ }^{\circledR}$

\section{DEDICATORIA}


Dedicamos esta tesis a todas las personas interesadas y creyentes de la Filosofía Lean Construction para seguir contribuyendo en nuestro desarrollo y constante mejora continua. 


\section{AGRADECIMIENTO}


Primero queremos agradecer a Dios por todas las oportunidades que nos dio en nuestras vidas para poder contribuir en bien de nuestra sociedad. A nuestros padres por su apoyo incondicional en nuestro crecimiento personal y profesional. A nuestra Universidad y a todas aquellas personas que contribuyeron al desarrollo de esta tesis y de manera especial a nuestros jefes y colegas del trabajo con quienes aprendimos mucho. 


\section{RESUMEN}

El objetivo de la siguiente tesis es crear una visión integral de las metodologías de planeamiento y control que forman parte de la filosofía "Lean Construction" para validarlas como buenas prácticas en construcción de obras de ingeniería. Para ello, se eligió el proyecto encargado de la construcción de un Túnel de trinchera cubierta en el Perú y se evaluó la forma de trabajo de las áreas de planeamiento y producción en el contexto de la implementación de las metodologías. Esto define dos momentos diferentes en el proyecto; inicialmente, cuando se trabajaba de manera tradicional y luego con las metodologías ya implementadas. Durante todo este largo proceso se lograron mejoras en el desempeño de la ejecución del túnel. Para constatar ello, se evaluaron las ventajas y limitaciones de los diferentes enfoques. Asimismo, el análisis de la información recopilada permitió mostrar de manera efectiva las mejoras a partir de la evaluación del grado de adherencia o cumplimiento y el análisis de los desvíos entre lo planeado y realizado. Finalmente, como propuesta y aplicación de mejora, la tesis presenta la forma ideal de implantar este sistema de gestión del tiempo en cualquier proyecto de construcción y la propuesta se expone mediante diagramas de flujos y diagramas funcionales de las etapas y procesos del sistema.

Palabras Clave: Planeamiento, Lean Construction, Túnel de Trinchera Cubierta 


\section{ABSTRACT}

The aim of the thesis is to create a holistic view of planning and control methodologies that are part of the philosophy of "Lean Construction" to validate them as best practices in construction engineering. To this end, we chose the project manager of the construction of a tunnel covered trench in Peru and it was evaluated the way of work of the areas of planning and production in the context of the implementation of the methodologies. This defines two different moments in the project; initially, when working in a traditional way and then with the already implemented methodologies. Throughout this long process improvement were achieved in the implementation performance of the tunnel. To verify this, the advantages and limitations of different approaches were evaluated. Also, analysis of the collected information effectively allowed to show improvements from the evaluation of the degree of adherence or compliance and analysis of deviations between planned and realized. Finally, as a proposal and application of enhancing the thesis presents the ideal way to implement this system of time management in any construction project and the proposal set forth by functional flowcharts and diagrams of the stages and processes of the system.

Key Words: Planning, Lean Construction, Tunnel cut and cover 


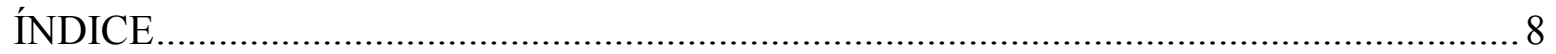





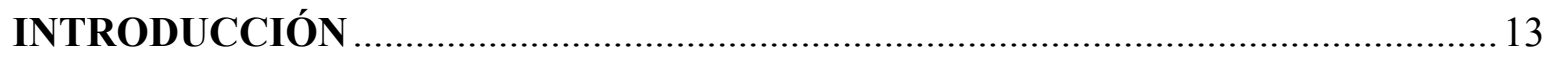







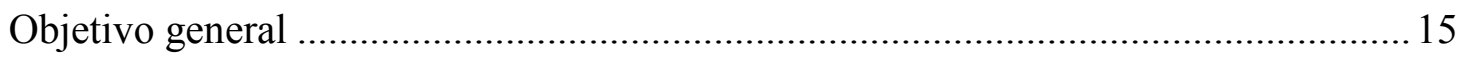

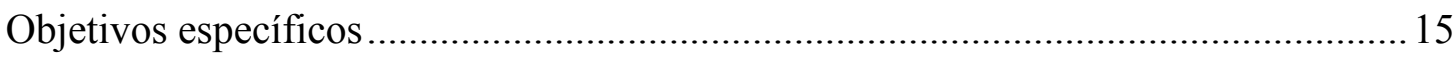

CAPÍTULO II: METODOLOGÍA DE INVESTIGACIÓN ............................................. 17

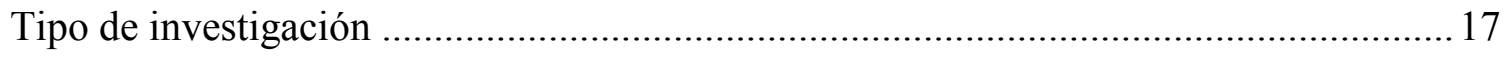

Planteamiento, formulación del problema e hipótesis..................................................... 17

Planteamiento del problema ...................................................................................... 17

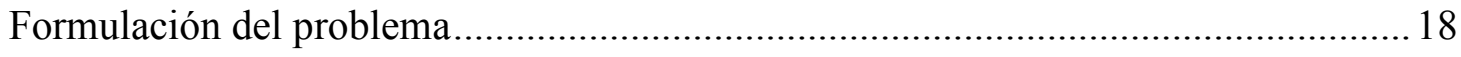

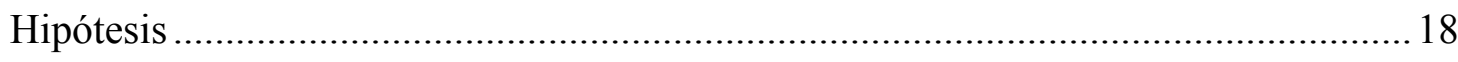

Diseño de la investigación....................................................................................... 18



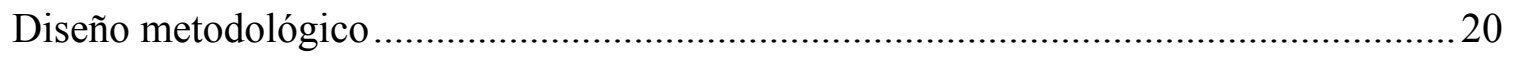

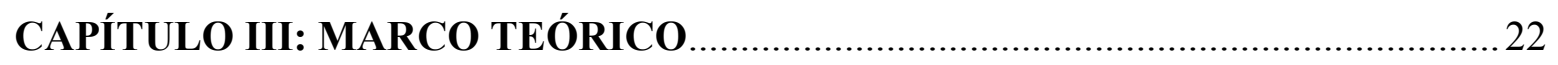



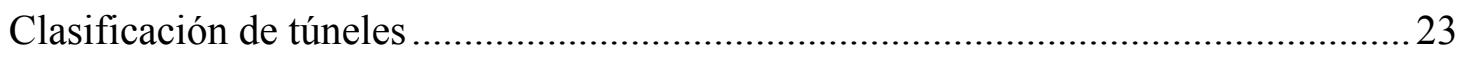

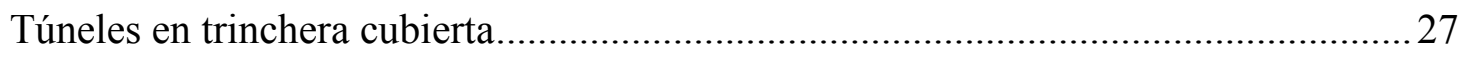

Metodología constructiva en túneles de trinchera cubierta ............................................ 31

Lean Construction en el planeamiento y control estratégico de la construcción................32

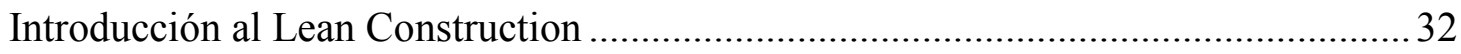

Diferencias de planificación entre el modelo tradicional y el enfoque lean................... 34




Herramientas Lean

Comparación de la filosofía Lean Construction en edificaciones y en túneles de trinchera cubierta 46

\section{CAPÍTULO IV: LEVANTAMIENTO Y ANÁLISIS DE LA INFORMACIÓN} 48

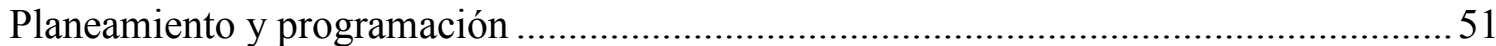

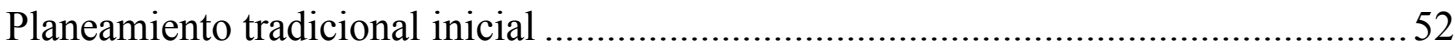

Planeamiento con enfoque Lean Construction ........................................................59

Comparación del planeamiento tradicional inicial y el planeamiento con enfoque Lean

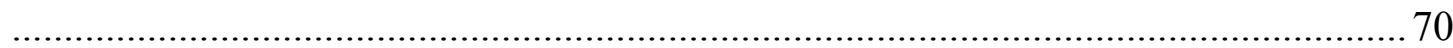

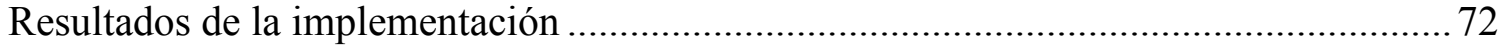

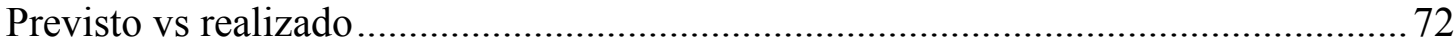

Porcentaje del plan cumplido - PPC …............................................................ 74

Análisis de la evolución del porcentaje plan cumplido (PPC) ….............................. 76



CAPÍTULO V: PROPUESTA DE LA MEJORA ................................................ 81

Implementación de las herramientas del sistema de planificación................................ 81

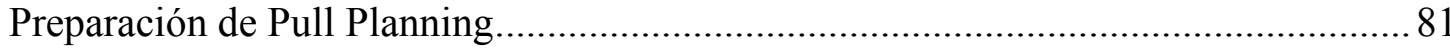

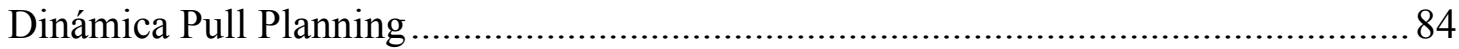

Modelo sistemático de planeamiento, programación y control .................................. 87

Manual de planeamiento y programación en Primavera P6 ........................................ 90

Medición de la adherencia de la programación al planeamiento ................................... 90

CAPÍTULO VI: APLICACIÓN DE LA MEJORA .............................................. 91

Generación de agendas y roles de los ingenieros de planeamiento y producción............91

Análisis de rentabilidad de la implementación del sistema........................................92

Nivel de satisfacción del sistema de planeamiento: integración de Last Planner System y

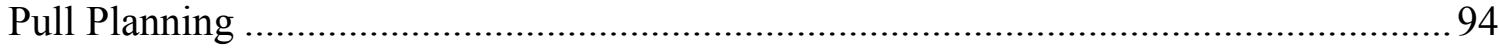

Indicador de adherencia de la programación al planeamiento .....................................95

CONCLUSIONES Y RECOMENDACIONES .................................................... 97 


\section{LISTA DE FIGURAS}

Gráfico Nro. 1: “Diseño de serie de tiempo cuasi experimental con múltiples grupos”...... 19

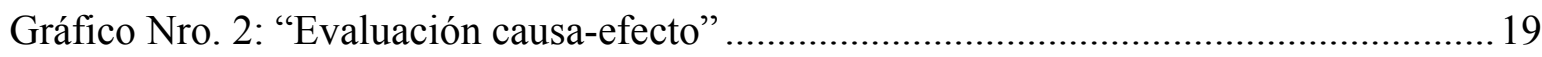

Figura Nro. 1: "Evolución de la construcción de túneles" .............................................. 22

Gráfico Nro. 3: "Clasificación de túneles”. .................................................................... 23

Figura Nro. 2: "Túnel proyecto integral Olmos" ............................................................ 24

Figura Nro. 3: "Proyecto Interconexión Vial Rímac - San Juan de Lurigancho”................ 24

Figura Nro. 4: "Túnel Baluarte - Autopista Durango-Mazatlán” .................................... 25



Figura Nro. 6: "Túnel urbano subacuático de Tokio" ..................................................... 27

Figura Nro. 7: "Túnel de la Costanera Norte - Autopista Central (Chile)" .......................28

Figura Nro. 8: "Tramo 1 - Estaciones Plaza de Toros y Las Feria" ...................................2 29

Figura Nro. 9: "Vía Parque Rímac" ........................................................................... 29

Figura Nro. 10: "Túnel en el tramo IIIB de la Av. Néstor Gambetta” .............................. 30

Gráfico Nro. 4: "Filosofía Lean Construction" ................................................................... 32

Gráfico Nro. 6: "PDCA Last Planner System” ............................................................ 44

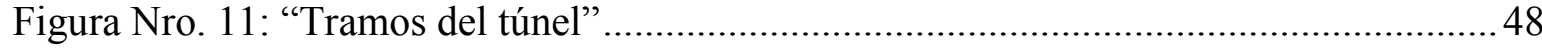

Figura Nro. 12: "Entrada del túnel en trinchera cubierta"................................................ 49

Figura Nro. 13: "Sección transversal del túnel” ........................................................ 49

Figura Nro. 14: "Dimensiones de elementos estructurales en sección típica" ....................50

Gráfico Nro. 7: "Metodologías de planeamiento aplicadas en la ejecución del túnel”........50

Figura Nro. 15: "Plan de ataque general del túnel" ...................................................... 51

Figura Nro. 16: "Plan de ataque del túnel - unidades constructivas de 30m” ...................52

Figura Nro. 17: "Secuencia constructiva de elementos de concreto del túnel”..................54

Figura Nro. 18: "Secuencia de ejecución de losas de fondo 1" .........................................55

Figura Nro. 19: "Secuencia de ejecución de arranques de muros 1” ............................... 55

Figura Nro. 20: "Secuencia de ejecución de paredes centrales 1" ...................................56

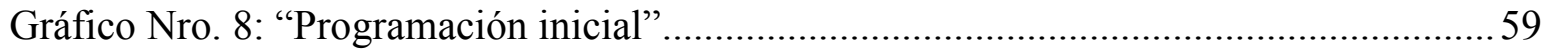




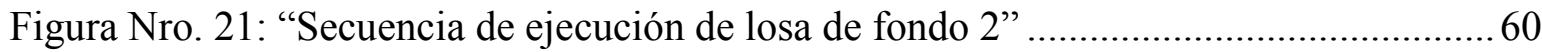

Figura Nro. 22: "Secuencia de ejecución de arranques 2.1" ............................................. 60

Figura Nro. 23: "Secuencia de ejecución de arranques 2.2" ......................................... 60

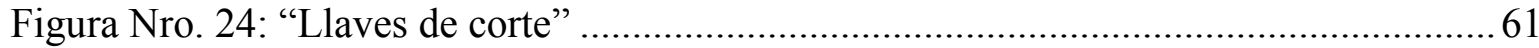

Figura Nro. 25: "Secuencia de ejecución de paredes centrales 2.1" .................................61 61

Figura Nro. 26: "Secuencia de ejecución de paredes centrales 2.2" ................................6 62

Figura Nro. 27: "Secuencia de ejecución de paredes centrales 2.3” ................................6 62

Figura Nro. 28: "Secuencia de ejecución de paredes centrales 2.4" ...............................63 63

Figura Nro. 29: "Secuencia de ejecución de paredes centrales 2.5" .................................63

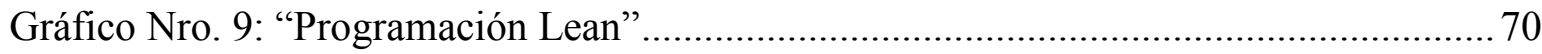

Gráfico Nro. 10: "Previsto vs realizado - losa inferior (frente norte)" ............................. 72

Gráfico Nro. 11: "Previsto vs realizado - losa inferior (frente sur)" ............................... 72

Gráfico Nro. 12: "Previsto vs realizado - muros (frente norte)" ..................................... 73

Gráfico Nro. 13: "Previsto vs realizado - muros (frente sur)" ......................................... 73

Gráfico Nro. 14: "PPC semanal - frente norte" ........................................................... 75

Gráfico Nro. 15: "PPC semanal - frente sur”.......................................................... 75

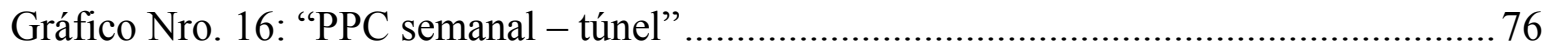

Gráfico Nro. 17: “Análisis de la evolución del PPC semanal - frente norte”.................... 77

Gráfico Nro. 18: “Análisis de la evolución del PPC semanal - frente sur” ....................... 78

Gráfico Nro. 19: “Análisis de la evolución del PPC semanal - túnel” ............................. 79

Gráfico Nro. 20: “Avance físico de ejecución del túnel” .................................................. 80

Gráfico Nro. 21: “Diagrama de flujo de preparación de Pull Planning”........................... 83

Gráfico Nro. 22: "Diagrama de flujo de dinámica Pull Planning”. ................................... 86

Gráfico Nro. 23: "Diagrama sistemático de planeamiento, programación y control” .........88

Gráfico Nro. 24: "Resultados de encuesta de satisfacción Pull Planning”......................... 94

Gráfico Nro. 25: "Indicador de adherencia de la programación al planeamiento" ............. 96 


\section{LISTA DE TABLAS}

Tabla Nro. 1: "Diseño de serie de tiempo con múltiples grupos aplicados al proyecto" .....20

Tabla Nro. 2: "Leyenda de diseño de serie de tiempo con múltiples grupos aplicados al

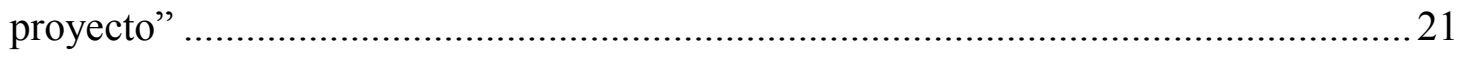

Tabla Nro. 3: "La producción convencional y la producción sin pérdidas"......................... 36

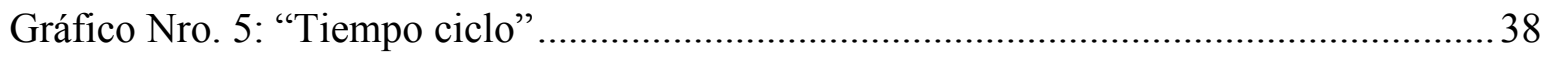

Tabla Nro. 4: “Comparación de la aplicación de la filosofía Lean Construction en

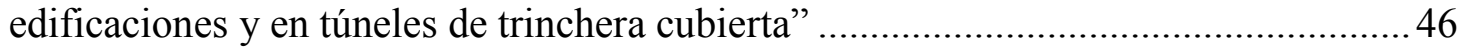

Tabla Nro. 5: "Ventajas y desventajas de la programación mensual"...............................57

Tabla Nro. 6: "Ventajas y desventajas de la programación trimestral".............................66

Tabla Nro. 7: "Ventajas y desventajas de la programación semanal" ................................ 68

Tabla Nro. 8: "Planeamiento tradicional inicial y planeamiento con enfoque Lean" .......... 70

Tabla Nro. 9: "Roles de los involucrados" ................................................................ 91

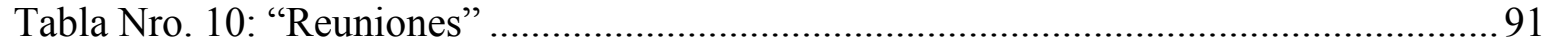

Tabla Nro. 11: “Agenda y roles del área de planeamiento y producción” ......................... 92

Tabla Nro. 12: "Dimensionamiento del personal FTE - área de planeamiento y control



Tabla Nro. 13: "Dimensionamiento del personal FTE - área de planeamiento y control






\section{INTRODUCCIÓN}

En la actualidad, se han desarrollado varias herramientas de gestión para la construcción de proyectos de infraestructura. Sin embargo, pocas organizaciones implementan o intentan implementar dichas herramientas por el grado de incertidumbre que representa realizar cambios en su metodología de trabajo habitual. Se cree que nuevas filosofías requieren gran esfuerzo y tiempo para lograr buenos resultados y generar beneficios para una organización. En el Perú, la filosofía Lean Construction se llega a conocer y difundir a partir del año 2002 y en los últimos años logra tener mayor acogida por el sector de la construcción, en la medida que diversas empresas reconocidas empiezan a implementarla y utilizarla en su sistema de trabajo. Sin embargo, existe poca información del proceso de implementación, aprendizaje y de los resultados obtenidos de la aplicación de estas herramientas.

En este contexto, con el desarrollo de esta tesis se logrará evaluar las herramientas de la filosofía Lean Construction: Last Planner System y el Pull Planning System en el marco de su implementación, aplicación y proceso de mejora durante la etapa de ejecución de un proyecto de infraestructura de tipo túnel trinchera cubierta en el Perú. Todo ello con la finalidad de dar a conocer y validar las ventajas de su aplicación en proyectos de construcción.

El capítulo uno, "Generalidades", presenta el fundamento e importancia de este estudio, asimismo, el objetivo general y los objetivos específicos. El capítulo dos, "Metodología de investigación", inicia con la descripción del tipo y naturaleza de la investigación, luego presenta el planteamiento y la formulación del problema, seguido del desarrollo de las hipótesis. La tercera parte de este capítulo presenta el diseño de la investigación donde se hace la identificación de las variables y finalmente, el diseño metodológico.

El capítulo tres, "Marco teórico", está dividido en dos partes, la primera comprende el marco conceptual de definición de túneles. Su desarrollo inicia con la clasificación, luego se enfatiza en el tipo de túneles en trinchera cubierta para finalmente dar a conocer su metodología constructiva. La segunda parte muestra el marco conceptual de la filosofía Lean Construction y sus herramientas: Last Planner System y Pull Planning. 
El capítulo cuatro, "Levantamiento y análisis de la información", está compuesto por dos partes, la primera describe la planificación y la programación de la ejecución del túnel en estudio en dos momentos diferentes, definidos básicamente por la aplicación de la filosofía Lean Construction. La segunda parte muestra los resultados de la implementación y aplicación de las herramientas Lean. Primero con el contraste de adherencia entre lo previsto y realizado, luego mediante el análisis de la mejora del desempeño con la aplicación del PPC (porcentaje de plan cumplido), antes y durante la aplicación de la metodología Lean y finalmente su repercusión en el avance físico del proyecto.

El capítulo cinco y seis muestra la "Propuesta y aplicación de la mejora". Se parte de la concepción e integración sistemática de todos los procesos y roles de los actores involucrados en el planeamiento para esquematizar un diagrama funcional que permita aplicar la metodología de Last Planner System y Pull Planning en cualquier proyecto de ingeniería civil. 


\section{CAPÍTULO I: GENERALIDADES}

\section{Fundamentación e importancia}

Actualmente, la ejecución de proyectos de ingeniería se rige sobre sobre cuatro pilares importantes: el alcance, el costo, el tiempo y la calidad. Su buena gestión y equilibrio puede garantizar el éxito y la rentabilidad de los proyectos. En este sentido, se entiende que las actividades encargadas de la gestión y administración del tiempo en un proyecto son el planeamiento y la programación, pues representan un rol muy importante para el desarrollo de toda la obra, siendo responsables de crear y dar ritmo al avance físico para cumplir con los plazos establecidos.

He aquí la importancia de identificar, implementar y seguir innovando en buenas prácticas para la planificación estratégica de proyectos de ingeniería que permitan optimizar procesos en la construcción y gestión con la finalidad de cumplir el alcance en el plazo establecido, con el costo óptimo y satisfaciendo la calidad del cliente.

\section{Objetivos}

\section{Objetivo general}

- Integrar y validar un modelo sistémico de planeamiento y control de proyectos aplicable a la construcción de túneles de trinchera cubierta, basado en dos herramientas de la filosofía Lean Construction: Last Planner System y Pull Planning.

\section{Objetivos específicos}

- Describir los principios de la filosofia Lean Construction en el planeamiento de proyectos de construcción.

- Describir las fases y procesos de la herramienta Last Planner System: Master Plan, Pull Planning, Six Week Look Ahead, Programación Semanal; en base al ciclo PDCA. 
- Comparar metodologías de planeamiento y control de la producción aplicadas durante la construcción de un túnel de trinchera cubierta: planeamiento tradicional inicial y planeamiento con enfoque Lean.

- Evaluar y consolidar resultados de la implementación de las herramientas del Lean Construction a través de indicadores.

- Integrar y validar un modelo sistémico de planificación y control aplicable a la construcción de túneles de trinchera cubierta basado en las herramientas Lean: Last Planner y Pull Planning. 


\section{CAPÍTULO II: METODOLOGÍA DE}

\section{INVESTIGACIÓN}

\section{Tipo de investigación}

Esta investigación es de carácter descriptivo dado que analiza características y propiedades de herramientas de gestión de planificación para la ejecución de un proyecto de infraestructura a través de la selección de variables susceptibles a medir o conjeturar. De esta manera adopta la forma de un estudio descriptivo de campo y descriptivo de tendencia.

En cuanto al estudio descriptivo de campo, la investigación desarrolla el marco conceptual de los túneles y su clasificación. Asimismo, profundiza en los túneles urbanos de tipo trinchera cubierta y cita ejemplos principales de este tipo en el Perú y en el mundo. Luego describe las principales metodologías constructivas para finalmente establecer el vínculo con herramientas de planeamiento y control estratégico para su ejecución.

La etapa de estudio descriptivo de tendencia se basa en comprobar los cambios generados en el proyecto a través del tiempo, es decir, que a partir de la implementación de las herramientas ya mencionadas se comprueban los efectos en el desempeño de la ejecución del túnel. Para lograr ello, se realiza un estudio retrospectivo en la búsqueda y análisis de información de la etapa preliminar y se compara con la información adquirida post implementación.

\section{Planteamiento, formulación del problema e hipótesis}

\section{Planteamiento del problema}

Existen diversas metodologías de planeamiento para la construcción de proyectos de ingeniería civil tales como Last Planner System, Pull Planning System y Look Ahead Planning que son aplicadas en la búsqueda del cumplimiento de plazos de entrega. Sin embargo, el problema surge cuando el enfoque se limita solo a la utilización de herramientas dejando de lado la concepción sistémica e integrada de todos los procesos que la componen. Las consecuencias de ello en la mayoría de los casos van desde la desacreditación de las 
metodologías, incumplimiento de plazos contractuales, baja productividad, sobrecostos, re trabajos, hasta pérdida de credibilidad en los responsables por la ejecución del proyecto y generación de barreras para postular a futuras contrataciones.

\section{Formulación del problema}

¿Cómo la ausencia de integración sistémica de las herramientas de Lean Construction: Last Planner System y Pull Planning influyen en la adherencia a la planificación y en el control adecuado para la ejecución de un túnel de trinchera cubierta en el Perú?

\section{Hipótesis}

Si no existe una integración sistémica de las herramientas Lean: Last Planner y Pull Planning en el planeamiento y control de obras civiles que envuelva a todas las áreas de apoyo (Ingeniería, Planeamiento, Costos, Producción, Seguridad, Calidad, Salud Ocupacional, Medio Ambiente y Administración) entonces los resultados de avance físico no atenderán a la demanda del plan inicial de obra ni a las expectativas del cliente.

En esta hipótesis se identifican tres variables relacionadas:

- Integración sistémica de herramientas Lean

- Áreas de apoyo involucradas

- Avance físico del proyecto

A través de la relación de estas tres variables se puede predecir cuál sería el resultado si no se le da la debida importancia a la integración sistémica de las herramientas Lean. Más aún si no se logra difundirla a todos los sectores y niveles de la organización.

\section{Diseño de la investigación}

La siguiente investigación se basa en un diseño cuasi experimental de serie cronológica con múltiples grupos, dado que se manipula una variable independiente para medir su efecto relacionado con una o más variables dependientes en el mediano o largo plazo. En ese sentido, se seleccionan grupos equiparables y se les aplica mediciones periódicas para constatar su evolución. El diseño se puede esquematizar de la siguiente manera: 
Gráfico Nro. 1: "Diseño de serie de tiempo cuasi experimental con múltiples grupos”

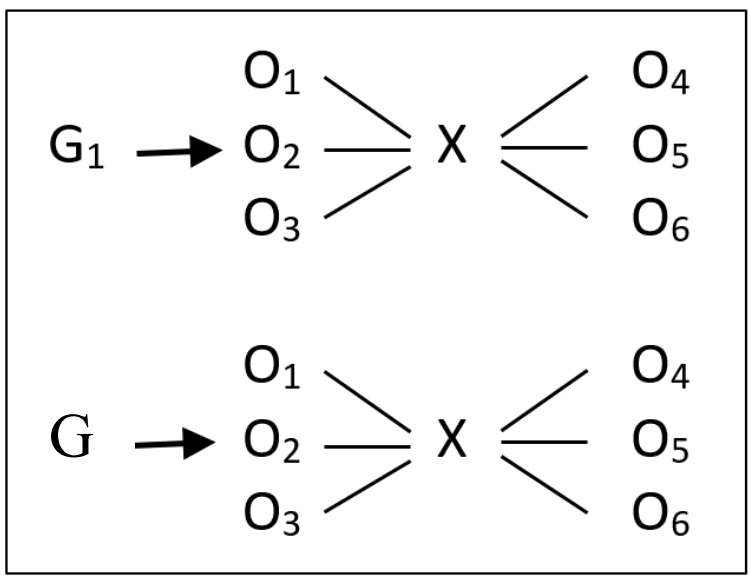

Fuente: Metodología de la Investigación - Pino 2007

Donde:

- $\mathrm{O}_{1}, \mathrm{O}_{2}, \mathrm{O}_{3}$ : Son prepruebas

- $\mathrm{O}_{4}, \mathrm{O}_{5}, \mathrm{O}_{6}$ : Son post pruebas

- $\mathrm{G}_{1}, \mathrm{G}_{2}$ : Son los grupos analizados

- X: Tratamiento experimental

\section{Identificación de variables}

Se entiende por variable todo aquello que pueda causar cambios susceptibles a medirse, observarse $\mathrm{y} / \mathrm{o}$ evaluarse. Se distingue entre variable independiente, dependiente y controlada. La esencia de esta investigación es la manipulación de una variable independiente para determinar sus efectos sobre una variable dependiente. A continuación, en la gráfica nro. 2 se muestra una explicación gráfica del proceso. 1

Gráfico Nro. 2: "Evaluación causa-efecto"

1 Cfr. Pino 2007: 129 
MANIPULACIÓN DE LA VARIABLE

INDEPENDIENTE

$\mathrm{X}_{1}$

$\mathrm{X}_{2}$
MEDICIÓN DEL EFECTO SOBRE LA

VARIABLE DEPENDIENTE

Y

Fuente: Metodología de la investigación - Pino 2007

Los resultados del proceso serán registrados, comparados y podrán describirse mediante tablas y gráficos, con la finalidad de hacer análisis que muestren y confirmen la hipótesis emitida.

\section{Variable dependiente}

Es la variable que actúa como efecto de una causa que ejerce coerción y se denotará con la letra Y.

- Y1: PPC

- Y2: Avance Físico

\section{Variable independiente}

Es la variable causante del efecto que se da en la variable dependiente y se denotará con la letra X.

- X1: Aplicación integrada de herramientas de la filosofía Lean Construction: Last Planner System y Pull Planning

\section{Diseño metodológico}

Una vez definido el diseño de la investigación e identificado las variables se puede esquematizar el diseño experimental de la siguiente manera:

Tabla Nro. 1: "Diseño de serie de tiempo con múltiples grupos aplicados al proyecto" 


\begin{tabular}{|c|c|c|c|c|}
\hline & & 01 & 02 & On \\
\hline \multirow{6}{*}{ G1 } & \multirow{2}{*}{ SG11 } & Y1-11-1 & Y1-11-2 & Y1-11-n \\
\hline & & Y2-11-1 & Y2-11-2 & Y2-11-n \\
\hline & \multirow{2}{*}{ SG12 } & Y1-12-1 & Y1-12-2 & Y1-12-n \\
\hline & & Y2-12-1 & Y2-12-2 & Y2-12-n \\
\hline & \multirow{2}{*}{ SG13 } & Y1-13-1 & Y1-13-2 & Y1-13-n \\
\hline & & Y2-13-1 & Y2-13-2 & Y2-13-n \\
\hline \multirow{6}{*}{ G2 } & \multirow{2}{*}{ SG21 } & Y1-21-1 & Y1-21-2 & Y1-21-n \\
\hline & & Y2-21-1 & Y2-21-2 & Y2-21-n \\
\hline & \multirow{2}{*}{ SG22 } & Y1-22-1 & Y1-22-2 & Y1-22-n \\
\hline & & Y2-22-1 & Y2-22-2 & Y2-22-n \\
\hline & \multirow{2}{*}{ SG23 } & Y1-23-1 & Y1-23-2 & Y1-23-n \\
\hline & & Y2-23-1 & Y2-23-2 & Y2-23-n \\
\hline
\end{tabular}

Fuente: Elaboración propia

Donde las variables están definidas de acuerdo con la leyenda que se muestra en la siguiente tabla:

Tabla Nro. 2: "Leyenda de diseño de serie de tiempo con múltiples grupos aplicados al proyecto"

\begin{tabular}{|c|c|c|}
\hline \multirow{4}{*}{ G } & \multicolumn{2}{|c|}{ Grupo de Control: Frentes de Trabajo } \\
\cline { 2 - 3 } & G1 & Frente Norte \\
\cline { 2 - 3 } & G2 & Frente Sur \\
\hline \multirow{4}{*}{ SG } & \multicolumn{2}{|c|}{ Sub-Grupo: Servicio } \\
\cline { 2 - 3 } & SG1 & Acero \\
\cline { 2 - 3 } & SG2 & Encofrado \\
\cline { 2 - 3 } & SG3 & Concreto \\
\hline \multirow{4}{*}{ Y } & Variable Dependiente: Indicador de Planeamiento \\
\cline { 2 - 3 } & Y1 & PPC \\
\cline { 2 - 3 } & Y2 & Avance Físico \\
\hline \multirow{2}{*}{ O } & \multicolumn{2}{|c|}{ Observación: Desempeño } \\
\cline { 2 - 3 } & On & Medición Periódica de Desempeño \\
\hline
\end{tabular}

Fuente: Elaboración propia 


\section{CAPÍTULO III: MARCO TEÓRICO}

\section{Túnel}

Según el Diccionario de la Real Academia Española define a un túnel como "paso subterráneo abierto artificialmente para establecer una comunicación a través del monte, por debajo de un río u otro obstáculo". Un túnel, es una obra subterránea artificial normalmente horizontal o inclinada de gran longitud con el objetivo de comunicar dos puntos entre sí.Se ejecutan túneles con la finalidad de construir carreteras, ferrocarriles, canales, pasos inferiores en canales, ríos, estrechos o brazos del mar, almacenamiento de materiales o sustancias, instalaciones y refugios subterráneos, desde los tiempos más remotos. En el mundo, se construyen túneles para líneas de alta velocidad, obras hidráulicas, obras urbanas, explotaciones mineras e investigaciones científicas; estos tipos de infraestructuras viabilizan el desarrollo en múltiples disciplinas.

En el Perú, los túneles tienen un papel muy importante para el desarrollo del país. En la actualidad, se encuentran construyendo líneas de alta velocidad con la intención de resolver el tráfico vehicular, además la ejecución de túneles para la canalización y almacenamiento de agua que sirve para alimentar el consumo de nuevas ciudades. La tecnología que se viene implementando en las obras antes mencionadas es la misma que se utiliza en los países desarrollados del oriente.

Figura Nro. 1: "Evolución de la construcción de túneles"



Fuente: Elaboración propia 
A continuación, se muestra un esquema de la clasificación de túneles de acuerdo con su uso, sección, ubicación, material y características constructivas.

Gráfico Nro. 3: "Clasificación de túneles"

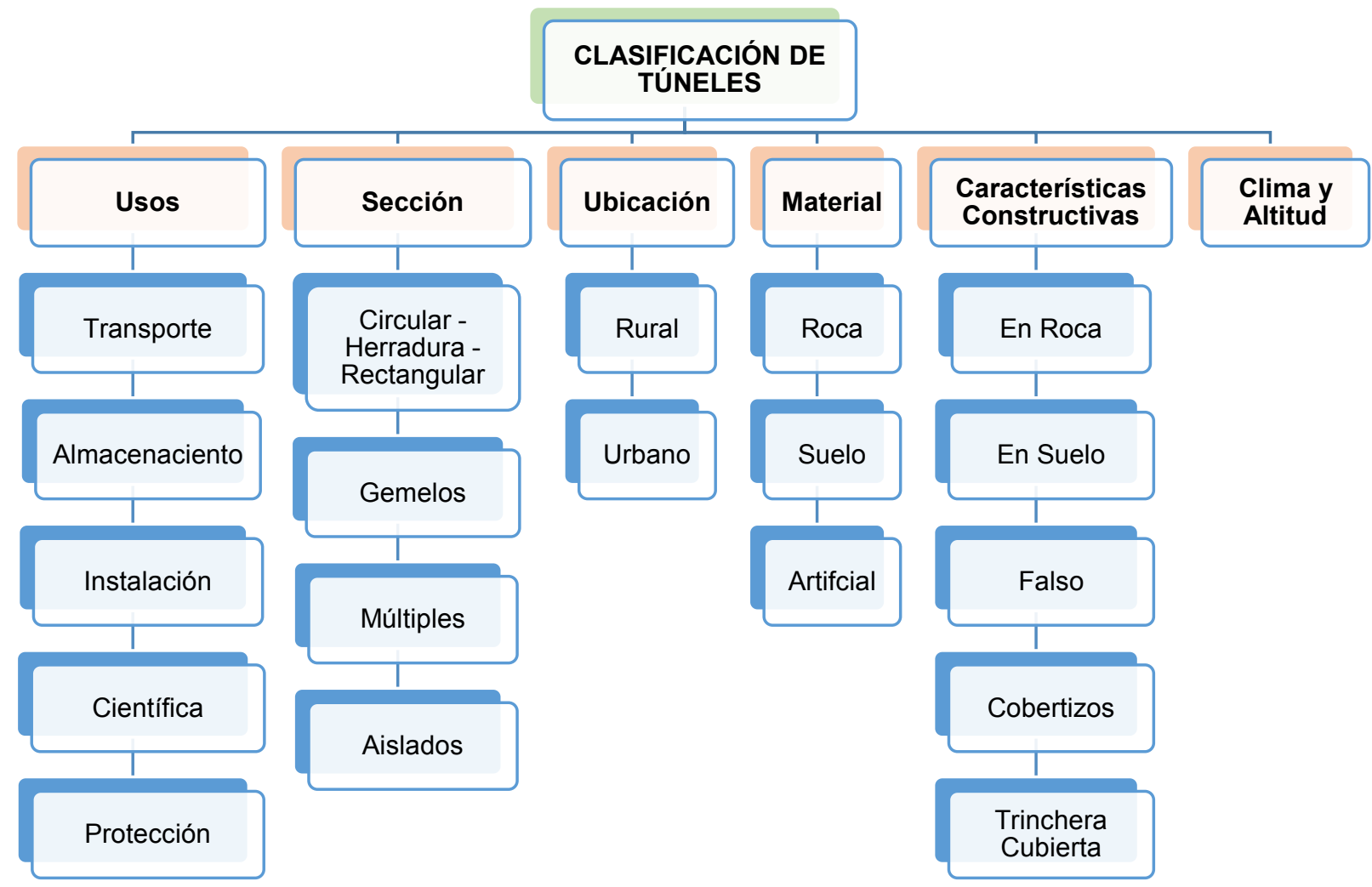

Fuente: Elaboración propia

\section{Clasificación de túneles}

Los túneles según características estructurales y de construcción puede ser definidos como:

\section{En roca}

Los túneles en roca son normalmente construidos a través de montaña. El método de ejecución para este tipo de túneles es muy complejo, por la necesidad de utilizar equipo o maquinaria especial ya sea de voladura o perforación, a su vez, se caracterizan por ser los más costosos y riesgosos por ser trabajos en espacios confinados. Actualmente, la ingeniería ha desarrollado numerosos métodos para construir este tipo de túneles por la complejidad en el diseño y el enfrentamiento a la geotecnia (rocas). En muchos casos, la utilización de este tipo de túneles es para el tránsito vial (carretero, ferrovial, metro) o la conducción de materiales o recursos hídricos. En la figura número 2, se muestra el túnel trasandino del 
proyecto integral Olmos con una longitud de $20 \mathrm{~km}$, que fue construido con la finalidad de servir de trasvase de las aguas del río Huancabamba de la vertiente del Atlántico a la vertiente del Pacífico. El proyecto se ubica a $900 \mathrm{~km}$ al norte de Lima en la región de Lambayeque.

Figura Nro. 2: "Túnel proyecto integral Olmos"

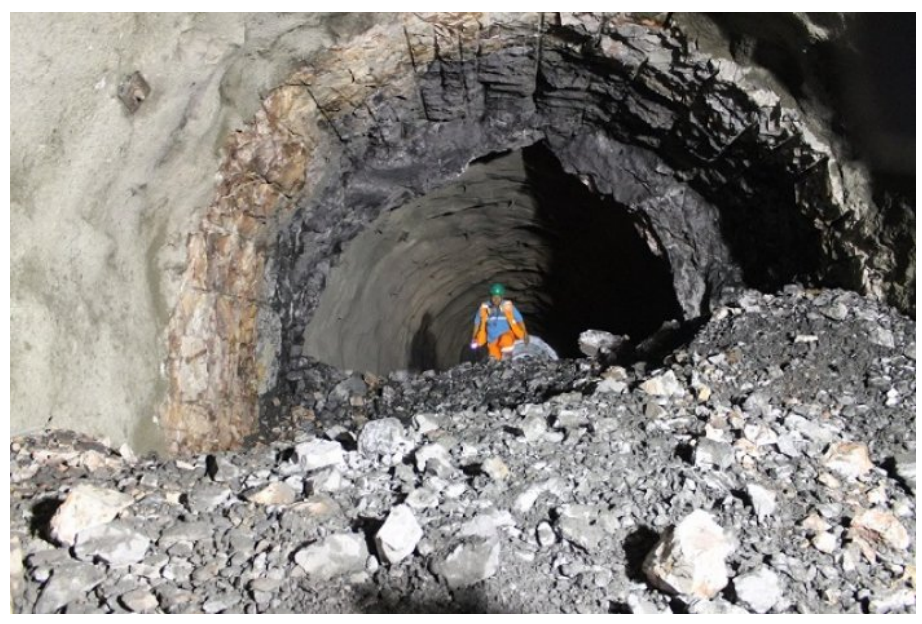

Fuente: El Digital 2013

\section{En suelo}

Los túneles en suelo generalmente son urbanos. Los túneles en suelo pueden ser para el tránsito peatonal, carretero, ferrocarriles subterráneos, para el abastecimiento de agua, sistemas de alcantarillado o energía eléctrica. La construcción este tipo de túneles se hacen de manera convencional con procesos de excavación, sostenimiento y obras estructurales. La ingeniería y ejecución se complica cuando hay presencia de napa freática, esta condición natural demanda la aplicación de soluciones y uso de nuevas tecnologías para la depresión de los niveles de agua superficial y la protección de las estructuras a ejecutarse.

En la figura número 3 se muestra una imagen del proyecto de interconexión vial de dos distritos Limeños: Rímac y San Juan de Lurigancho. Su diseño contempla la ejecución de 2 túneles de 300 metros de longitud que penetran roca viva a través del cerro Santa Rosa Lima.

Figura Nro. 3: "Proyecto Interconexión Vial Rímac - San Juan de Lurigancho" 


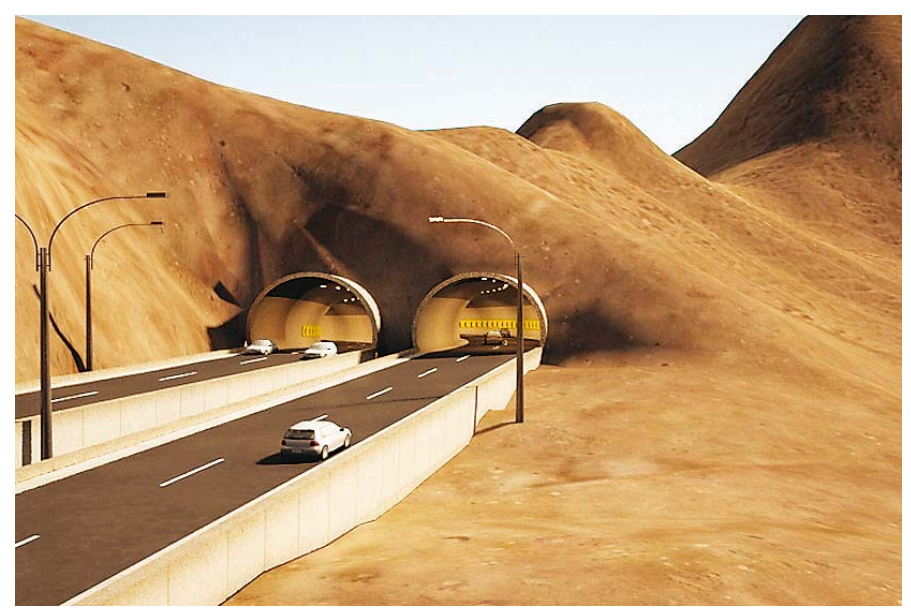

Fuente: La Primera Digital 2012

\section{Falso}

Los túneles en falso tienen la finalidad de proteger a los vehículos de la caída de rocas, se construyen antes de la entrada a los túneles roca. La estructura es de concreto armado, sigue las dimensiones del túnel entrante y luego es rellenado con material natural; cumpliendo con la protección en el ingreso.

La figura número 4 corresponde al acceso del túnel Baluarte, este tiene una longitud de 556 m y un ancho de 20.40 m. y se encuentra ubicado en la autopista Durango-Mazatlán, México. En la figura se puede apreciar el ingreso en falso túnel.

Figura Nro. 4: "Túnel Baluarte - Autopista Durango-Mazatlán”

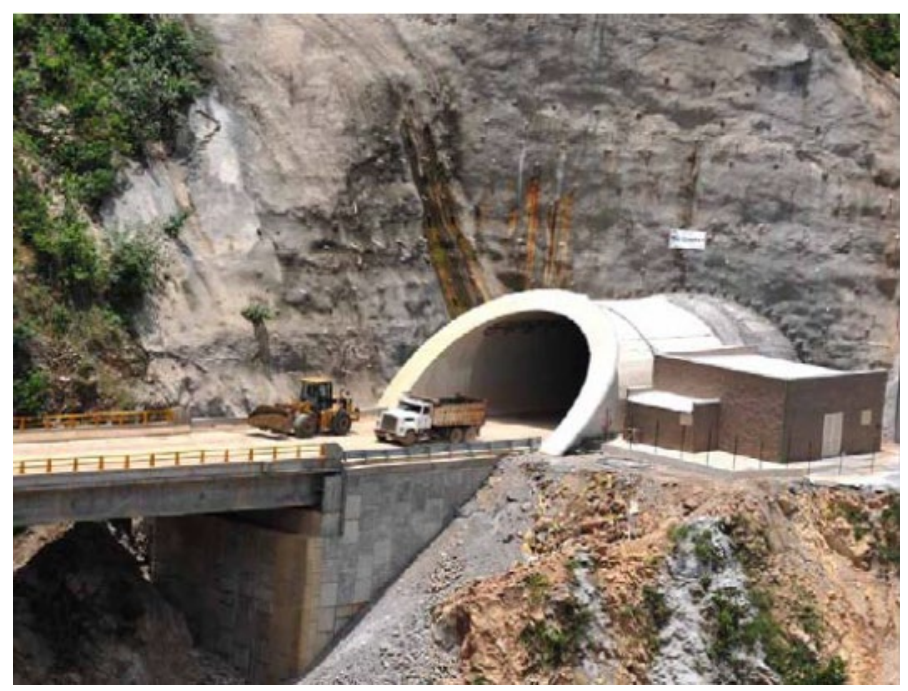

Fuente: Poon 2013 


\section{Cobertizos}

Los túneles cobertizos tienen como finalidad proteger a los vehículos de las avalanchas de nieve en zonas montañosas. Estas estructuras son de sección rectangular conformada por concreto armado y siempre es abierta en uno de sus extremos de la sección.

\section{Trinchera cubierta}

Un túnel de trinchera cubierta se define como una estructura de concreto armado de sección rectangular, conformado por losas y muros, que es construida sobre una superficie plataformada y posteriormente es recubierta o rellenada. Estos tipos de túneles por lo general son construidos con la finalidad de crear viaductos para el tránsito vial (carretero, ferrovial, metro). La complejidad de ejecución de estos tipos de proyectos aumenta cuando de por medio existe presencia del agua.

La ejecución de túneles de trinchera cubierta exige excavaciones previas con soporte, por medio de tablestacas o muros colados. Este soporte mantiene la trinchera abierta durante la construcción y evita los desplazamientos de tierra que pueden causar daños a las estructuras cercanas.

Figura Nro. 5: "Trinchera cubierta"

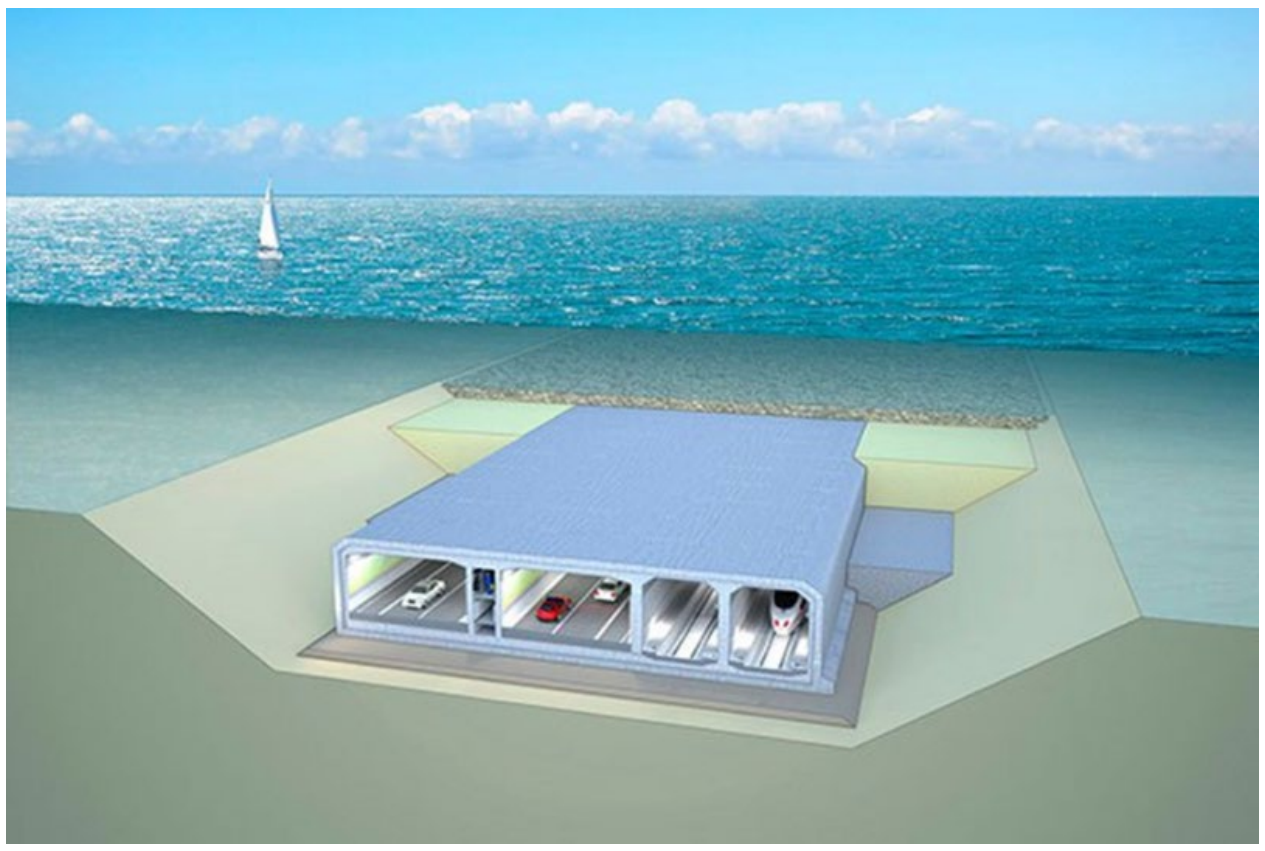

Fuente: Fieras de la ingeniería 2014 


\section{Túneles en trinchera cubierta}

\section{En el mundo}

\section{- Túnel urbano subacuático (Tokio):}

El Aqualine Bahía de Tokio es una obra que conecta dos ciudades, Kawasaki y Kisarazu, a través de un paso marino. El proyecto tiene una longitud total de $15.1 \mathrm{~km}$ que son 2/3 de un túnel en trinchera cubierta y $1 / 3$ de puente. El túnel subterráneo cuenta con tres vías con dos carriles para cada uno.

Según el ITA-AITES, para ir de una ciudad a otra sólo hacen falta 15 minutos, por lo que la autopista desempeña un papel clave a la hora de integrar estas dos zonas de gran importancia industrial. El recorrido alternativo tiene una longitud de 100 kilómetros y hay que atravesar el centro del Tokio metropolitano, de modo que la Aqualine también sirve para descongestionar el tráfico en la gran red viaria metropolitana.

Figura Nro. 6: "Túnel urbano subacuático de Tokio"

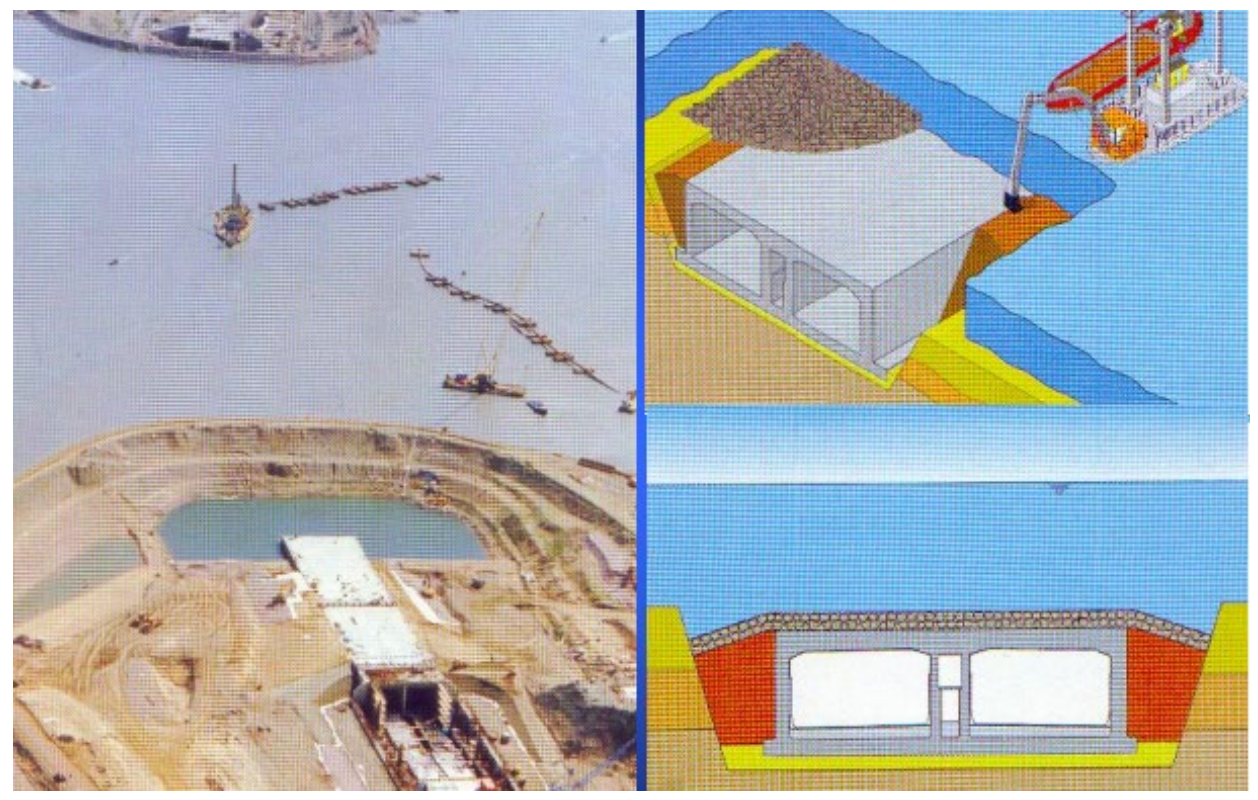

Fuente: Geotecnia Andina 2011

\section{- Américo Vespucio Oriente, Tramo Av. El Salto - Príncipe de Gales (Chile):}

Según la Coordinación de Concesiones de Obras Públicas del Gobierno de Chile se muestra El proyecto de concesión Américo Vespucio Oriente, Tramo el Salto -Príncipe de Gales, consiste en la construcción y explotación de una autopista urbana con una longitud 
aproximada de 9,3 Km, cuyo trazado abarca 5 comunas: La Reina, Las Condes, Vitacura; Recoleta y Huechuraba.

Por su diseño y proceso de ejecución este proyecto se considera como un túnel en trinchera cubierta, presenta dos niveles de pistas para dos sentidos de vía y cada una contará con 3 carriles. Una de las características resaltantes de la construcción de este túnel es que estará por debajo de un parque con el fin de mejorar el medio ambiente para la ciudad de Santiago.

Figura Nro. 7: "Túnel de la Costanera Norte - Autopista Central (Chile)"

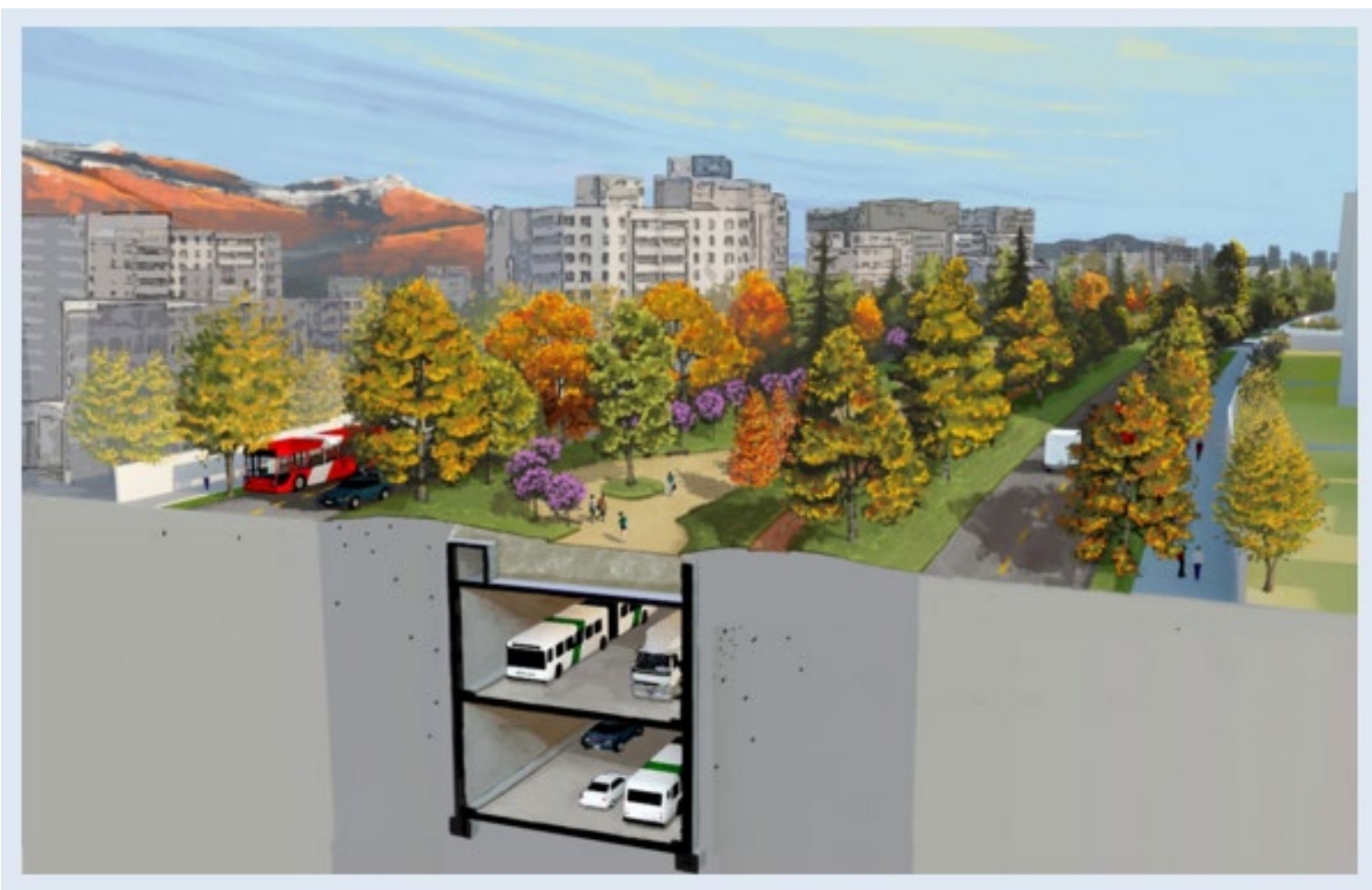

Fuente: Gobierno de Chile 2015

\section{- Línea 1 del metro de Valencia (España)}

Otro ejemplo de túneles de trinchera cubierta en el mundo es la obra la Línea 1 del metro de Valencia, entre las estaciones de Plaza de Toros y Guarapo. El proyecto fue ejecutado por la empresa Ghella-Soggene. La línea 1 presenta dos tramos de túneles construidos con sistema de tuneladoras y en trinchera cubierta.

El tramo de túnel en trinchera cubierta tiene una sección rectangular es de $9 \mathrm{~m}$ de ancho $\mathrm{x}$ $4.72 \mathrm{~m}$ de alto. Para la protección de los taludes inclinados se utilizó un reforzamiento con malla metálica anclada al terreno y con concreto proyectado de $7.5 \mathrm{~cm}$ de espesor. La estructura está conformada por una losa inferior, muros y una losa superior, todas estas de 
concreto armado y fue cubierto con relleno estructural de aproximadamente $3 \mathrm{~m}$ hasta la rasante.

Figura Nro. 8: "Tramo 1 - Estaciones Plaza de Toros y Las Feria"


Fuente: Colmig Engineering 2000

\section{En el Perú}

\section{- Vía Parque Rímac:}

Vía Parque Rímac es un proyecto de gran envergadura, su alcance es la construcción de un túnel debajo del río Rímac. Por su naturaleza y diseño de ingeniería es un túnel en trinchera cubierta con una longitud de $2 \mathrm{~km}$ y consta de dos vías vehiculares que permitirá conectar de manera rápida y segura en la Vía de Evitamiento con el Callao, con la finalidad de reducir la congestión vehicular entre estos sectores. Según la Municipalidad de Lima, Vía Parque Rímac es un proyecto de desarrollo integral de la ciudad y su desarrollo urbano, que además de modernizar la gestión del tráfico mejorará las condiciones ambientales del río Rímac.

Figura Nro. 9: "Vía Parque Rímac" 


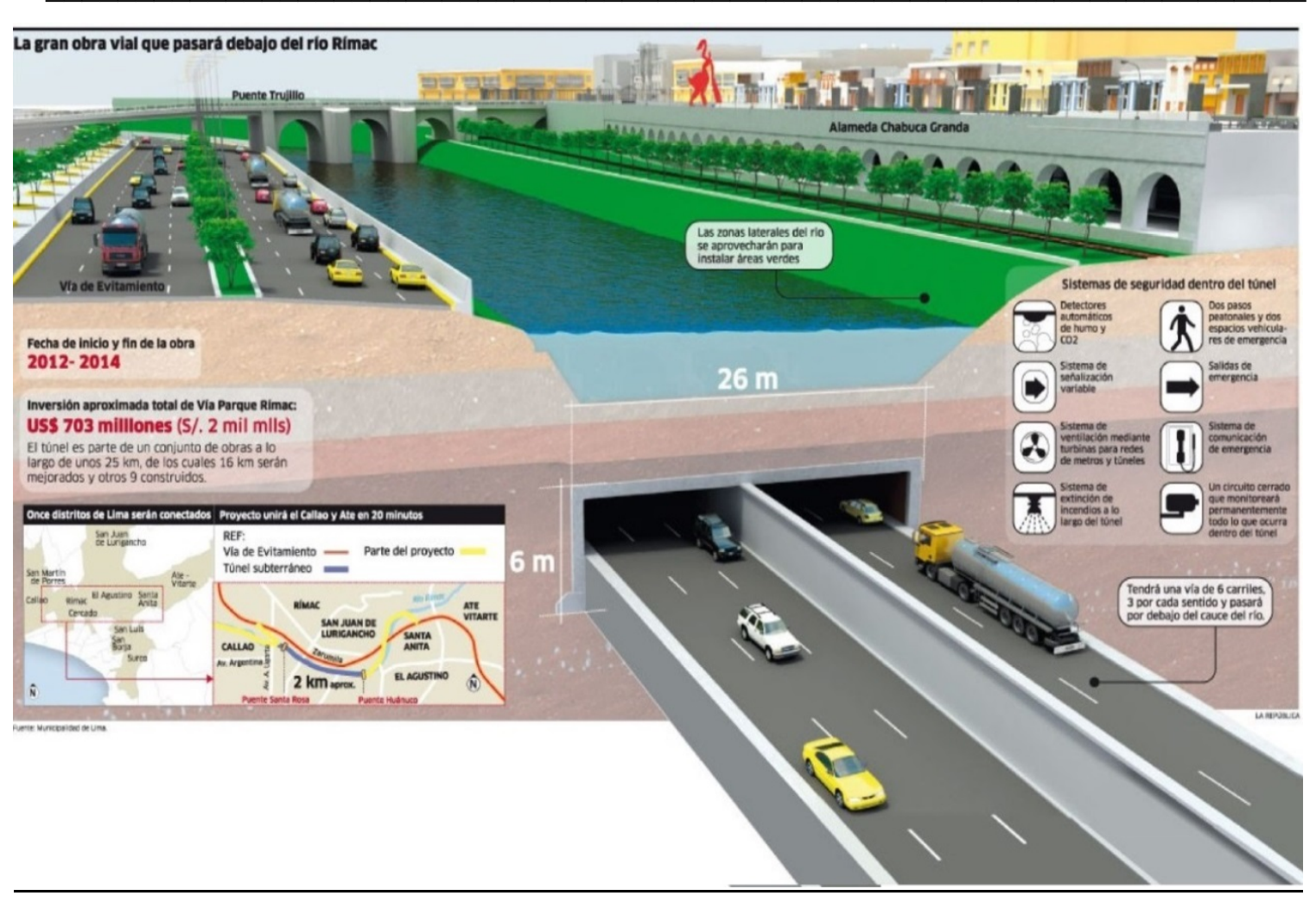

Fuente: El Comercio 2014

\section{- Mejoramiento de la Av. Néstor Gambetta del tramo IIIB:}

El proyecto "Construcción del Túnel en el Tramo IIIB de la Av. Néstor Gambetta". fue concebido con la finalidad de ordenar y mantener el tránsito de vehículos de carga pesada en zona logística del Callao. Asimismo, para dar lugar a la futura construcción de la nueva pista de aterrizaje del Aeropuerto Internacional Jorge Chávez la cual estará proyectada por encima del túnel.

El alcance del proyecto, es la construcción de un túnel subterráneo que comprende obras civiles e instalaciones electromecánicas. Consta de dos pistas vehiculares con tres carriles cada una, además una vía central para un futuro ferrocarril y túneles laterales de emergencia para evacuación peatonal, conocidas como galerías. El túnel en trinchera cubierta tiene una longitud efectiva de desarrollo de $960 \mathrm{~m}$.

Figura Nro. 10: "Túnel en el tramo IIIB de la Av. Néstor Gambetta" 


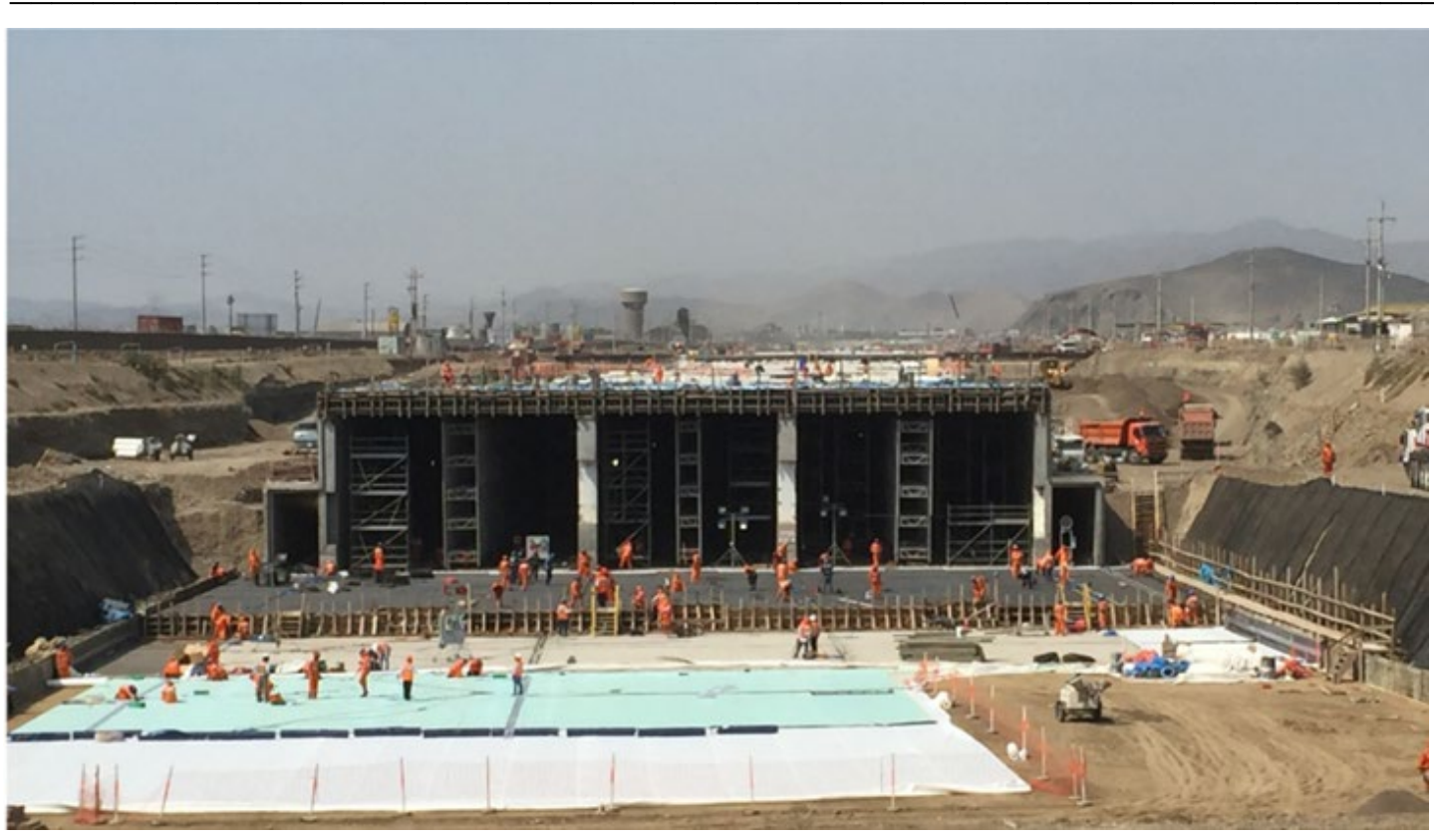

Fuente: Elaboración propia

\section{Metodología constructiva en túneles de trinchera cubierta}

\section{Proceso constructivo - "cut and cover"}

Para la ejecución de túneles en trinchera cubierta es común utilizar el método constructivo de "cut and cover", que en español significa "cortar y cubrir". Este método se basa en realizar excavaciones en forma de zanja a lo largo de la proyección del túnel. Una vez alcanzada la cota de fundación, se procede a la construcción de elementos estructurales de concreto. Finalmente, se vuelve a cubrir las estructuras con relleno estructural.

Existen dos formas de realizar este procedimiento constructivo:

- Método "bottom up": este método cosiste en la ejecución del túnel de abajo hacia arriba. Es decir, se realiza la excavación de la superficie a tajo abierto en su totalidad y se construye el túnel desde las bases hasta las estructuras superiores, luego se rellena y cubre la estructura. El túnel puede ser construido con concreto in situ, estructuras de concreto prefabricado, arcos con acero corrugado, acero prefabricado, entre otros.

- Método "top down": este método consiste en realizar la construcción del túnel de arriba hacia abajo. Se comienza con la excavación parcial del área de la superficie, 
luego se ejecutan los elementos verticales tales como muros de sostenimiento y la losa superior. Por último, se realiza la excavación y construcción de los elementos al interior del túnel tales como losa de fundación y las superficies de rodadura.

\section{Lean Construction en el planeamiento y control estratégico de la construcción}

\section{Introducción al Lean Construction}

Lean Construction es una filosofía de trabajo que puede aplicarse en todas las fases de un proyecto de construcción: en el diseño, ingeniería, logística y cadena de suministro, ejecución, operación y mantenimiento. Su objetivo principal es la reducción de pérdidas y la mejora continua de los procesos constructivos.

Según el Instituto de Lean Construction (ILC), es una filosofía que se orienta hacia la administración de la producción en construcción y su objetivo principal es reducir o eliminar las actividades que no agregan valor al proyecto y optimizar aquellas que sí lo hacen mediante la mejora continua. De esta manera, a través de diferentes herramientas específicas aplicadas a los procesos de ejecución del proyecto busca la implementación de un sistema de producción enfocado en la minimización de pérdidas. Además, Lean Construction busca incrementar la productividad en los procesos de ejecución de proyecto, con la optimización del uso de recursos para la creación de valor agregado.

Según Jorge Luis Izquierdo (Vicepresidente del Capítulo Peruano Lean Construction Institute) define a la gestión de la producción como el manejo sistemático y metódico de las actividades de ejecución y soporte necesarias para la producción, sobre la base de principios, técnicas y teorías formales que permitan lograr la continuidad del flujo de producción y una constante optimización de la misma, aplicando estrategias para reducir la variabilidad o mitigar su impacto en el proyecto.

A continuación, en el gráfico número 4 se muestra el concepto, los principios y metodologías de la "Filosofía Lean Construction".

Gráfico Nro. 4: "Filosofía Lean Construction"

CONCEPTO

Según Pons muestra que la aplicación de los principios y herramientas del sistema Lean a lo largo de todo el ciclo de vida de un proyecto de 


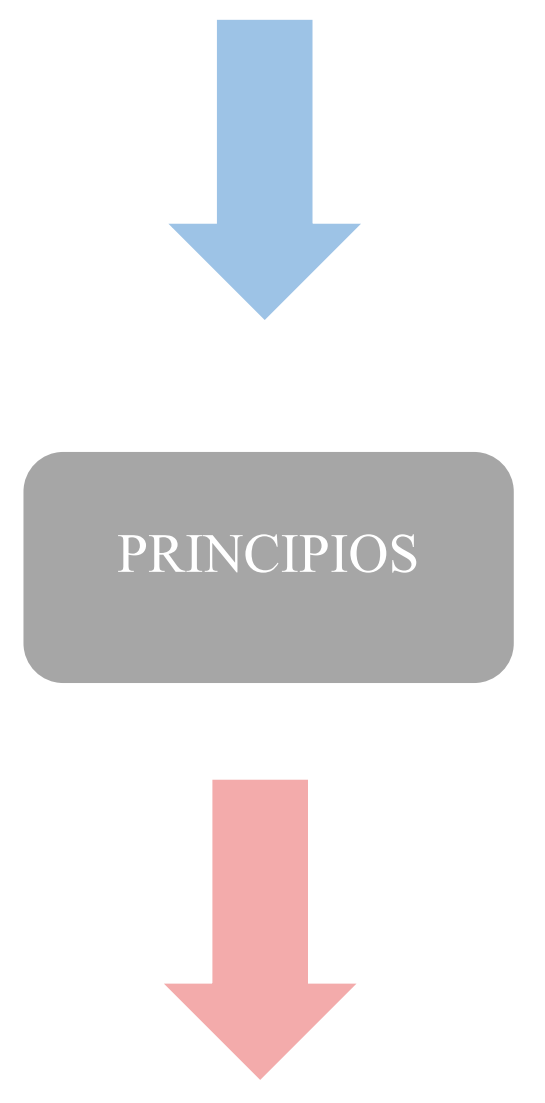

1. Reducción o eliminación de las actividades que no agregan valor

2. Incremento del valor del producto a través de la consideración sistemática de las necesidades del cliente

3. Reducir la variabilidad

4. Reducir el tiempo del ciclo

5. Simplificación de procesos

6. Incrementar la flexibilidad de la producción

7. Transparencia del proceso

8. Enfoque del control al proceso completo

9. Mejoramiento continuo del proceso

10.Balance de mejoramiento de flujo con meioramiento de conversión

1. Just in Time

2. Businees Process Reeingeneering

3. Location Based Management System

METODOLOGÍA

4. Total Quality Management

5. Last Planner System

6. Building Information Modeling

7. Value Based Management

8. Total Productive Maintenance

Fuente: Elaboración propia 


\section{Diferencias de planificación entre el modelo tradicional y el enfoque lean}

En la gestión integral de proyectos, el modelo tradicional de planificación presenta problemas recurrentes como:

- Centralización de las informaciones y toma de decisiones. La planificación del proyecto no involucra a todas las áreas de apoyo el alcance y plan de ataque no queda claro para los principales involucrados en el proyecto.

- Objetivos y las metas planeadas en el proyecto son solo de conocimiento de los encargados de las áreas de planificación y producción.

- Falta de participación de las áreas de apoyo en la planificación del alcance del proyecto.

- Falta de conocimiento, experiencia y entrenamiento de nuevos sistemas de gestión en los proyectos.

- Identificación y solución de restricciones de la ejecución del proyecto sin anticipación o previsión muy corta.

Estos problemas son causas potenciales de incertidumbre y variabilidad de los proyectos que pueden repercutir en incumplimiento de plazos del contrato, sobrecostos, accidentes laborables y baja calidad de los trabajos del proyecto. 2

El enfoque Lean Construction se basa en una nueva forma de ver la producción de la construcción. La esencia radica en cuatro principios: filosofía, proceso, gente y resolución de problemas. La filosofía enfatiza la toma de decisiones con pensamiento a largo plazo; el proceso, busca la eliminación de desperdicios; el tercer principio, gente, incentiva el respeto y trabajo en equipo; y el último principio, resolución de problemas, busca la mejora continua y el aprendizaje. En este sentido, Lean Construction no es una matriz o un procedimiento de gestión, sino la aplicación de principios teóricos de una cultura de trabajo a través de diferentes herramientas. 3

A continuación, se listan características y enfoques de Lean Construction en los proyectos de construcción:

2 Cfr. Pons 2014: 11

3 Cfr. Avances 2014: 38 
- En la ejecución de los proyectos de construcción, el trabajo es una labor productiva que busca maximizar el valor en los procesos y reducir los desperdicios.

- El control del proyecto pasa de "monitorear los resultados" a "hacer que las cosas que sucedan". Para ello, es importante la toma de decisiones en base a indicadores de seguimiento y control.

- La filosofía Lean Construction busca siempre la relación entre el tiempo, el costo y la calidad, los niveles óptimos de calidad y el cumplimiento de plazos no debe significar incremento de costos. 4

- Los objetivos y metas planeadas del proyecto se difunden para conocimiento de los todos los trabajadores en todos los niveles de la empresa.

- La gestión del proyecto debe velar por la comunicación y trabajo colectivo de las diferentes áreas del proyecto, entre especialistas en diseño, suministro, montaje y ejecución.

- La mejora continua (kaizen) es base esencial del enfoque Lean y se basa en el análisis continuo de los procesos y la búsqueda de optimizar recursos ya sea de tiempo, mano de obra o materiales.

- Durante la producción, se busca la reducción de los trabajos no contributorios (trabajos con desperdicio evidente), aumento del trabajo productivo (trabajo que agrega valor) y la disminución de los trabajos contributorios.

- El eficiente uso de los recursos como: equipos, materiales y personas hacen que se reduzcan los costos de la construcción del proyecto. Trae consigo también, una gran reducción en el plazo de la obra.

En resumen, el objetivo de Lean Construction es maximizar las actividades que agreguen valor al proyecto para la reducción de los tiempos, la optimización de recursos y la prevención de accidentes laborables. Esta medida debe ser implementada en todas las fases del ciclo de vida de un proyecto de construcción, con el fin de involucrar a todas las partes que intervienen desde el proceso inicial de diseño hasta la operación. De esta manera busca

4 Cfr. Pons 2014: 27-28 
generar una cultura de trabajo en los empleados, empresas subcontratistas y otros actores involucrados en el flujo de valor,5

En la tabla número 3 se muestran las principales diferencias entre la producción convencional y la producción sin pérdidas.

Tabla Nro. 3: "La producción convencional y la producción sin pérdidas"

\begin{tabular}{|c|c|c|}
\hline & $\begin{array}{c}\text { PRODUCCIÓN } \\
\text { CONVENCIONAL }\end{array}$ & $\begin{array}{l}\text { PRODUCCIÓN SIN } \\
\text { PÉRDIDAS }\end{array}$ \\
\hline Objeto & $\begin{array}{l}\text { Afecta a productos y } \\
\text { servicios }\end{array}$ & $\begin{array}{l}\text { Afecta a todas las } \\
\text { actividades de la empresa }\end{array}$ \\
\hline Alcance & Control & $\begin{array}{l}\text { Gestión, asesoramiento, } \\
\text { control }\end{array}$ \\
\hline $\begin{array}{l}\text { Modo } \\
\text { Aplicación }\end{array}$ & Impuesta por la dirección & $\begin{array}{l}\text { Por convencimiento y } \\
\text { participación }\end{array}$ \\
\hline Metodología & Detectar y corregir & Prevenir \\
\hline Responsabilidad & Departamento de calidad & $\begin{array}{l}\text { Compromiso de todos los } \\
\text { miembros de la empresa }\end{array}$ \\
\hline Clientes & Ajenos a la empresa & Internos y externos \\
\hline $\begin{array}{l}\text { Conceptualización } \\
\text { de la Producción }\end{array}$ & $\begin{array}{l}\text { La producción está } \\
\text { compuesta por una serie de } \\
\text { actividades de conversión } \\
\text { que todos añaden valor al } \\
\text { producto. }\end{array}$ & $\begin{array}{l}\text { La producción está } \\
\text { compuesta por actividades } \\
\text { que no agregan valor (flujos) } \\
\text { y agregan valor } \\
\text { (conversiones) }\end{array}$ \\
\hline Control & $\begin{array}{l}\text { Dirigido al costo de las } \\
\text { actividades }\end{array}$ & $\begin{array}{l}\text { Dirigido al tiempo, costo y } \\
\text { valor de los flujos. }\end{array}$ \\
\hline
\end{tabular}

5 Cfr. Pons 2014: 27 


\begin{tabular}{|c|c|c|}
\hline & $\begin{array}{c}\text { PRODUCCIÓN } \\
\text { CONVENCIONAL }\end{array}$ & $\begin{array}{l}\text { PRODUCCIÓN SIN } \\
\text { PÉRDIDAS }\end{array}$ \\
\hline Mejora & $\begin{array}{l}\text { Incremento de la eficiencia } \\
\text { de las conversiones a través } \\
\text { de la utilización de nuevas } \\
\text { tecnologías. }\end{array}$ & $\begin{array}{l}\text { Eliminación de las } \\
\text { actividades que no agregan } \\
\text { valor (pérdidas), } \\
\text { incrementando la eficiencia } \\
\text { de las actividades que lo } \\
\text { generan, a través del } \\
\text { mejoramiento continuo y la } \\
\text { implementación de nueva } \\
\text { tecnología. }\end{array}$ \\
\hline
\end{tabular}

Fuente: Campero y Alarcón - 2008

\section{Principios de Lean Construction}

Lauri Kosquela, uno de los representantes del desarrollo de la filosofía Lean Construction, propuso once principios claves para lograr su implementación en cualquier proyecto de ingeniería civil. La aplicación de estos principios y la mejora continua constante contribuye a la reducción de pérdidas y mejora en la seguridad, la calidad y eficiencia del proyecto. A continuación, se listarán y describirán estos principios:

- Reducción o eliminación de las actividades que no agregan valor

Para lograr la reducción de actividades que no agregan valor primero es necesario entender el concepto de valor lo que representa para nosotros.

“(...). El valor es el punto de partida del pensamiento Lean. Se puede definir como el aprecio que un cliente o consumidor le da a un producto o servicio para satisfacer sus necesidades a un precio concreto, en un momento determinado." (Pons 2014: 21)

Las actividades que agregan valor son aquellas que convierten material y/o información requerida por parte del cliente. Por otro lado, las actividades que no agregan valor son las que conocemos como desperdicio y son aquellas que requieren tiempo, recursos y/o espacio 
sin agregar valor al producto final. Las principales causas de la existencia de estas actividades están en el diseño, la ignorancia y la naturaleza inherente de la producción.

La mayoría de los principios que se muestran a continuación buscan la eliminación de las actividades que no agregan valor.

- Incremento del valor del producto a través de la consideración sistemática de las necesidades del cliente

El valor se genera mediante el cumplimiento de los requerimientos del cliente y no necesariamente por el proceso de conversión. Asimismo, existen dos tipos de clientes para una actividad y son la actividad sucesora y el cliente final. Para incrementar el valor del producto es importante identificar las necesidades y requisitos de los clientes. Este principio está basado en crear un flujo sistemático, en el cual se define a los clientes en cada etapa juntamente con el análisis de sus requerimientos.

\section{- Reducción de la variabilidad}

La naturaleza de la producción y de sus procesos es variable, más aún en construcción civil, se puede tener dos artículos y a pesar de que sean el mismo producto los recursos para su producción (mano de obra, tiempo y materiales) pueden variar. He aquí la importancia de este principio para reducir la variabilidad en los procesos y recursos al momento de la creación de un producto. La reducción de la variabilidad va más allá del cumplimiento de las especificaciones dadas por el cliente, es un esfuerzo por reducir la incertidumbre (generador de pérdidas y desperdicios en los procesos) y aumentar la previsibilidad.

\section{- Reducción del tiempo del ciclo}

El tiempo es una herramienta de medida para el flujo de procesos y tiene relación directa con el costo y la calidad, por lo tanto, su reducción puede contribuir a la mejora de estas últimas. El tiempo del ciclo es una de las características de un flujo de producción, y se entiende por el tiempo necesario para que un material atraviese el flujo.

Gráfico Nro. 5: "Tiempo ciclo" 


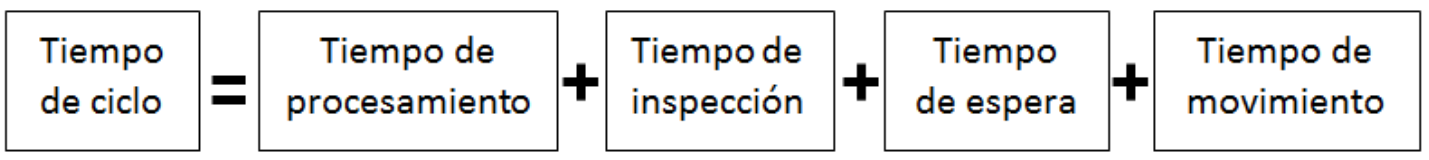

Fuente: Elaboración propia

Un aspecto clave en la implementación de la filosofía lean es la reducción del tiempo de ciclo. Esto obliga a reducir los tiempos de inspección, de movimientos y esperas.

\section{- Simplificación de procesos}

La simplificación se puede comprender como la reducción del número de componentes de un producto o la reducción del número de pasos en un flujo de material o información. Este principio se logra aplicar mediante la eliminación de actividades que no añaden valor o mediante la reconfiguración de las partes o etapas de valor añadido.

Otra manera de llevar a cabo la simplificación son los cambios en la organización. Las divisiones verticales y horizontales del trabajo dan lugar a actividades que no añaden valor y que podrían ser eliminados a través de unidades independientes como equipos multidisciplinarios y autónomos.

Algunos esfuerzos prácticos para la simplificación son:

- Acortamiento de flujos mediante la consolidación de las actividades.

- La reducción de la cantidad de partes del producto mediante cambios de diseño o partes prefabricadas.

- La normalización o estandarización de las piezas, materiales, herramientas.

- Reducir al mínimo la cantidad de información de control, es decir, solo procesar la información necesaria.

\section{- Incremento de la flexibilidad de la producción}

Para lograr la flexibilidad uno de los elementos clave es el diseño de un producto modular asociado al uso agresivo de otros principios, especialmente el de compresión de ciclo y la transparencia.

Algunos esfuerzos prácticos para una mayor flexibilidad incluyen: 
- Minimizar los tamaños de lotes de producción para asemejarse a la demanda.

- Reducir la dificultad de hacer cambios y configuraciones.

- Personalización del proceso lo más tarde posible.

- Entrenar mano de obra multi-disciplinaria

\section{- Transparencia del proceso}

La falta de transparencia en los procesos incrementa la posibilidad a errar, disminuye la visibilidad de los errores y disminuye la motivación por mejorar. Por lo tanto, el objetivo de este principio es hacer que el proceso de producción sea transparente y observable para facilitar el control y la mejora. De esta forma, el flujo de operaciones desde el principio hasta el fin debe ser comprensible para todos los empleados. Esto se puede lograr haciendo que los procesos sean directamente observables, así por ejemplo a través de exhibición pública de la información.

Algunos enfoques prácticos para la mejora en la transparencia pueden ser:

- Implementar programas para eliminar el desorden: El método de las 5S.

- Haciendo que el proceso sea directamente observable mediante señalización adecuada.

- Representación de atributos no visibles de procesos visibles a través de mediciones.

- Incorporar información de los procesos en las áreas de trabajo, herramientas, contenedores, materiales y sistemas de información.

- El uso de controles visuales para que cualquier persona pueda comprender de inmediato de los estándares y desvíos de estos.

\section{- Enfoque del control al proceso completo}

Existen dos causas para la segmentación del flujo de control: cuando el flujo atraviesa diferentes unidades en una organización jerárquica o cuando cruza la frontera de la 
organización. Y en estos dos casos existe el riesgo de sub-optimización. Para garantizar el enfoque del control del proceso completo existen dos requisitos que deben cumplirse, el primero estipula que el proceso competo debe ser medido, y el segundo que debe haber una autoridad de control para el proceso completo. En la actualidad se usan varias alternativas. Sin embargo, en organizaciones jerárquicas se toman soluciones más radicales dejando equipos auto-dirigidos en el control de sus procesos.

Para flujos inter-organizacionales es necesaria la cooperación con los proveedores y formación de equipos con el fin de obtener beneficios mutuos de un flujo total optimizado.

\section{- Mejoramiento continuo del proceso}

Es el esfuerzo que se emplea para reducir las pérdidas y aumentar el valor, es una actividad interna e iterativa que puede llevarse a cabo de manera continua. Existen algunos métodos necesarios para la institucionalización de la mejora continua:

- Medición y monitoreo de la mejora.

- Extensión de ajuste de objetivos

- Dar la responsabilidad de mejora para todos los colaboradores, la mejora constante de cada unidad organizacional debe ser requerida y recompensada.

- Uso de procedimientos estándar como supuestas mejores prácticas, al ser cuestionada constantemente por emplear mejores formas.

- Vincular de la mejora para el control, es decir, la mejora debe estar orientada al control de las restricciones y problemas del proceso. El objetivo es eliminar la raíz de los problemas en lugar de hacer frente a sus efectos.

\section{- Balance de mejoramiento de flujo con mejoramiento de conversión}

En cualquier proceso de producción, los aspectos de flujo y conversión poseen diferente potencial de mejora. Es así que cuando mayor sea la complejidad del proceso, el impacto de 
la mejora de flujo será mayor. La mayoría de los desperdicios son inherentes a los procesos de producción y lo más rentable es mejorar el flujo en lugar de la mejora de la conversión. En ese sentido, dada una situación en la que los flujos fueron descuidados, el potencial de mejora del flujo será más alto que la mejora de la conversión. Por otro lado, las mejoras de flujos demandan inversiones pequeñas, pero requiere mayor tiempo que una mejora de conversión.

Sin embargo, ambas mejoras tienen una relación directa:

- Mejores flujos requieren menor capacidad de conversión en efecto menos inversión.

- Nueva tecnología de conversión puede brindar menor variabilidad y por lo tanto el flujo de beneficios, las inversiones en tecnología pueden estar dirigidas a la mejora del flujo o rediseño.

\section{- Referenciación}

Los mejores procesos de flujo no son comercializados por nosotros, debemos encontrar algún proceso de clase mundial. A menudo la referencia es un estímulo para poder alcanzar la brecha del mejoramiento.

Esto ayuda a vencer viejas rutinas arraigadas y malas prácticas. Mediante este principio se puede descubrir defectos lógicos fundamentales en nuestros procesos. Para ello es importante conocer el proceso, saber de los líderes de la industria o competidores, incorporar las mejores prácticas en nuestros procesos y ganar superioridad mediante la combinación de fortalezas existentes y lo mejor de prácticas referenciadas.

\section{Herramientas Lean}

\section{Last Planner System}

El sistema del último planificador fue desarrollado por Glenn Ballard y Greg Howell y hace parte de la filosofía Lean Construction. Esta herramienta desarrolla un sistema de 
planificación y control de la producción con la finalidad de mejorar la variabilidad en las obras de construcción y reducir la incertidumbre de las actividades programadas. 6

El Last Planner, o último planificador es la persona con la capacidad de garantizar el flujo de trabajo previsible aguas abajo, es aquella que asigna las tareas directamente a los colaboradores o trabajadores con el fin de cumplir los compromisos de entrega basándose en premisas reales concebidas en campo en lugar de planes teóricos. Esta persona es normalmente el capataz, encargado o jefe de obra.

El Last Planner System está basado en un sistema de planificación pull en lugar de un sistema push, puesto que la última actividad de la cadena de flujo de valor es la que marca el ritmo de avance y tira de la demanda, contrario al sistema tradicional en donde las actividades aguas arriba (predecesoras) empujan a las actividades aguas abajo (sucesoras) produciendo inventario, cuellos de botella y otros desperdicios.7

A continuación, a través del siguiente gráfico se dará a conocer las fases del Last Planner System: 
Gráfico Nro. 6: "PDCA Last Planner System"
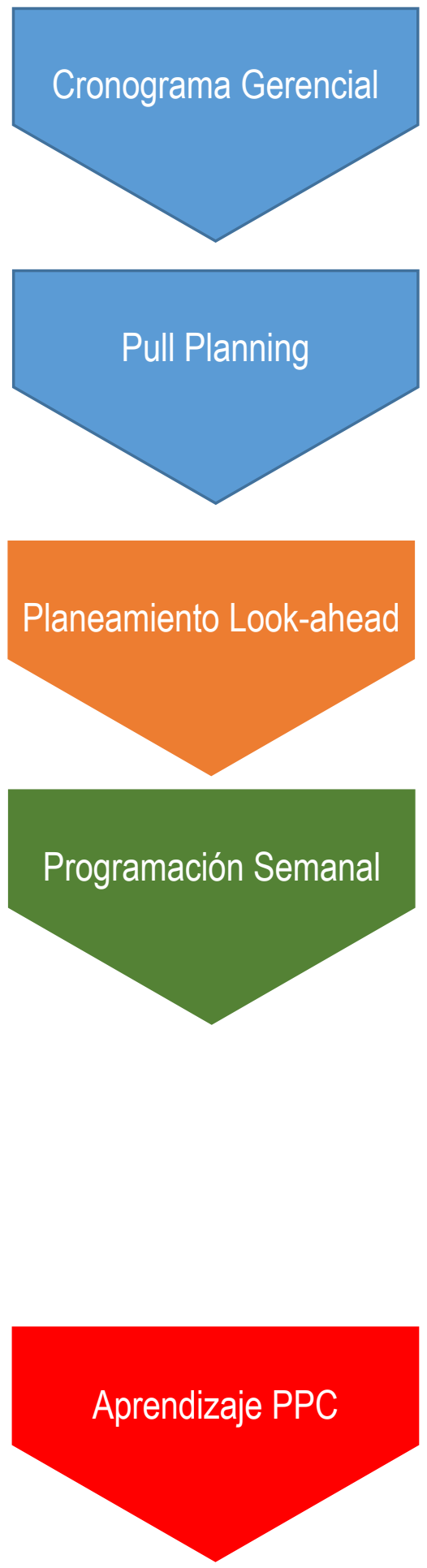

Reuniones Diarias de

Desempeño
Vista general de todos los marcos. Definición y programación de los principales hitos del proyecto Plan general de trabajo con la lógica y el tiempo de construcción general.

Secuencia detallada para alcanzar el siguiente hito importante - 3 meses visión. Plan de trabajo a nivel de disciplinas para alcanzar el siguiente hito. La pertenencia y el compromiso que surge de la planificación colaborativa.

Restricciones sobre las actividades pendientes para iniciar en las próximas 6 semanas, con la designación de responsables y los plazos para la eliminación.

Plan de trabajo en el nivel de los trabajadores. Plantilla de plan de trabajo semanal definición de cantidades, ubicaciones, requisitos


Breve discusión en el trabajo que detalla el funcionamiento de cada tipo de actividad profesional en relación con el plan, las últimas limitaciones de tiempo, así como el blan bara el día siauiente.

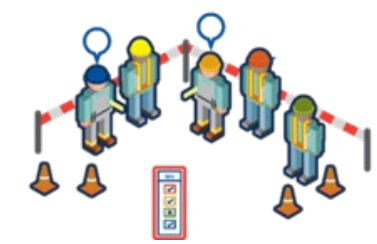






\section{Análisis semanal de unirse al programa. Aprendizaje rápido a través de análisis de causa raíz. Plan}

Fuente: Andrade Gutiérrez 2015

\section{Pull planning}

El pull planning o planeamiento jalado es un cronograma elaborado para una fase especifica de un proyecto usando el principio Pull, es decir, la actividad aguas abajo en la cadena de valor es quien marca el ritmo y tira de la demanda. Es preparado por el equipo responsable por la ejecución del trabajo. En la fase de diseño deben participar los arquitectos, ingenieros, residentes; ya para la etapa de ejecución del Pull Planning, participan los proyectistas, ingenieros, subcontratistas y demás encargados. Esta metodología permite la visualización de las actividades de atrás para adelante, identificando a medida que se avanza los criterios para detallar cada sub-actividad y las necesidades para iniciar cada fase. Una buena práctica se considera establecer las duraciones definiendo un flujo de trabajo con ritmo continuo y eficiente.

Para preparar la reunión Pull Planning es necesario definir bien los siguientes aspectos:

- Definición del marco meta a para tirar de atrás hacia adelante

- Estudiar los mejores procesos ejecutivos, índices de productividad, y otros aspectos que contribuyan a decidir cuál es la forma más eficiente de ejecutar el frente de trabajo.

- Identificación de todos los recursos necesarios para las tareas o entregables del proceso.

- Definición de las actividades y relación entre ellas. Es decir, establecer su secuencia, identificar el responsable, el entregable, sus restricciones, la cantidad, los recursos previstos, la productividad prevista y su duración. 
- Todas las informaciones arriba mencionadas deberán ser organizadas para transferirlas a un Cronograma Gantt con el objetivo de tener una visión preliminar conteniendo la mejor información hasta el momento.

\section{Comparación de la filosofía Lean Construction en edificaciones y en túneles de trinchera cubierta}

En Lima, el desarrollo inmobiliario propició la implementación de metodologías de planificación y producción de la construcción de edificaciones basadas en la filosofía Lean Construction. Sin embargo, su aplicación en obras de infraestructura vial aún es desconocida en el ámbito.

A continuación, se muestra un cuadro comparativo de las principales diferencias de la aplicación de la filosofía Lean Construction en obras de edificaciones y en obras viales como los túneles de trinchera cubierta.

Tabla Nro. 4: “Comparación de la aplicación de la filosofía Lean Construction en edificaciones y en túneles de trinchera cubierta"

\begin{tabular}{|l|l|l|}
\hline \multicolumn{1}{|c|}{ EDIFICACIONES } & \multicolumn{1}{|c|}{$\begin{array}{c}\text { TÚNELES DE TRINCHERA } \\
\text { CUBIERTA }\end{array}$} \\
\hline Alcance & $\begin{array}{l}\text { Diseñado para uso habitacional de } \\
\text { personas. }\end{array}$ & $\begin{array}{l}\text { Diseñado para comunicar dos } \\
\text { puntos entre sí. }\end{array}$ \\
\hline Plan de Ataque & $\begin{array}{l}\text { Por lo general, las edificaciones } \\
\text { tienen una estructura plataformada } \\
\text { por lo que siempre la secuencia } \\
\text { constructiva arrancará desde el } \\
\text { nivel inferior hacia los superiores. }\end{array}$ & $\begin{array}{l}\text { Son obras lineales y por lo general } \\
\text { su plan de ataque obedece a una } \\
\text { secuencia constructiva horizontal } \\
\text { y lineal que da la opción de abrir } \\
\text { diferentes frentes de ataque. }\end{array}$ \\
\hline Sectorización & $\begin{array}{l}\text { En edificaciones la sectorización se } \\
\text { da por plataforma o número de } \\
\text { pisos y en función a la cantidad de } \\
\text { metrados. }\end{array}$ & $\begin{array}{l}\text { Para este tipo de obras, la } \\
\text { sectorización está dividida por } \\
\text { tramos o unidades de } \\
\text { construcción. }\end{array}$ \\
\hline $\begin{array}{l}\text { Análisis } \\
\text { Restricciones }\end{array}$ & $\begin{array}{l}\text { Se logra identificar la mayoría de } \\
\text { las restricciones al inicio de la obra } \\
\text { dado que el alcance y los procesos }\end{array}$ & $\begin{array}{l}\text { Existe mayor variabilidad para } \\
\text { tratar las restricciones dado que la } \\
\text { ingeniería de detalle demanda }\end{array}$ \\
\hline
\end{tabular}




\begin{tabular}{|c|c|c|}
\hline & EDIFICACIONES & $\begin{array}{c}\text { TÚNELES DE TRINCHERA } \\
\text { CUBIERTA }\end{array}$ \\
\hline & $\begin{array}{l}\text { ya son conocidos en proyectos } \\
\text { similares. }\end{array}$ & $\begin{array}{l}\text { procedimientos y materiales no } \\
\text { convencionales en el mercado. }\end{array}$ \\
\hline Procura & $\begin{array}{l}\text { La mayoría de los equipos y } \\
\text { materiales están al alcance en el } \\
\text { mercado local, por lo que } \\
\text { disminuye el nivel de incertidumbre } \\
\text { para su gestión de logística. }\end{array}$ & $\begin{array}{l}\text { Para la construcción de los } \\
\text { túneles de trinchera cubierta, los } \\
\text { equipos y materiales se } \\
\text { encuentran en el mercado } \\
\text { internacional, por lo general es } \\
\text { necesario solicitarlos con mayor } \\
\text { previsión. }\end{array}$ \\
\hline $\begin{array}{l}\text { Planeamiento } \\
\text { Look-ahead }\end{array}$ & $\begin{array}{l}\text { En relación con lo mencionado } \\
\text { anteriormente, en edificaciones el } \\
\text { Look-ahead se realiza con una } \\
\text { previsión de cuatro semanas. }\end{array}$ & $\begin{array}{l}\text { En relación con lo mencionado } \\
\text { anteriormente, en edificaciones el } \\
\text { Look-ahead se realiza con una } \\
\text { previsión de seis semanas. }\end{array}$ \\
\hline
\end{tabular}

Fuente: Elaboración propia 


\section{CAPÍTULO IV: LEVANTAMIENTO Y ANÁLISIS DE LA INFORMACIÓN}

Para el desarrollo de esta investigación, se escogió un proyecto que consiste en la construcción de un túnel de trinchera cubierta en el Perú. La ejecución de este fue otorgada a un consorcio conformado por tres empresas especialistas del rubro, cada una de ellas con diferentes sistemas de gestión y planeamiento. Esta condición, como en la mayoría de los consorcios, dificulta la integración de metodologías de gestión a causa de las diferentes culturas y políticas organizacionales de las empresas. El alcance de este proyecto es la construcción civil y las instalaciones electromecánicas de un túnel en concreto armado de $930 \mathrm{~m}$ de longitud con una profundidad de $13 \mathrm{~m}$ en promedio. Este está constituido por dos calzadas rodoviarias y un carril central de vía ferroviaria. El área donde se proyectó su construcción presenta nivel de agua subterránea muy cercana a la superficie del terreno con profundidades entre 0.00 y $1.20 \mathrm{~m}$, razón por la cual el diseño de la ingeniería incluye la impermeabilización de todas las estructuras.

La estructura principal consiste en un túnel monolítico de concreto armado de sección rectangular enterrado a ejecutarse con la metodología constructiva "cut and cover", corte y relleno en zanja a cielo abierto. En el desarrollo de la longitud del túnel se identifica los siguientes tramos: tramo cubierto (túnel), tramo abierto (trinchera con vigas y trinchera sin vigas).

Figura Nro. 11: "Tramos del túnel”

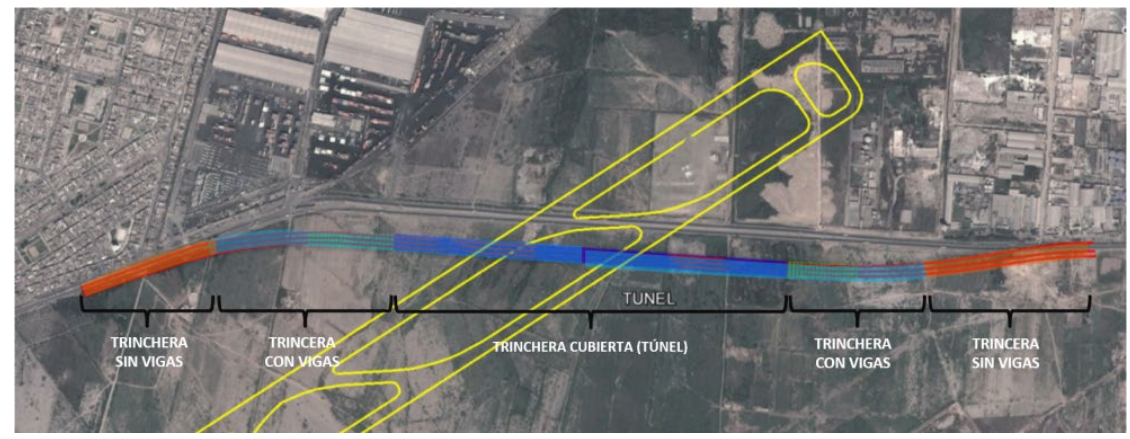

Fuente: Área de planeamiento - Consorcio Túnel Callao 
Los principales servicios que hacen parte de la construcción de este proyecto son los siguientes:

1. Excavación masiva

2. Impermeabilización

3. Protección mecánica

4. Elementos de concreto armado fabricados in situ, tales como losas inferiores, muros, losas superiores

5. Elementos de concreto armado pre-fabricados (vigas)

6. Pavimento rígido y pavimento flexible

7. Instalación de Sistemas Electromecánicos

8. Acabados y paisajismo

Figura Nro. 12: "Entrada del túnel en trinchera cubierta"



Fuente: Modelos virtuales - Consorcio Túnel Callao

En la figura número 13 se muestra la sección transversal del túnel con la denominación de los principales elementos estructurales que la conforman, del mismo modo se indica el recubrimiento perimetral de la impermeabilización y el relleno estructural que se conformará después del concretado y la impermeabilización del techo del túnel.

Figura Nro. 13: "Sección transversal del túnel”



TÚNEL EN THINCHERA CUBIERTA

Fuente: Área de ingeniería - Consorcio Túnel Callao 
Figura Nro. 14: "Dimensiones de elementos estructurales en sección típica"

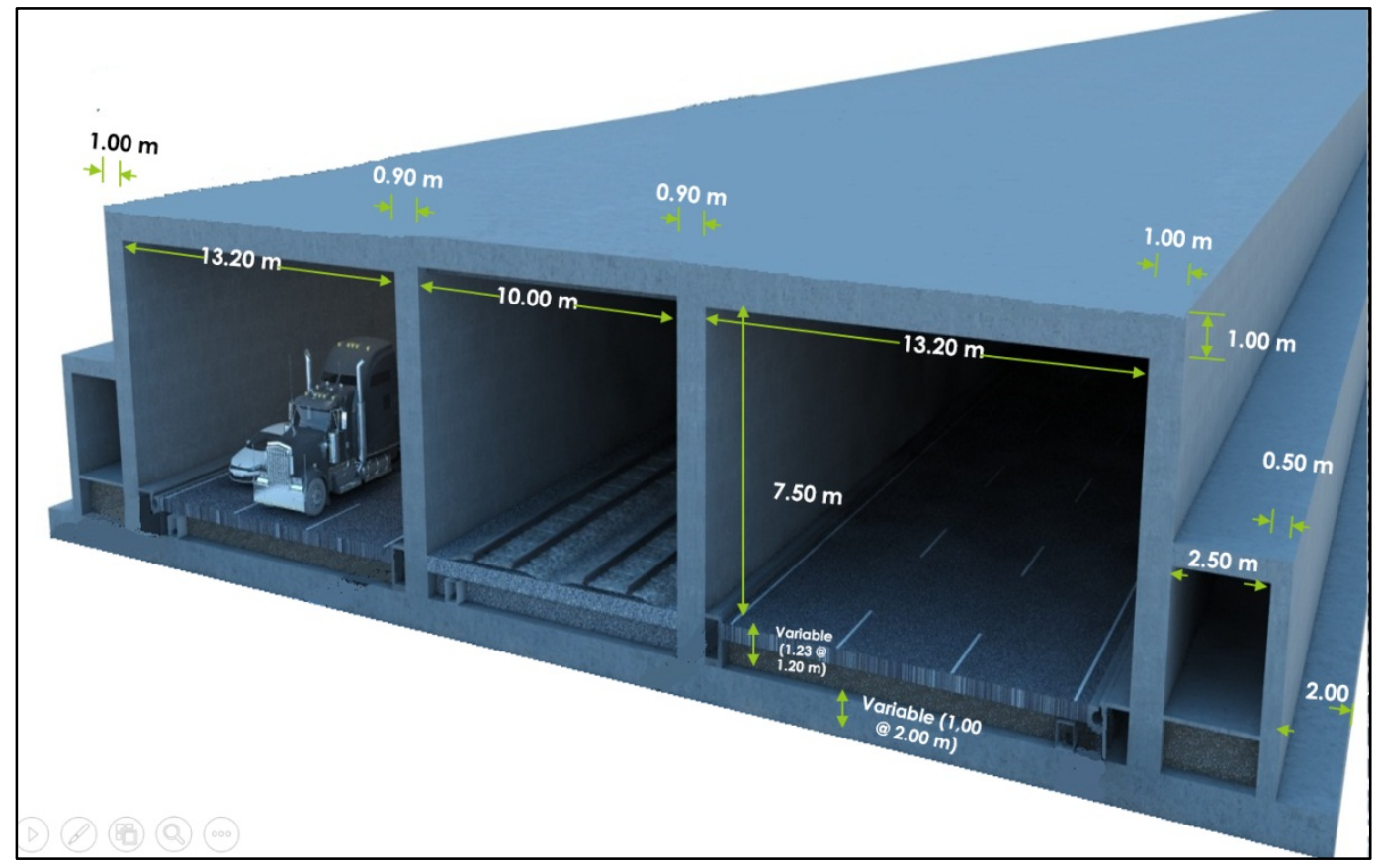

Fuente: Área de planeamiento - Consorcio Túnel Callao

El siguiente gráfico muestra de manera general una línea cronológica del proyecto. En este se puede observar las metodologías de planeamiento adoptadas y aplicadas durante el período de construcción del túnel. El hito de inicio se marcó el 04 diciembre del 2014 con la ejecución de obras provisionales y trabajos preliminares, esto comprende las instalaciones del campamento, las plantas industriales, la instalación del sistema de depresión de la napa freática e inicio de las excavaciones por los dos frentes de ataque. El inicio de la ejecución de los elementos estructurales se dio en la primera semana del mes de abril del 2015. La metodología de planeamiento adoptada durante los tres primeros meses a partir del inicio de los elementos estructurales tenía como premisa elaborar programaciones mensuales usando principios "push". Y a partir del mes de agosto se implementa la nueva metodología de planeamiento y programación con enfoque Lean Construction basada en principios "pull”.

Gráfico Nro. 7: "Metodologías de planeamiento aplicadas en la ejecución del túnel" 


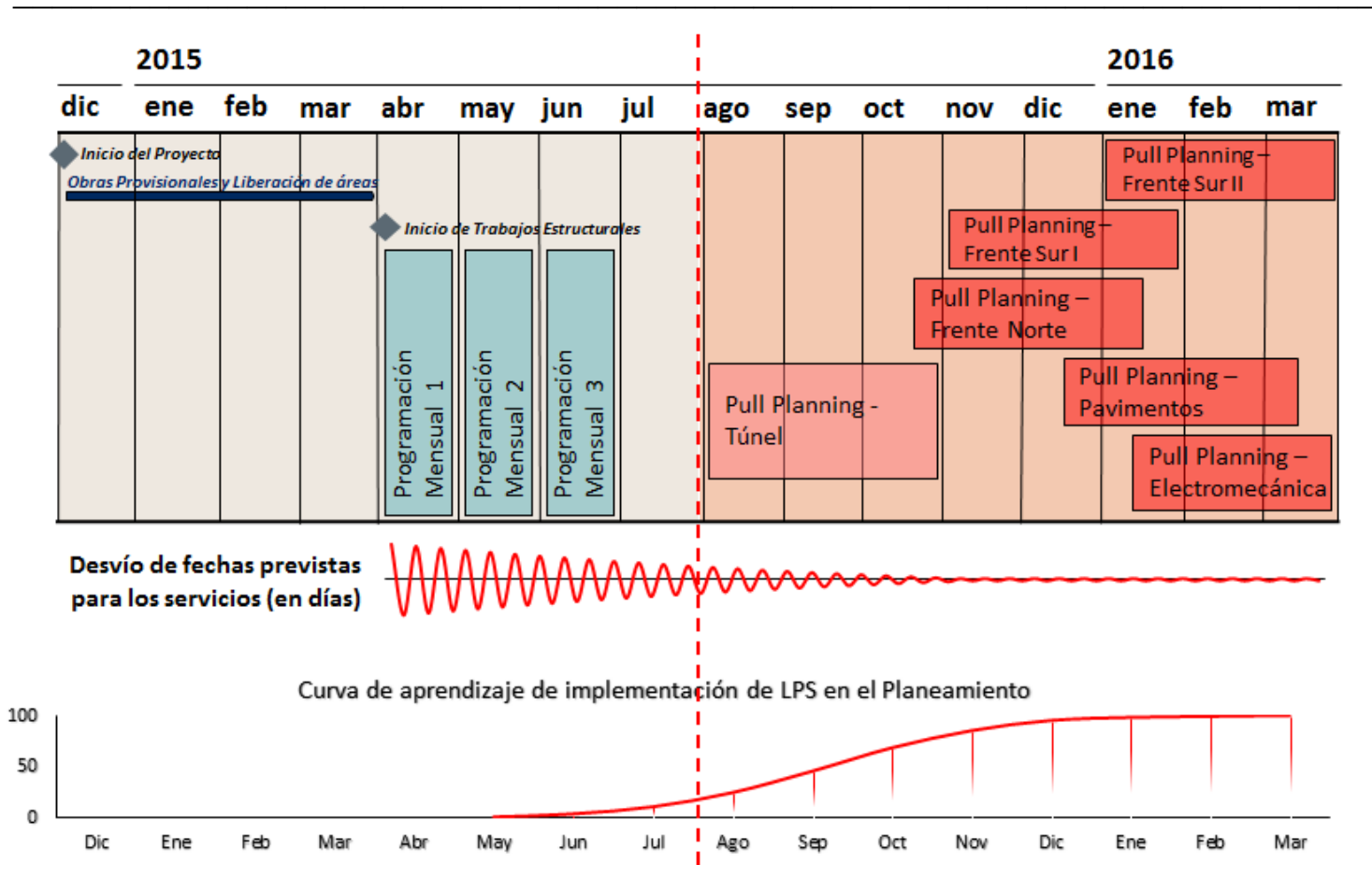

Fuente: Elaboración propia

A continuación, se presenta el estudio detallado de la planificación y control del túnel en trinchera cubierta en dos periodos de tiempo diferentes para poder evaluar los efectos de la implementación de las herramientas de la filosofía Lean Construction.

\section{Planeamiento y programación}

El plan de ataque contempla el inicio de la ejecución en el tramo cubierto con la finalidad de liberar con mayor anticipación sectores de trabajo para las instalaciones electromecánicas, que en su mayoría están dentro del túnel. En este sentido, se plantea el ataque por dos frentes en simultaneo que van al encuentro con la finalidad de garantizar menor plazo en la ejecución, véase la figura número 15. Asimismo, como parte de la concepción de este plan de ataque se define también la sectorización de los tramos del túnel en base a criterios de ingeniería y logística, de esta forma se configuran sectores o "unidades constructivas" cada 30 metros.

Figura Nro. 15: "Plan de ataque general del túnel” 


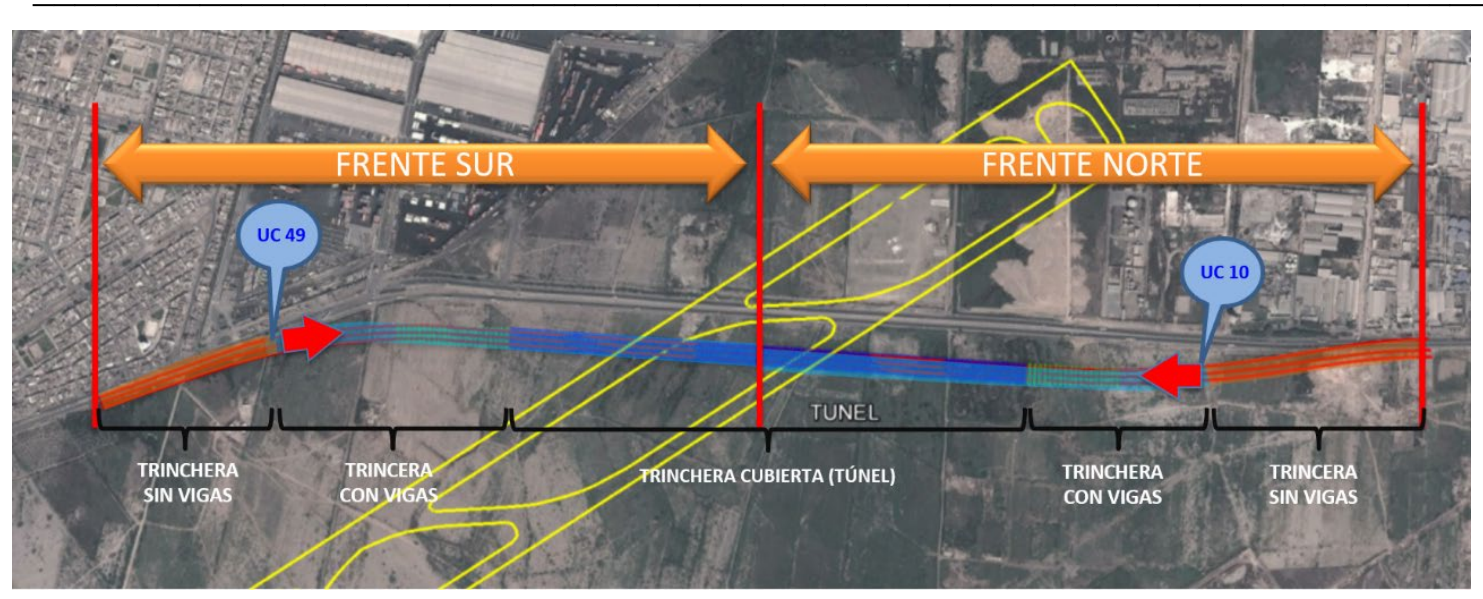

Fuente: Área de planeamiento - Consorcio Túnel Callao

Figura Nro. 16: "Plan de ataque del túnel - unidades constructivas de 30m"

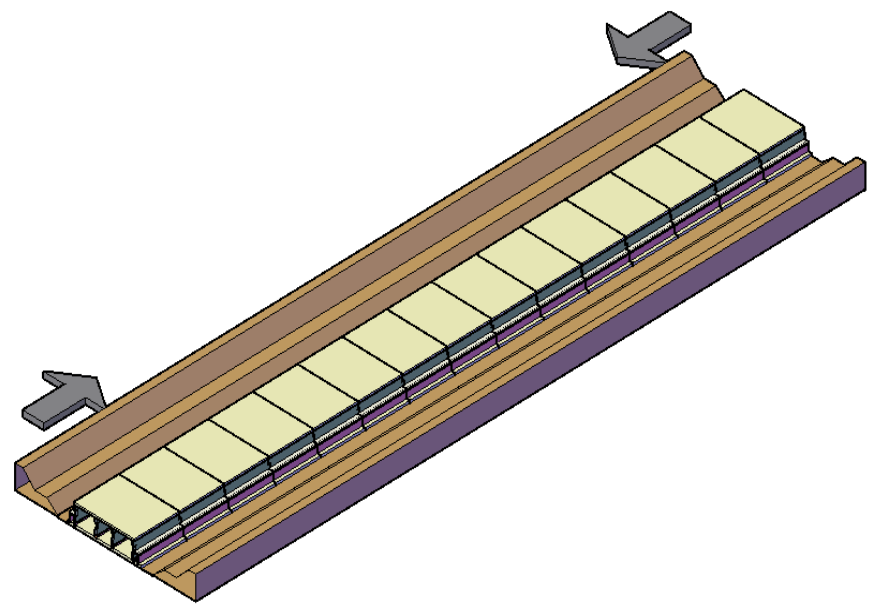

Fuente: Elaboración propia

El levantamiento y análisis de la información se hace a partir de la evaluación de dos sectores importantes de la ejecución del proyecto, planificación y producción. El periodo de análisis es desde el inicio del mes de abril hasta el fin de octubre del 2015. Definiéndose como hito clave la primera semana del mes de agosto en la que se dio mayor fuerza a la implementación de las metodologías de planeamiento Lean.

\section{Planeamiento tradicional inicial}

El planeamiento inicial contempla la elaboración del cronograma maestro con el alcance total del proyecto. Para ello se parte con la definición de la estructura de descomposición del trabajo o conocida también como la WBS (work breakdown structure). Luego se detallan todas las actividades que hacen parte de cada uno de los procesos y se determinan sus 
duraciones. Finalmente, se establecen las relaciones de dependencia entre ellas, creándose una red de precedencia. Esta metodología de trabajo emplea demasiado esfuerzo en detallar todas las actividades que se ejecutaran a lo largo del ciclo de vida del proyecto, incluso en aquellas que hacen parte de la etapa final. El desdoblamiento a este nivel de detalle trae como consecuencia un cronograma muy extendido sin posibilidad de hacer un análisis crítico de secuencias para toma de decisiones.

\section{Secuencia constructiva}

La secuencia constructiva del túnel en trinchera cubierta de acuerdo con el planeamiento inicial se basa en la ejecución de actividades según la dirección de ataque, es decir en el sentido de las progresivas del túnel. Ello con el fin de crear una secuencia lineal entre las actividades.

De esta manera, terminada la excavación y llegado a la cota de fundación se inicia con la instalación del geotextil, la geomembrana y la protección mecánica (solado). Se prosigue con la instalación del acero y el encofrado de losa para continuar con el vaciado de concreto masivo de este elemento. Luego de esperar el tiempo de fraguado de la losa de fondo se da inicio al armado e izaje del acero de los muros principales para continuar con la instalación del encofrado y el vaciado de concreto. Una vez fraguado el concreto de todos los muros de la unidad constructiva en ejecución se inicia con el izaje de las vigas prefabricadas para seguir con la instalación del acero de losa superior y finalmente hacer el vaciado de concreto de este elemento. El proceso constructivo de los muros y losas de las galerías está definido también en secuencia lineal, pero dependen de su ubicación a lo largo del desarrollo del túnel. Es decir, en el interior del túnel las galerías comparten la fundación con la losa de fondo y en los tramos de acceso y salida del túnel las galerías se encuentran a desnivel de la losa de fondo configurándose una losa de galería independiente.

En la figura número 17 se puede observar la secuencia constructiva prevista inicial del túnel. 
Figura Nro. 17: "Secuencia constructiva de elementos de concreto del túnel"



Fuente: Área de planeamiento - Consorcio Túnel Callao 


\section{- Losa de fondo}

A partir de la definición de secuencias lineales entre las actividades y procesos, el orden de ejecución de las losas es una después de otra siguiendo el sentido del plan de ataque, tal como se muestra en la figura número 18.

Figura Nro. 18: "Secuencia de ejecución de losas de fondo 1"

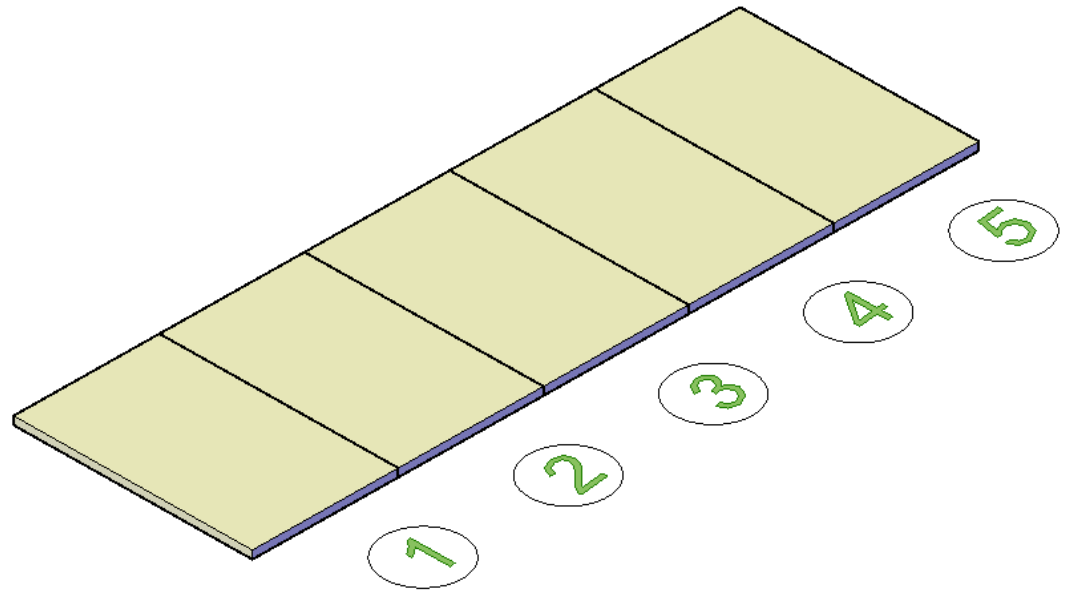

Fuente: Elaboración propia

\section{- Arranques}

La secuencia de ejecución de los arranques de los muros es en el mismo orden que el de las losas de fondo tal como se muestra en la figura número 19. Estos elementos nos permitirán continuar con la construcción de los muros centrales.

Figura Nro. 19: "Secuencia de ejecución de arranques de muros 1"

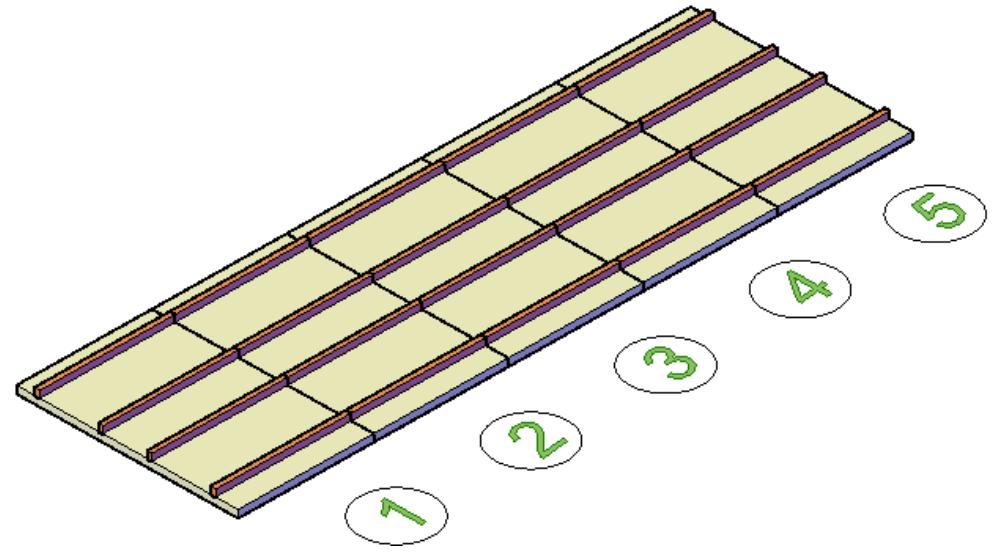

Fuente: Elaboración Propia 


\section{- Paredes centrales}

La ejecución de las paredes centrales, las cuales dividen el túnel para las vías rodoviarias y la vía ferroviaria, también están definidas en una secuencia lineal tal como se muestra en la figura número 20.

Figura Nro. 20: "Secuencia de ejecución de paredes centrales 1"



Fuente: Elaboración propia

\section{Programación de actividades}

- Alcance de la programación: Elaborar la programación mensual de las principales actividades a ejecutarse en obra durante este periodo.

- Responsables y sus funciones:

- Coordinador de planeamiento: definición de metas mensuales, acompañamiento y validación de la elaboración de la programación.

- Ingeniero de programación: elaboración de la programación de acuerdo a las metas mensuales.

- Gerente de producción: definición de estrategia de ejecución para la programación mensual. 
- Ingeniero encargado del frente: definición de duraciones y secuencias de las actividades a ejecutarse en el periodo.

- Metodología: La programación mensual es realizada por el ingeniero de programación con el coordinador de planeamiento y es validada por el gerente de producción.

- El proceso de la programación se inicia con el estudio de duraciones de las actividades en función a las productividades históricas y a los metrados.

$$
\text { Duración }=\text { Productividad } \times \text { Metrado } \times \frac{1}{\text { Jornada }} \times \frac{1}{\# \text { Hombres }}
$$

- Una vez obtenido las duraciones de las actividades se pasa a identificar la secuencia natural de los procesos constructivos de un elemento estructural típico (losa de fondo, arranque y muro). Luego, se estudia la mejor secuencia de ataque del conjunto de elementos estructurales que se realizarán durante el mes.

- Finalmente, se consolida la información de manera gráfica en un cronograma mensual de obra elaborado en una hoja de cálculo de Excel.

- Ventajas y desventajas:

Tabla Nro. 5: "Ventajas y desventajas de la programación mensual"

\begin{tabular}{|l|lll|}
\hline \multicolumn{2}{|c|}{ VENTAJAS } & \multicolumn{3}{|c|}{ DESVENTAJAS } \\
\hline - Facilidad de uso de planillas Excel & - Dificultad de actualización de \\
para la elaboración de la & reprogramaciones cada vez que se \\
programación mensual. & presenta un problema. & \\
- Cumplimiento de metas mensuales & - Retrabajos del equipo de \\
financieras en base a la programación & planeamiento por reprogramación de \\
realizada. & & \\
\end{tabular}




\begin{tabular}{|l|l|l|}
\hline \multicolumn{2}{|c|}{ VENTAJAS } & \multicolumn{2}{|c|}{ DESVENTAJAS } \\
\hline planeamiento y producción. & $\begin{array}{l}\text { las actividades en los frentes en } \\
\text { ejecución. } \\
\text { - Falta de participación de las áreas de } \\
\text { apoyo en la elaboración de la la } \\
\text { programación mensual. } \\
\text { - Retraso en la llegada de los equipos y } \\
\text { materiales necesarios para la } \\
\text { construcción por falta de previsión. }\end{array}$ \\
\hline
\end{tabular}

Fuente: Elaboración propia

- Programaciones del primer trimestre:

- Programación mensual Abril 2015: La programación se muestra en el “Anexo 01: Programación Mensual de Abril 2015".

- Programación mensual Mayo 2015: La programación se muestra en el “Anexo 02: Programación Mensual de Mayo 2015".

- Programación mensual Junio 2015: La programación se muestra en el “Anexo 03: Programación Mensual de Junio 2015".

\section{Secuencia de actividades}

La programación de los primeros tres meses de la construcción del túnel se hizo de acuerdo con el plan de ataque inicial basado en la secuencia constructiva de cada elemento y en la logística de los procesos con la finalidad de garantizar la secuencia de ejecución lineal prevista inicialmente. Sin embargo, ello no garantizaba líneas de flujo de los recursos de mano de obra empleados en la ejecución de las actividades. 
La gráfica número 8 muestra la secuencia de programación de servicios de dos losas de fondo durante el primer periodo. Como se muestra, la actividad que marca el ritmo de ejecución es la instalación del acero, y las demás actividades se ajustan a ella sin necesidad de tener flujo continuo entre ellas. Sucede lo mismo en la programación de arranques y muros verticales.

Gráfico Nro. 8: "Programación inicial"

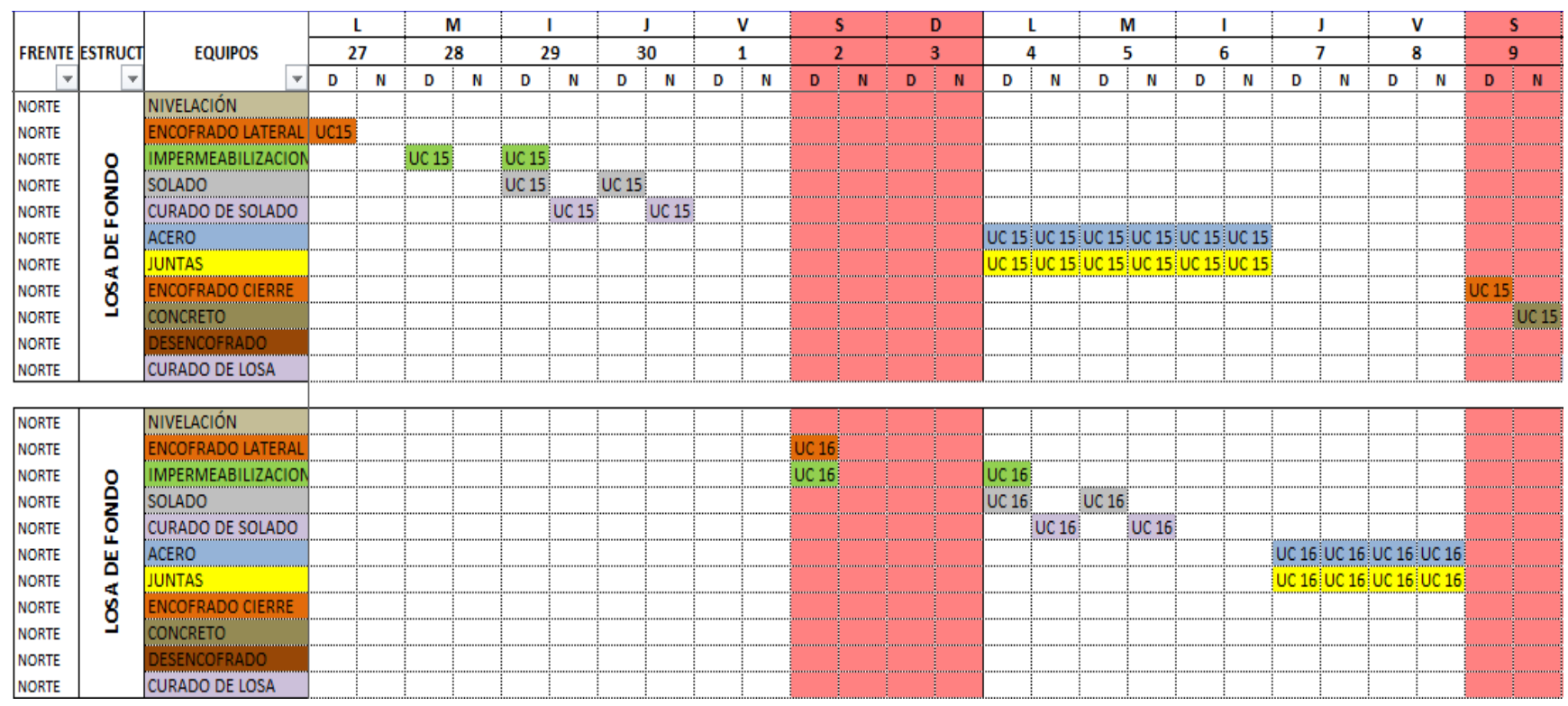

Fuente: Programación mensual - Área de planeamiento CTC

\section{Planeamiento con enfoque Lean Construction}

A partir de las metodologías para el planeamiento basada en Last Planner System y Pull Planning el periodo de previsión para la elaboración de las programaciones es de aproximadamente 3 meses. El plan de ataque del túnel en general sigue siendo el mismo, es decir, ambos frentes de trabajo tanto el frente norte y el frente sur avanzan a su encuentro; sin embargo, las secuencias entre las estructuras de concreto, principalmente la de las paredes centrales, cambia con el fin de garantizar mayor flujo y balance en el uso de recursos de las actividades (mano de obra, materiales y equipos).

\section{Secuencia constructiva}

La secuencia de ataque de las losas de fondo no presento cambios entre el planeamiento inicial y el planeamiento con enfoque de Lean Construction debido a que la ejecución de 
estos elementos ya tenía gran porcentaje de avance y fue este con el cual los operarios iniciaron los primeros trabajos y se especializaron en su ejecución.

- Losa de fondo

En la figura número 21 se muestra la secuencia de ejecución de las losas de fondo que no cambia con la aplicación del Planeamiento Lean.

Figura Nro. 21: "Secuencia de ejecución de losa de fondo 2"

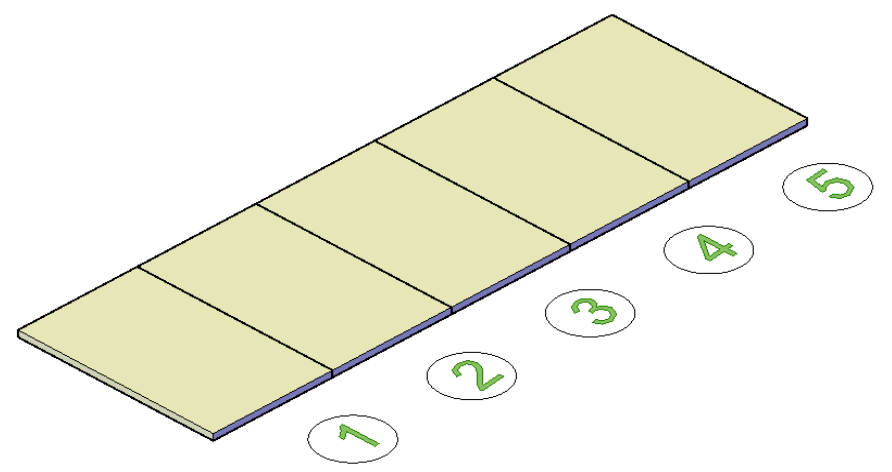

Fuente: Elaboración propia

\section{- Arranques}

La construcción de los arranques se cambió de una secuencia lineal a una secuencia alternada como se muestra a continuación, en la figura número 22 y 23 , con la finalidad de atender la secuencia prevista para las paredes centrales.

Figura Nro. 22: "Secuencia de ejecución de arranques 2.1"



Fuente: Elaboración propia

Figura Nro. 23: "Secuencia de ejecución de arranques 2.2" 


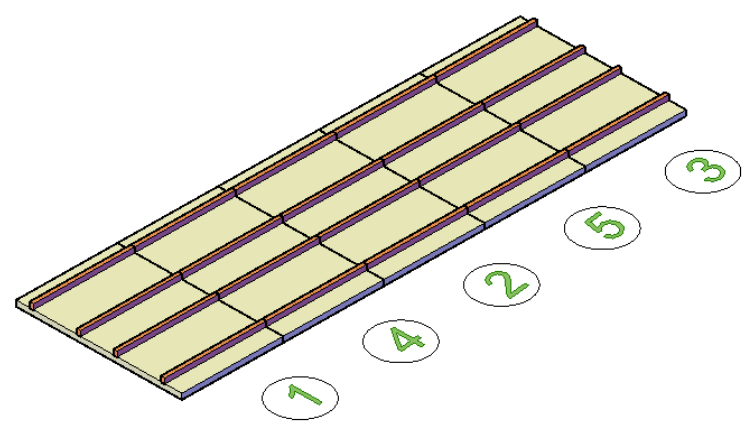

Fuente: Elaboración propia

\section{- Paredes centrales}

El diseño de estos elementos estructurales contempla llaves de corte que cumplen la finalidad de engranar una pared con otra con un sistema similar al machimbrado. En la figura número 24 se muestra el detalle de las llaves de corte.

Figura Nro. 24: "Llaves de corte"

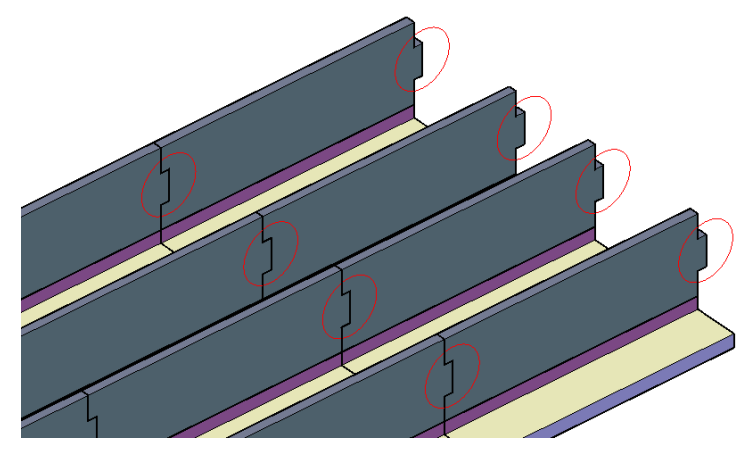

Fuente: Elaboración propia

Las paredes centrales sufrieron un cambio sustancial en su secuencia, esta vez se concibió ejecutarlas de manera alternada para mejorar los tiempos y el flujo de los recursos entre las actividades. Seguir trabajando de forma lineal, donde la secuencia es una detrás de otra no fue una solución favorable porque existían tiempos tecnológicos muertos entre la ejecución de muros contiguos, básicamente por la espera de curado y desencofrado de las llaves de corte, puesto que se consideraban a estos elementos como vigas en voladizo, las cuales necesitaban un apuntalamiento hasta llegar a la madurez deseada del concreto.

Figura Nro. 25: "Secuencia de ejecución de paredes centrales 2.1" 


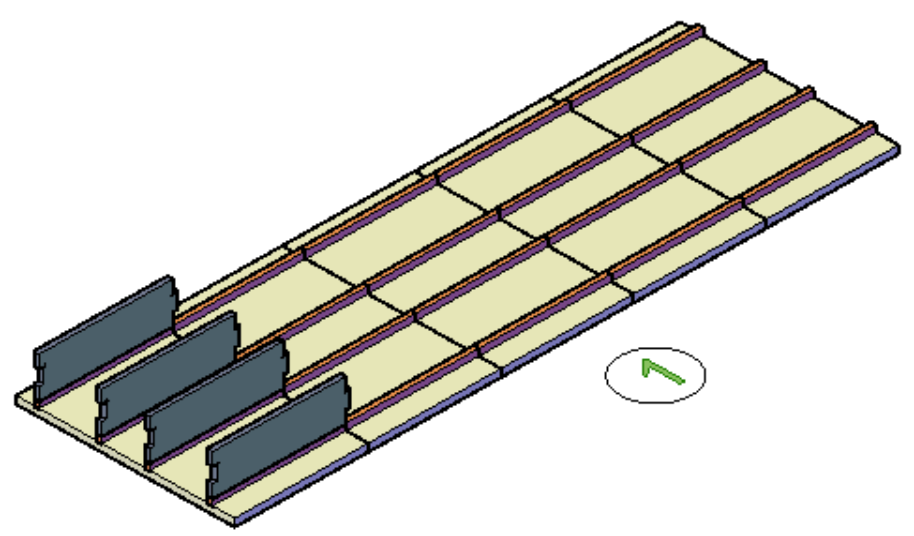

Fuente: Elaboración propia

Figura Nro. 26: "Secuencia de ejecución de paredes centrales 2.2"

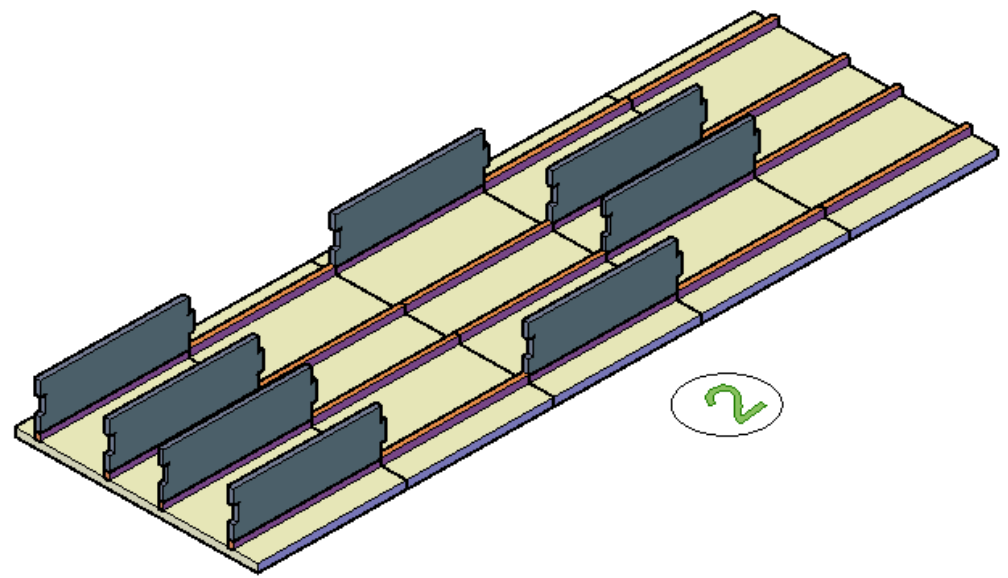

Fuente: Elaboración propia

Figura Nro. 27: "Secuencia de ejecución de paredes centrales 2.3"



Fuente: Elaboración propia 
Figura Nro. 28: "Secuencia de ejecución de paredes centrales 2.4"



Fuente: Elaboración propia

Figura Nro. 29: "Secuencia de ejecución de paredes centrales 2.5"

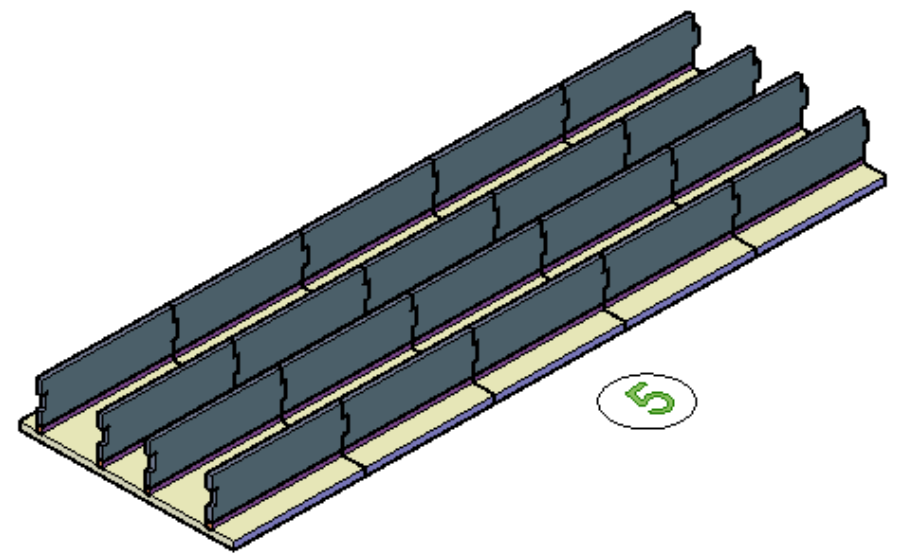

Fuente: Elaboración propia

\section{Programación trimestral (Agosto - Septiembre - Octubre 2015)}

- Alcance: Elaborar la programación trimestral de las principales actividades a ejecutarse en obra en base a la metodología de Pull Planning.

- Responsables y sus funciones:

- Coordinador de planeamiento: definición de marcos y entregables de los servicios a ejecutarse en los próximos tres meses de obra. 
- Ingeniero de programación: estudio de secuencias de actividades (duraciones y recursos) necesarios para cumplir con los marcos definidos en los próximos tres meses. Elaboración de cronograma pull planning en el software de planeamiento (Primavera P6).

- Ingeniero de sala técnica, establecimiento de prioridades en la liberación de proyectos de acuerdo con la previsión del cronograma de pull planning.

- Ingeniero de calidad: identificación de restricciones en base a la secuencia de ataque para la elaboración de procedimientos operacionales $\mathrm{y}$ entrenamientos del personal para asegurar de la calidad de los procesos.

- Ingeniero de seguridad: identificaciones de restricciones asociadas a peligros y riesgos de las actividades a ejecutarse en los próximos tres meses con la finalidad de asegurar la ejecución de trabajos con cero accidentes.

- Gerente de producción: definición de estrategias de ejecución en los próximos tres meses con el objetivo de asegurar el flujo continuo y balance de las actividades.

- Ingeniero encargado del frente: definición de duraciones, secuencias y asignación de recursos en las actividades con el objetivo de asegurar el flujo continuo y balance en el uso de recursos.

- Jefe de producción: garantizar y velar por la aplicación de las estrategias planteadas según la programación trimestral (pull planning)

- Supervisores y capataces: identificación de restricciones para la ejecución de las actividades previstas en los próximos tres meses. Participación activa en la dinámica de pull planning para validación de las secuencias y metas esperadas. 
- Administrador de obra: identificación de los principales servicios a ejecutarse en los próximos tres meses para atención a las demandas del proyecto.

- Metodología:

- Preparación de la información necesaria: el proceso de programación comienza con la identificación de los marcos y/o metas a alcanzar en los próximos tres meses. Continua con el estudio detallado de las actividades, secuencias y duraciones que harán parte del cronograma Pull Planning, según las especificaciones técnicas y planos de la ingeniería del proyecto. Luego, se pasa a la identificación de los recursos de las actividades detalladas tales como materiales, mano de obra y equipos, por último, se asigna los responsables de ejecución a cada una de estas actividades. Los resultados de este proceso se consolidan en una base de datos. El tiempo estimado para esta primera etapa es de dos semanas y se cierra con la creación del cronograma Pull Planning.

- Preparación de la sesión de Pull Planning: implica la separación de un espacio para la sesión de planificación y la elaboración de los materiales didácticos a emplearse, tales como la presentación gráfica de secuencias del proceso constructivo, papelógrafos en forma de calendario semanal y los post-it que representan cada una de las actividades y sus duraciones. La duración de esta segunda etapa es de una semana y finaliza con la invitación a todos los participantes de la sesión (áreas de apoyo, supervisores y capataces).

- Sesión de Pull Planning: durante la reunión se reconoce la secuencia de trabajos, los marcos y/o hitos meta de los próximos tres meses. Se crea un plan de trabajo colectivo con objetivos definidos, se identifica las dependencias, interrelaciones, riesgos y restricciones relevantes asociadas a las actividades previstas. Para finalizar, se consolidan todas estas informaciones, se cierra la línea base del cronograma pull planning y se 
ratifica la meta con el compromiso de todos los participantes y áreas de apoyo.

- Próximos pasos: insertar la programación en un software de planeamiento (MS Project, Primavera P6) con los recursos mapeados para dar inicio a las programaciones semanales.

- Ventajas y desventajas:

Tabla Nro. 6: "Ventajas y desventajas de la programación trimestral"

\begin{tabular}{|l|l|}
\hline VENTAJAS & \multicolumn{1}{|c|}{ DESVENTAJAS } \\
\hline -Nivel de detalle necesario y & - El tiempo de estudio, preparación y \\
suficiente en la planificación de los & dinámica del Pull Planning es un \\
próximos 3 meses, con enfoque en & proceso con una duración aproximada \\
flujo de procesos. & de 20 días. \\
-Cumplimiento de marcos generales & \\
del proyecto con visión a largo plazo. & \\
- Participación colaborativa de las & \\
áreas de apoyo, supervisores y & \\
capataces en la elaboración de & \\
cronograma Pull Planning. & \\
- Identificación y difusión de & \\
restricciones de los próximos tres & \\
meses por todas las áreas de apoyo. & \\
- Nivelación y optimización de &
\end{tabular}

Fuente: Elaboración propia 


\section{Programación semanal por encargado y servicio}

- Alcance: Elaborar la programación semanal de las principales actividades a ejecutarse en obra por encargado y servicio.

- Responsables y sus funciones:

- Coordinador de planeamiento: asegurar que las programaciones semanales sean adherentes a la línea base pull planning para garantizar el cumplimiento de los marcos y/o hitos meta.

- Ingeniero de programación: elaboración de la programación semanal en coordinación con el ingeniero encargado de frente

- Ingeniero encargado del frente: reportar los avances semanales para la actualización del cronograma pull planning y la elaboración de la programación semanal con el ingeniero de programación.

- Metodología:

- Liberación de restricciones: la regla básica para la programación semanal es programar actividades libres de restricciones, de tal forma que todas estas puedan ser ejecutadas sin inconvenientes por el personal en obra.

- Avance del cronograma pull planning: otra etapa preliminar a la programación semanal es la actualización del cronograma pull planning con los avances de la última semana programada-ejecutada.

- Programación semanal: consiste en la asignación de actividades diarias por tipo de servicios o responsables a través de un formato de programación semanal.

- Las programaciones semanales son distribuidas a todos los responsables de las áreas de apoyo, supervisores y/o capataces el primer día de cada semana para dar alcance de todas las actividades a cumplirse de acuerdo al cronograma pull planning. 
- Ventajas y desventajas:

Tabla Nro. 7: "Ventajas y desventajas de la programación semanal"



Fuente: Elaboración propia

\section{Línea de balance de actividades}

Las líneas de balance es una herramienta adoptada del balanceo de líneas de ensamblaje industrial y adaptado para balancear las actividades o servicios para la ejecución de los elementos estructurales. La finalidad de la técnica de balanceo de la línea de ensamblaje radica en:

- Igualar la carga de trabajo entre los ensambladores. 
- Identificar la operación cuello de botella.

- Establecer la velocidad de la línea de ensamblaje.

- Determinar el número de estaciones de trabajo.

- Determinar el costo por mano de obra de ensamblaje y empaque.

- Establecer la carga de trabajo porcentual de cada operador.

- Ayudar en la disposición física de la planta.

- Reducir el costo de producción.

El objetivo de esta técnica es dar a cada operador la misma cantidad de trabajo estableciendo estaciones de trabajo que contemplen actividades con duraciones similares. 8 Análogamente la finalidad de la creación de las líneas de balance de actividades en construcción es:

- Igualar la carga de trabajo entre los colaboradores dimensionando equipo de trabajo.

- Identificar la actividad cuello de botella.

- Establecer la velocidad de la línea de balance (takt).

- Determinar el número de grupos y secuencia de ataque.

- Servir de base para la dinámica Pull Planning y las programaciones en software de planeamiento Primavera P6.

$\underline{\text { Takt }}$

El takt es una expresión alemana que establece la relación entre el tiempo disponible de producción entre la demanda del cliente.

$$
T A K T=\frac{\text { tiempo disponible }}{\text { demanda del cliente }}
$$

"La tasa o ritmo de la planta (valor R) y el tiempo takt le indican al ingeniero industrial a qué velocidad se debe operar la planta para satisfacer la demanda del cliente. Todas las máquinas y operaciones de la planta se sincronizan con ese ritmo; asimismo, las piezas deben ser suministradas a la misma velocidad con que las líneas de ensamble las utiliza." (Meyers 2000: 258).

8 Cfr. Meyers 2000:70 
Las informaciones necesarias para el cálculo del takt en construcción civil son:

- Datos sobre volumen de producción. Conocido también como metrados.

- Las tolerancias del proceso. Se entiende por la estimación del porcentaje de tiempo que la línea de producción estará parada.

- Prever el grado de eficiencia. Entiéndase por diseñar los procesos para con una eficiencia que nos permita cumplir las metas como la producción y la productividad.

En el siguiente gráfico, se muestra un ejemplo de línea de balance de actividades para las losas de fondo del túnel.

El proceso constructivo de estas comprende las actividades de excavación, mejoramiento de suelos, nivelación de superficie, encofrado lateral, impermeabilización, protección mecánica, instalación de acero, encofrado frontal, vaciado de concreto y finalmente el desencofrado. Se puede observar que todas las actividades están definidas bajo el ritmo de trabajo de la actividad de instalación de acero y encofrado, debido a que son el cuello de botella por la cantidad de metrados a ejecutar.

Gráfico Nro. 9: "Programación Lean"

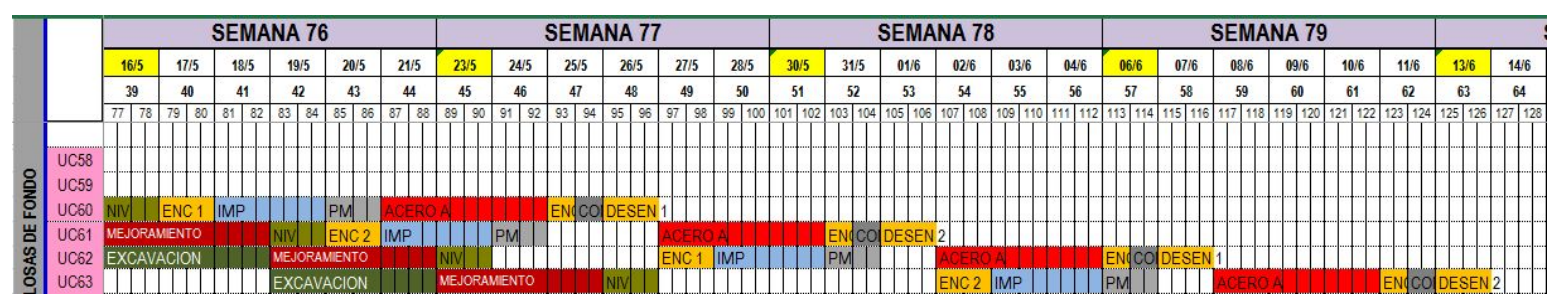

Fuente: Elaboración propia

\section{Comparación del planeamiento tradicional inicial y el planeamiento con enfoque Lean}

A continuación, se muestra un cuadro comparativo de las metodologías de planeamiento. Se toma en cuenta el alcance general de la metodología, las herramientas de programación y control y por último la identificación de los participantes directos encargados del funcionamiento del sistema.

Tabla Nro. 8: "Planeamiento tradicional inicial y planeamiento con enfoque Lean" 


\begin{tabular}{|c|c|c|}
\hline & $\begin{array}{l}\text { PLANEAMIENTO TRADICIONAL } \\
\text { INICIAL }\end{array}$ & $\begin{array}{c}\text { PLANEAMIENTO CON ENFOQUE } \\
\text { LEAN }\end{array}$ \\
\hline Alcance & $\begin{array}{l}\text { Desarrollar el planeamiento del } \\
\text { proyecto con enfoque lineal e } \\
\text { independiente a la programación. } \\
\text { Realizar control semanal de la } \\
\text { producción de acuerdo con las } \\
\text { previsiones del área de } \\
\text { planeamiento. }\end{array}$ & $\begin{array}{l}\text { Desarrollar y garantizar el } \\
\text { funcionamiento del planeamiento } \\
\text { estratégico mediante creación de } \\
\text { rutinas y asignación de } \\
\text { responsabilidades con las demás } \\
\text { áreas del proyecto, especialmente } \\
\text { con el área de producción }\end{array}$ \\
\hline $\begin{array}{l}\text { Cronograma } \\
\text { Gerencial }\end{array}$ & $\begin{array}{l}\text { Crear un cronograma gerencial } \\
\text { con un nivel de detalle que } \\
\text { contemple todas las actividades } \\
\text { del proyecto. Su actualización es } \\
\text { muy tediosa y poco eficiente. } \\
\text { Dificulta hacer análisis de } \\
\text { informaciones y KPI's del } \\
\text { planeamiento. }\end{array}$ & $\begin{array}{l}\text { Crear un cronograma reducido que } \\
\text { defina como último nivel los } \\
\text { principales marcos e hitos de inicio y } \\
\text { fin de los servicios del proyecto. } \\
\text { Desdoblar en detalle mediante } \\
\text { cronogramas pull planning con } \\
\text { previsión trimestral. }\end{array}$ \\
\hline Programaciones & $\begin{array}{l}\text { Elaborar programaciones } \\
\text { mensuales de actividades que se } \\
\text { ejecutaran en los frentes de trabajo } \\
\text { del proyecto. }\end{array}$ & $\begin{array}{l}\text { Elaborar programaciones trimestrales } \\
\text { de los frentes de trabajo con } \\
\text { participación colaborativa de los } \\
\text { capataces. Elaborar programaciones } \\
\text { semanales con asignación de } \\
\text { responsables para garantizar su } \\
\text { cumplimiento. }\end{array}$ \\
\hline $\begin{array}{l}\text { Secuencia } \\
\text { Constructiva }\end{array}$ & $\begin{array}{l}\text { Secuencia lineal entre las } \\
\text { actividades de acuerdo a los } \\
\text { procedimientos de ejecución de los } \\
\text { servicios de la obra. }\end{array}$ & $\begin{array}{l}\text { La secuencia de trabajo se elabora a } \\
\text { partir de balance de actividades y } \\
\text { tiempos. }\end{array}$ \\
\hline Responsables & $\begin{array}{l}\text { Área de planeamiento y gerente } \\
\text { del área de producción. }\end{array}$ & $\begin{array}{l}\text { Área de planeamiento y el área } \\
\text { producción (jefes, supervisores y } \\
\text { capataces). }\end{array}$ \\
\hline Control & $\begin{array}{l}\text { El control de la ejecución de } \\
\text { servicios se hace semanalmente } \\
\text { mediante un recorrido al proyecto y }\end{array}$ & $\begin{array}{l}\text { El control de avance del proyecto se } \\
\text { hace a diario mediante reuniones de }\end{array}$ \\
\hline
\end{tabular}




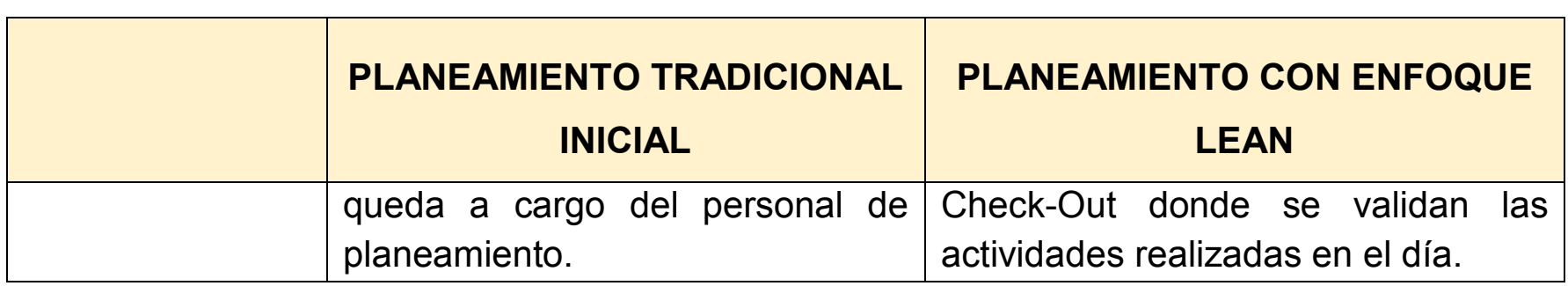

Fuente: Elaboración propia

\section{Resultados de la implementación}

\section{Previsto vs realizado}

La adherencia de la ejecución al planeamiento se muestra con la comparación entre lo previsto y lo realizado. La evaluación en esta parte del estudio solo se enfoca en los elementos estructurales de losas inferiores y muros porque tanto en el periodo de planificación tradicional como en el de lean fueron las estructuras con más complicaciones en cumplir con la programación. En cambio, otros elementos tales como los arranques de muros no presentaron mayor dificultad porque la cantidad de acero, encofrado y concreto era menor, además que su ejecución era dependiente del concretado de la losa de fondo.

A continuación, se muestra las gráficas de previsto vs realizado de la losa inferior y paredes centrales de los dos frentes de trabajo en los dos periodos de evaluación.

Gráfico Nro. 10: "Previsto vs realizado - losa inferior (frente norte)"

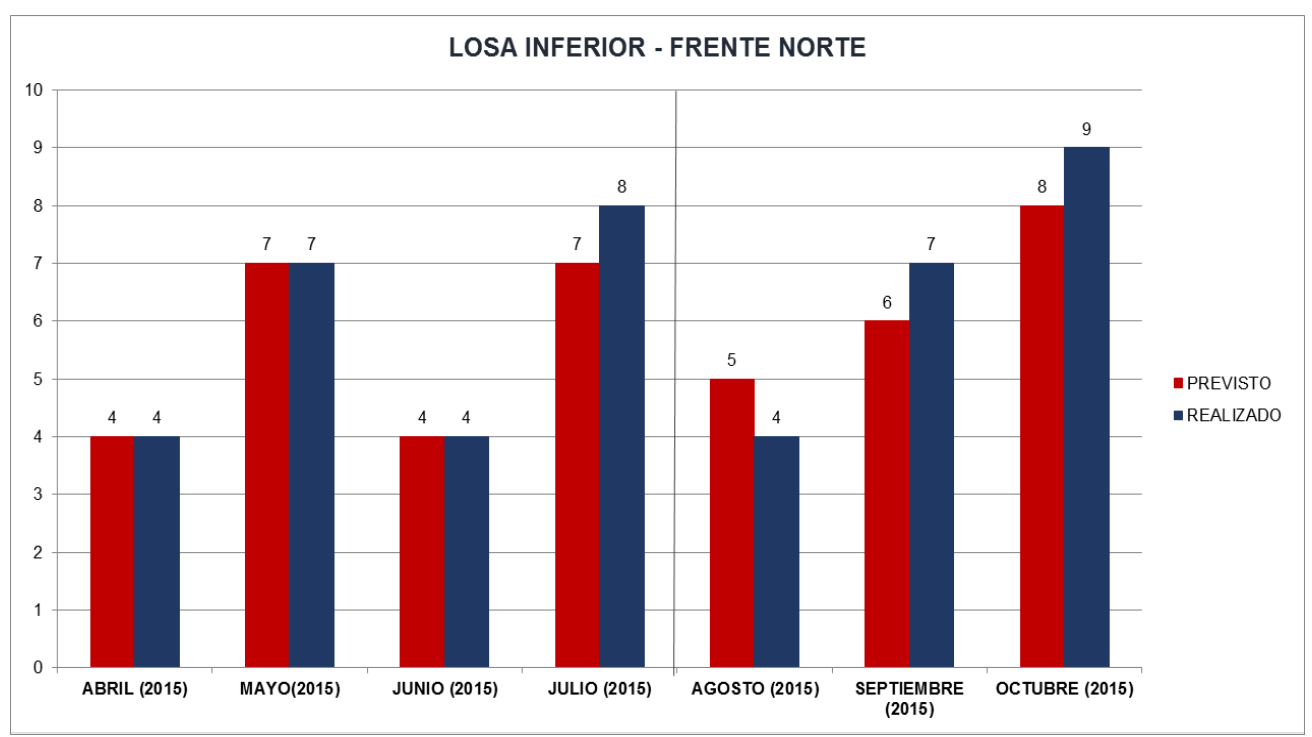

Fuente: Elaboración propia

Gráfico Nro. 11: "Previsto vs realizado - losa inferior (frente sur)" 




Fuente: Elaboración propia

Gráfico Nro. 12: "Previsto vs realizado - muros (frente norte)"

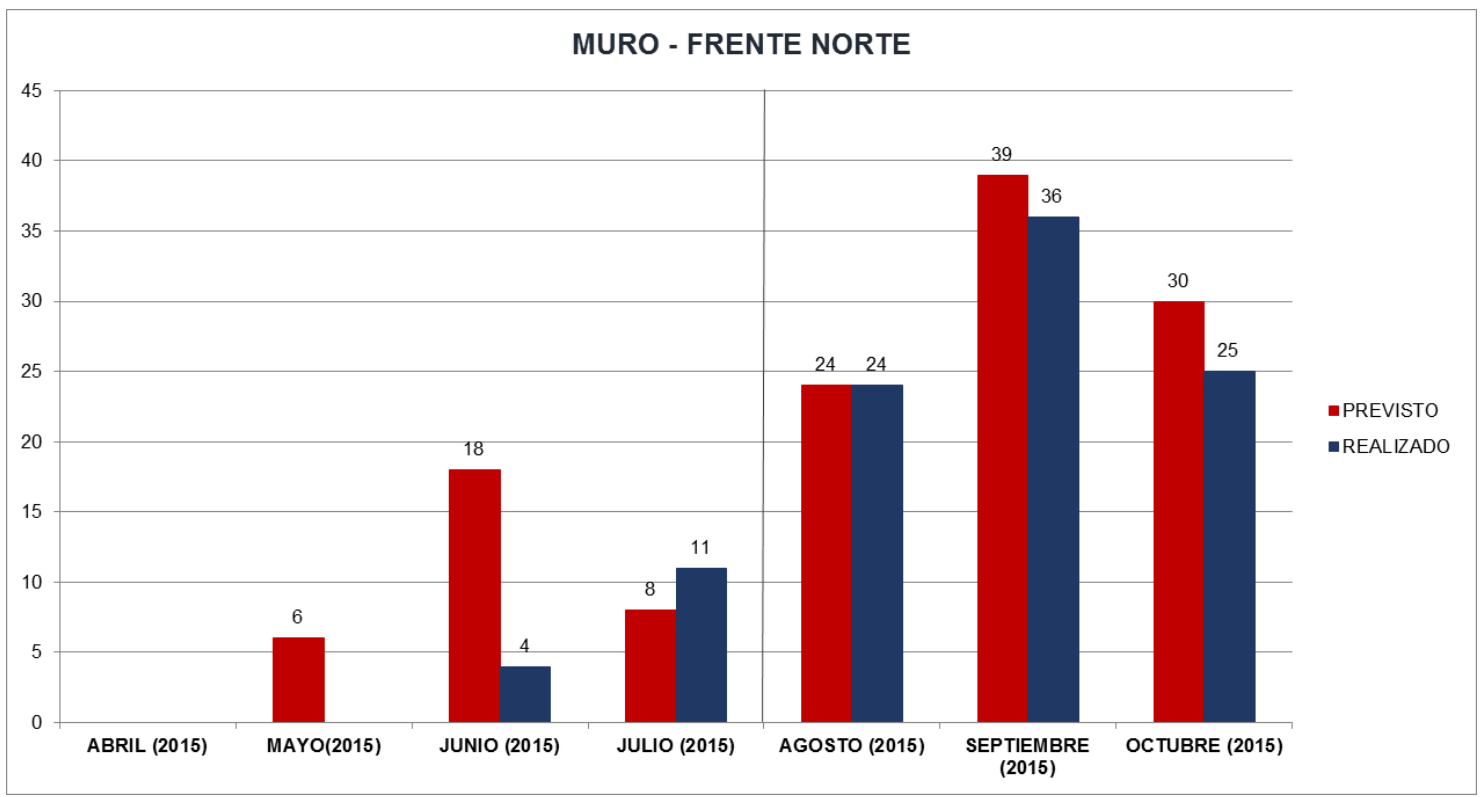

Fuente: Elaboración Propia

Gráfico Nro. 13: "Previsto vs realizado - muros (frente sur)" 


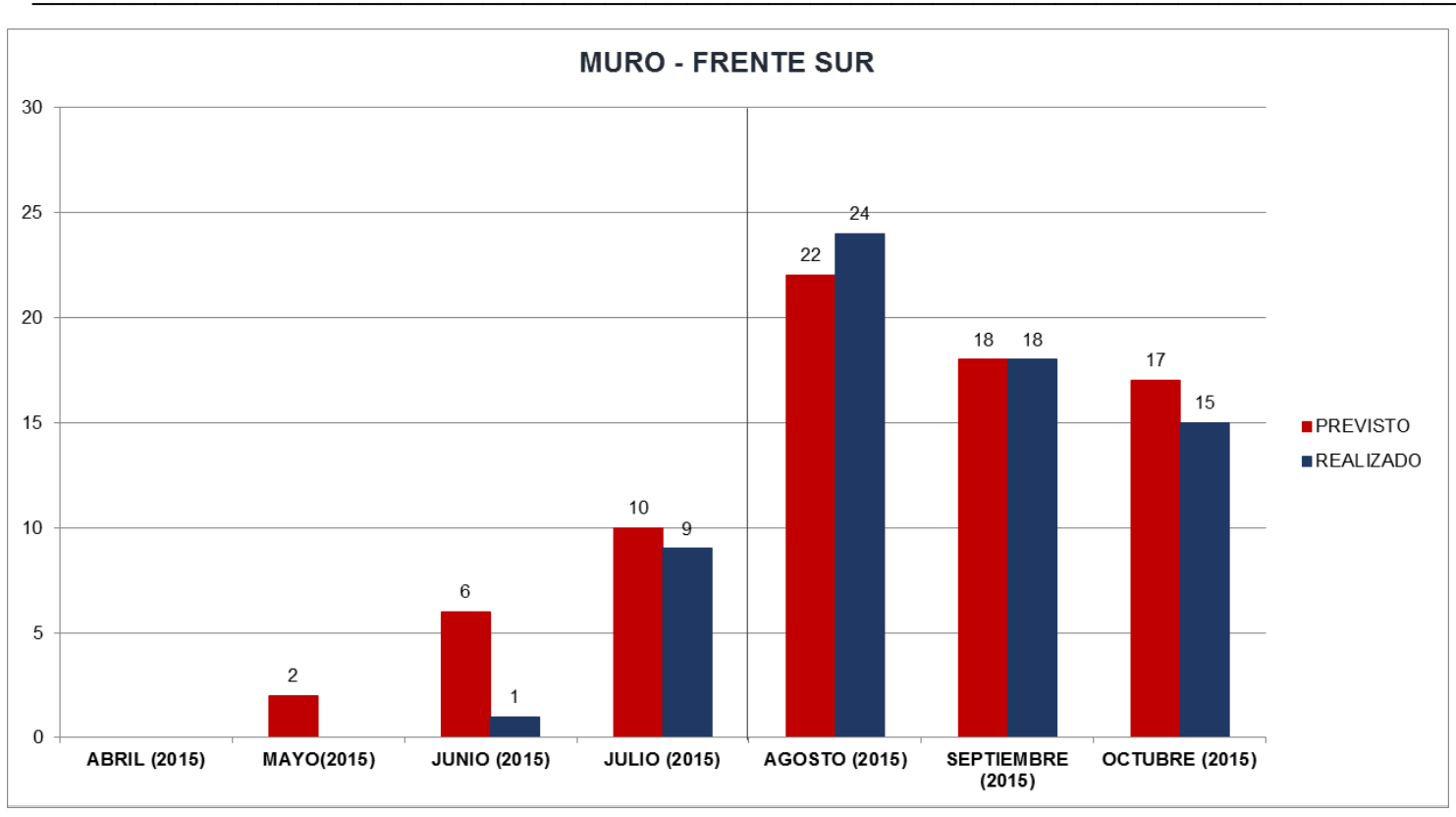

Fuente: Elaboración propia

Los trabajos de montaje de vigas, losas superiores, galerías y relleno exterior del túnel se iniciaron en los meses de septiembre y octubre. Por ello, no es factible analizar el previstorealizado de la ejecución de dichos servicios ya que solo se empezaron a desarrollar en los últimos meses del periodo de estudio y no desde el periodo de planeamiento inicial.

\section{Porcentaje del plan cumplido - PPC}

El PPC (Porcentaje de plan cumplido) es un indicador de desempeño que mide la efectividad de la programación semanal, es decir el grado de adherencia de los trabajos ejecutados a los programados al inicio de la semana.

Su aplicación permite monitorear el alcance de metas diarias y/o semanales de las personas en obra y hacer planes de acción en caso de desvíos o incumplimiento. Es importante que se haga a nivel de responsables de los servicios programados para crear compromiso con el cumplimiento de los objetivos.

En los gráficos número 14 y 15 se muestran los PPC alcanzados semana a semana durante el periodo de planeamiento inicial y planeamiento lean. Se puede observar que en los meses de abril, mayo, junio y julio la desviación estándar de los PPC fue de 0.35 , esto demuestra la gran variabilidad en el cumplimiento de las programaciones semanales. Asimismo, se observa que durante este periodo inicial el PPC oscila drásticamente entre picos de 100\% y 0\% debido a que una vez elaborada las programaciones mensuales, solo la primera semana 
era más adherente a lo planificado y las siguientes tres semanas perdían adherencia por causa de cambios de secuencias y/o prioridades.

A partir de la tercera semana de julio hasta el final de octubre se puede constatar que la variabilidad disminuye y la curva de PPC ya no presenta picos tan pronunciados, como resultado de ello la desviación estándar disminuye a 0.12 y los datos muestran mayor adherencia a la programación con un compartimiento ascendente.

Gráfico Nro. 14: "PPC semanal - frente norte"

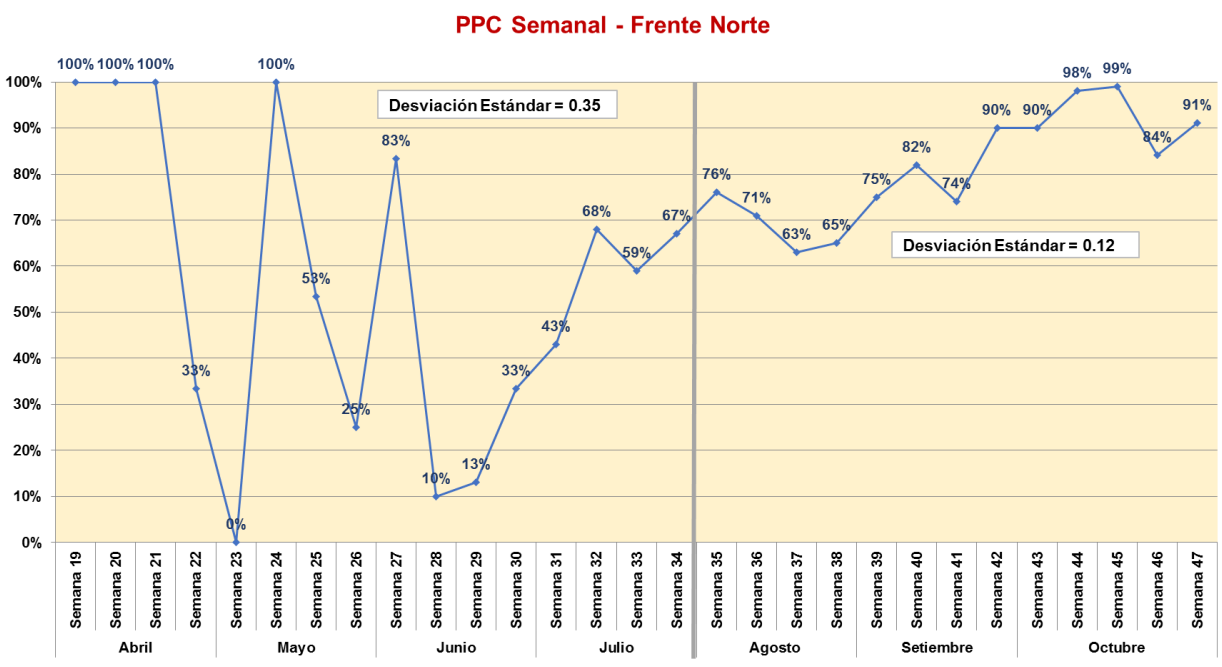

Fuente: Elaboración propia

Gráfico Nro. 15: "PPC semanal - frente sur"



Fuente: Elaboración Propia 
En el gráfico número 16 se muestra el PPC general de ambos frentes evaluados en los dos periodos, planeamiento tradicional y planeamiento lean. En términos generales se puede constatar la mejora de la variabilidad de la adherencia de los servicios ejecutados con los programados durante los periodos que se aplicó programaciones mensuales y programaciones semanales. Esto se refleja claramente en la disminución de la desviación estándar entre ambos periodos de 0.27 a 0.09 .

Gráfico Nro. 16: "PPC semanal - túnel"

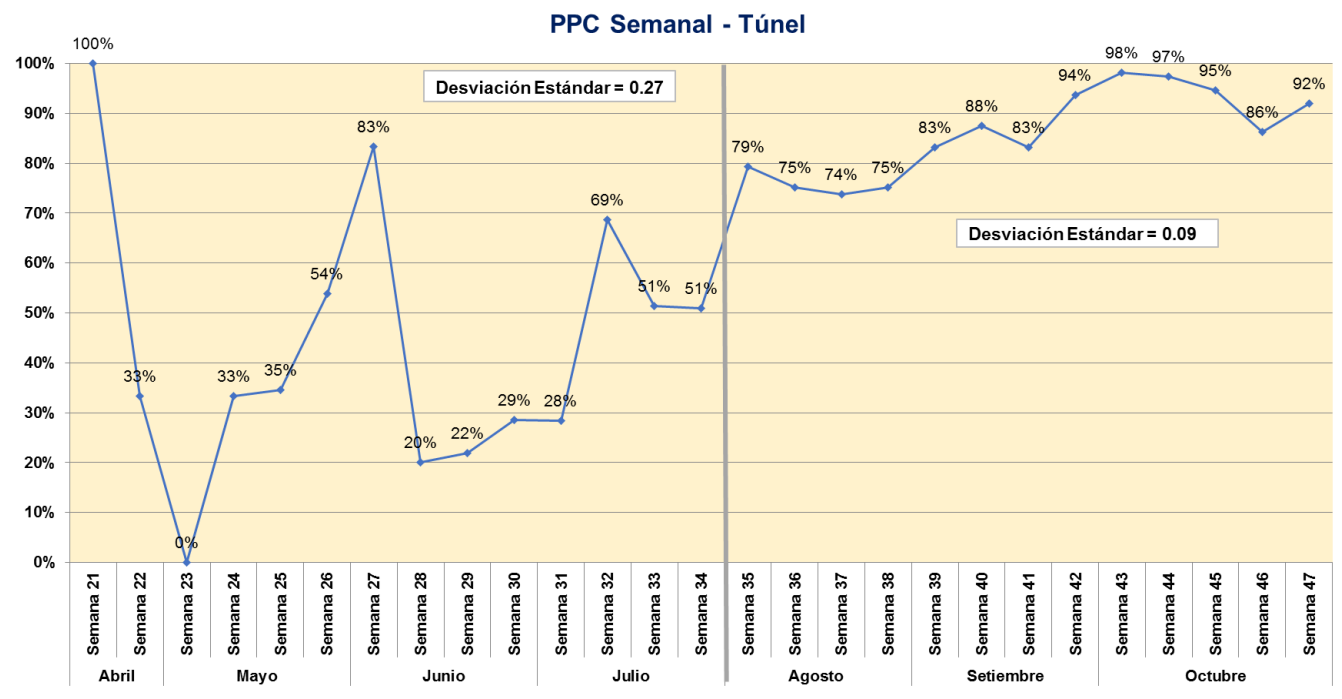

Fuente: Elaboración propia

\section{Análisis de la evolución del porcentaje plan cumplido (PPC)}

Es importante evaluar la evolución del "PPC" principalmente durante la aplicación de las herramientas de Last Planner System y Pull Planning, con la finalidad de validar la implementación del sistema. En este sentido, se debe de ajustar los resultados de la curva de evolución semanal a la ecuación lineal de la recta.

Dada la ecuación:

$$
y=a * x \pm b
$$

Donde:

- Variable dependiente (y), representa el valor del porcentaje de plan cumplido PPC. 
- Variable independiente (x), representa el tiempo o periodo semanal para la evaluación de resultandos.

- (a), es el valor de la pendiente de la recta y expresa porcentualmente la confiabilidad del sistema en la medida de que el valor del PPC incrementa semana a semana.

- Constante (b), es el intercepto de la recta y establece el valor ponderado inicial del "PPC", es decir, con el cual el proyecto empezó a implantar el sistema de planificación.

- El valor R cuadrado ( $\left.\mathrm{R}^{\wedge} 2\right)$, muestra la confiabilidad de la línea de tendencia. Una línea de tendencia es más confiable cuando su valor R cuadrado está establecido en 1 o cerca de 1 .

A continuación, se muestra el análisis de la evolución de los PPC de cada frente de trabajo y del túnel en general a través de su ajuste de tendencia lineal con sus respectivas ecuaciones de la recta.

En el gráfico número 17, “Análisis de evolución de PPC semanal - Frente Norte”, se observa la ecuación del ajuste lineal del PPC acumulado semanal del frente norte entre las semanas 35 y 47. La pendiente de esta recta nos indica que el PPC del sistema evolucionó con una tasa de crecimiento de $0.72 \%$, asimismo que al inicio de los trabajos el PPC del sistema fue $69.27 \%$ muy por debajo de la meta esperada de $85 \%$. Por otro lado, la confiabilidad el ajuste de la curva es de $51.86 \%$.

Gráfico Nro. 17: “Análisis de la evolución del PPC semanal - frente norte”

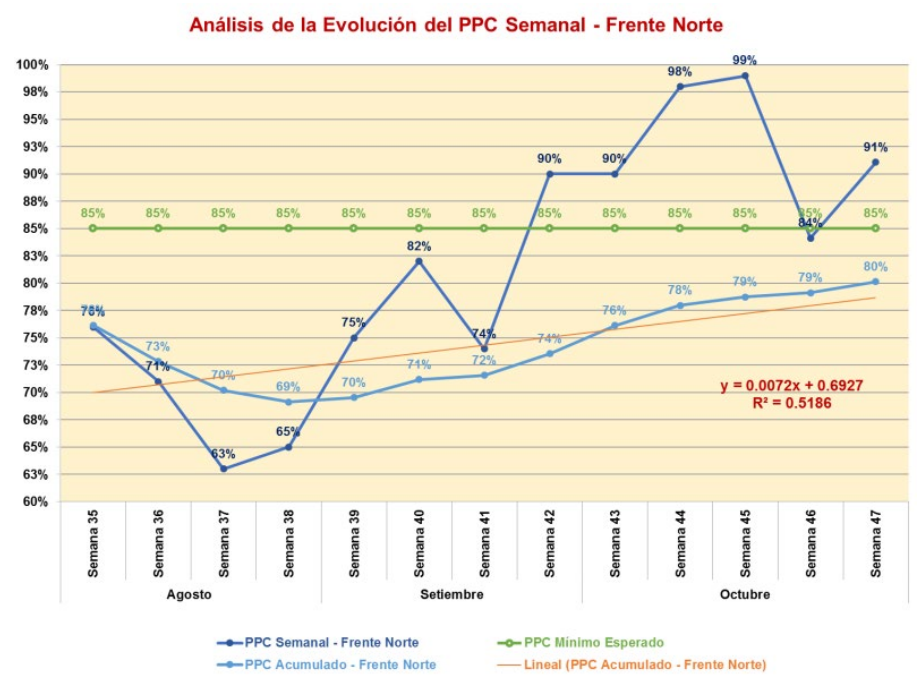

Fuente: Elaboración propia 
En el gráfico número 18, “Análisis de evolución de PPC semanal - Frente Sur”, se observa la ecuación del ajuste lineal del PPC acumulado semanal del frente sur entre las semanas 35 y 47. La pendiente de esta recta nos indica que el PPC del sistema evolucionó con una tasa de crecimiento de $0.69 \%$, asimismo que al inicio de los trabajos el PPC del sistema fue $85.96 \%$ encima de la meta esperada de $85 \%$. Por otro lado, la confiabilidad el ajuste de la curva es de $87.03 \%$ lo que indica ejecución de los trabajos de producción están adheridos a sus programaciones.

Gráfico Nro. 18: "Análisis de la evolución del PPC semanal - frente sur"

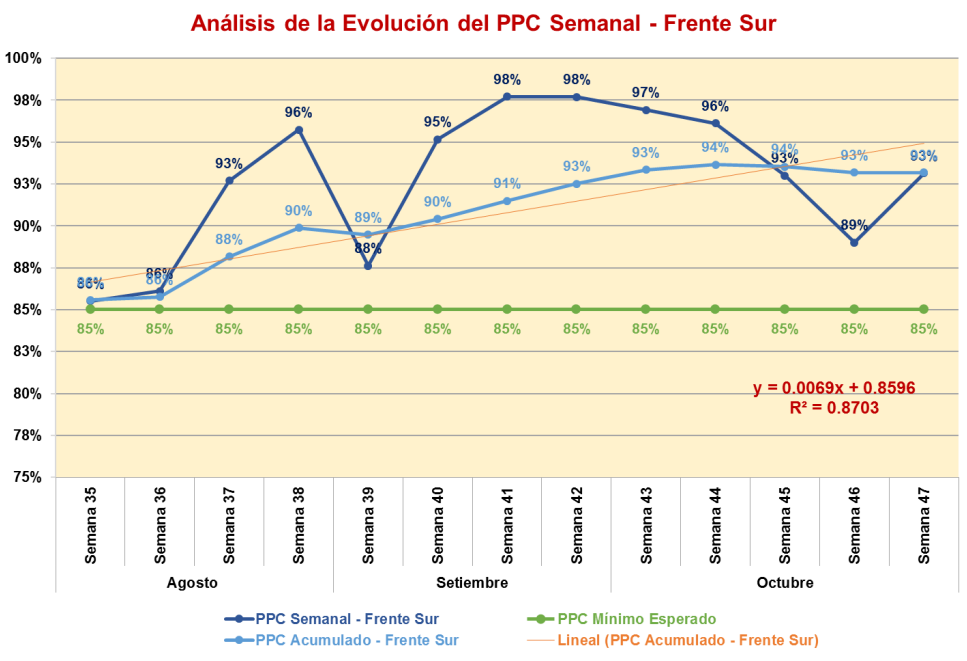

Fuente: Elaboración propia

En el gráfico número 19, "Análisis de evolución de PPC semanal - Túnel", se observa la ecuación del ajuste lineal del PPC acumulado semanal entre las semanas 35 y 47. La pendiente de esta recta nos indica que el PPC del sistema evolucionó con una tasa de crecimiento de $0.88 \%$, asimismo que al inicio de los trabajos el PPC del sistema fue $74.15 \%$ por debajo de la meta esperada de $85 \%$. Por otro lado, la confiabilidad el ajuste de la curva es de $79.04 \%$. 
Gráfico Nro. 19: “Análisis de la evolución del PPC semanal - túnel”



Fuente: Elaboración propia

En conclusión, las ecuaciones analizadas indican que el grado de cumplimiento del PPC de los frentes de trabajo durante el periodo analizado siempre muestra tendencias positivas. Asimismo, a pesar de que su valor inicial de implementación estuvo por debajo de la meta prevista, existe $79 \%$ de confiabilidad de mejora del sistema.

\section{Avance físico}

El objetivo principal de la aplicación de planeamiento estratégico es garantizar el cumplimiento de plazos y avance físico de la obra durante su ejecución. A partir de la hipótesis planteada en la presente investigación se realiza el estudio de avances físicos del proyecto en base a la cantidad de esfuerzo o trabajo aplicado y se representa mediante la curva "s".

Para esto, se toma en consideración la curva de línea base inicial de la planificación del proyecto, la curva de avance físico real hasta el mes de octubre-2015, la curva de tendencia de avance físico con fecha de corte del avance real hasta el mes de julio-2015 en base a la metodología de planeamiento tradicional y por último la curva de tendencia de avance físico con fecha de corte de avance físico real hasta el mes de octubre-2015 en base a la metodología de planeamiento Lean. 
Gráfico Nro. 20: “Avance físico de ejecución del túnel”

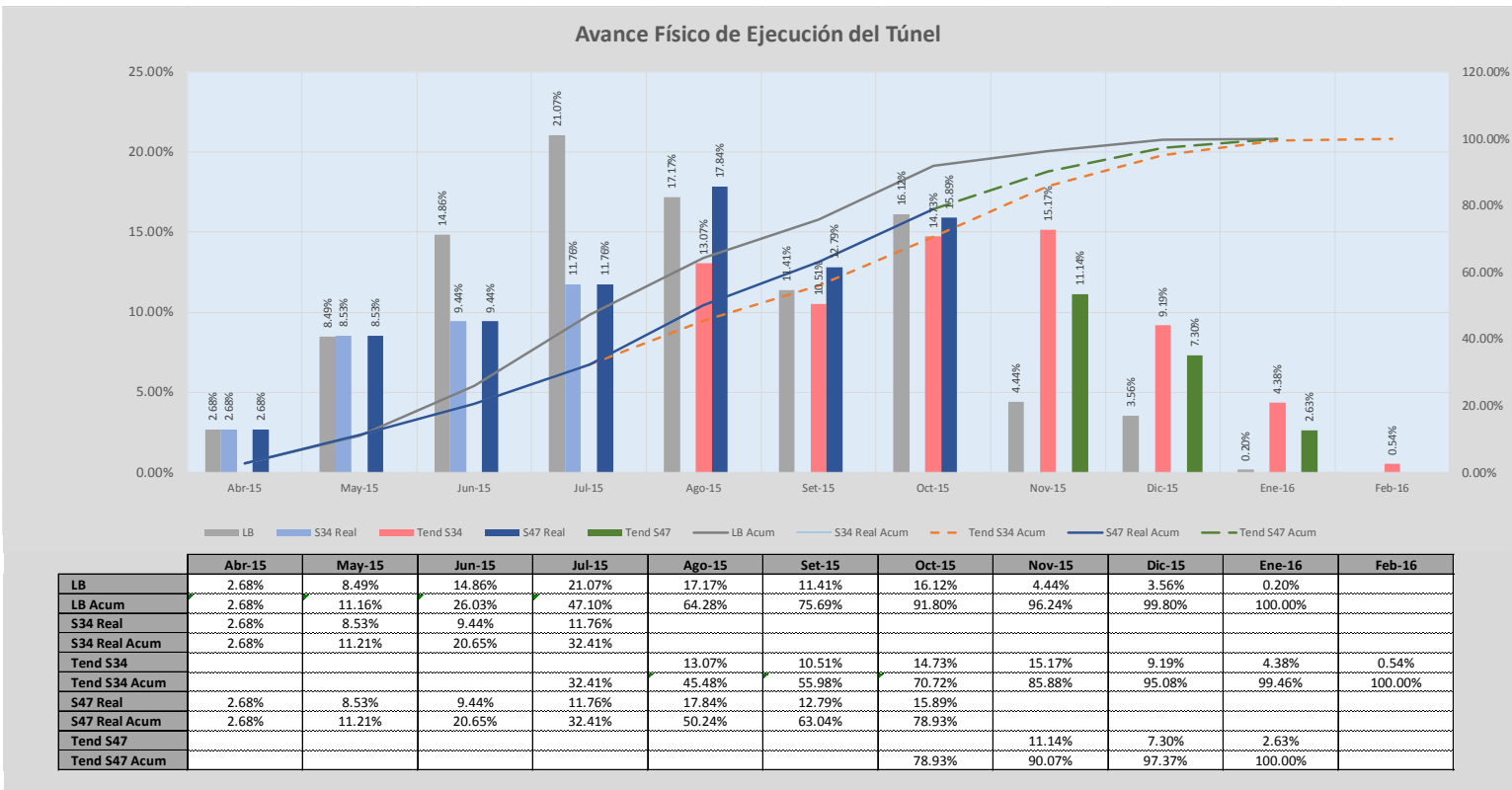

Fuente: Elaboración propia

En el gráfico número 20 se puede observar que de acuerdo con la línea base original de la construcción de las estructuras de concreto del túnel, evaluadas en este estudio, se tenía previsto finalizar en enero del 2016. Al cierre del mes de julio del 2015 se presenta un desvío de $14,69 \%$ de avance físico que en términos de plazo representa un mes de retraso. Luego, la tendencia evaluada en la semana 34, fin del mes de julio-2015, con la aplicación de metodologías de planeamiento tradicional indican que el fin previsto del proyecto es para el mes de febrero-2016. Sin embargo, a partir de la primera semana de agosto, fecha en la que se empieza a implementar y aplicar las metodologías de planeamiento Lean, el avance físico supera las expectativas de dicha tendencia y de esta manera al cabo del mes de octubre cierra con $78,93 \%$ cuando las previsiones de la tendencia evaluada en la semana 34 indicaba $70,72 \%$, es decir, con un avance mayor de $8,21 \%$. Asimismo, al fin del mes de octubre, la nueva tendencia de acuerdo con el planeamiento Lean indica que la finalización del proyecto será en el mes de enero-2016 de acuerdo a la línea base original. 


\section{CAPÍTULO V: PROPUESTA DE LA MEJORA}

Este capítulo, tiene como objetivo principal establecer y mostrar los pasos a seguir para la aplicación del modelo sistémico de planeamiento, que integra las herramientas Last Planner System y Pull Planning, en cualquier proyecto de construcción de túneles de trinchera cubierta. Para ello, se identifican las etapas de la metodología, luego se desglosa los subprocesos que la componen interrelacionándolos directamente con los actores involucrados.

\section{Implementación de las herramientas del sistema de planificación}

Una vez conocida las fases de desarrollo del Last Planner System y Pull Planning para el planeamiento de proyectos, es importante saber cuál es el punto de partida para la implementación. Con esa finalidad, a continuación, se presenta la manera más apropiada para desarrollar las herramientas.

\section{Preparación de Pull Planning}

El siguiente diagrama de flujo, muestra los roles y tareas que desarrollan los involucrados en la preparación del Pull Planning.

- El proceso inicia cuando el gestor del cronograma gerencial filtra las actividades de los próximos tres meses para poder desarrollar la futura programación Pull Planning.

- Los ingenieros de producción junto a los ingenieros de planeamiento identifican todas las actividades de los próximos tres meses, en donde también estudiarán el futuro plan de ataque, secuencias, procesos constructivos, metrados, productividades, duraciones y recursos que se van a utilizar. Al finalizar emiten las líneas de balance (takt) en una hoja Excel del Pull Planning mostrando la secuencia elaborada.

- Los ingenieros del área de planeamiento transportan la programación al software Primavera P6 que parte de este proceso se encuentra explicado en el manual de planeamiento y programación de Primavera P6 elaborado en este estudio. En esta parte del proceso, se tendrá que transportar las líneas de balance a planilla de importación para 
Primavera P6, importar al software, vincular de actividades, insertar los pesos de acuerdo al cronograma gerencial y cerrar la línea base (Pull Planning).

- Al finalizar la línea base (Pull Planning) el gestor del cronograma gerencial ajusta el cronograma gerencial de acuerdo a secuencias y duraciones de la programación trimestral.

- Teniendo las líneas de balance el área de ingeniería elabora los 3D y 4D y material de apoyo del Pull Planning, en donde los ingenieros de planeamiento prepararán los materiales para la presentación y dinámica.

Se muestra a continuación el diagrama de flujo de preparación de Pull Planning. 
Gráfico Nro. 21: "Diagrama de flujo de preparación de Pull Planning”

\section{Diagrama de Flujo de Preparación Pull Planning}

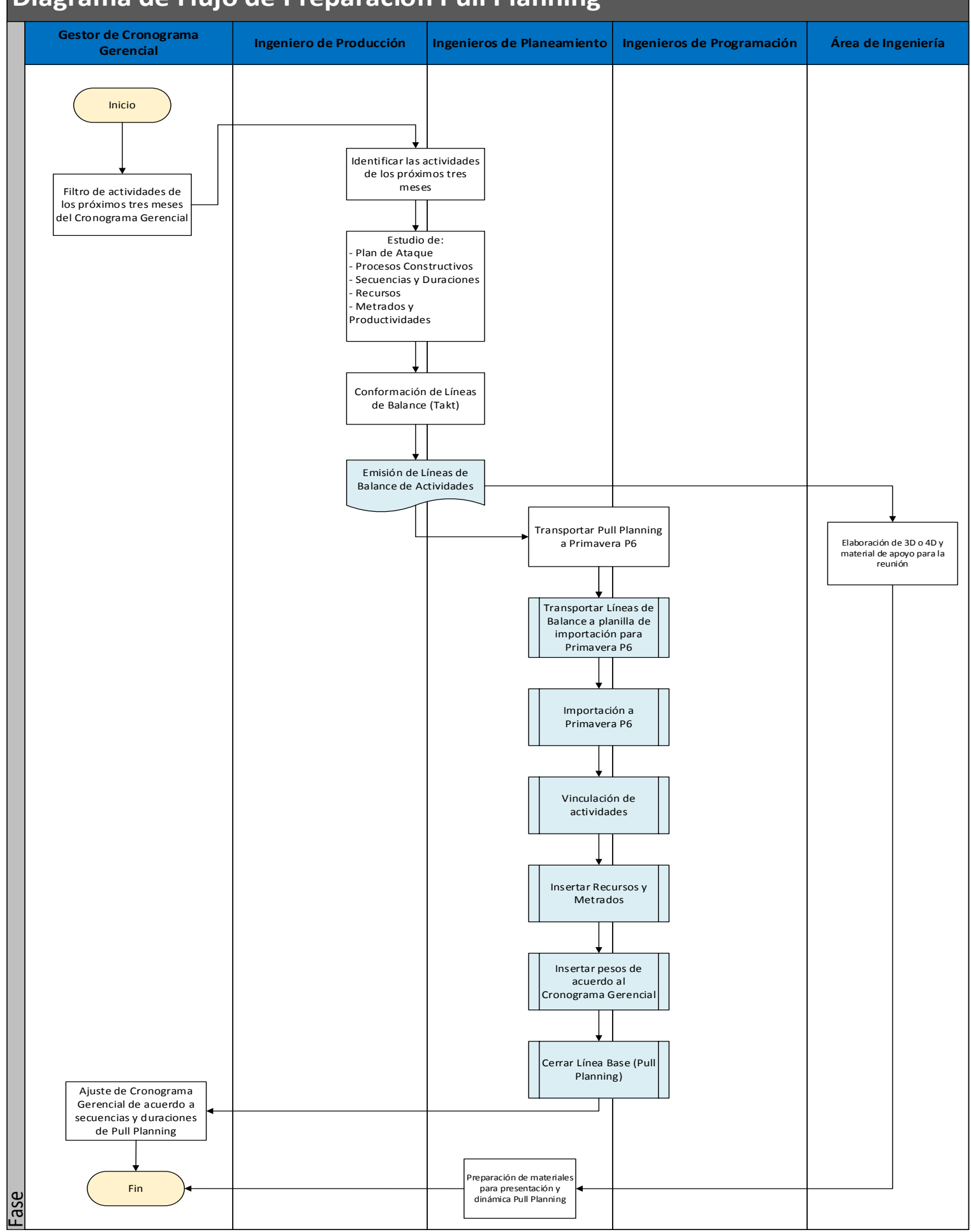

Fuente: Elaboración propia 


\section{Dinámica Pull Planning}

El siguiente diagrama de flujo, muestra los roles y tareas que desarrollan los involucrados de la dinámica Pull Planning.

- El ingeniero de producción quien es el líder de la reunión da inicio al Pull Planning, presentando los objetivos y a todos los participantes tantos capataces, encargados, supervisores, sub-contratistas, colaboradores e invitados.

- El líder da a conocer el marco de los tres meses planeados, según el plan de ataque estudiado que se apoyará en la presentación con el modelamiento en 3D o 4D que ha desarrollado el área de ingeniería.

- El jefe de producción explica la secuencia de los servicios, para que todo el público conozca de los procesos constructivos típicos del planeamiento elaborado.

- En esta parte de la reunión, comienza la dinámica Pull Planning con la elaboración de adhesivos por parte de los capataces, encargados o sub-contratistas en donde menciona el responsable, la duración, el equipo a necesitar, el turno, el servicio predecesor y sucesor, entregable y restricciones.

- Después, cada responsable coloca los adhesivos en una escala temporal semanal de los tres meses de trabajo según a la secuencia establecida al inicio de la reunión. Para ello, los ingenieros que elaboraron las líneas de balance aprobarán si los adhesivos se encuentran conforme al estudio previo, si es conforme comienza la dinámica de pasar la posta y compromiso de entrega de todos los responsables de los servicios, y si no es conforme se procede al abordaje y corregir el adhesivo.

- Al finalizar la dinámica, los ingenieros de planeamiento y el líder de la reunión analizan y consolidan las líneas de balance estudiadas en la preparación de la reunión.

- La identificación de restricciones, es la actividad en donde participan todos los involucrados de la reunión. En ella, se aplica la metodología Ishikawa 6M (mano de obra, materiales, método, maquinaria, medio ambiente y medida) para lograr identificar todas las restricciones o problemas se puedan en encontrar al pasar de los días. La intención de emplear está herramienta es para poder adherirse a la programación planeada. 
- El ingeniero de producción validad la reunión junto con los ingenieros de planeamiento, para luego, estos últimos desarrollan una encuesta de nivel de satisfacción de la dinámica Pull Planning con el fin de lograr que todos los involucrados conozcan la programación de los próximos tres meses.

A continuación, se muestra a continuación el diagrama de flujo de preparación de Pull Planning. 
Gráfico Nro. 22: "Diagrama de flujo de dinámica Pull Planning"

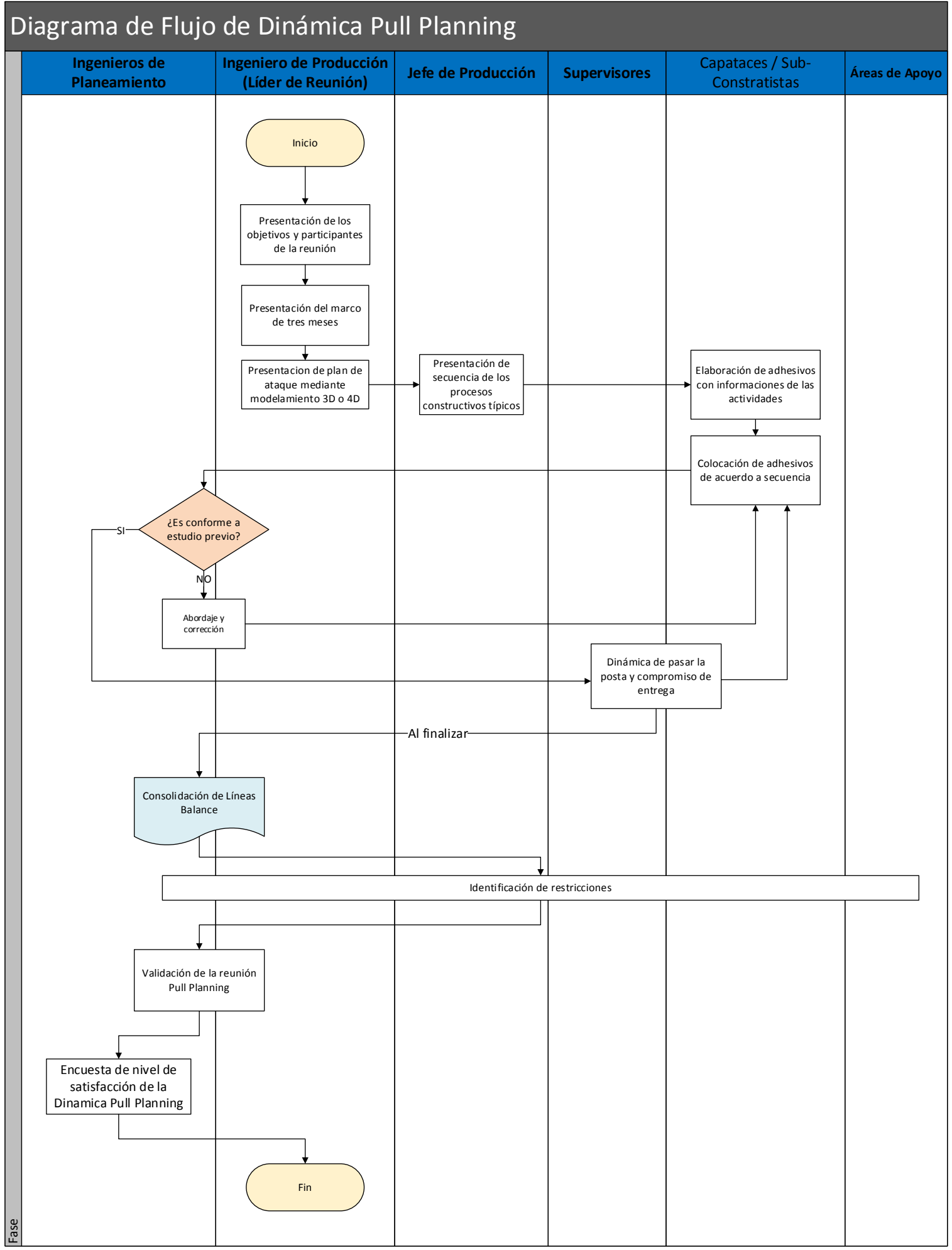

Fuente: Elaboración propia 


\section{Modelo sistemático de planeamiento, programación y control}

En el siguiente modelo sistemático se esquematiza los roles de cada responsable del área de planeamiento y control y producción, y de sus actividades para poder trabajar de manera sistemática e integrada con las metodologías adoptadas.

El esquema que se mostrará a continuación será en resumen del diagrama funcional sistemático de planeamiento, programación y control a presentar después:

- El proceso inicia en la creación del cronograma Pull Planning en donde el ingeniero responsable de la programación semanal se encarga de importar las líneas de balance del planeamiento realizado al software de Primavera P6.

- Luego emite las programaciones semanales (hojas tarea) que fueron elaboradas junto con el jefe de producción, para ser validadas y difundidas por el coordinar de planeamiento.

- El ingeniero de producción publica las hojas tareas de los capataces o encargados en el panel de gestión visual del mismo frente de trabajo y junto con el jefe de producción al inicio de la jornada de trabajo en las reuniones Check In asignan las actividades y los recursos necesarios a utilizar en el día, mientras al finalizar el día en las reuniones de Check Out se obtiene el PPC y la productividad efectuada de los capataces, y si no se cumplió una actividad se identifica la causa raíz del problema.

- Al cierre de la semana, el ingeniero de producción envía el avance semanal al área de planeamiento para actualizar el cronograma Pull Planning y el ingeniero responsable de la programación semanal se reúne con el jefe de producción para realizar la programación de la semana siguiente, que será aprobado por el ingeniero de producción que luego será emitida y difundida.

- Al emitir el reporte de avance de producción semanal, el ingeniero de la programación calcula el PPC semanal para que sea publicado en una torre de control donde también se muestra los indicadores o resultados de la semana de todas las áreas del proyecto.

- El ingeniero encargado del cronograma gerencial con el reporte actualiza el cronograma gerencial y genera los indicadores de planeamiento y control para mostrar en la torre.

- Él área de costos con el avance de la producción y el control desarrollado en la semana de los recursos utilizados calcula la producción y productividad de todos los servicios del 
frente, pero tendrá que ser validada por el ingeniero de producción para ser publicado también en la torre de control junto todos los indicadores del área.

Se muestra a continuación el diagrama funcional sistemático de planeamiento, programación y control.

Gráfico Nro. 23: "Diagrama sistemático de planeamiento, programación y control” 


\section{Diagrama Funcional Sistemático de Planeamiento, Programación y Control}


Fuente: Elaboración propia 


\section{Manual de planeamiento y programación en Primavera P6}

Este documento tiene como objetivo describir el flujo de procesos de las actividades que el área de planeamiento deberá aplicar si desea desempeñar la metodología Last Planner System en la planificación, programación y control del avance del proyecto. En primer lugar, se describe detalladamente el proceso de creación del cronograma Pull-Planning en el software Primavera P6 a partir de las líneas de balance de actividades utilizadas para esta dinámica. Luego, se describe paso a paso la operación del Primavera P6 y Excel para la elaboración de las hojas tarea, actualización de avances y emisión de reportes de avance físico de obra. Este manual se presenta en el Anexo Nro. 04: “Descripción de Metodología de Trabajo del Área de Planeamiento".

\section{Medición de la adherencia de la programación al planeamiento}

Para la implementación de las metodologías de Last Planner System y Pull Planning en la planificación y ejecución de las actividades del proyecto se tiene que atravesar por una curva de aprendizaje, es decir, lograr en el menor tiempo posible que los involucrados directos del sistema comprendan la importancia y trabajen bajo esta modalidad. El resultado del proceso se logró evidenciar en este estudio mediante la evolución del indicador de adherencia de la producción a la programación "PPC".

Después de haber completado el proceso de implementación y desarrollado por completo la curva de aprendizaje, la tendencia del "PPC" fluctuará siempre en un intervalo de 90\% a 100\%. Esto indica, que el área de producción ha logrado desarrollar la capacidad de previsión semanal al momento de programar los servicios y que realmente se cumplirán durante este período. Sin embargo, mantener este indicador en ese intervalo no quiere decir que el proyecto este avanzando de la mejor manera. Aquí surge la pregunta si de verdad se está logrando programar la cantidad necesaria para atender el cronograma gerencial, la ruta crítica y la necesidad del proyecto viendo desde un enfoque global de largo plazo.

Ante este hecho, surge la necesidad de conocer el grado de adherencia de la programación al planeamiento. Para ello, se buscará establecer un vínculo entre el programa gerencial y las programaciones Pull Planning a través de ponderaciones de peso físico o costos de los servicios programados - ejecutados. 


\section{CAPÍTULO VI: APLICACIÓN DE LA MEJORA}

Este capítulo surge como resultado de la aplicación directa de las propuestas mencionadas en el capítulo anterior.

\section{Generación de agendas y roles de los ingenieros de planeamiento y producción}

Para garantizar el funcionamiento del sistema de planificación es importante que los involucrados cumplan con los roles que se definieron en el capítulo anterior y a partir de ello se generarán las siguientes agendas y reuniones que marcarán una pauta de rutinas semanales que se deben seguir. Los principales involucrados que deben mantener esta rutina son los siguientes:

Tabla Nro. 9: "Roles de los involucrados"

\begin{tabular}{|l|l|}
\hline & Coordinador de Planeamiento \\
\hline & Ingeniero Responsable del Cronograma Gerencial \\
\hline & Ingenieros Responsables de la Programación \\
\hline & Ingenieros de Producción \\
\hline
\end{tabular}

Fuente: Elaboración propia

Las reuniones en las que deben participar de acuerdo a nuestra metodología son:

Tabla Nro. 10: "Reuniones"

\begin{tabular}{|l|l|}
\hline & Gerente del Área Planeamiento y Producción \\
\hline & Área de Planeamiento y Control \\
\hline Coordinador de Planeamiento, Gerente e Ingenieros de Producción y Áreas de Apoyo \\
\hline & Ingenieros Responsables de la Programación y Jefes de Producción \\
\hline
\end{tabular}

Fuente: Elaboración propia

A continuación, se muestra una distribución semanal de todas las actividades y reuniones que involucran a las áreas de planeamiento y control, y producción. 
Tabla Nro. 11: “Agenda y roles del área de planeamiento y producción”

\begin{tabular}{|c|c|c|c|c|c|c|}
\hline & Lunes & Martes & Miércoles & Jueves & Viernes & Sábado \\
\hline $6: 00-6: 30$ & & & & & & \\
\hline $6: 30-7: 00$ & \multicolumn{6}{|c|}{ Asignación de las Actividades del Día - Reunión de Check In } \\
\hline 7:00 - 7:30 & & & & & & \\
\hline 7:30 - 8:00 & \multirow{3}{*}{$\begin{array}{c}\text { Ajuste de la } \\
\text { Programación } \\
\text { Semanal en Función } \\
\text { al Avance del Fin de } \\
\text { Semana }\end{array}$} & & & & & Emisión de Hojas \\
\hline $8: 00-8: 30$ & & & & & \multirow{4}{*}{$\begin{array}{l}\text { Actualizar } \\
\text { Cronogramas } \\
\text { Pull - Planning }\end{array}$} & Tarea \\
\hline $8: 30-9: 00$ & & & & & & $\begin{array}{l}\text { Validación de } \\
\text { Hojas Tarea }\end{array}$ \\
\hline 9:00 - 09:30 & \multirow{4}{*}{ Cálculo de PPC } & & & & & Actualización \\
\hline $9: 30-10: 00$ & & & & & & $\begin{array}{l}\text { Cronograma } \\
\text { Gerencial }\end{array}$ \\
\hline 10:00 - 10:30 & & \multirow{4}{*}{$\begin{array}{l}\text { Reunión de } \\
\text { Producción en } \\
\text { la Torre de } \\
\text { Control }\end{array}$} & & & \multirow{4}{*}{$\begin{array}{l}\text { Reunión } \\
\text { 6WLAP }\end{array}$} & Parte I \\
\hline 10:30 - 11:00 & & & & & & \\
\hline 11:00 - 11:30 & \multirow{2}{*}{\begin{tabular}{|c|}
$\begin{array}{c}\text { Validación de PPC e } \\
\text { Îndices de } \\
\text { Producción }\end{array}$ \\
\end{tabular}} & & & & & \\
\hline $11: 30-12: 00$ & & & & & & \\
\hline $12: 00-12: 30$ & \multirow{2}{*}{\multicolumn{6}{|c|}{ ALMUERZO }} \\
\hline $12: 30-13: 00$ & & & & & & \\
\hline \multicolumn{7}{|l|}{$13: 00-13: 30$} \\
\hline \multicolumn{7}{|l|}{$13: 30-14: 00$} \\
\hline 14:00 - 14:30 & Actualización & \multirow{4}{*}{$\begin{array}{l}\text { Reunión de } \\
\text { Planeamiento } \\
\text { en la Torre de } \\
\text { Control }\end{array}$} & \multirow{4}{*}{$\begin{array}{l}\text { Reunión } \\
\text { Gerencial }\end{array}$} & & \multirow{5}{*}{$\begin{array}{l}\text { Realizar la } \\
\text { Programación } \\
\text { Semanal }\end{array}$} & \\
\hline $14: 30-15: 00$ & $\begin{array}{l}\text { Cronograma } \\
\text { Gerencial } \\
\text { Parte II }\end{array}$ & & & & & \\
\hline 15:00 - 15:30 & $\begin{array}{l}\text { Actividades Críticas } \\
\text { y Sub-críticas }\end{array}$ & & & & & \\
\hline $15: 30-16: 00$ & $\begin{array}{l}\text { Marcos e Hitos del } \\
\text { Planeamiento }\end{array}$ & & & & & \\
\hline 16:00 - 16:30 & $\begin{array}{l}\text { Adherencia de la } \\
\text { Programación al } \\
\text { Planeamiento }\end{array}$ & & & & & \\
\hline $16: 30-17: 00$ & $\begin{array}{l}\text { Avance Físico / } \\
\text { Tiempo Camino } \\
\text { (mensualmente) }\end{array}$ & & & & & \\
\hline $17: 00-17: 30$ & $\begin{array}{l}\text { Publicar Indicadores } \\
\text { en la Torre de } \\
\text { Control }\end{array}$ & & & & & \\
\hline 17:30 - 18:00 & & Acompañamientc & los Servicios & jecutados - Reunión & de Check Out & \\
\hline $18: 00-18: 30$ & & & & \begin{tabular}{|c|} 
Envío de avances \\
parciales de la \\
semana (Lunes- \\
Jueves)
\end{tabular} & & \\
\hline
\end{tabular}

Fuente: Elaboración propia

\section{Análisis de rentabilidad de la implementación del sistema}

Después de haber mostrado el modelo de implementación del sistema de planificación basado en la metodología Last Planner System y Pull Planning, ahora se analiza la rentabilidad de la implementación mediante la comparación del dimensionamiento de personal o FTE por sus siglas en inglés (Full-Time Equivalent), que es una forma de medir la cantidad de empleados 
a tiempo completo que se necesitarían para llevar a cabo el trabajo, del área de planeamiento y control en las dos situaciones de tiempo.

Tabla Nro. 12: "Dimensionamiento del personal FTE - área de planeamiento y control (planeamiento inicial)"

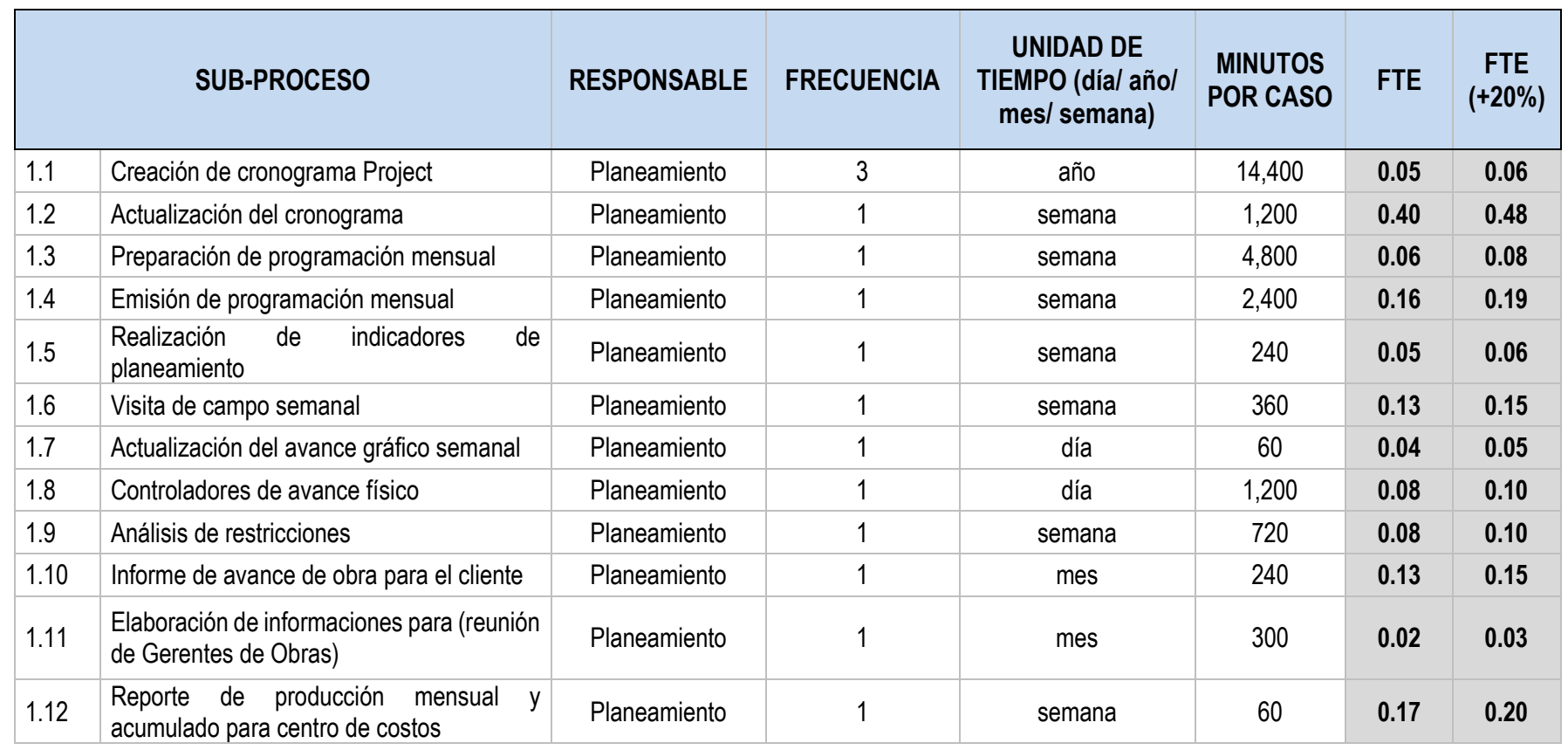

TOTAL DE PERSONAL REQUERIDO

Fuente: Elaboración propia

Tabla Nro. 13: "Dimensionamiento del personal FTE - área de planeamiento y control (planeamiento Lean)"

\begin{tabular}{|c|c|c|c|c|c|c|c|}
\hline \multicolumn{2}{|c|}{ SUB-PROCESO } & \multirow{2}{*}{$\begin{array}{l}\text { RESPONSABLE } \\
\text { Planeamiento }\end{array}$} & \multirow{2}{*}{$\begin{array}{c}\text { FRECUENCIA } \\
1\end{array}$} & \multirow{2}{*}{$\begin{array}{c}\text { UNIDAD DE } \\
\text { TIEMPO (día/ año/ } \\
\text { mes/ semana) } \\
\text { mes }\end{array}$} & \multirow{2}{*}{$\begin{array}{c}\text { MINUTOS } \\
\text { POR CASO } \\
600\end{array}$} & \multirow{2}{*}{$\begin{array}{l}\text { FTE } \\
0.05\end{array}$} & \multirow{2}{*}{$\begin{array}{c}\text { FTE } \\
(+20 \%)\end{array}$} \\
\hline 1.1 & Cronograma gerencial & & & & & & \\
\hline 1.2 & Preparación de Pull Planning & Planeamiento & 0.75 & mes & 6,000 & 0.40 & 0.48 \\
\hline 1.3 & Previa y dinámica de Pull Planning & Planeamiento & 1 & mes & 720 & 0.06 & 0.08 \\
\hline 1.4 & Creación de cronograma Primavera & Planeamiento & 1 & mes & 1,800 & 0.16 & 0.19 \\
\hline 1.5 & Ajustes del cronograma gerencial & Planeamiento & 1 & mes & 600 & 0.05 & 0.06 \\
\hline 1.6 & Emisión de hojas tareas & Planeamiento & 1 & semana & 360 & 0.13 & 0.15 \\
\hline 1.7 & Difusión de hojas tareas & Planeamiento & 1 & semana & 120 & 0.04 & 0.05 \\
\hline 1.8 & Actualización de cronograma Pull Planning & Planeamiento & 1 & semana & 240 & 0.08 & 0.10 \\
\hline 1.9 & 6WLA & Planeamiento & 1 & semana & 240 & 0.08 & 0.10 \\
\hline 1.10 & Rodada de Restricciones & Planeamiento & 1 & semana & 360 & 0.13 & 0.15 \\
\hline 1.11 & $\begin{array}{l}\text { Reporte de producción mensual y } \\
\text { acumulado para centro de costos }\end{array}$ & Planeamiento & 1 & semana & 60 & 0.02 & 0.03 \\
\hline 1.12 & Programación de la semana siguiente & Planeamiento & 1 & semana & 480 & 0.17 & 0.20 \\
\hline
\end{tabular}




\begin{tabular}{|c|c|c|c|c|c|c|c|}
\hline \multicolumn{2}{|c|}{ SUB-PROCESO } & \multirow{2}{*}{$\begin{array}{c}\text { RESPONSABLE } \\
\text { Planeamiento }\end{array}$} & \multirow{2}{*}{$\begin{array}{c}\text { FRECUENCIA } \\
1\end{array}$} & \multirow{2}{*}{$\begin{array}{l}\text { UNIDAD DE } \\
\text { TIEMPO (día/ año/ } \\
\text { mes/ semana) } \\
\text { semana }\end{array}$} & \multirow{2}{*}{$\begin{array}{c}\text { MINUTOS } \\
\text { POR CASO } \\
120\end{array}$} & \multirow{2}{*}{$\begin{array}{l}\text { FTE } \\
0.04\end{array}$} & \multirow{2}{*}{$\begin{array}{c}\begin{array}{c}\text { FTE } \\
(+20 \%)\end{array} \\
0.05\end{array}$} \\
\hline 1.13 & $\begin{array}{l}\text { Emisión de reporte avance producción } \\
\text { semanal }\end{array}$ & & & & & & \\
\hline 1.14 & Informe de avance de obra para el cliente & Planeamiento & 1 & mes & 240 & 0.02 & 0.03 \\
\hline 1.15 & Información para previsión de valorización & Planeamiento & 1 & semana & 240 & 0.08 & 0.10 \\
\hline 1.16 & Cálculo de PPC & Planeamiento & 1 & semana & 120 & 0.04 & 0.05 \\
\hline 1.17 & $\begin{array}{l}\text { Actualización semanal de cronograma } \\
\text { gerencial }\end{array}$ & Planeamiento & 1 & semana & 120 & 0.04 & 0.05 \\
\hline 1.18 & $\begin{array}{l}\text { Generación de curvas de tendencia costo- } \\
\text { programado }\end{array}$ & Planeamiento & 1 & mes & 240 & 0.02 & 0.03 \\
\hline 1.19 & $\begin{array}{l}\text { Elaboración de informaciones para (reunión } \\
\text { de Gerentes de Obras) }\end{array}$ & Planeamiento & 1 & mes & 300 & 0.03 & 0.03 \\
\hline 1.2 & 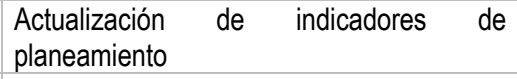 & Planeamiento & 1 & semana & 180 & 0.06 & 0.08 \\
\hline 1.21 & $\begin{array}{l}\text { Información para reunión interna de análisis } \\
\text { mensual }\end{array}$ & Planeamiento & 1 & mes & 600 & 0.05 & 0.06 \\
\hline 1.22 & $\begin{array}{l}\text { Reunión de revisión de cronograma } \\
\text { gerencial (2veces) }\end{array}$ & Planeamiento & 2 & mes & 90 & 0.02 & 0.02 \\
\hline 1.23 & Emisión Indicadores Torre Control & Planeamiento & 1 & semana & 60 & 0.02 & 0.03 \\
\hline 1.24 & Emisión de Indicadores & Planeamiento & 1 & semana & 120 & 0.04 & 0.05 \\
\hline 1.25 & Reuniones de Torre de control & Planeamiento & 1 & semana & 300 & 0.10 & 0.13 \\
\hline 1.26 & Reunión interna de planeamiento & Planeamiento & 1 & semana & 120 & 0.04 & 0.05 \\
\hline 1.27 & Visita de campo semanal & Planeamiento & 1 & semana & 360 & 0.13 & 0.15 \\
\hline 1.28 & Capacitaciones Lean Construction & Planeamiento & 2 & mes & 360 & 0.06 & 0.08 \\
\hline
\end{tabular}

Fuente: Elaboración propia

Según los resultados obtenidos de los FTE del planeamiento inicial y el planeamiento Lean existe una diferencia de cincuenta por ciento de la cantidad de colaboradores para desarrollar los trabajos encomendados en el área de planeamiento y control. Lo que representa reducir en un $64.6 \%$ el costo de mano de obra indirecta del área antes mencionada.

\section{Nivel de satisfacción del sistema de planeamiento: integración de Last Planner System y Pull Planning}

A partir de las reuniones y dinámicas de Pull Planning se realizaron encuestas de satisfacción a todos los participantes y los resultados se muestran a continuación en la siguiente gráfica.

Gráfico Nro. 24: "Resultados de encuesta de satisfacción Pull Planning" 


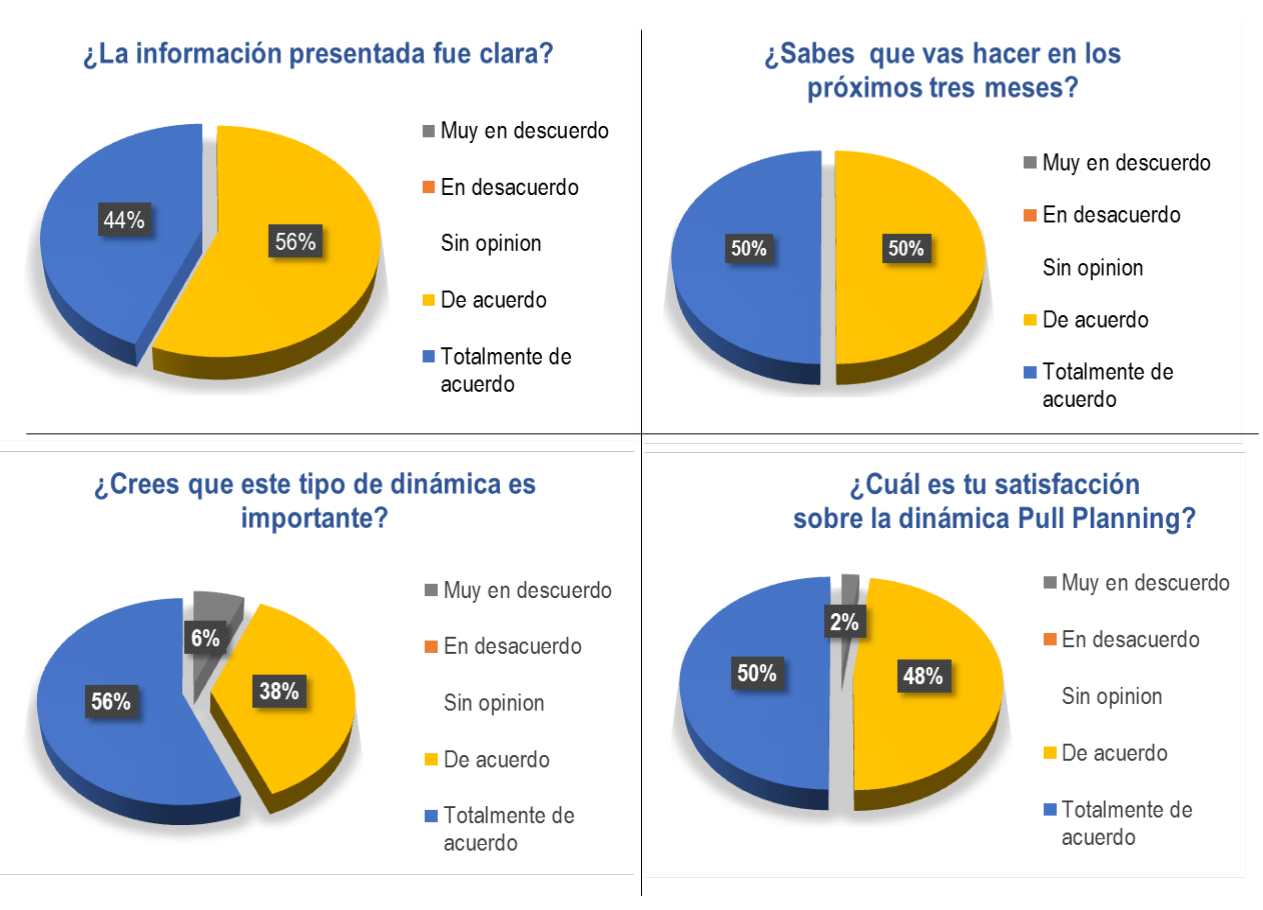

Fuente: Elaboración propia

A partir de los resultados obtenidos, se evidencia que hay un nivel alto de satisfacción de todos participantes de la reunión de Pull Planning porque existe porcentaje mayor en las opciones de estar de acuerdo o totalmente de acuerdo con las preguntas realizadas sobre el sistema de planificación.

\section{Indicador de adherencia de la programación al planeamiento}

Un indicador que nos ayudará a medir el grado de adherencia de la programación al planeamiento como una herramienta que servirá de alerta para saber si se está programando lo necesario para atender los marcos gerenciales del proyecto.

Ahora, imagínese un frente de servicio con actividades programadas para diez semanas, en donde la suma de la distribución de sus pesos de avance físico es igual a 100\%. Antes de iniciar la semana 1 se congela la línea base que servirá como línea de medición y comparación de lo planeado con lo programado y realizado. Si se quiere garantizar el cumplimiento de las actividades en el plazo se debe programar el peso necesario para atender la demanda del planeamiento inicial, asimismo, la producción debe encargarse de realizar las actividades previstas en la programación, es decir, lograr que su PPC sea adherente al 100\%. En 
ocasiones las condiciones de la obra nos permiten hacer actividades que no están contempladas en la programación generando "avances fuera de la programación”, esto da lugar a modificar, desbalancear las previsiones planeadas inicialmente y en efecto también el peso de las programaciones.

Gráfico Nro. 25: "Indicador de adherencia de la programación al planeamiento"

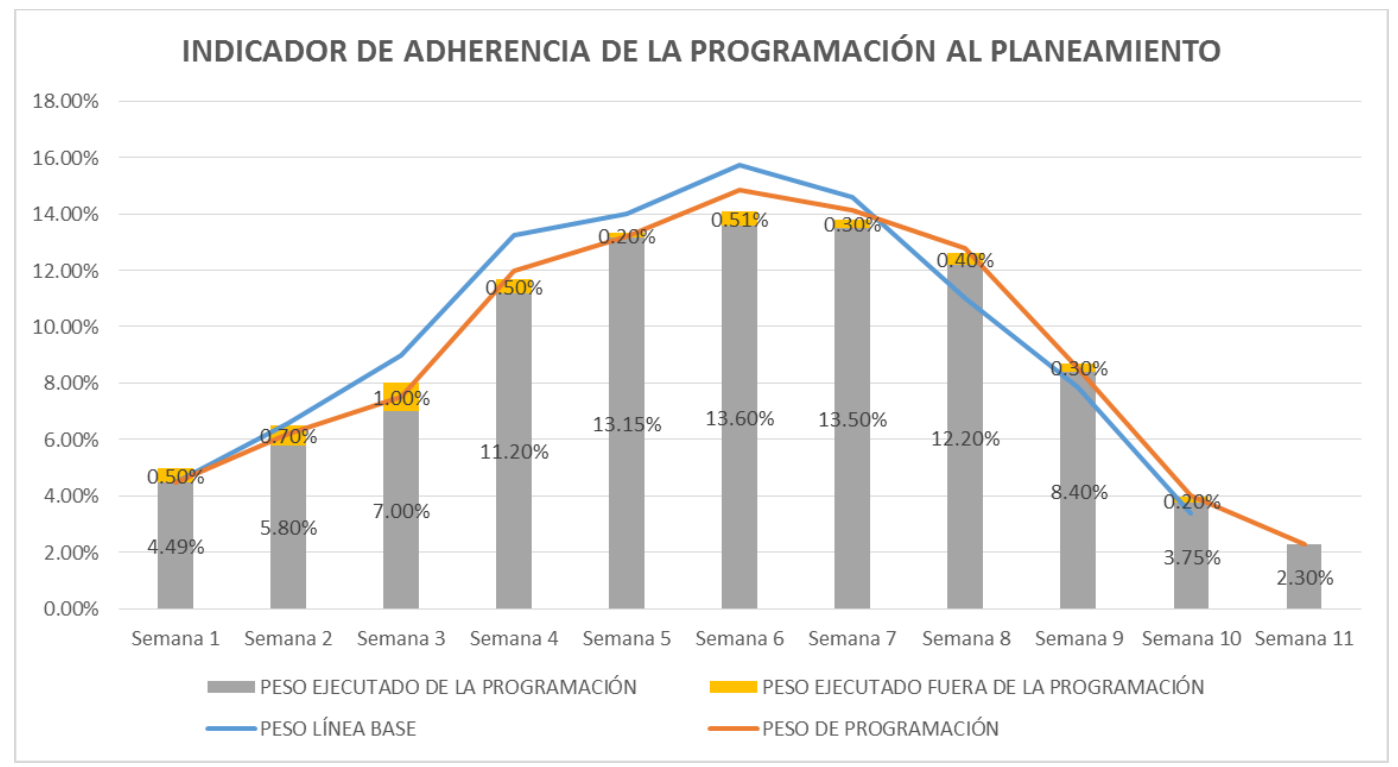

Fuente: Elaboración propia 


\section{CONCLUSIONES Y RECOMENDACIONES}

- Los proyectos de ingeniería se rigen sobre pilares importantes como el alcance, el costo, el tiempo y la calidad. El enfoque principal de esta investigación es la gestión del tiempo, de esta manera el desarrollo de la misma es en base a la filosofía Lean Construction y aplicación sistémica de sus herramientas.

- La tesis crea una visión integral y sistémica de metodologías y herramientas de Lean Construction aplicadas al planeamiento y control de la producción de proyectos de ingeniería. Para ello evalúa el comportamiento de la construcción de un túnel de trinchera cubierta en el Perú durante la implementación de estas metodologías.

- Last Planner System está directamente relacionado con el ciclo Deming (planear, ejecutar, controlar y ajustar) y la mejora continua. Es un sistema que involucra é interrelaciona todos los niveles jerárquicos de la construcción de un proyecto de ingeniería civil, desde los gerentes de las áreas de planeamiento, producción, y otras áreas de apoyo hasta los colaboradores que ejecutan los trabajos en obra, en este sentido logra crear un enfoque único en la dirección y ejecución del proyecto.

- Pull Planning es la herramienta de planificación con visión trimestral que nos ayuda a cumplir los marcos de entrega contractual contemplados en el cronograma gerencial. Para su preparación es necesario contar con representantes de todas las áreas de apoyo a fin de que todos conozcan las actividades que se realizaran en el proyecto en el próximo período mencionado. Las actividades de Pull Planning finaliza con la realización de la dinámica en donde se reúnen todos los supervisores, capataces, encargados o sub-contratistas para identificar sus tareas o entregables y crear en conjunto una línea de balanceamiento de todas las actividades en una escala temporal semanal.

- Antes de la implementación de las metodologías de planeamiento cuando se trabajaba de manera tradicional el PPC de los frentes tanto norte como sur, era muy oscilante, en ocasiones se lograba $100 \%$ y en otras hasta $0 \%$, el reflejo de ello es la desviación estándar que es igual a 0.35 y a 0.36 en los frentes de trabajo respectivamente; y luego con la 
implementación de las herramientas de la filosofía Lean la oscilación del PPC disminuyó a 0.12 y 0.04 . Esto quiere decir, que se logró garantizar una mayor adherencia al cumplimiento de las actividades programadas dentro de la semana.

- Luego de 13 semanas de la aplicación de las herramientas de Last Planner System y de la realización de las dinámicas Pull planning, previo al inicio de las actividades previstas para un periodo determinado, se fue midiendo el PPC semana a semana y de esa configuración el progreso acumulado del PPC que se fue obteniendo en el transcurso del tiempo. Al final del periodo analizado se realizó un ajuste lineal del PPC acumulado, logrado durante la etapa de aplicación del pull planning. Los datos obtenidos de la ecuación de la recta a base del análisis de la evolución del PPC del túnel, interpreta lo siguiente:

- La pendiente adquiere un valor de $0.88 \%$, que representa un incremento en el porcentaje de confiabilidad de la programación de la obra y una sinergia entre el equipo de trabajo perteneciente a la obra.

- $\quad$ El intercepto representa el 74.15\%, es un valor medio alto, el cual se incrementó durante las semanas de aplicación del sistema.

- $\quad$ La curva es adecuada para el ajuste, porque el 0.79 de R cuadrado se encuentra en el intervalo de aceptación.

- Según la gráfica de avance físico, se demuestra que en la construcción de un túnel de trinchera cubierta se reducen y recuperan los plazos de ejecución, a través de la implementación y aplicación de las metodologías de planeamiento con enfoque Lean Construction. A su vez, se obtuvieron de los resultados de la gráfica que la culminación del proyecto llegaría a extenderse un mes de trabajo si se hubiese mantenido el planeamiento tradicional, perjudicando totalmente la entrega del túnel. Por último, es importante mencionar que el desarrollo de la obra consiguió la integración sistémica de las áreas involucradas del proyecto gracias a la ayuda de las herramientas de planificación. 
- Para trabajar bajo los lineamientos de la metodología Last Planner System debemos tener una concepción sistémica de los miembros del soporte del sistema y de sus actividades, es decir, comprender las interrelaciones, dependencias y responsabilidades entre ellos, ya que forma pieza clave para el funcionamiento del sistema.

- De los resultados obtenidos en las encuestas para medir el grado de satisfacción de las dinámicas Pull Planning se evidencia que los participantes tienen un nivel alto de satisfacción con la reunión y saben que van a hacer en los próximos tres meses, como también creen que este tipo de dinámica es importante para el desarrollo del proyecto.

- A partir de los cálculos del dimensionamiento de personal (FTE) para el área de planeamiento y control en los dos momentos del proyecto, con y sin la metodología implementada podemos concluir que trabajando con el enfoque tradicional necesitábamos de 7.14 personas que luego de haber implementado las metodologías hubo una reducción de personal del $64.6 \%$ que es aproximadamente 2.62 personas. 


\section{BIBLIOGRAFÍA}

ABAD, Alan y HUISA, Freddy (2011) Procedimientos de excavación y sostenimiento de túneles proyecto de derivación Huascacocha - Rímac. (tesis de título profesional de Ingeniería Civil). Lima: Universidad Ricardo Palma.

ÁVILA, Jorge y QUINTANA, Adriana (2014) Simulación de eventos discretos y líneas de balance, aplicadas al mejoramiento del proceso constructivo del edificio universidad ciudad - PUJ. (tesis de magister de Ingeniería Civil). Bogotá: Pontificia Universidad Javeriana.

HERNÁNDEZ, Roberto y otros (2006) Metodología de la Investigación. $4^{\circ}$ ed. Ciudad de México: McGraw-Hill Interamericana.

CAÑA, Cristhian y ESCAJADILLO, Pedro (2006) Diagnóstico y evaluación de la relación entre el tipo estructural y la integración de los contratistas y subcontratistas con el nivel de productividad en obras de construcción. (tesis de título profesional de Ingeniería Civil). Lima: Pontificada Universidad Católica del Perú.

DÍAZ, Daniela (2007) Aplicación del sistema de planificación Last Planner a la construcción de un edificio habitacional de mediana altura. (tesis de título profesional de Ingeniería Civil). Santiago de Chile: Universidad de Chile.

GALVÍS, José y otros (2014) Filosofía Lean Construction para la gestión de proyectos de construcción: una revisión actual, pp. 32-53. En: revista Avances Investigación en Ingeniería vol. 11 , No. 1.

GARCÍA, Oswaldo (2012) Aplicación de la metodología Lean Construction en la vivienda de interés social. (tesis de postgrado de Especialización en Gerencia de Proyectos). Bogotá: Universidad EAN.

GRANADOS, Brenda (2011) Implementación de la metodología Lean Construction para actividades de estructura del proyecto Natura del consorcio Campo Empresarial Campestre. (tesis de título profesional de Ingeniería Industrial). Santander: Universidad Industrial de Santander.

HERRANDIZ, Salvador (2009) Aplicación del Lean Thinking a la construcción. (tesis de título profesional de Ingeniería Civil). Catalunya: Universidad Politécnica de Catalunya.

HURTADO, PARDO y REY, Alberto (2010) Túneles y Obras Subterráneas. España: Sika S.A.U. 
IBARRA, Luis (2011) Lean Construction. (tesis de especialista de Ingeniería Civil). Ciudad de México: Universidad Nacional Autónoma de México.

JARA, Elizabeth (2010) Colaboración extrema y gestión de compromisos en la etapa de diseño de proyectos. (tesis de magister en Ciencias de la Ingeniería). Santiago de Chile: Pontificia Universidad Católica de Chile.

LÓPEZ, Carlos (2012) Planificación, proyecto y construcción de túneles de gran longitud. Catalunya: Universidad Politécnica de Catalunya.

MEYERS. Fred (2000) Estudios de tiempos y movimientos. 2da.Ed. Estado de México: Pearson Educación.

PONS, Felipe (2014) Introducción a Lean Construction. Madrid: Fundación Laboral de la Construcción.

POON, Clemente (2013) Innovaciones en el Diseño y Construcción de Túneles. México: AJMéxico.

RODRÍGUEZ, Walter (2003) Presentación PowerPoint del curso Lean Construction. Amazonas: Colegio de Ingenieros del Perú.

SOTO, Pedro (2004) Construcción de Túneles. (tesis de título de Constructor Civil) Valdivia: Universidad Austral de Chile.

TERCERO, Jhonattan (2011) Propuesta de metodología para la implementación de la Filosofía Lean (construcción esbelta) en proyectos de construcción. (tesis de magister en Administración). Bogotá: Universidad Nacional de Colombia. 
Laureate International Universities ${ }^{\circledR}$

ANEXOS 


\section{Anexo Nro. 01:}

\section{"Programación Mensual de Abril 2015"}









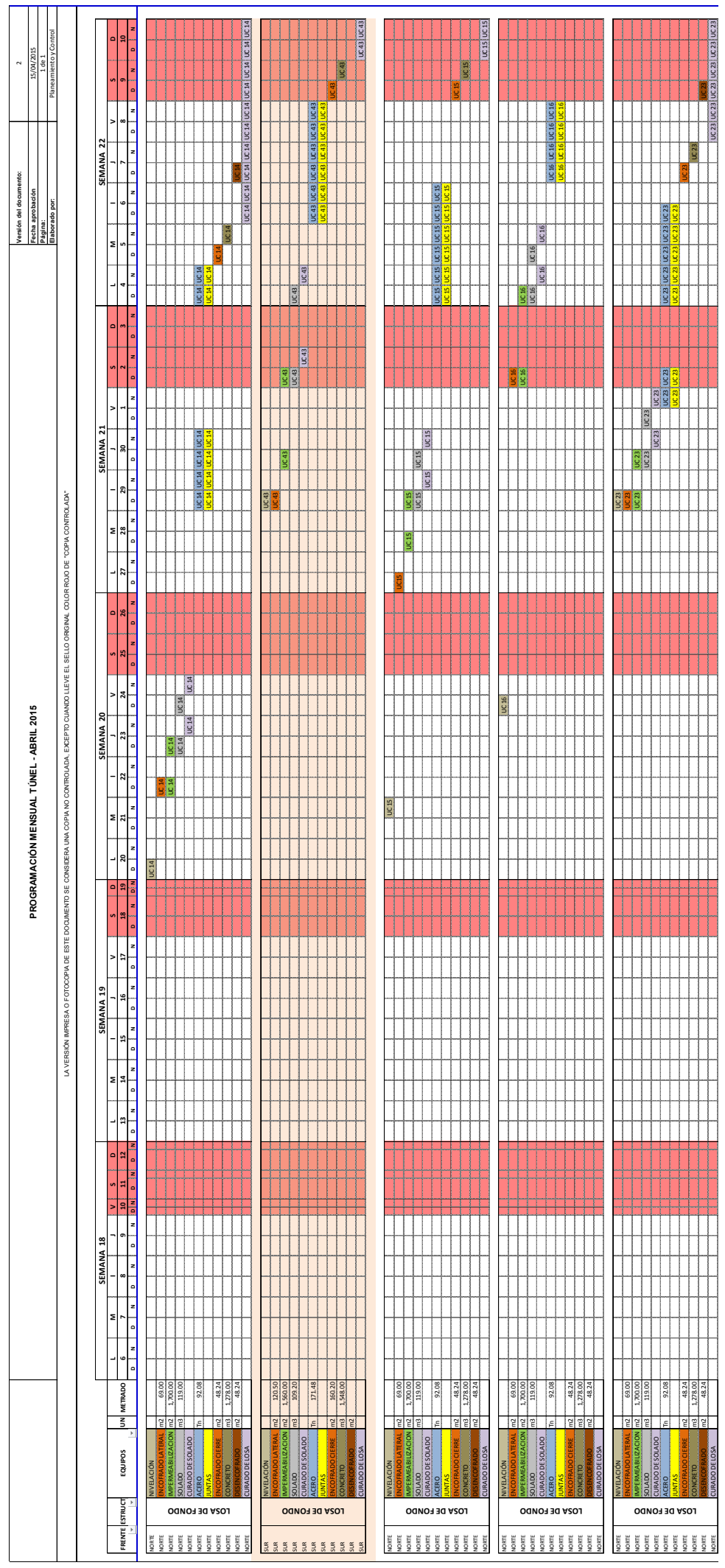




\section{Anexo Nro. 02: "Programación Mensual de Mayo 2015"}


UNIVERSIDAD PERUANA DE CIENCIAS APLICADAS

Laureate International Universities ${ }^{\circledR}$






\section{Anexo Nro. 03:}

\section{"Programación Mensual de Junio 2015"}


UNIVERSIDAD PERUANA DE CIENCIAS APLICADAS

Laureate International Universities ${ }^{\circledR}$

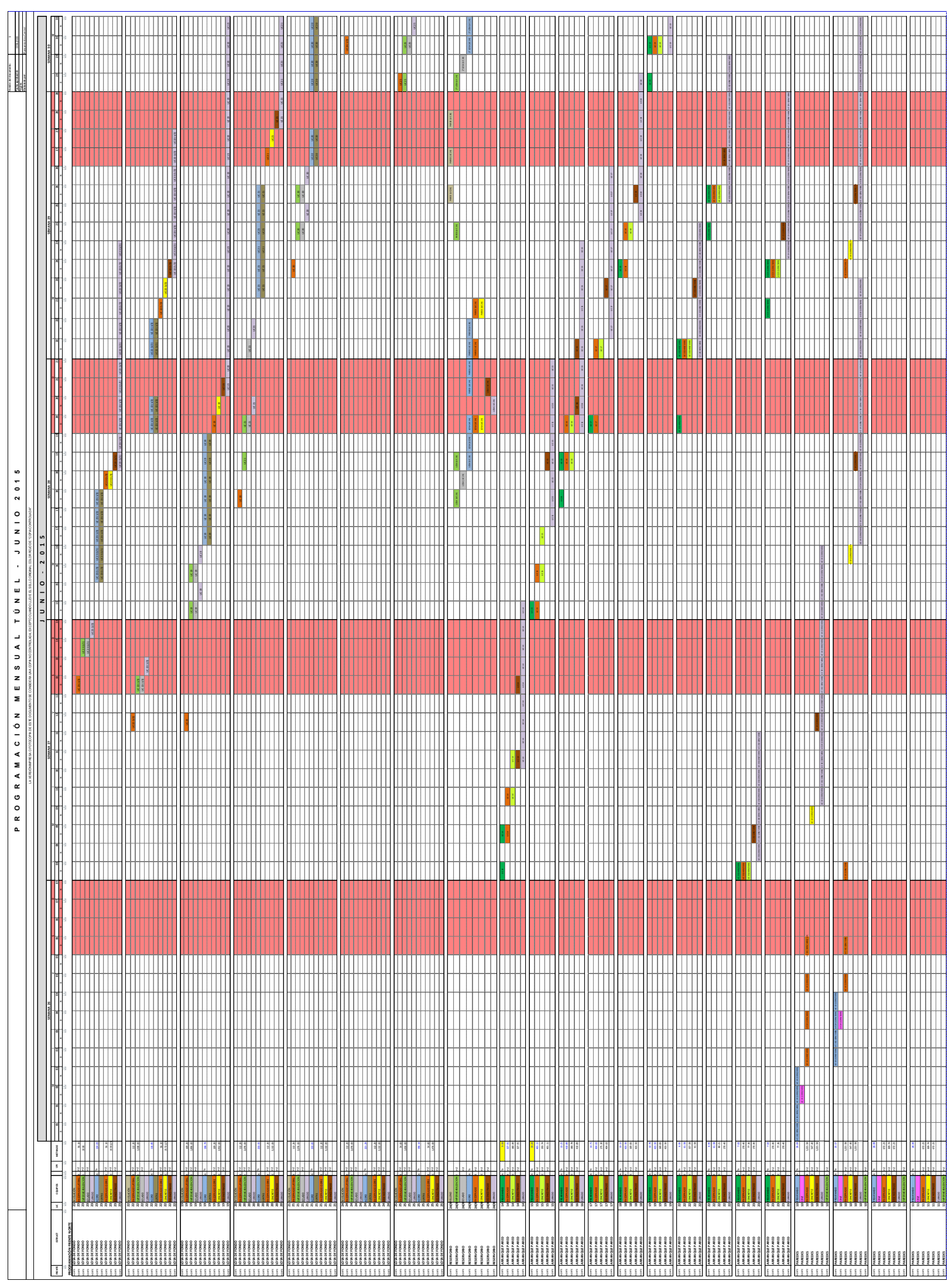


UNIVERSIDAD PERUANA DE CIENCIAS APLICADAS

Laureate International Universities ${ }^{\circledR}$






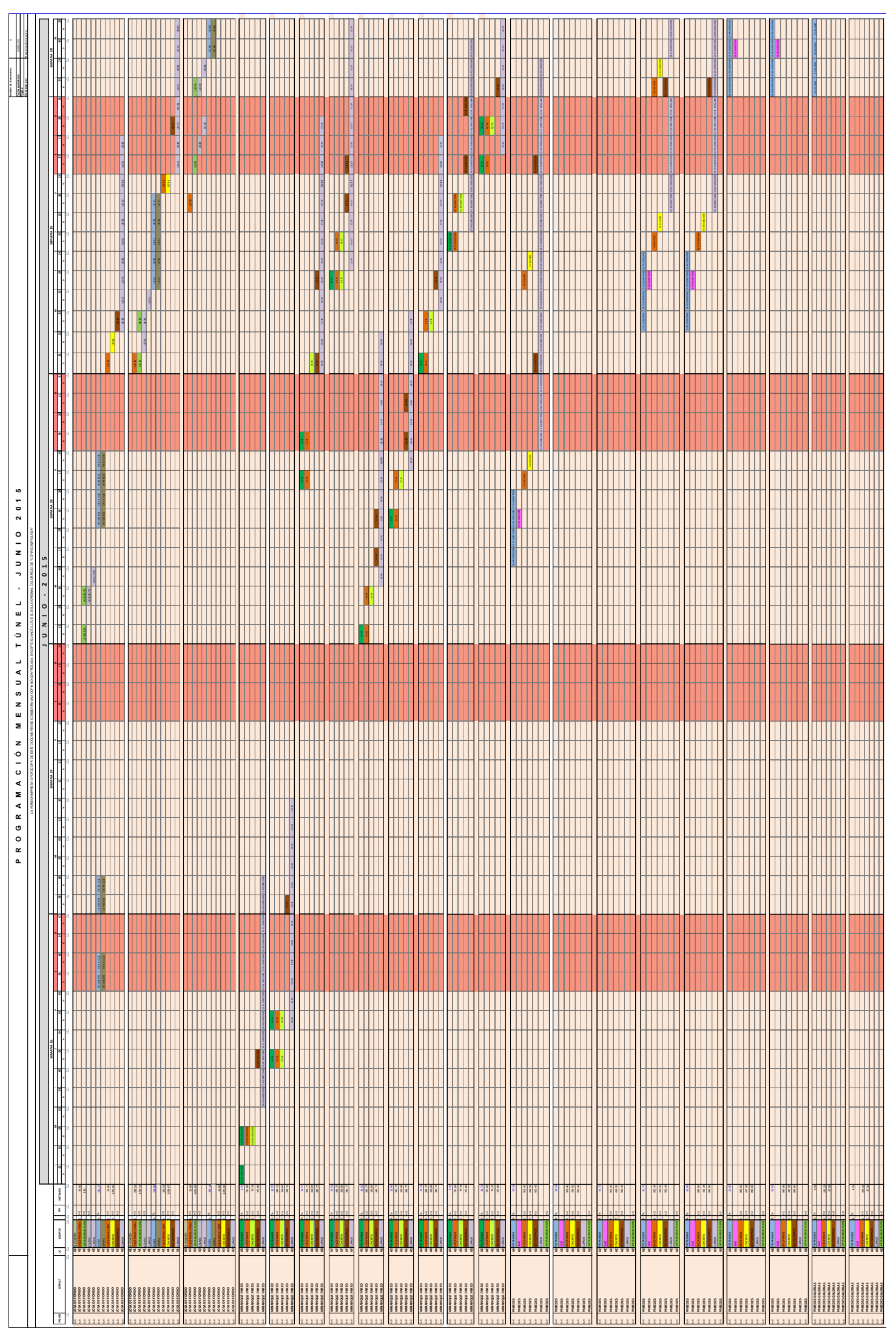


UNIVERSIDAD PERUANA DE CIENCIAS APLICADAS

Laureate International Universities ${ }^{\circledR}$

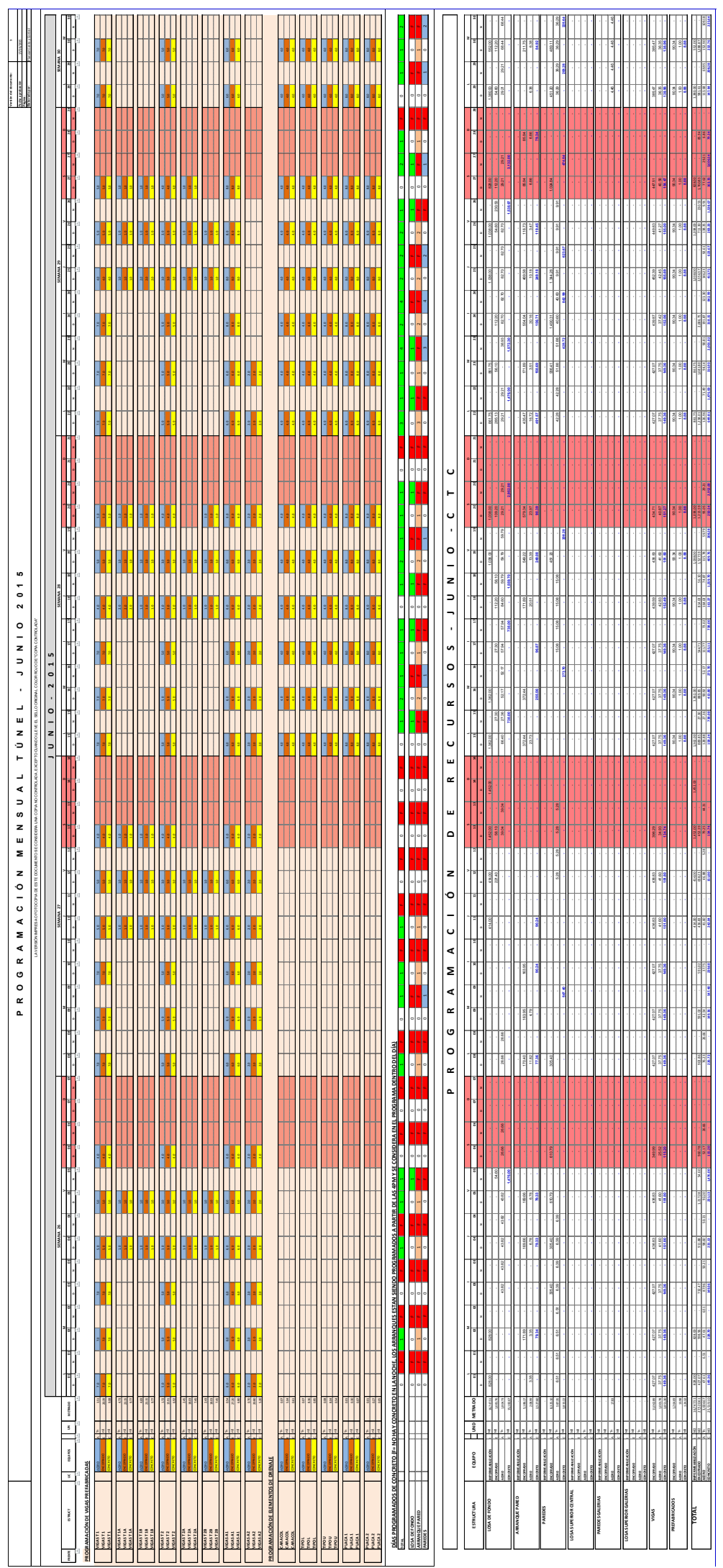




\section{Anexo Nro. 04: \\ “Descripción de Metodología de Trabajo del Área de Planeamiento"}




\section{Creación del cronograma Pull-Planning}

\section{Responsable:}

Ingeniero responsable de la programación semanal

\section{Alcance:}

Una vez elaborada y aprobada la línea de balance de las actividades para la dinámica PullPlanning se crea un proyecto en el software Primavera P6 para trasladar todas estas informaciones de las actividades con sus duraciones, vínculos y recursos para tener una herramienta de programación y control.

Figura 1: Líneas de Balance de actividades del Pull Planning - Pavimentos Dic/2015

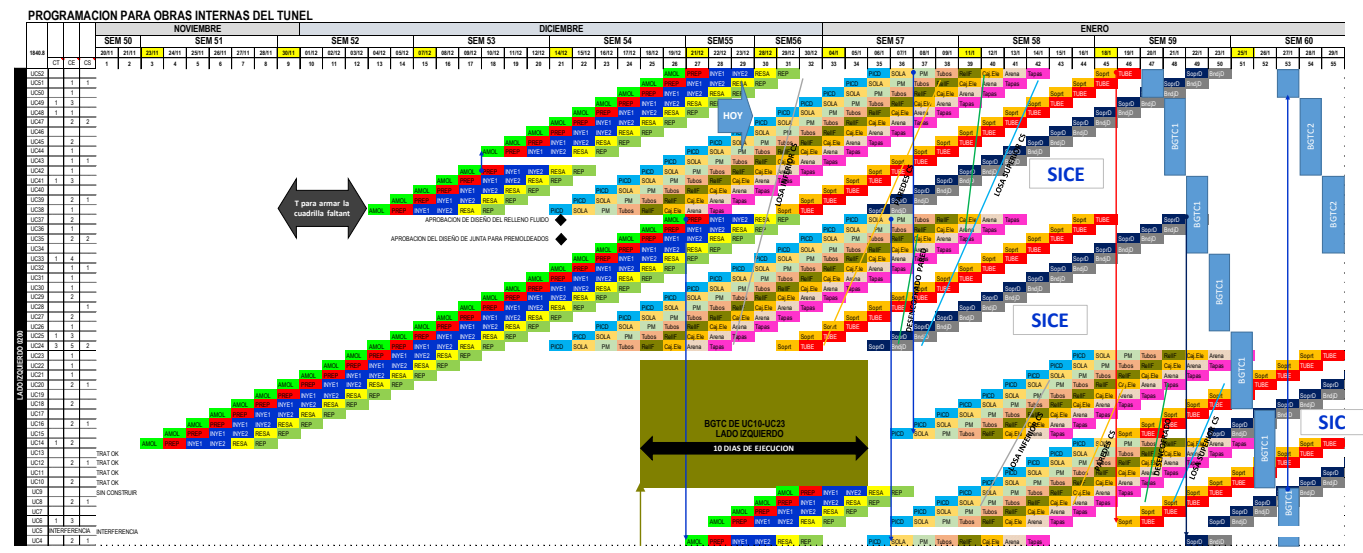

\section{Procedimiento:}

Paso 1: Trasladar Líneas de Balance a la Planilla de Importación (Excel).

Para esto es necesario hacer una lista de todas las actividades previstas de las líneas de balance en una hoja de Excel con el formato de una base de datos. En los títulos de las diversas columnas de la hoja de cálculo se debe asignar los nombres de los campos generales de las etiquetas de las actividades como: Unidad constructiva (UC) a la que pertenece, estructura, elemento, servicio, turno, duración, responsable, metrados, e incluso el capataz al que se le asignará la actividad. Además, en las filas se asignarán todos los registros o etiquetas propias de cada actividad. 
Figura 2: Planilla de importación (Excel) del Pull Planning Sur - Nov/2015

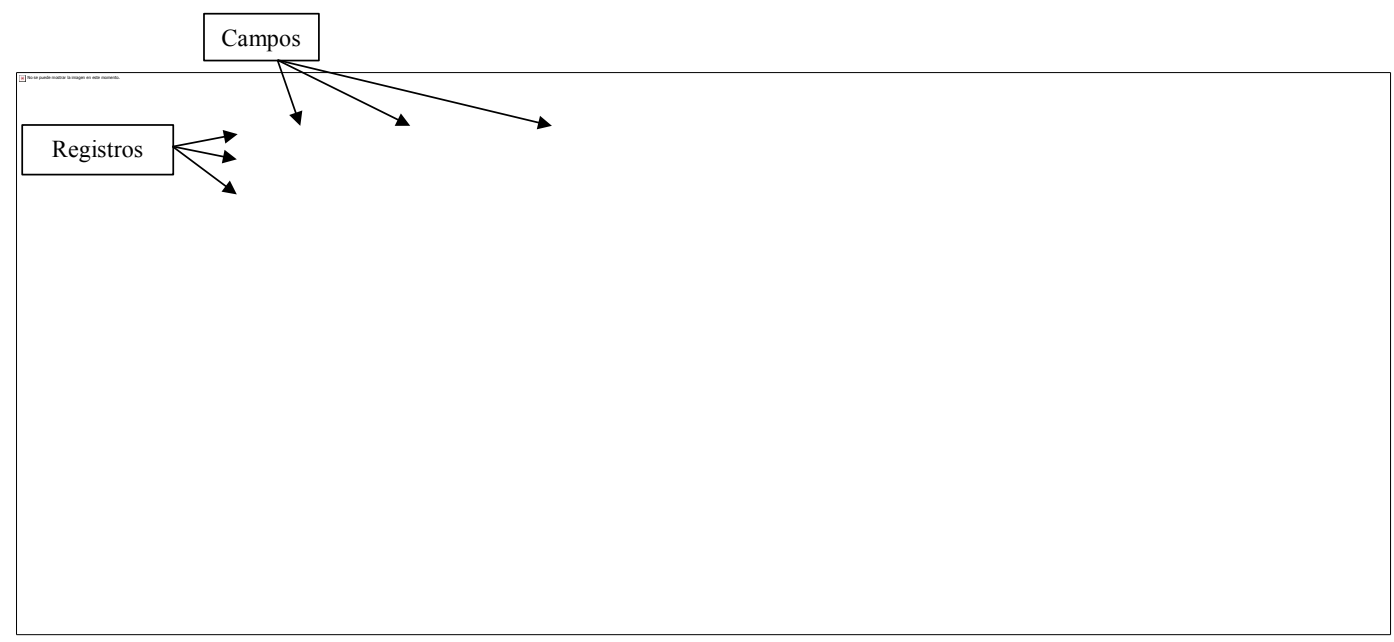

Paso 2: Creación de Proyecto en Primavera P6.

Antes de cargar la planilla de importación al Primavera P6, es necesario crear y preparar el entorno de nuestro proyecto en el software para que pueda recibir la información sin inconvenientes.

Ya dentro del programa Primavera P6 nos dirigimos al botón "New" ubicado en la parte superior izquierda de la ventana.

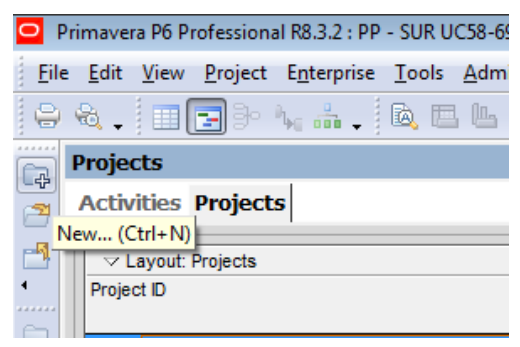

Al hacer click sobre él, emergerá un asistente de creación con cinco pasos. El primero solicita seleccionar el nivel de estructura de proyecto empresarial para el nuevo proyecto, luego el nombre e ID del Proyecto, como tercer paso la fecha de inicio de la planificación, cuarto, el gestor responsable y por último el tipo de cuota de asignación. Luego de hacer click sobre el botón "Finish" el proyecto ya está creado. 




Por lo general para todo proyecto en Primavera se debe crear una WBS (Work breakdown structure); sin embargo, para los cronogramas de Pull Planning no se creará una WBS, en lugar de ello se crearán Activity Codes, en base a los campos y registros asignados a las actividades que están en la planilla de importación. De esta manera se podrá ordenar, agrupar e incluso filtrar las actividades de múltiples formas de acuerdo a nuestras necesidades de programación.

Paso 3: Creación de los Activity Codes. 
En la barra de menús buscar la pestaña Enterprise y luego hace click sobre el botón "Activity Codes"

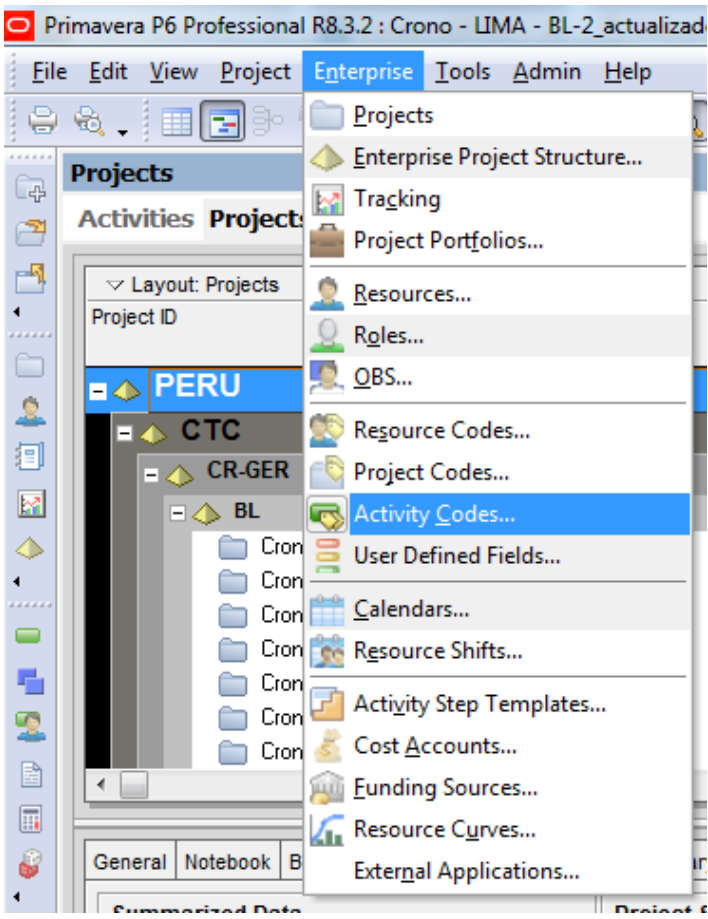

En la ventana que aparecerá a continuación se debe marcar "Global” para que más adelante el software permita utilizar y actualizar los Activity Codes en cualquier proyecto o copia de este. En seguida, se debe hacer click sobre el botón "Modify..."

\begin{tabular}{|c|c|c|c|c|c|}
\hline \multicolumn{4}{|c|}{ - Activity Codes } & \multicolumn{2}{|c|}{$x$} \\
\hline - Globa & $C$ EPS & \multicolumn{4}{|c|}{$C$ Project } \\
\hline \multicolumn{6}{|c|}{ Select Activity Code } \\
\hline 1CAPATAZ & \multicolumn{2}{|c|}{$\nabla$} & 国 & \multicolumn{2}{|c|}{ Modify... } \\
\hline \multicolumn{3}{|c|}{$\checkmark$ Display: Current Project's Values } & \multirow[t]{2}{*}{ 匈 } & \multicolumn{2}{|c|}{ Close } \\
\hline Code Value & Descriptior & Color & & & \\
\hline & & & њ & \multicolumn{2}{|c|}{ Add } \\
\hline & & & x & \multicolumn{2}{|c|}{ Delete } \\
\hline & & & d & \multicolumn{2}{|c|}{ Cut } \\
\hline & & & in & \multicolumn{2}{|c|}{ Copy } \\
\hline & & & a & \multicolumn{2}{|c|}{ Paste } \\
\hline & & & \multirow{2}{*}{4} & $\Delta$ & \multirow{2}{*}{ 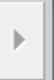 } \\
\hline & & & & $\nabla$ & \\
\hline & & & (?) & \multicolumn{2}{|c|}{ Help } \\
\hline
\end{tabular}

En la siguiente ventana se muestra una lista de todos los campos de Activity Codes predeterminados, los cuales podemos eliminar porque no se usarán. Al presionar el botón 
“Add" se podrá agregar los títulos de los campos que contendrán a todos los registros de los Activity Codes que se asignarán a las actividades.

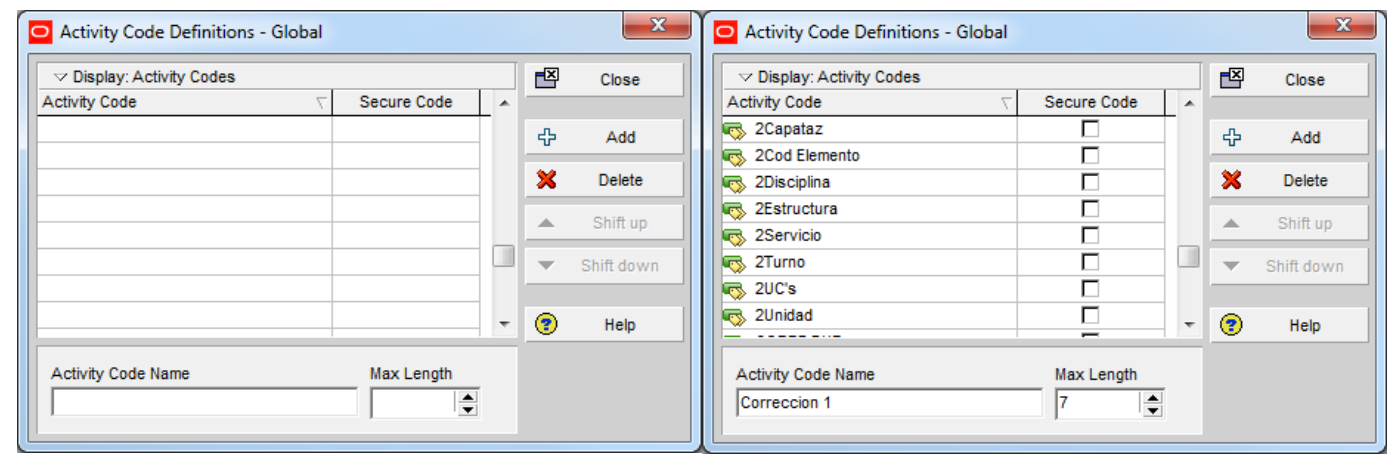

Al cerrar esta ventana, podemos seleccionar cada campo y dentro de este insertar todos los registros correspondientes.

En las figuras que se muestra a continuación se pueden ver todos los registros ingresados de los diferentes campos.

Importante: Para acelerar el proceso de creación del cronograma usaremos importaciones, para ello es muy importante que los nombres de los registros ingresados contengan los mismos caracteres que los de la planilla de importación.

\begin{tabular}{|c|c|c|c|c|c|c|c|c|c|c|c|}
\hline \multicolumn{2}{|l|}{ Activity Codes } & & \multicolumn{2}{|r|}{$x$} & \multicolumn{5}{|l|}{ 이 Activity Codes } & \multicolumn{2}{|c|}{$x$} \\
\hline C Global $C$ EPS & $C$ Project & & & & C. Global & $C$ EPS & & & & & \\
\hline \multicolumn{5}{|l|}{ Select Activity Code } & \multicolumn{7}{|c|}{ Select Activity Code } \\
\hline 2Capataz & \multicolumn{2}{|l|}{ 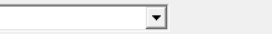 } & \multicolumn{2}{|c|}{ E Modify... } & \multicolumn{2}{|l|}{2 Cod Elemento } & \multicolumn{2}{|c|}{$\nabla$} & E & \multicolumn{2}{|l|}{ Modify... } \\
\hline \multicolumn{3}{|l|}{$\checkmark$ Display: All Values } & \multirow[t]{2}{*}{ 匈 } & Close & \multicolumn{2}{|c|}{$\checkmark$ Display: All Values } & & & 包 & \multirow{2}{*}{\multicolumn{2}{|c|}{ Close }} \\
\hline Code Value & Description & Color & & & Code Value & Description & Color & $A$ & 5 & ciose & \\
\hline$\Rightarrow$ CASTILLO/ARMAS & CASTILLO /ARMAS & & \multirow{2}{*}{\multicolumn{2}{|c|}{ Add }} & $\Rightarrow 200$ & 200 & & $\square$ & ↔ & \multicolumn{2}{|l|}{ Add } \\
\hline CASTLLO/CRUZADO & CASTILLO/CRUZADO & & & & 300 & 300 & & & & \multirow{2}{*}{\multicolumn{2}{|c|}{ Delete }} \\
\hline CHAMORRO & CHAMORRO & & \multicolumn{2}{|c|}{$\$$ Delete } & 400 & 400 & & & $x$ & & \\
\hline $\begin{array}{l}\text { CUENCAIHUANCA } \\
\text { NAN DIAZ/ RAMOS }\end{array}$ & $\begin{array}{l}\text { CUENCA/HUANCA } \\
\text { NAN DIAZI RAMOS }\end{array}$ & & \multicolumn{2}{|c|}{ of cut } & $\begin{array}{l}=1100 \\
=1200\end{array}$ & $\begin{array}{l}1100 \\
1200\end{array}$ & & & of & \multicolumn{2}{|l|}{ Cut } \\
\hline JOEL RETO & JOEL RETO & & \multirow{2}{*}{\multicolumn{2}{|c|}{ 䭪 Copy }} & $200(1 / 3)$ & $200(1 / 3)$ & & & 㬝 & \multirow{2}{*}{\multicolumn{2}{|c|}{ Copy }} \\
\hline JUVENAL RUIZ & JUVENAL RUIZ & & & & 1300 & 1300 & & & 㽪 & \multirow{2}{*}{\multicolumn{2}{|c|}{ Paste }} \\
\hline $\begin{array}{l}\text { MARTINEZ/ARMATEK } \\
\text { T\&T CARLOS }\end{array}$ & $\begin{array}{l}\text { MARTINEZ/ARMATEK } \\
\text { T\&T CARLOS }\end{array}$ & & \multicolumn{2}{|l|}{ 롱 } & $\begin{array}{l}\Rightarrow 400(1 / 3) \\
=1400\end{array}$ & $\begin{array}{l}400(1 / 3) \\
1400\end{array}$ & & & A & & \\
\hline ROBERTO YNGA & ROBERTO YNGA & & \multirow{3}{*}{4} & \multirow[b]{2}{*}{  } & $400(2 / 3)$ & $400(2 / 3)$ & & & 4 & $\boldsymbol{\Delta}$ & \multirow{2}{*}{ 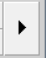 } \\
\hline ROMAINA & ROMAINA & & & & $200(2 / 3)$ & $200(2 / 3)$ & & & 4 & $\nabla$ & \\
\hline SERVANDO/GARCIA & SERVANDO/GARCIA & & & & 1500 & 1500 & & & & & \\
\hline YUCRAMELO & YUCRAMELLO & & (2) & Help & $=1600$ & 1600 & & & (3) & Help & \\
\hline TMOTEO/CONCUERA & TMMOTEO/CONCUERA & & & & 2100 & 2100 & & - & & & \\
\hline
\end{tabular}


UNIVERSIDAD PERUANA DE CIENCIAS APLICADAS

Laureate International Universities ${ }^{\circledR}$

\begin{tabular}{|c|c|c|c|c|c|}
\hline \multicolumn{2}{|l|}{ Activity Codes } & & & \multicolumn{2}{|c|}{$x$} \\
\hline C. Global & \multicolumn{2}{|l|}{$C$ Project } & & & \\
\hline \multicolumn{6}{|l|}{ Select Activity Code } \\
\hline 2Estructura & \multicolumn{2}{|l|}{ 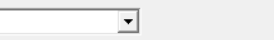 } & 모 & \multicolumn{2}{|c|}{ Modify... } \\
\hline \multicolumn{3}{|l|}{$\checkmark$ Display: All Values } & \multirow{2}{*}{ 匈 } & \multicolumn{2}{|c|}{ Close } \\
\hline Code Value & Description & Color & & & \\
\hline \multirow{2}{*}{$\begin{array}{l}\text { ARRANQUES } \\
\text { INTERIOR GALERIA }\end{array}$} & ARRANQUES & & $њ$ & \multicolumn{2}{|l|}{ Add } \\
\hline & INTERIOR GALERIA & & & \\
\hline LOSADE FONDO & LOSADE FONDO & & $\boldsymbol{x}$ & \multicolumn{2}{|c|}{ Delete } \\
\hline $\begin{array}{l}\text { LOSADE FONDO GALERIA } \\
\text { LOSA SUPERIOR }\end{array}$ & LOSADE FONDO GALERIA & & & \multicolumn{2}{|l|}{ Cut } \\
\hline \multirow[b]{2}{*}{ LOSA SUPERIOR GALERIA } & $\begin{array}{l}\text { LOSA SUPERIOR } \\
\text { LOSA SUPERIOR GALERIA }\end{array}$ & & do & \multirow{2}{*}{\multicolumn{2}{|c|}{ Copy }} \\
\hline & $\begin{array}{l}\text { LOSA SUPERIOR GALERIA } \\
\text { NUDOS }\end{array}$ & & 墫 & & \\
\hline$\Longrightarrow$ PARAPETOS & PARAPETOS & & 2 & \multicolumn{2}{|l|}{ Paste } \\
\hline PAREDES & PAREDES & &  & \multirow[b]{2}{*}{$\Delta$} & \multirow{2}{*}{ D } \\
\hline PAREDES DE GALERIA & PAREDES DE GALERIA & & \multirow{2}{*}{4} & & \\
\hline RESERVORIO & RESERVORIO & & & \multicolumn{2}{|l|}{$\checkmark$} \\
\hline \multirow{2}{*}{\multicolumn{2}{|c|}{1}} & & (3) & \multicolumn{2}{|l|}{ Help } \\
\hline & & & & & \\
\hline
\end{tabular}

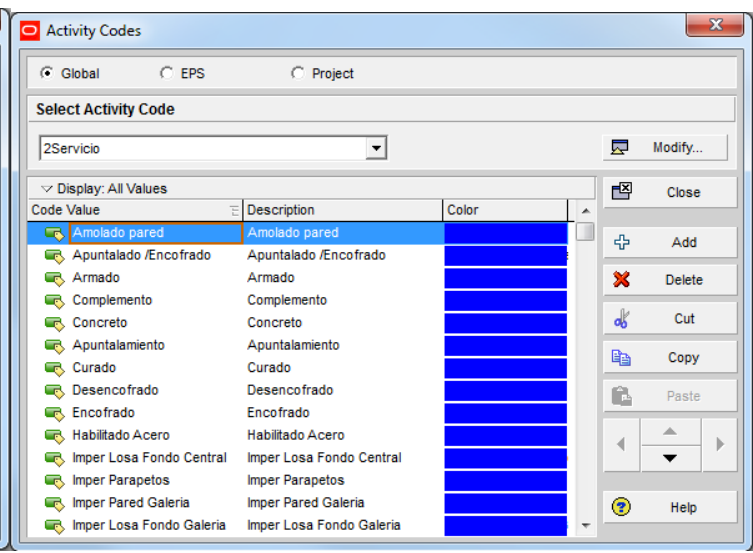

\begin{tabular}{|c|c|c|c|c|c|c|c|c|c|c|c|}
\hline \multicolumn{3}{|c|}{ 으 Activity Codes } & \multicolumn{3}{|c|}{$x$} & \multicolumn{4}{|c|}{ Activity Codes } & \multicolumn{2}{|c|}{$x$} \\
\hline C. Global & $C$ EPS & \multicolumn{4}{|c|}{$C$ Project } & - Global & $C$ EPS & \multicolumn{4}{|c|}{$\checkmark$ Project } \\
\hline \multicolumn{6}{|c|}{ Select Activity Code } & \multicolumn{6}{|c|}{ Select Activity Code } \\
\hline \multicolumn{2}{|l|}{2 2Turno } & $\nabla$ & 봉 & \multicolumn{2}{|l|}{ Modify... } & \multicolumn{3}{|c|}{ 2Unidad $=$} & E & \multicolumn{2}{|l|}{ Modify... } \\
\hline \multicolumn{3}{|c|}{$\checkmark$ Display: All Values } & \multirow{2}{*}{ 困 } & \multicolumn{2}{|l|}{ Close } & \multicolumn{3}{|c|}{$\checkmark$ Display: All Values } & \multirow[t]{2}{*}{ 圆 } & \multicolumn{2}{|c|}{ Close } \\
\hline \multirow{8}{*}{$\begin{array}{c}\text { Code value } \\
\Rightarrow \mathrm{D} \\
\mathrm{N} \\
\mathrm{DN}\end{array}$} & Description & Color & & & & Code Value & Description & Color & & \multirow{2}{*}{\multicolumn{2}{|c|}{ Add }} \\
\hline & \multirow{7}{*}{$\begin{array}{l}\text { Diache } \\
\text { Dia/Noche }\end{array}$} & & \multicolumn{3}{|c|}{ \& Add } & \multirow{7}{*}{ 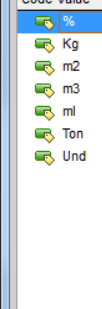 } & \multirow{7}{*}{$\begin{array}{l}\text { Porcentaje } \\
\text { Kilogramo } \\
\text { Metro cuadrado } \\
\text { Metro cubico } \\
\text { Metro Lineal } \\
\text { Tonelada } \\
\text { Unidad }\end{array}$} & & $\nLeftarrow$ & & \\
\hline & & & \multicolumn{3}{|c|}{$\boldsymbol{X}$ Delete } & & & &  & \multicolumn{2}{|l|}{ Delete } \\
\hline & & & \multicolumn{3}{|c|}{ of $\quad$ Cut } & & & & db & \multicolumn{2}{|l|}{ Cut } \\
\hline & & & 㬝 & \multicolumn{2}{|l|}{ Copy } & & & & 覩 & \multicolumn{2}{|l|}{ Copy } \\
\hline & & & a & \multicolumn{2}{|l|}{ Paste } & & & & 을 & \multicolumn{2}{|c|}{ Paste } \\
\hline & & & 4 & & $\triangleright$ & & & & 4 & \multicolumn{2}{|c|}{$\vec{\Delta}$} \\
\hline & & & (2) & \multicolumn{2}{|l|}{ Help } & & & & (2) & Help & \\
\hline
\end{tabular}

\begin{tabular}{|c|c|c|c|c|c|c|}
\hline \multicolumn{5}{|c|}{ A Activity Codes } & \multicolumn{2}{|c|}{$x$} \\
\hline • Global & $C$ EPS & \multicolumn{5}{|l|}{ C Project } \\
\hline \multicolumn{7}{|c|}{ Select Activity Code } \\
\hline \multicolumn{2}{|l|}{$20 \mathrm{Cls}$} & I. & \multicolumn{2}{|r|}{ 园 } & \multicolumn{2}{|c|}{ Modify... } \\
\hline \multicolumn{2}{|c|}{$\checkmark$ Display: All Values } & & \multirow{2}{*}{\multicolumn{2}{|c|}{ 匈 }} & \multirow{2}{*}{\multicolumn{2}{|c|}{ Close }} \\
\hline Code Value & Eescription & Color & & & \multirow{2}{*}{\multicolumn{2}{|c|}{ Add }} \\
\hline Ucol & UC 01 & & \multirow{2}{*}{\multicolumn{2}{|c|}{ ↔ }} & & \\
\hline UC 02 & UC 02 & & & & \multirow{2}{*}{\multicolumn{2}{|c|}{ Delete }} \\
\hline Uc 03 & UC 03 & & & * & & \\
\hline UC 04 & UC 04 & & & \multirow{2}{*}{ db } & \\
\hline UC 05 & UC 05 & & & & & \\
\hline $\begin{array}{l}\text { UC } 06 \\
\text { uc } 07\end{array}$ & $\begin{array}{l}\text { UC } 06 \\
\text { UC } 07\end{array}$ & & & \multicolumn{3}{|c|}{ 覩 Copy } \\
\hline UC 08 & UC 08 & & & \multirow[t]{2}{*}{ B } & \multicolumn{2}{|c|}{ Paste } \\
\hline UC 09 & $\begin{array}{l}\text { UC } 09 \\
\text { UC } 10\end{array}$ & & & & \multirow{2}{*}{\multicolumn{2}{|c|}{$\frac{\Delta}{\nabla}$}} \\
\hline UC 10 & $\begin{array}{l}\text { UC } 10 \\
\text { UC } 11\end{array}$ & & \multirow{2}{*}{\multicolumn{2}{|c|}{4}} & & \\
\hline$\Rightarrow$ Uc 12 & UC 12 & & & & & \\
\hline UC 13 & UC 13 & & & \multirow{2}{*}{ (2) } & \multirow{2}{*}{\multicolumn{2}{|c|}{ Help }} \\
\hline$=$ UC 14 & UC 14 & & - & & & \\
\hline
\end{tabular}

Paso 4: Creación de actividades.

Una vez creado el proyecto y los Activity Codes, hacer click derecho sobre el nombre del proyecto creado y presionar "Open Project" 


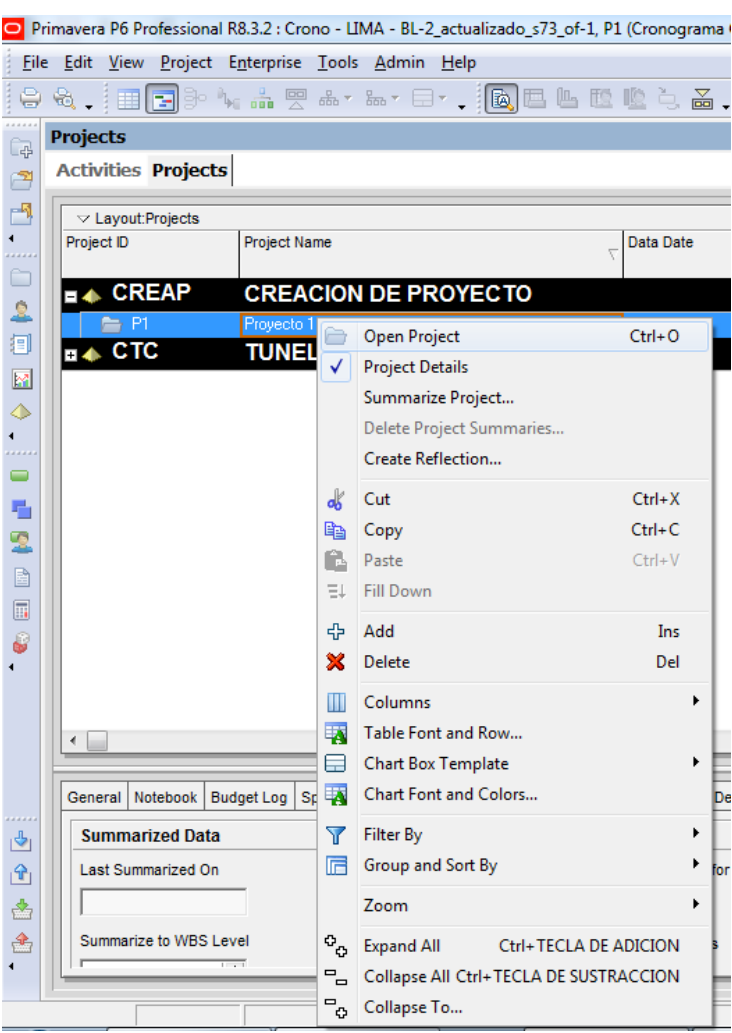

Luego se debe crear tantas actividades como el número que se listaron en la planilla de importación. Para crear una actividad se debe presionar el botón " $A d d$ ” ઐ

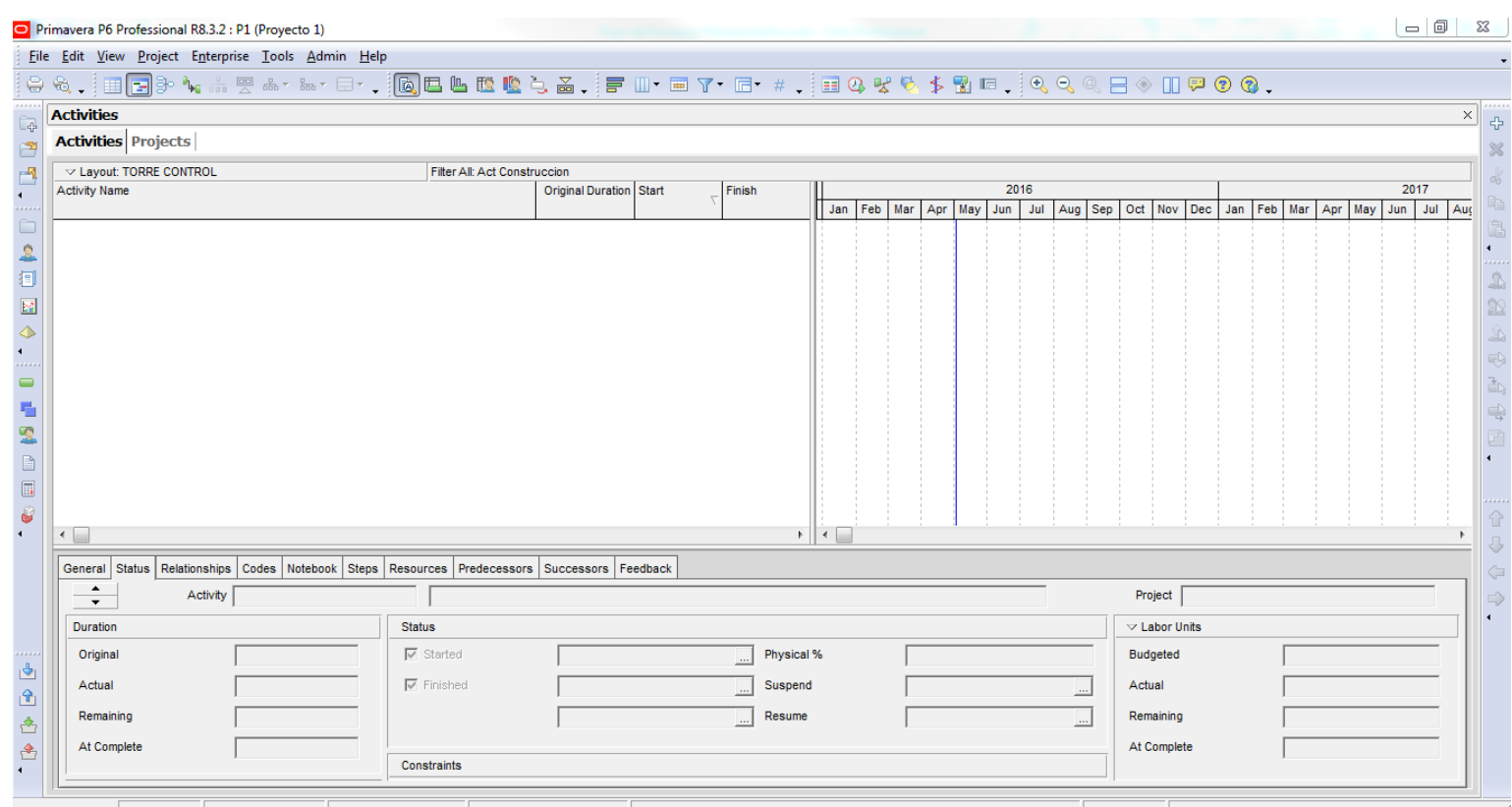


A continuación se mostrarán las siguientes ventanas, en la primera se definirá el ID y nombre de actividad (en este caso aún no es necesario definir el nombre porque se modificará mediante la importación), en la ventana siguiente se selecciona la WBS de la actividad (en este caso se tiene un solo nivel de WBS definido), en la tercera ventana se define el tipo de actividad como tarea dependiente o "Task Dependent", en la cuarta ventana se obviará la asignación de recursos porque se realizará más adelante, en la quinta ventana se debe selección el tipo de duración como unidades y duración fija "Fixed Duration and Units", en la sexta ventana se definirá la duración de la actividad con un día por defecto pues luego se modificará mediante la importación. Las siguientes ventanas solicitan asignación de vínculos y otros detalles que no se realizaran por el momento, así se termina el proceso de creación de una actividad.
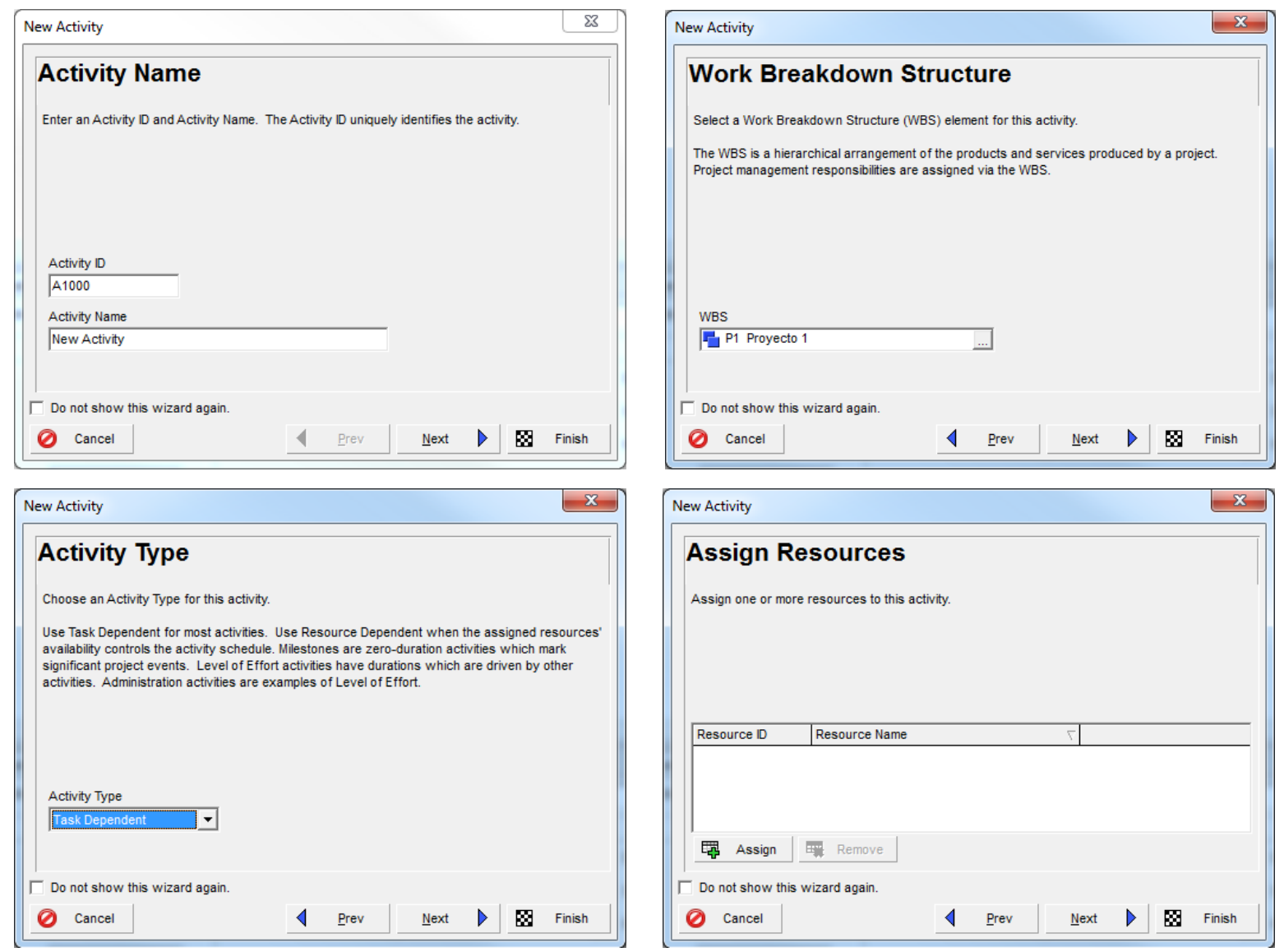
UNIVERSIDAD PERUANA DE CIENCIAS APLICADAS

Laureate International Universities ${ }^{\circledR}$


Para acelerar y facilitar el proceso de creación de las actividades se puede copiar $(\mathrm{Ctrl}+\mathrm{C})$ y pegar $(\mathrm{Ctrl}+\mathrm{V})$ la primera actividad creada las veces necesarias. 




Paso 5: Exportación de Planilla

Hacer click sobre el menú "File" y seleccionar la opción "Export..."



A continuación, se mostrará una ventana asistente donde se debe completar los siguientes pasos:

En la primera ventana se debe elegir el formato de exportación, para este caso seleccionaremos hoja de cálculo "Spreadsheet - (XLS)"

Seleccionar el tipo de información que se exportará: "Activities"

Seleccionar el proyecto que se exportará. 
Seleccionar o crear la plantilla de exportación. Por ser la primera vez, presionaremos el botón "Add". A continuación, se mostrará una ventana donde seleccionaremos las columnas o campos de importación creados en un paso anterior como Activity Codes. Por ultimo hacemos click sobre el botón OK.

En la ventana siguiente seleccionamos la ubicación donde se guardará el archivo de la exportación.

En la última ventana del asistente de exportación presionamos el botón "Finish" para finalizar.
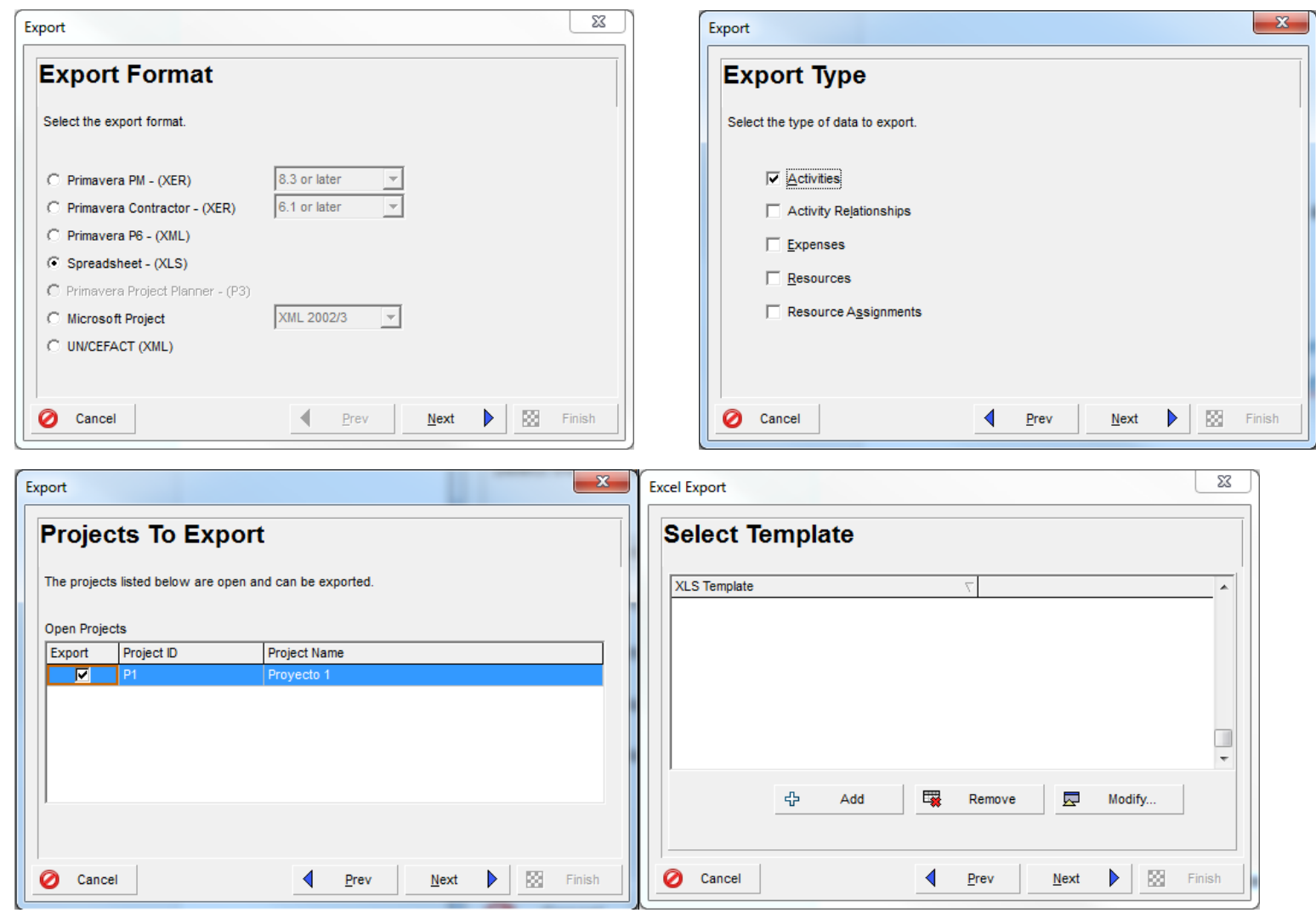
Laureate International Universities ${ }^{\circledR}$


Paso 6: Importación de Planilla.

Realizada la exportación, buscamos la planilla en la ubicación en la que se guardó. 
UNIVERSIDAD PERUANA DE CIENCIAS APLICADAS

Laureate International Universities ${ }^{\circledR}$



$\mathrm{Al}$ abrir el archivo se observarán los campos creados sin ninguna información. Ver figura.



Como siguiente paso, se debe completar el archivo exportado con los datos de la planilla de importación creada a partir de las líneas de balance. Ver figura. 


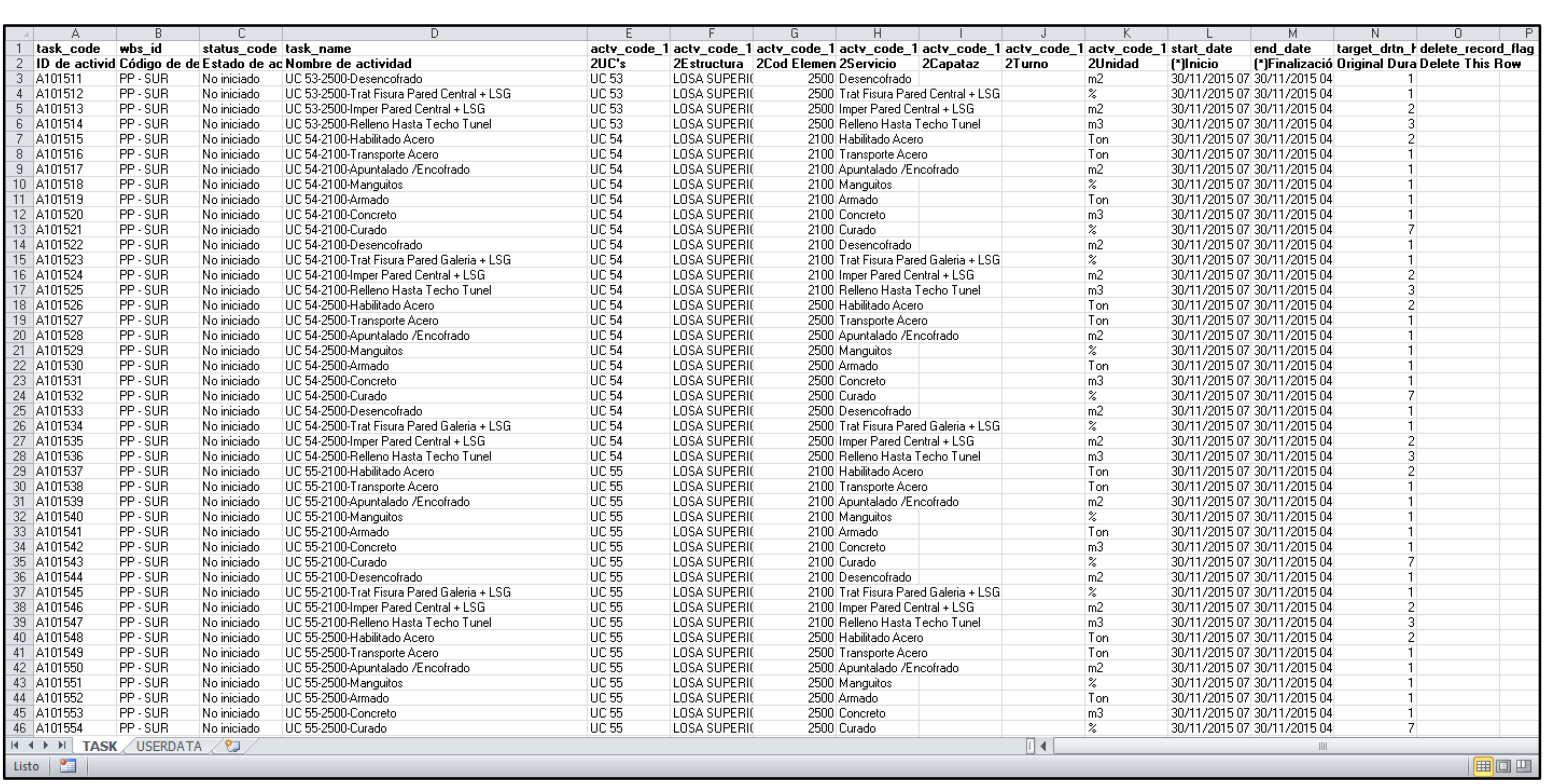

Finalmente se debe guardar los cambios realizados y cerrar el archivo.

Seguidamente, se debe retornar al Primavera P6 para realizar la importación.

En el menú File seleccionamos la opción Import y luego la opción Spreadsheet -(XLS).

En la ventana "Select Excel File" seleccionamos el archivo a importar y presionamos el botón Next.

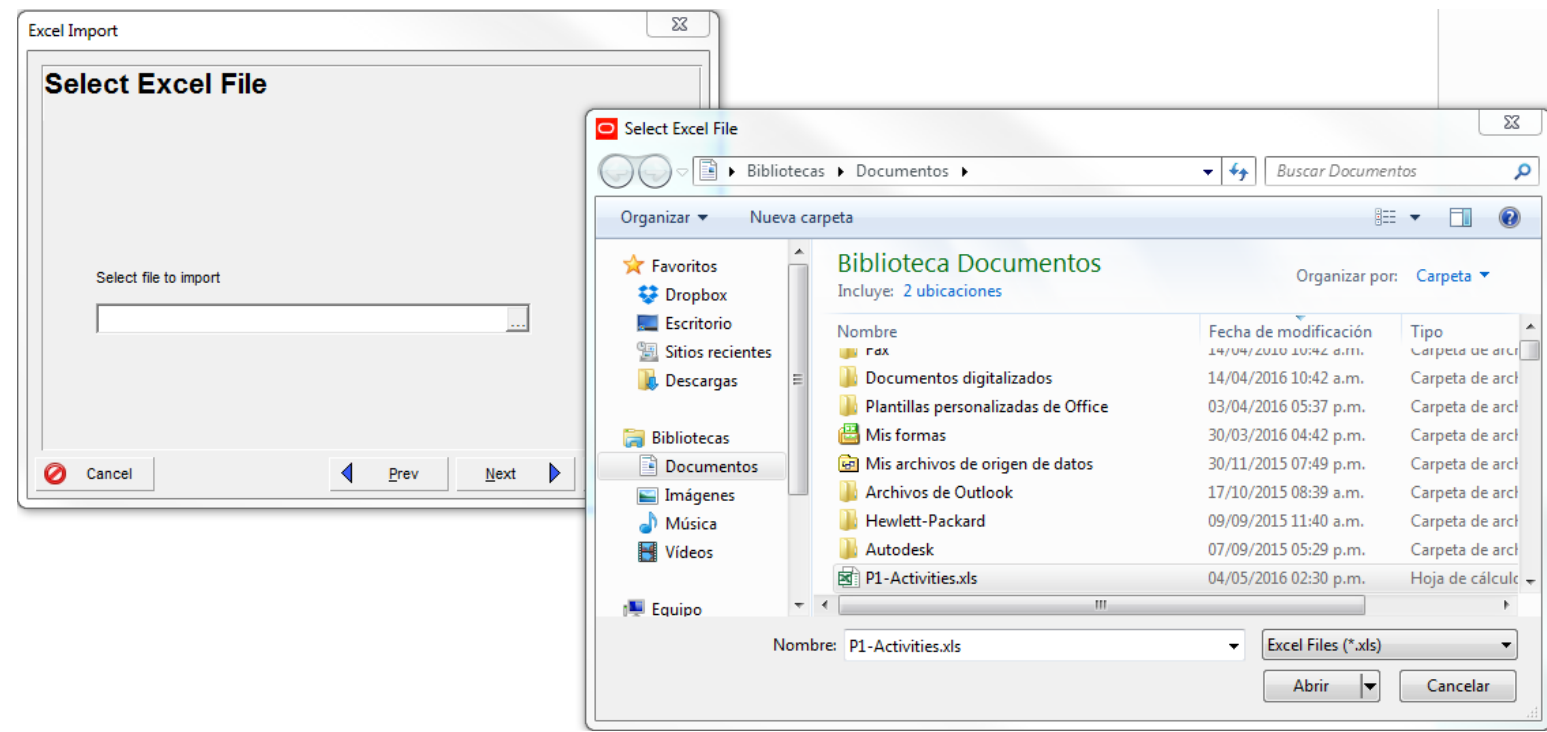

En la ventana que se mostrará seleccionamos el tipo de información a importar, para este caso seleccionamos "Activities" tal como se hizo en la exportación.



Seguidamente seleccionamos el proyecto de destino para la importación. 


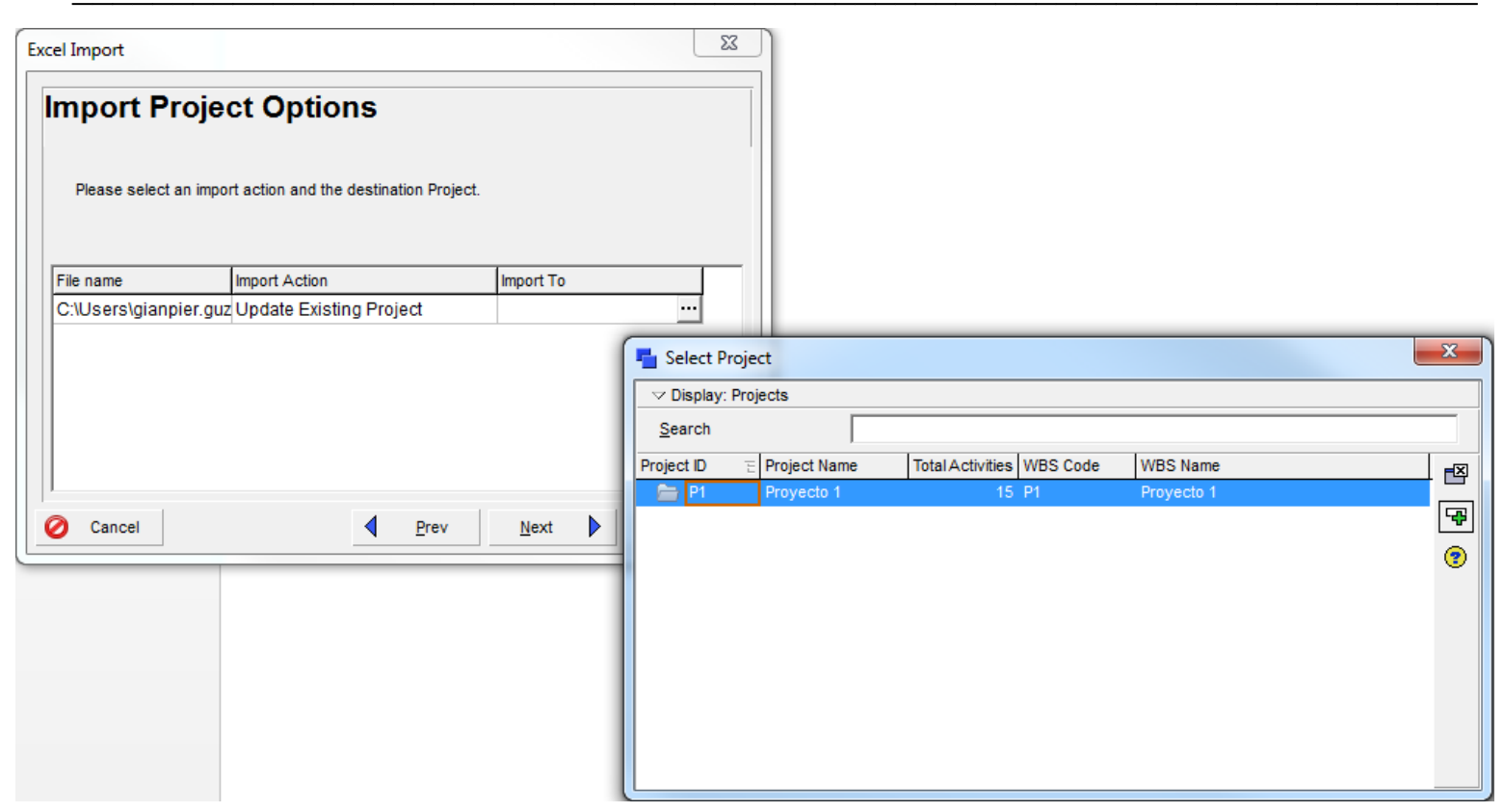

Para terminar, se debe hacer click en el botón "Finish".

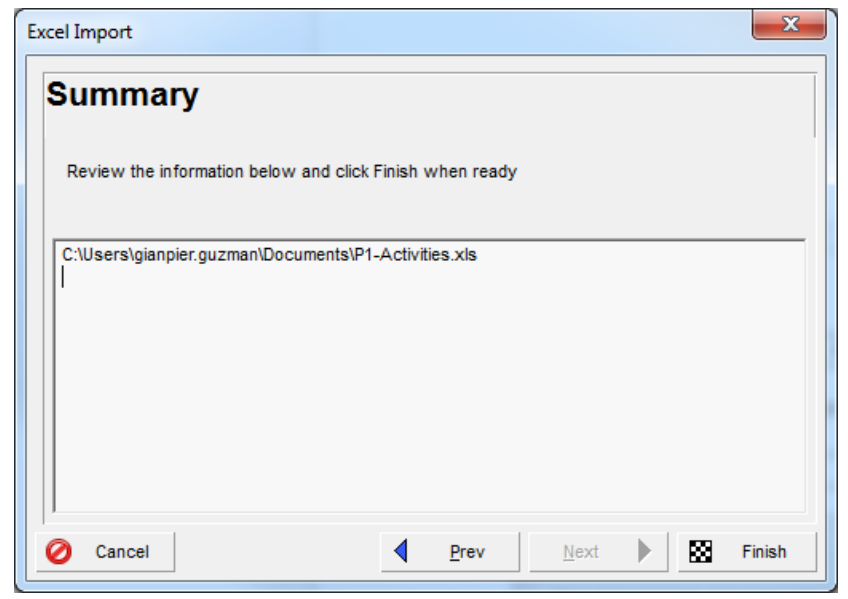

Nota: Cuando la importación haya finalizado se mostrará un mensaje donde se indicará si la importación fue realizada con éxito y si no, se deberán hacer las correcciones necesarias.

Paso 7: Columnas y Agrupación de actividades.

Antes de agrupar las actividades es necesario e importante ordenar la información mediante columnas para esto se debe seleccionar el icono "Colums" $\mathbb{W}$ - ubicado en la barra de herramientas. Luego, se mostrará la siguiente ventana donde se debe de seleccionar los campos que sean necesarios. Ver figura. 
UNIVERSIDAD PERUANA DE CIENCIAS APLICADAS

Laureate International Universities ${ }^{\circledR}$
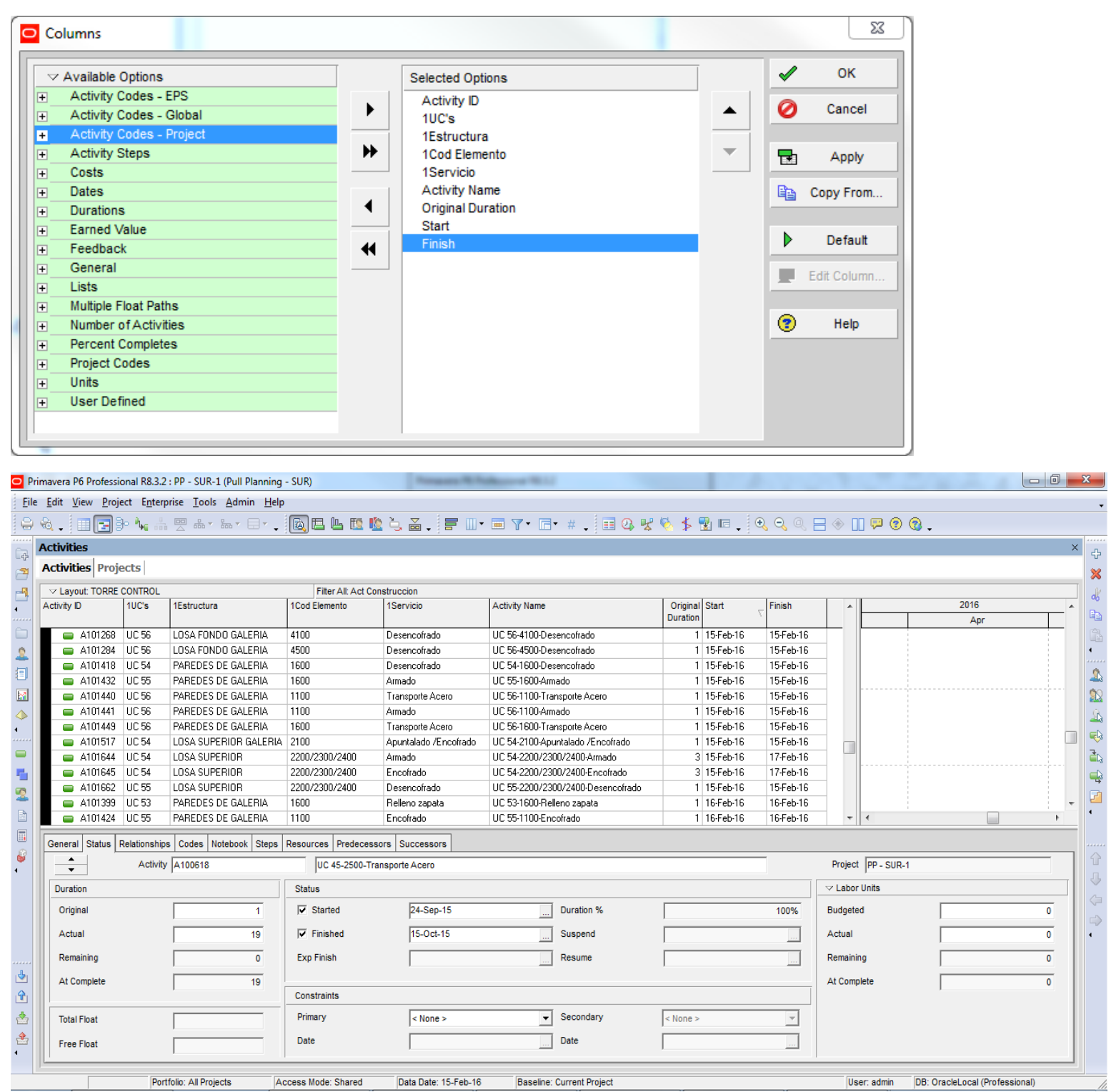

Para agrupar las actividades se debe buscar en la barra de herramientas el icono "Group and Sort By” $\sqrt{\square}$. Al hacer click se mostrará la siguiente ventana, donde se puede seleccionar los campos de acuerdo al nivel de organización requerido. 
UNIVERSIDAD PERUANA DE CIENCIAS APLICADAS

Laureate International Universities ${ }^{\circledR}$
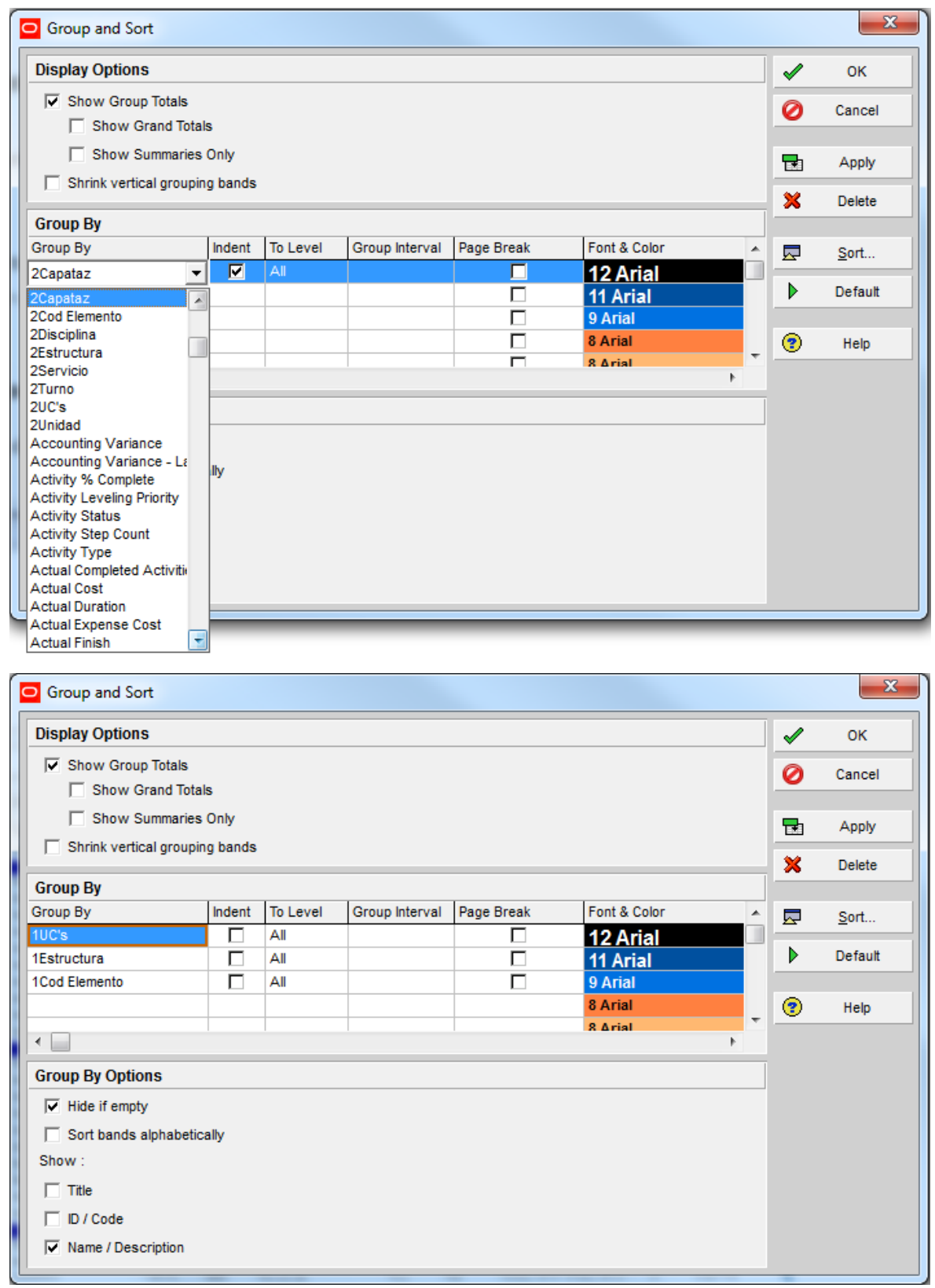

Luego de realizar los pasos indicados, el entorno de trabajo se mostrará como en la siguiente figura. Obsérvese que se logró agrupar las actividades de acuerdo a los niveles definidos. 


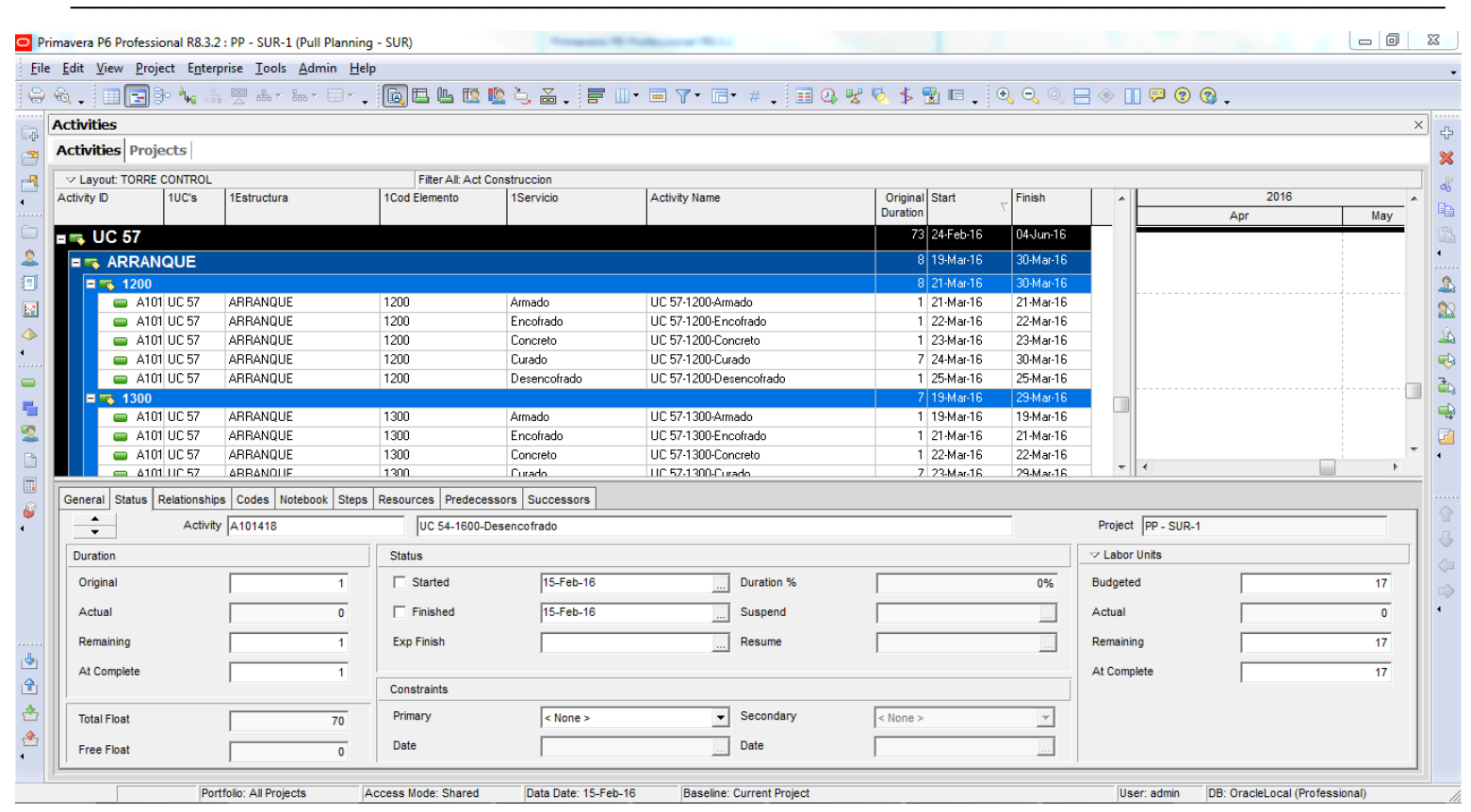

Paso 8: Vínculos entre actividades.

Una vez que tenemos toda la información ingresada y organizada de forma adecuada se puede iniciar la vinculación entre actividades según la secuencia presentada en la línea de balance.

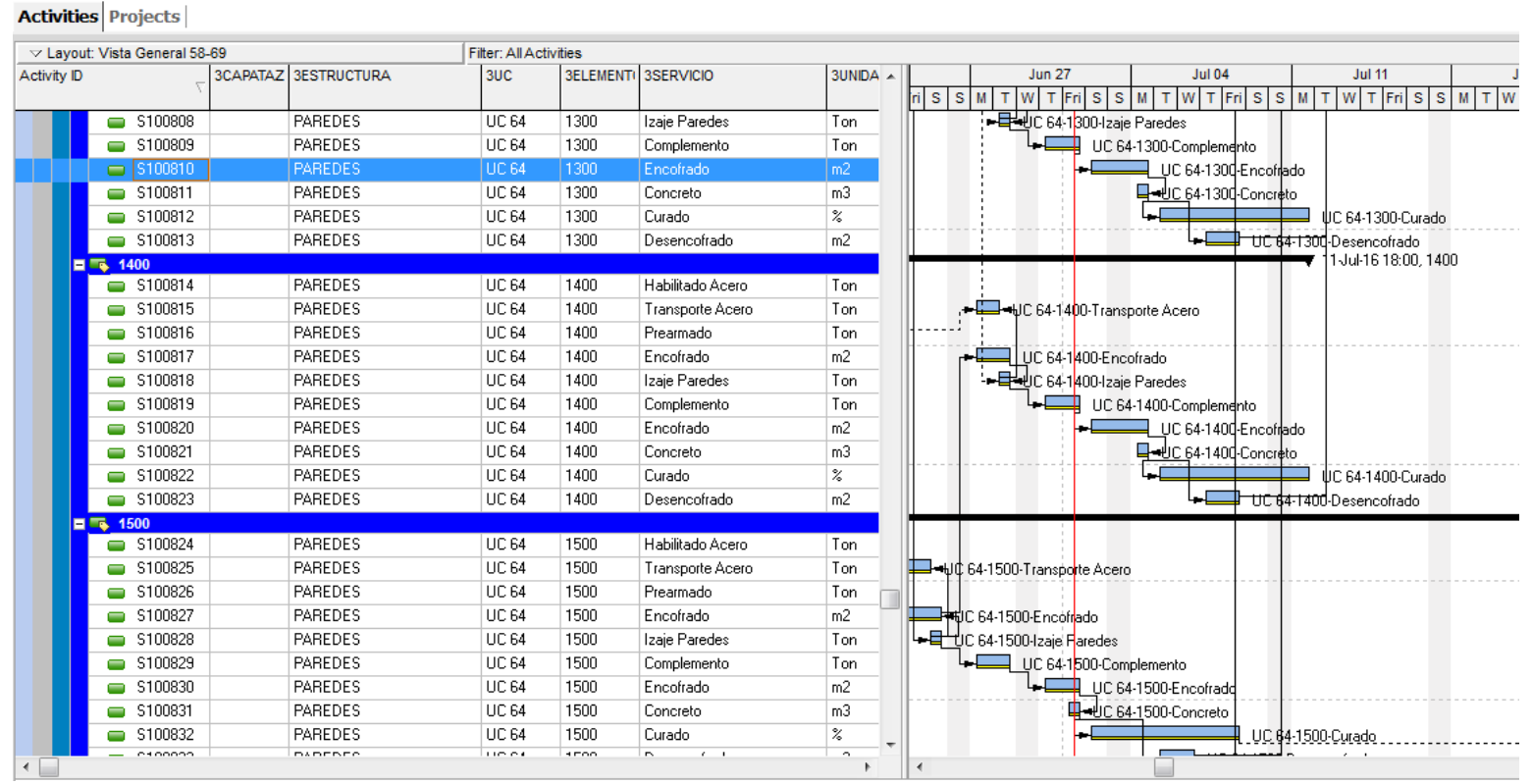


Paso 9: Creación y asignación de Línea Base de Pull Planning en Primavera P6

En el menú "Project" se debe seleccionar la opción "Maintain Baselines".



En la siguiente ventana mostrada presionamos en el botón Add.

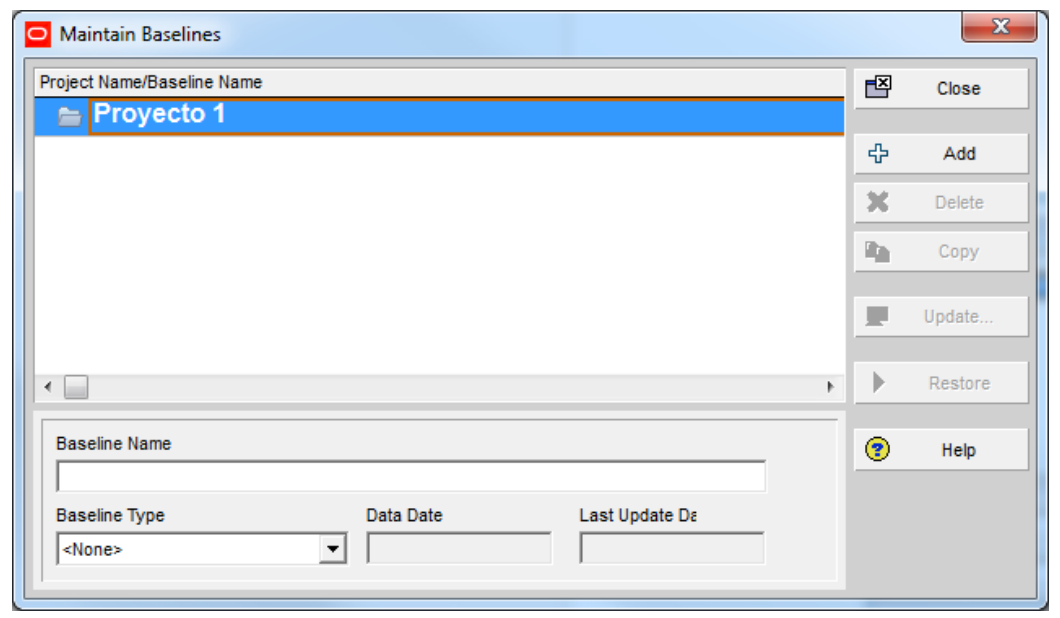

Luego, seleccionamos la opción "Save a copy of the current Project as a new baseline" y presionamos OK.

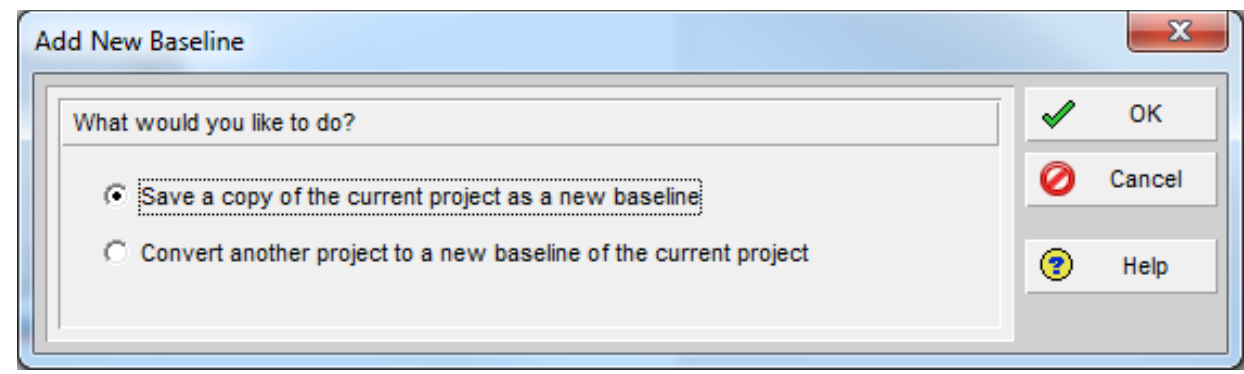

Luego de ello se mostrará la copia generada como Línea Base, seguidamente presionamos el botón Close. 


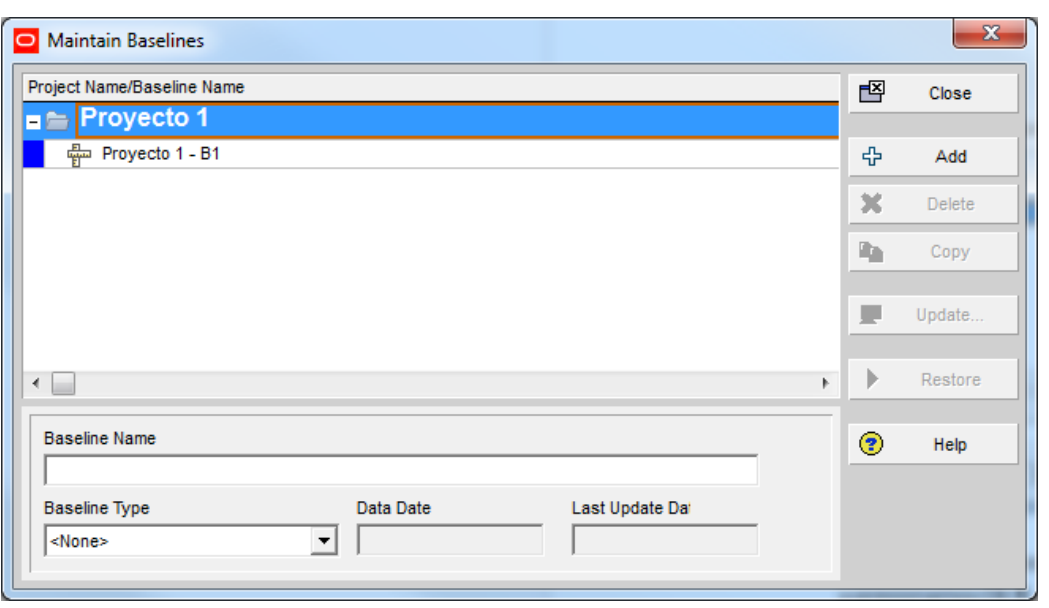

Ahora se debe ir nuevamente al menú Project y seleccionar la opción “Assign Baselines"

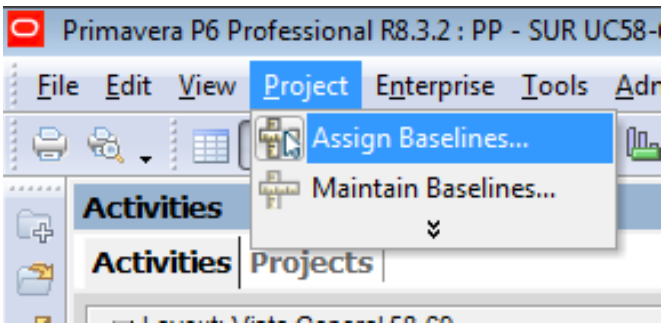

En la ventana que se muestra a continuación, en el desplegable "Project Baseline" seleccionamos el proyecto línea base creado, lo mismo en el desplegable "Primary", para finalizar presionamos $\mathrm{OK}$; de este modo ya tenemos nuestra línea base creada y asignada.
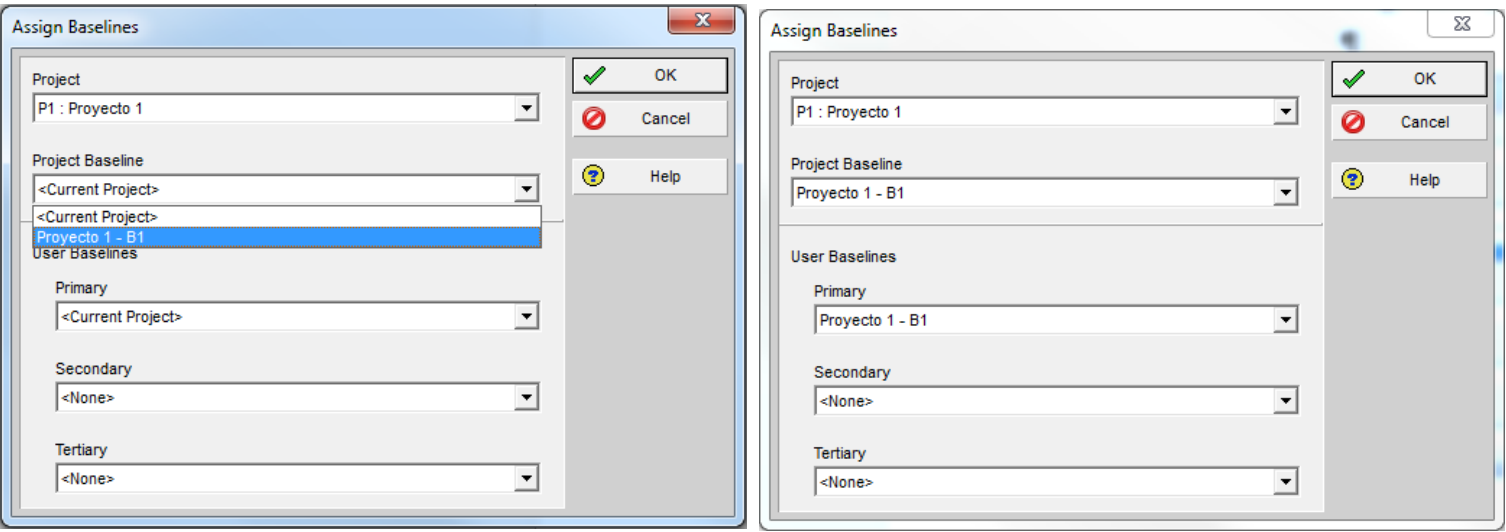
Programación de la semana siguiente

\section{Responsables:}

Ingeniero de Producción

Ingeniero Responsable de Programaciones

\section{Alcance:}

Al terminar la creación o actualización del cronograma, el Ingeniero de producción y el ingeniero responsable de la programación revisan la programación que se generó automáticamente en el Primavera P6 conforme los vínculos de las líneas de balance y hacen los ajustes necesarios, ya sean vínculos y/o duraciones, para programar las actividades que se realizaran durante la semana siguiente.



\section{Descripción del Proceso:}

Paso 1: Se aplica un filtro para las actividades comprendidas en la semana a programar considerando lo siguiente:

Actividades que ya iniciaron y que finalizarán durante la semana que se está programando Actividades que ya iniciaron y que finalizarán después de la semana que se está programando Actividades que iniciarán durante la semana y que finalizarán dentro de la semana que se está programando. 
Actividades que iniciarán durante la semana y que finalizarán fuera de la semana que se está programando.



Para esto en la barra de herramientas buscamos el icono "Filter by"

File Edit View Project Enterprise Iools Admin Help

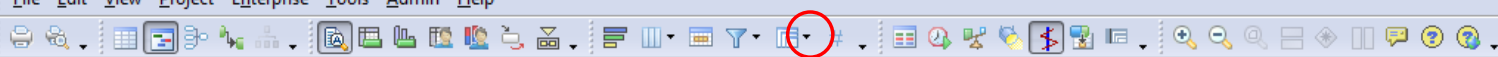

Al hacer click sobre él, aparecerá la siguiente ventana donde se creará o aplicará el filtro.

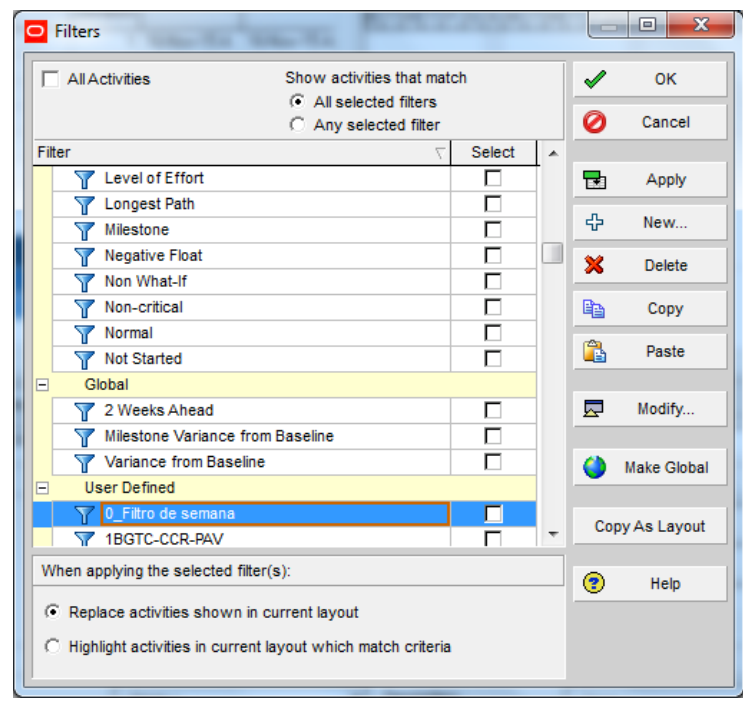

Para crear el nuevo filtro se debe hacer click en el botón "New" \& New..., y a continuación emergerá la siguiente ventana donde se debe parametrizar el filtro de la semana como en el ejemplo que se muestra a continuación. 
UNIVERSIDAD PERUANA DE CIENCIAS APLICADAS

Laureate International Universities ${ }^{\circledR}$



En seguida se filtrarán solo las actividades de la semana correspondiente, como se muestra en la figura.

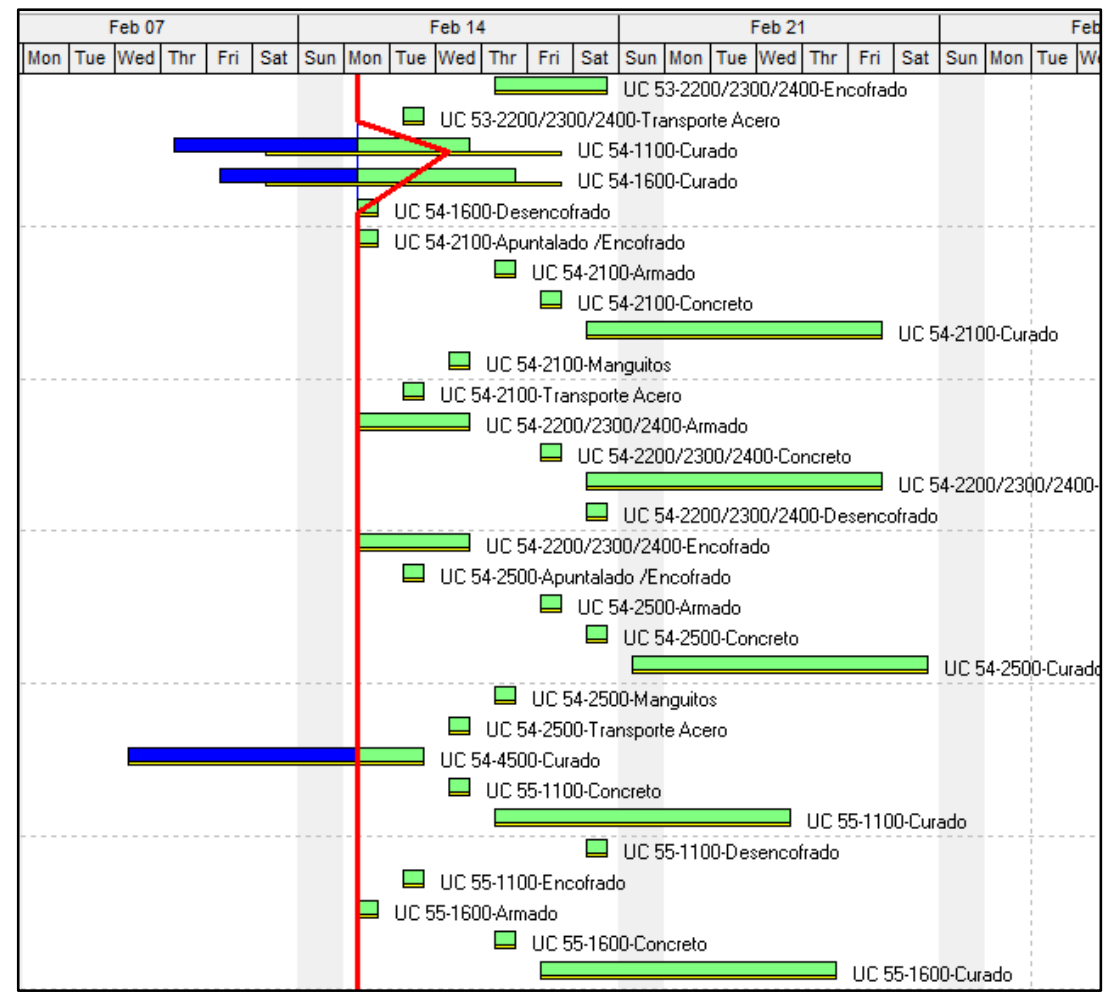

Paso 2: El ingeniero de producción verifica si todas las actividades que se muestran para la siguiente semana están libres de restricciones y si es necesario seguimos con el siguiente paso. 
Paso 3: En caso de que existan atrasos en algunas actividades de la semana anterior, el ingeniero de producción con el ingeniero responsable de programación evalúan la posibilidad de recuperar los atrasos, y si para ello es necesario modificar los vínculos se harán previo conocimiento y autorización del coordinador de planeamiento.

Desarrollo y Emisión de Hojas Tarea

\section{Responsables:}

Ingeniero responsable de programaciones

\section{Alcance:}

El ingeniero responsable de las programaciones agrupa las actividades filtradas de la semana ya programada de acuerdo a los capataces que ejecutaran los trabajos en obra y emite la "Hojas Tarea".

\section{Descripción del Proceso:}

Paso 1: En la barra de herramientas se debe dar click sobre el botón "Group and Sort By"

A continuación, aparece la siguiente ventana, donde se debe agrupar las actividades en el siguiente orden: capataz, servicio, estructura y código de elemento. 
UNIVERSIDAD PERUANA DE CIENCIAS APLICADAS

Laureate International Universities ${ }^{\circledR}$



Una vez realizado el agrupamiento, la ventana se mostrará de la siguiente manera:

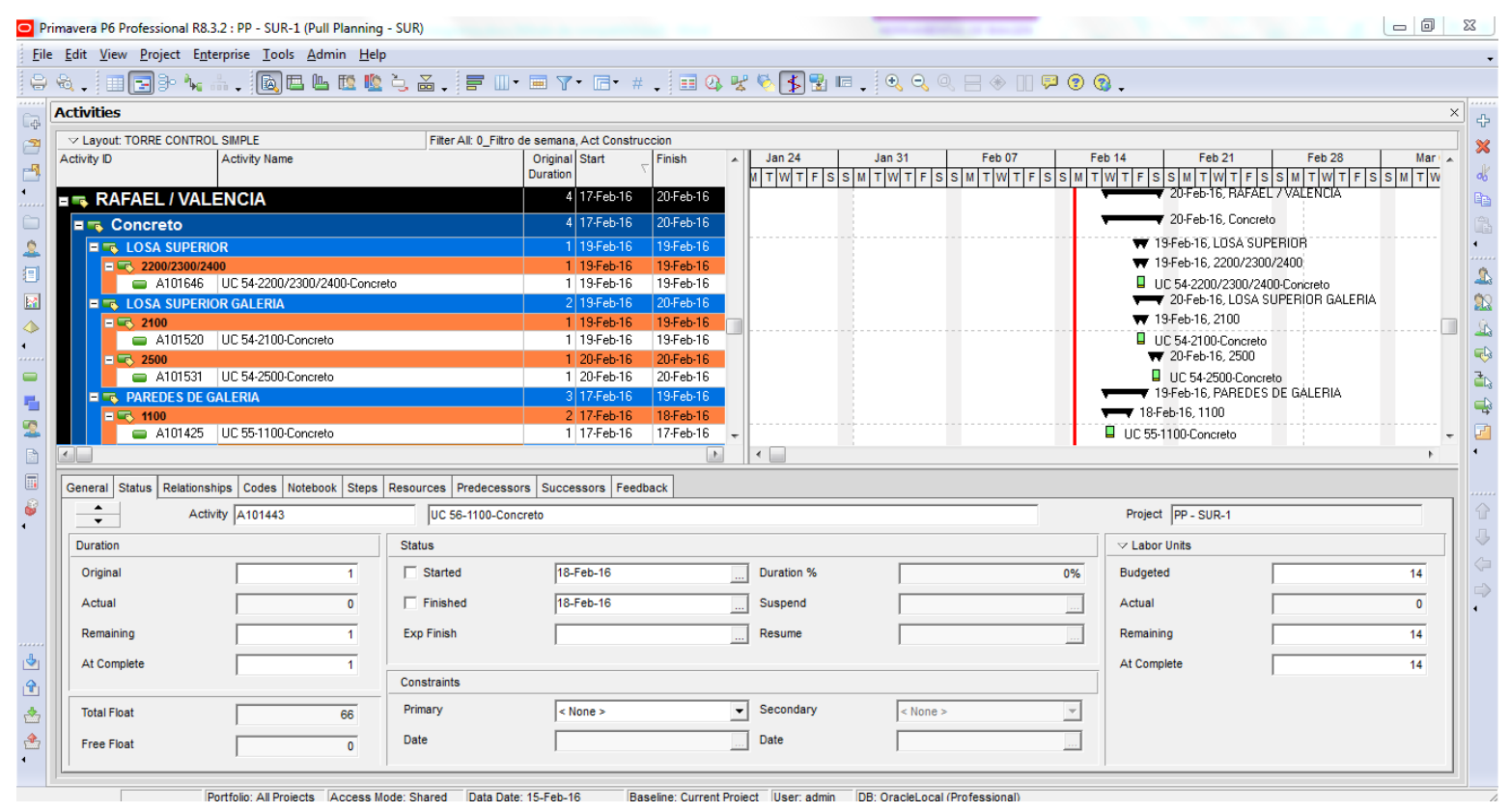




\begin{tabular}{|c|c|c|c|}
\hline$\checkmark$ Layout: TORRE CONTROL SIMPLE & \multicolumn{3}{|c|}{ Filter All: Act Construccion } \\
\hline \begin{tabular}{|l|l} 
Activity ID & Activity Name
\end{tabular} & \begin{tabular}{|c|} 
Original \\
Duration
\end{tabular} & Start & Finish \\
\hline ET ENRIQUEZ & 38 & $21-0 \mathrm{ct}-15 \mathrm{~A}$ & 01-Dec-15A \\
\hline + Izaje Paredes & 19 & $21-0 \mathrm{ct}-15 \mathrm{~A}$ & 12-Nov-15A \\
\hline Izaje Vigas T & 26 & 05-Nov-15A & 01-Dec-15A \\
\hline+ Izaje Vigas T 200 & 18 & 11-Nov-15A & 28-Nov-15A \\
\hline+ Izaje Vigas T 300/400 & 20 & $30-0 \mathrm{ct} \cdot 15 \mathrm{~A}$ & 24-Nov-15A \\
\hline E FRANK AGÜERO & 89 & 19-0ct-15A & 14Van-16A \\
\hline E Armado & 57 & $27-0 \mathrm{ct}-15 \mathrm{~A}$ & 08 Jan-16A \\
\hline ARRANQUE & 48 & 06-Nov-15A & 29-Dec-15A \\
\hline-1200 & 48 & 06-Nov-15A & 28-Dec-15A \\
\hline$\square$ A100045 UC 52-1200-Armado & 1 & 06-Nov-15A & 06-Nov-15A \\
\hline$\square$ A100873 UC 54-1200-Armado & 1 & 21-Dec-15A & 21-Dec-15A \\
\hline A100893 UC 55-1200-Armado & 1 & 28-Dec-15A & 28-Dec-15A \\
\hline$-\sigma 1300$ & 6 & 23-Dec-15A & 29-Dec-15A \\
\hline A100878 UC 54-1300-Armado & 1 & 23-Dec-15A & 23-Dec-15A \\
\hline A100898 UC 55-1300-Armado & 1 & 29-Dec-15A & 29-Dec-15A \\
\hline$+\infty 1400$ & 6 & 23-Dec-15A & 29-Dec-15A \\
\hline$+\square 1500$ & 10 & 21-Dec-15A & 28-Dec-15A \\
\hline + LOSA SUPERIOR & 38 & $27-0 \mathrm{ct}-15 \mathrm{~A}$ & 08-Dec-15A \\
\hline LOSA DE FONDO & 17 & 11-Dec-15A & 08 Jan- $16 \mathrm{~A}$ \\
\hline + LOSA SUPERIOR GALERIA & 35 & $30-0 \mathrm{ct}-15 \mathrm{~A}$ & 05-Dec-15A \\
\hline I PAREDES DE GALERIA & 26 & $31-0 \mathrm{ct}-15 \mathrm{~A}$ & 27-Nov-15A \\
\hline + Complemento & 66 & $22 \cdot 0 \mathrm{ct}-15 \mathrm{~A}$ & $14 \sqrt{ }$ an- $16 \mathrm{~A}$ \\
\hline + Prearmado & 89 & 19-0ct-15A & 09. $\operatorname{Van}-16 \mathrm{~A}$ \\
\hline E GIL / PEÑALOZA & 24 & 23-0ct-15A & 20-Nov-15A \\
\hline + Desencofrado & 19 & $30-0 \mathrm{ct}-15 \mathrm{~A}$ & 20-Nov-15A \\
\hline+ Encofrado & 20 & 23-0ct-15A & 16-Nov-15A \\
\hline = HILARIO & 98 & $29-0 \mathrm{ct}-15 \mathrm{~A}$ & 26 -Feb-16 \\
\hline + Apuntalado /Encofrado & 98 & $29-0 \mathrm{ct}-15 \mathrm{~A}$ & 26-Feb-16 \\
\hline Desencofrado & 18 & 06-Now-15A & 26-Nov-15A \\
\hline
\end{tabular}

Paso 2: A continuación, en la barra de herramientas hacemos click sobre "Activity Usage Spreadsheet"

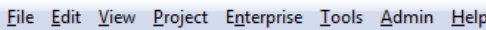
旦

Y la ventana general se mostrará de la siguiente manera: 


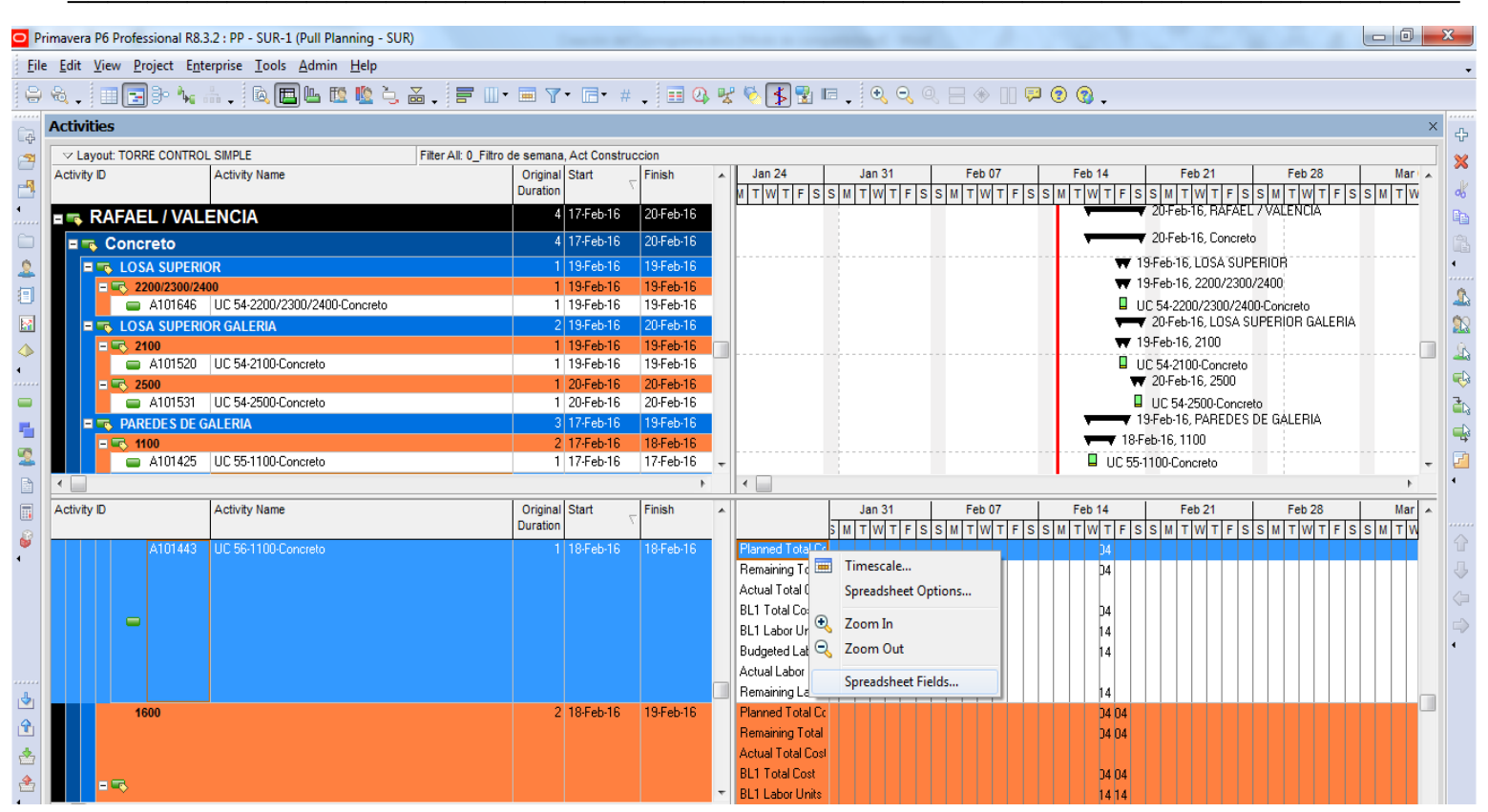

Hacer click con el e botón derecho sobre alguno de los elementos del campo y luego hacer click sobre "Spreadsheet Fields..." para elegir el campo que deseamos. Para tener la distribución de los metrados elegiremos el campo "Remaining Material Cost".

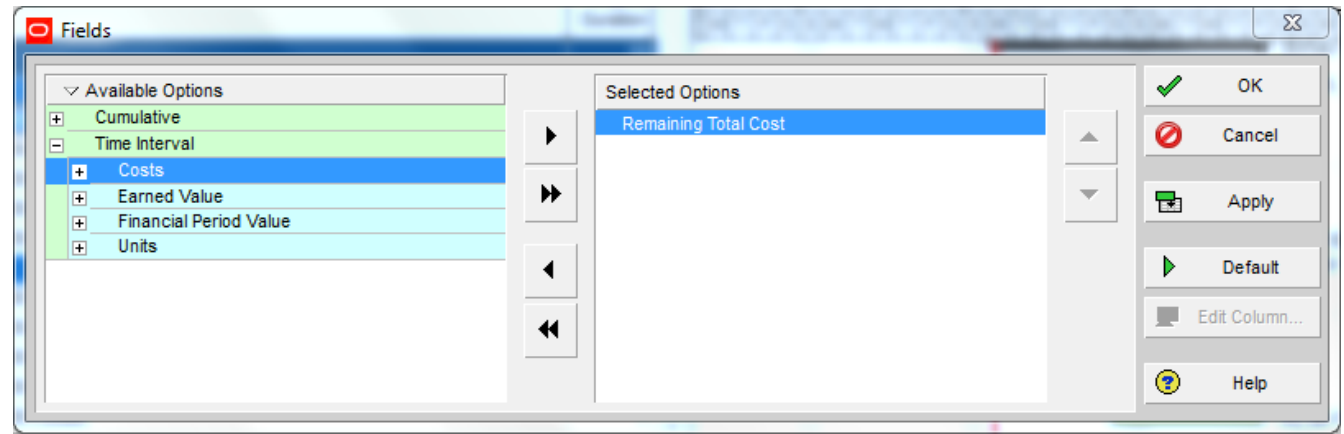

Es importante recordar que al momento de crear el proyecto las cantidades de los metrados fueron ingresados como materiales con costo igual a 1, de esta manera al momento de hacer la distribución de costo restante se está haciendo la distribución del metrado. 


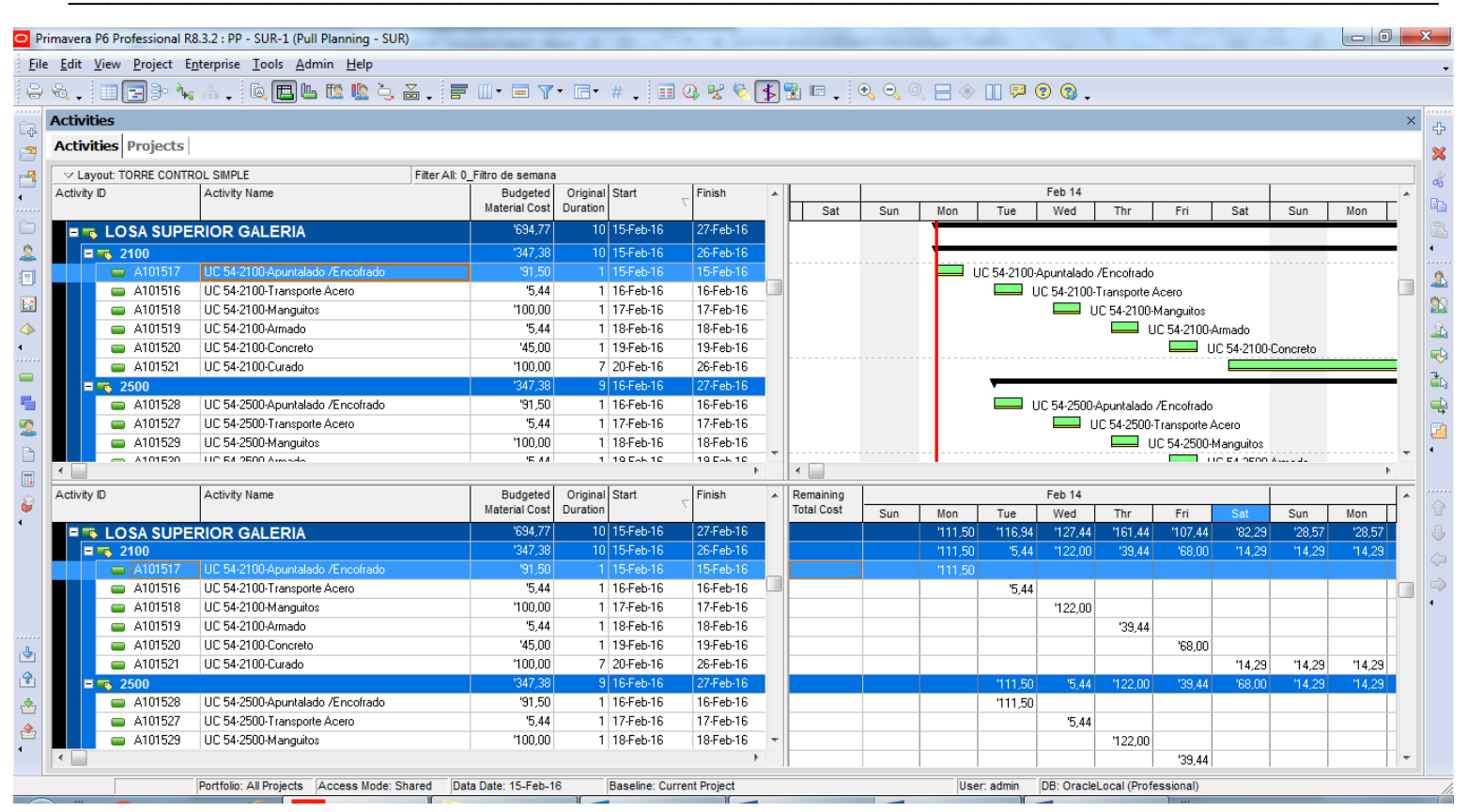

Paso 3: Finalmente para poder imprimir el reporte se debe hacer click sobre el botón "Print Preview" y a continuación aparecerá la siguiente ventana.

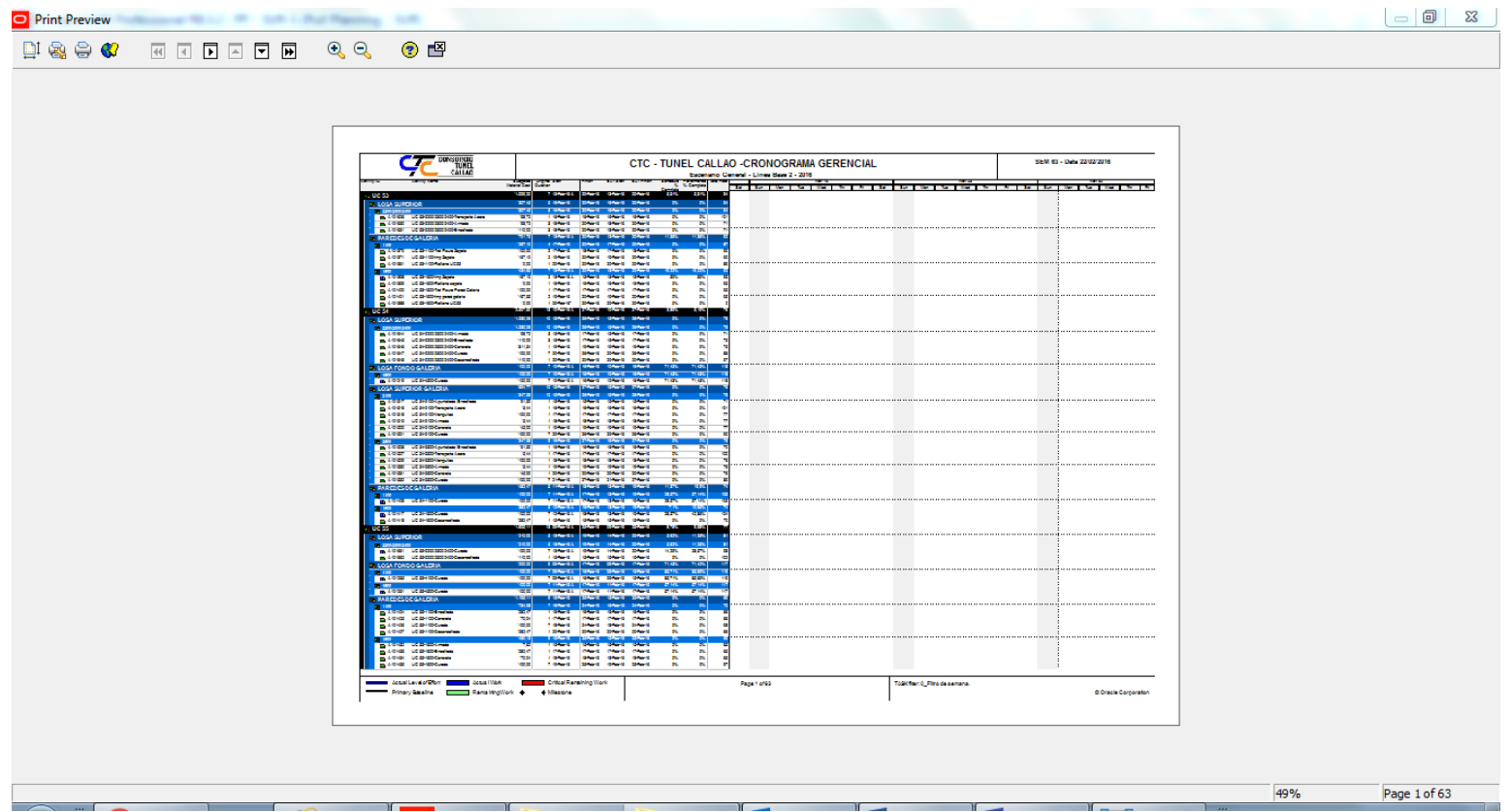

Para obtener una "Hoja Tarea" la primera vez tenemos que definir un formato y para ello hacemos click sobre el botón "Page Setup" 
En la ventana emergente aparecerán cinco pestañas donde daremos formato a las "Hojas Tarea". En la primera pestaña "Page" se puede elegir el tamaño y escala de impresión.

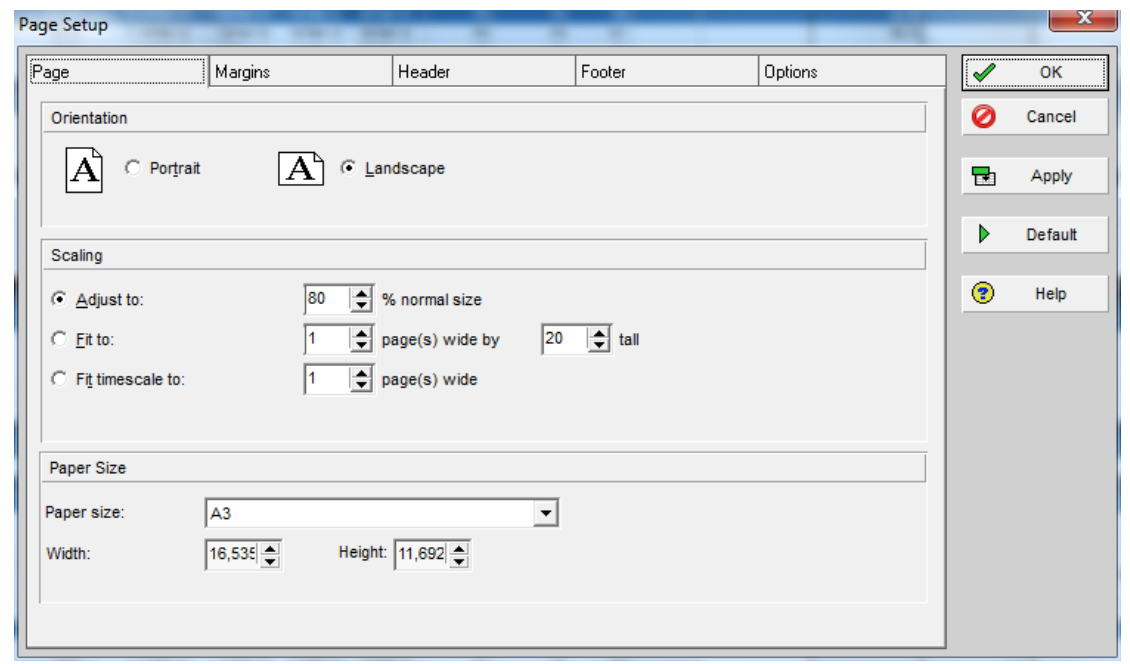

En la pestaña "Header" se puede editar los títulos de las hojas tarea con informaciones como logo de la empresa, título de la hoja y semana programada, ingeniero de frente, jefe de producción, etc.

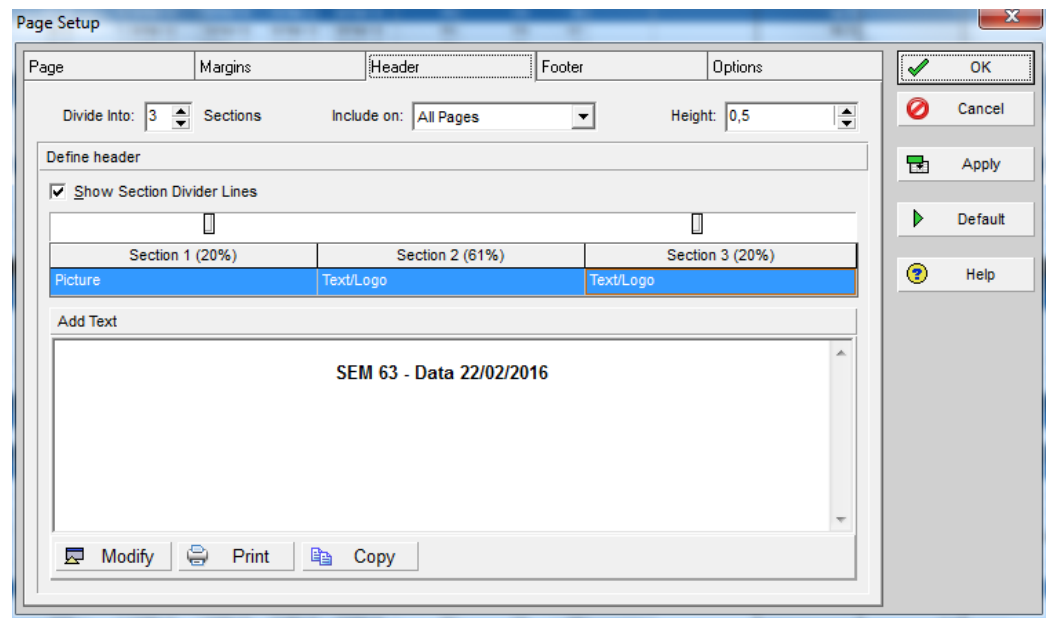

\begin{tabular}{|c|c|c|c|}
\hline  & $\frac{\text { PROGRAMACIÓN SEMANAL - FRENTE SUR }}{\text { SEMANA 65: DEL 29/02/16 AL 06603/16 }}$ & $\begin{array}{l}\text { INGENIERO DE FRENTE } \\
\text { JEFE DE PRODUCCIÓN }\end{array}$ & $\begin{array}{l}: \text { GUSTAVO PASSOS } \\
: \text { EDGAR CHAMORRC }\end{array}$ \\
\hline
\end{tabular}


En la pestaña "Options" se puede que definir la fecha de inicio y fin de la semana, luego activar el recuadro de "Spredsheet" para mostrar solo la distribución del campo seleccionado y finalmente activar el recuadro de "Break Page Every Group" para separar las hojas tarea por cada responsable.

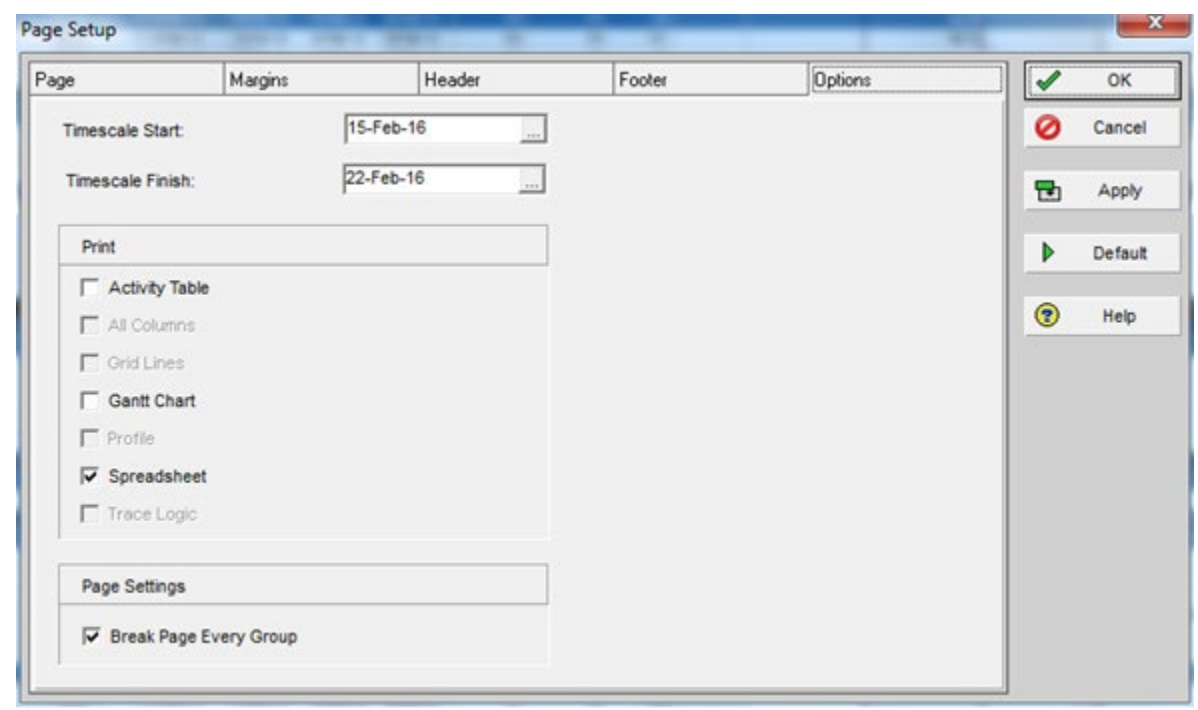

Una vez culminado todo esto debemos presionar el botón " $\mathrm{OK}$ ” y finalmente imprimir todas las Hojas Tareas. 


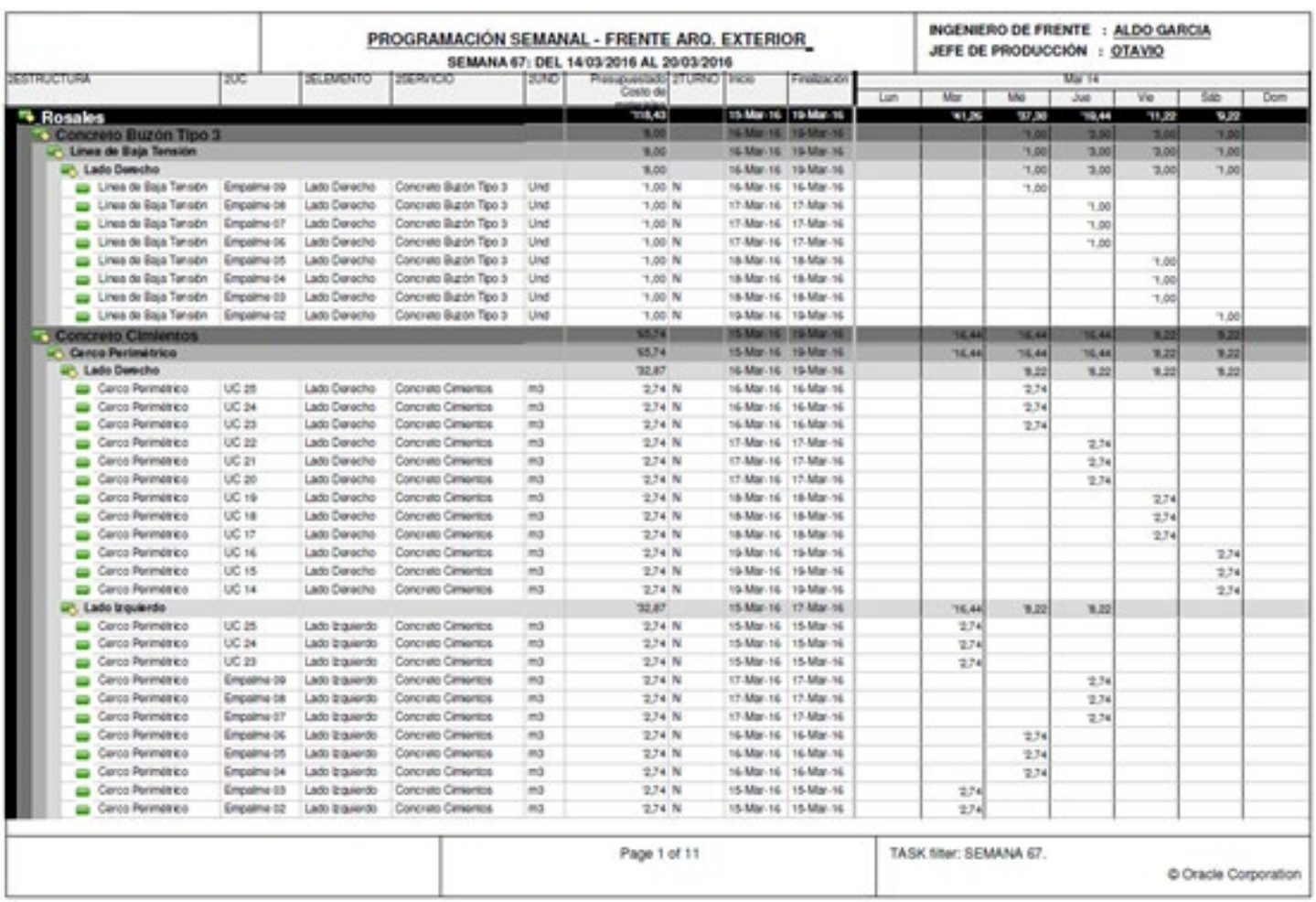

Paso 4: Para acelerar el proceso de desarrollo de las hojas tarea en las siguientes semanas es necesario guardar el formato de la plataforma de trabajo mediante un "Layout".




Paso 5: Después de emitir las Hojas Tarea, se hace una exportación de las actividades programadas a partir del "layout PPC" hacia Excel, este layout contiene las informaciones necesarias para facilitar el cálculo del PPC semanal. Estas son: Código de Actividad, Capataz, Estructura, UC, Código de Elemento, Servicio, Unidad, Metrado, Turno, Inicio, Fin y Porcentaje de Actividad Completada.

\begin{tabular}{|c|c|c|c|c|c|c|c|c|c|c|c|c|c|c|c|}
\hline \multicolumn{3}{|c|}{$\nabla$ Layout: PPC } & \multicolumn{13}{|c|}{ Filter All: Semana 72} \\
\hline \multirow[t]{2}{*}{ Activity ID } & \multirow[t]{2}{*}{ 1Capataz } & \multirow[t]{2}{*}{ 1Estructura } & \multirow[t]{2}{*}{ 1UC's } & \multirow{2}{*}{\begin{tabular}{|l}
1 Cod \\
Elemento
\end{tabular}} & \multirow[t]{2}{*}{ Servicio } & \multirow[t]{2}{*}{ 1Unid } & \multirow{2}{*}{$\begin{array}{r}\text { Budgeted } \\
\text { Material Cost }\end{array}$} & \multirow{2}{*}{ 1Turn } & \multirow[t]{2}{*}{ Start } & \multirow[t]{2}{*}{ Finish } & \multirow{2}{*}{$\begin{array}{c}\text { Activity } \% \\
\text { Complete }\end{array}$} & \multirow{2}{*}{$\hat{\square}$} & \multirow{2}{*}{\multicolumn{2}{|c|}{ Sat }} & \multirow[b]{2}{*}{ Sun } \\
\hline & & & & & & & & & & & & & & & \\
\hline A101447 & PIRES & PAREDES DE GALERIA & UC 56 & 1100 & Imp pared galeria & $\mathrm{m}^{2}$ & 740,08 & D & 21-Mar-1E & 09-May-16 & $75 \%$ & & & & \\
\hline A102042 & REYNALDO / PERCY & PAREDES DE GALLERIA & UC 57 & $1100 \mathrm{~F}$ & Curado & $\%$ & 100,00 & DN & 22-Apr-16 & 23-Apr-16 & $14,29 \%$ & & & & \\
\hline A102043 & GIL / SERVANDO & PAREDES DE GALLERIA & UC 57 & $1100 \mathrm{~F}$ & Desencofrado & $\%$ & 100,00 & DN & 20-Apr-16 & 20-Apr-16 & $0 \%$ & & & & \\
\hline A101759 & REYNALDO / PERCY & PAREDES & UC 57 & 1200 & Curado & $\%$ & 100,00 & DN & 12-Apr-16 & 18-Apr-16 & $85,71 \%$ & & & & \\
\hline A101456 & PIRES & PAREDES DE GALERIA & UC 56 & 1600 & Imp pared galeria & $\mathrm{m} 2$ & 140,08 & D & 22-Mar-1E & 25-Apr-16 & $66,67 \%$ & & & & \\
\hline A.101568 & PIRES & LOSA SUPERIOR GÄLERIA & UC 56 & 2100 & Imper Pared Central + LSG & $\mathrm{m} 2$ & 160,61 & & 21-Mar-1E & 09-May-16 & $75 \%$ & & & & \\
\hline A101579 & PIRES & LOSA SUPERIOR GALERIA & UC 56 & 2500 & Imper Pared Central + LSG & $\mathrm{m} 2$ & 160,61 & & 22-Mar-1E & 10-May-16 & $66,67 \%$ & & & & \\
\hline A101824 & SEGUNDO & LOSA FONDO GALERIA & UC 57 & 4100 & Trat FisuraZapata & $\%$ & 100,00 & D & 18-Apr-16 & 19-Apr-16 & $0 \%$ & & & & \\
\hline A101840 & SEGUNDO & LOSA FONDO GALERIA & UC 57 & 4500 & Trat Fisura Zapata & $\%$ & 100,00 & D & 20-Apr-16 & 21-Apr-16 & $0 \%$ & & & & \\
\hline A101843 & SEGUNDO & LOSA FONDO GALERIA & UC 57 & 4500 & Trat Fisura Pared Central & $\%$ & 100,00 & D & 22-Apr-16 & 23-Apr-16 & $0 \%$ & & & & \\
\hline A101638 & APONTE & LOSA SUPERIOR & UC 53 & $2200 / 2300 / 2$ & Relleno Losa Superior Tunel & m3 & $5.828,00$ & & 13-Apr-16 & 20-Apr-16 & $30 \%$ & & & & \\
\hline A101652 & APONTE & LOSA SUPERIOR & UC 54 & $2200 / 2300 / 2$ & Relleno Losa Superior Tunel & $\mathrm{m} 3$ & $4.722,00$ & & 14-Apr-16 & 22-Apr-16 & $30 \%$ & & & & \\
\hline A101666 & ANTONIO / APONTE & LOSA SUPERIOR & UC 55 & $2200 / 2300 / 2$ & Relleno Losa Superior Tunel & $\mathrm{m} 3$ & $3.756,00$ & & 14-Apr-16 & 25-Apr-16 & $30 \%$ & & & & \\
\hline A101680 & ANTONIO / APONTE & LOSA SUPERIOR & UC 56 & $2200 / 2300 / 2$ & Relleno Losa Superior Tunel & $\mathrm{m} 3$ & $2.686,00$ & & 13-Apr 16 & 25-Apr-16 & $40 \%$ & - & 10 & & \\
\hline \multirow[t]{2}{*}{ Activity ID } & \multirow[t]{2}{*}{ 1Capataz } & \multirow[t]{2}{*}{ 1Estructura } & \multirow[t]{2}{*}{ 1UC's } & \multirow{2}{*}{\begin{tabular}{|l|} 
Cod \\
Elemento
\end{tabular}} & \multirow{2}{*}{ 1Servicio } & \multirow{2}{*}{ 1Unid } & Budgeted & 1Turn & Start & Finish & Activity \% & & Costo de & & \\
\hline & & & & & & & & & & & Complete & & materiales & it & Sun \\
\hline A101447 & PIRES & PAREDES DE GALERIA & UC 56 & 1100 & Imp pared galeria & $\mathrm{m}^{2}$ & 1440,08 & D & 21-Mar-1E & $09 \cdot$ May-16 & $75 \%$ & & & & \\
\hline A102042 & REYNALDO / PERCY & PAREDES DE GALERIA & UC 57 & $1100 \mathrm{~F}$ & Curado & $\%$ & 100,00 & DN & 22-Apr-16 & 23-Apr-16 & $14,29 \%$ & & & & \\
\hline A102043 & GIL / SERVANDO & PAREDES DE GALERIAA & UC 57 & $1100 \mathrm{~F}$ & Desencofrado & $\%$ & 100,00 & DN & 20-Apr-16 & 20-Apr-16 & $0 \%$ & & & & \\
\hline A101759 & REYNALDO / PERCY & PAREDES & UC 57 & 1200 & Curado & $\%$ & 100,00 & DN & 12-Apr-16 & 18-Apr-16 & $85,71 \%$ & & & & \\
\hline A101456 & PIRES & PAREDES DE GALLERIA & UC 56 & 1600 & Imp pared galeria & $\mathrm{m} 2$ & 140,08 & D & 22-Mar-1E & 25-Apr-16 & $66,67 \%$ & & & & \\
\hline A101568 & PIRES & LOSA SUPERIOR GALLERIAA & UC 56 & 2100 & Imper Pared Central + LSG & $\mathrm{m} 2$ & 160,61 & & 21-Mar-1E & 09-Мау.16 & $75 \%$ & & & & \\
\hline A101579 & PIRES & LOSA SUPERIOR GALLERIA & UC 56 & 2500 & Imper Pared Central + LSG & $\mathrm{m} 2$ & 160,61 & & 22-Mar-1E & 10-May-16 & $66,67 \%$ & & & & \\
\hline A101824 & SEGUNDO & LOSA FONDO GALERIA & UC 57 & 4100 & Trat Fisura Zapata & $\%$ & 100,00 & D & 18-Apr-16 & 19-Apr-16 & $0 \%$ & & & & \\
\hline A101840 & SEGUNDO & LOSA FONDO GALERIA & UC 57 & 4500 & Trat Fisura Zapata & $\%$ & 100,00 & D & 20-Apr-16 & 21-Apr-16 & $0 \%$ & & & & \\
\hline A101843 & SEGUNDO & LOSA FONDO GALLEFIA & UC 57 & 4500 & Trat Fisura Pared Central & $\%$ & 100,00 & D & 22-Apr-16 & 23-Apr-16 & $0 \%$ & & & & \\
\hline A101638 & APONTE & LOSA SUPERIOR & UC 53 & $2200 / 2300 / 2 z$ & Relleno Losa Superior Tunel & $\mathrm{m} 3$ & $5.828,00$ & & 13-Apr-16 & 20-Apr-16 & $30 \%$ & & & & \\
\hline A101652 & APONTE & LOSA SUPERIOR & UC 54 & $2200 / 2300 / 2 i$ & Relleno Losa Superior Tunel & m3 & $4.722,00$ & & 14-Apr-16 & 22-Apr-16 & $30 \%$ & & & & \\
\hline A101666 & ANTONIO / APONTE & LOSA SUPERIOR & UC 55 & $2200 / 2300 / 2 t$ & Relleno Losa Superior Tunel & $\mathrm{m} 3$ & $3.756,00$ & & 14-Apr-16 & 25-Apr-16 & $30 \%$ & & & & \\
\hline A101680 & ANTONIO / APONTE & LOSA SUPERIOR & UC 56 & $2200 / 2300 / 2$ & Relleno Losa Superior Tunel & $\mathrm{m} 3$ & $2.686,00$ & & 13-Apr-16 & 25-Apr-16 & $40 \%$ & & & & \\
\hline$\triangle A 101972$ & SEGUNDO & LOSA SUPERIOR & UC 57 & $2200 / 2300 / 2$ & Amolado pared & $\%$ & $' 100,00$ & D & 18-Apr-16 & 21-Apr-16 & $0 \%$ & & & & \\
\hline
\end{tabular}

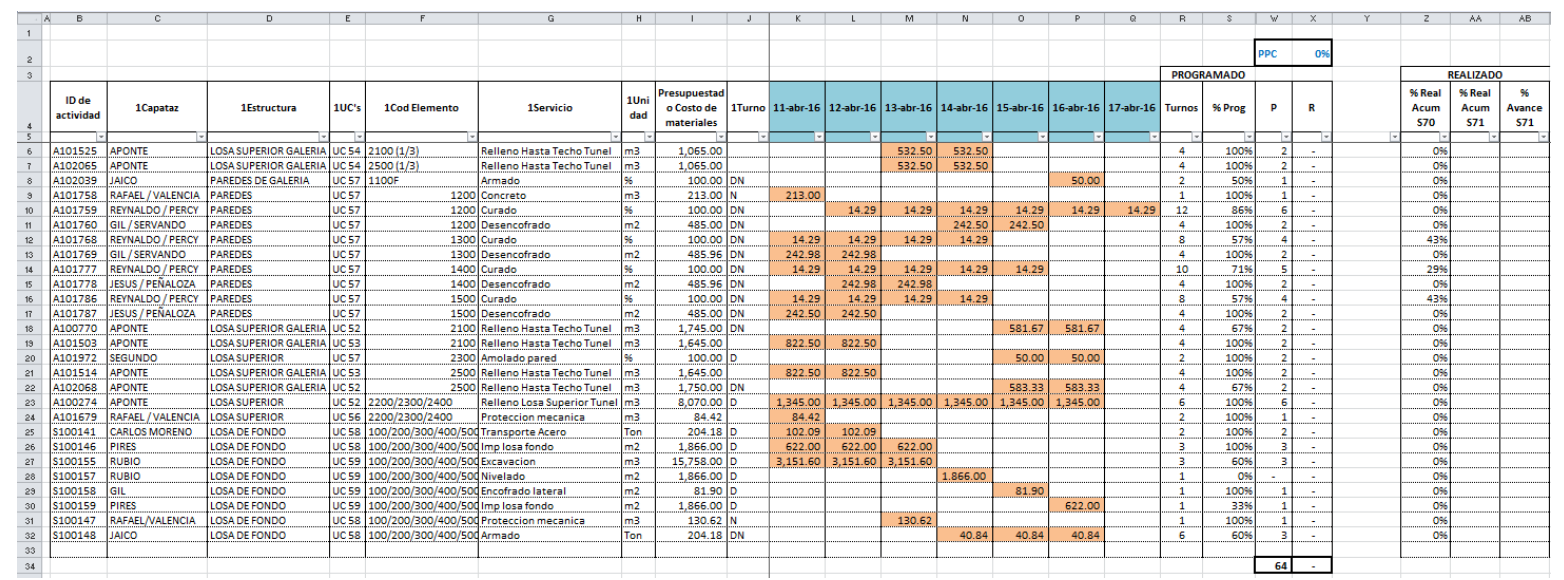

Envío de Avance Semanal 


\section{Responsable:}

Ingeniero de Producción

\section{Alcance:}

El Ingeniero de Producción recopila y envía al área de planeamiento todos los datos de avances físicos realizados en su frente de trabajo durante la semana. La información es consolidada sobre las hojas tarea.

\section{Descripción del Proceso:}

Emitidas las hojas tarea, estas son publicadas en los paneles de gestión visual de los diferentes frentes de trabajo. A partir de las reuniones diarias de Check In - Check Out durante la semana, el ingeniero de frente valida las actividades que se van realizando sobre las hojas tarea, ya sean actividades previstas en la programación o fuera de la programación. En vista de que las siguientes etapas del ciclo requieren de tiempo para el trabajo de las informaciones, el ingeniero de frente deberá reportar los avances reales realizados de lunes a viernes y estimar con alto grado de confiabilidad los avances que se harán en los últimos días de la semana.

Figura 1: Panel de Gestión Visual Frente Sur




Figura 2: Hoja Tarea con reporte de avances en el Check-Out

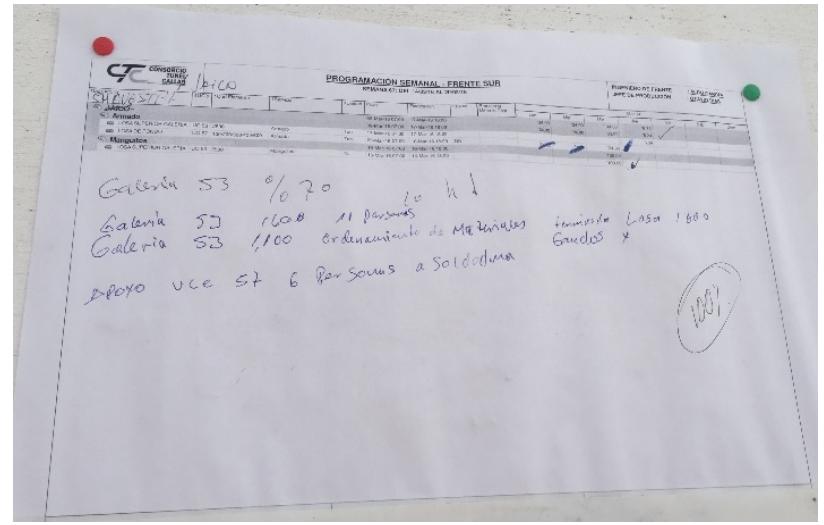

Actualización de Cronogramas Pull Planning

\section{Responsable:}

Ingeniero responsable de la Programación Semanal

\section{Alcance:}

Una vez reportados los avances por parte del Área de Producción, el responsable de las programaciones actualiza las actividades realizadas durante la semana en el cronograma pullplanning (software Primavera P6).

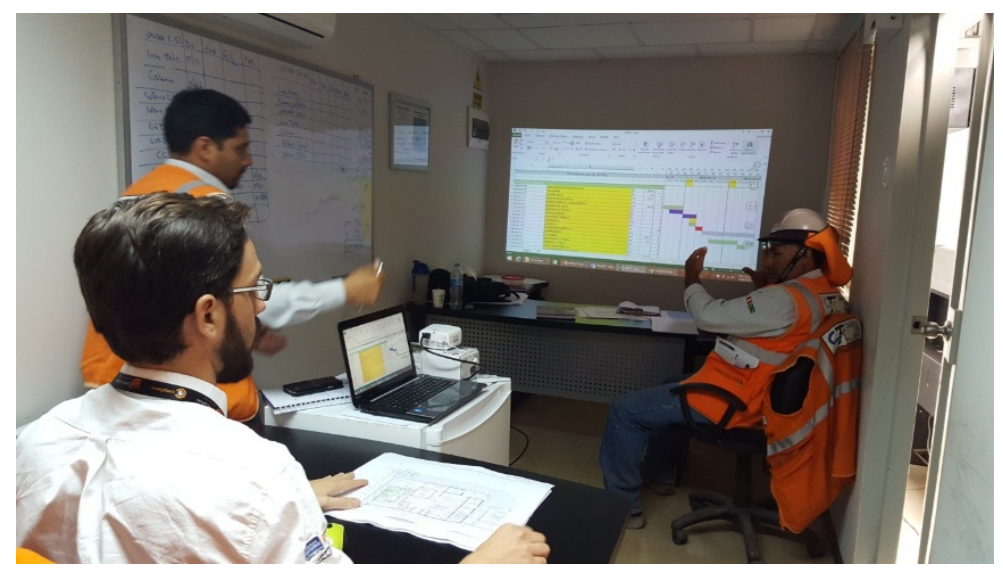

\section{Descripción del Proceso:}

Paso 1: Identificar, en las hojas tarea retornadas, todas las actividades realizadas ya sea dentro o fuera de la programación. 
Paso 2: En el software Primavera P6 se debe seleccionar la actividad a la que se dará avance.

Luego, en la barra de herramientas se debe dar click sobre el icono de "Details" 国画, A continuación, aparecerá en la parte inferior diversas pestañas que muestran detalles de la actividad seleccionada.

Paso 3: Seleccionar la pestaña "Status". Si la actividad inició, se debe marcar el icono Started y definimos la fecha correspondiente. Si la actividad aún no finalizó entonces se debe insertar el porcentaje de duración consumida de la actividad en la siguiente celda Duration \% $\sqrt{33,33 \%}$. Finalmente en caso de que la actividad haya finalizado entonces se debe dar click sobre el icono $\sqrt{\checkmark}$ Finished y definir la fecha correspondiente.

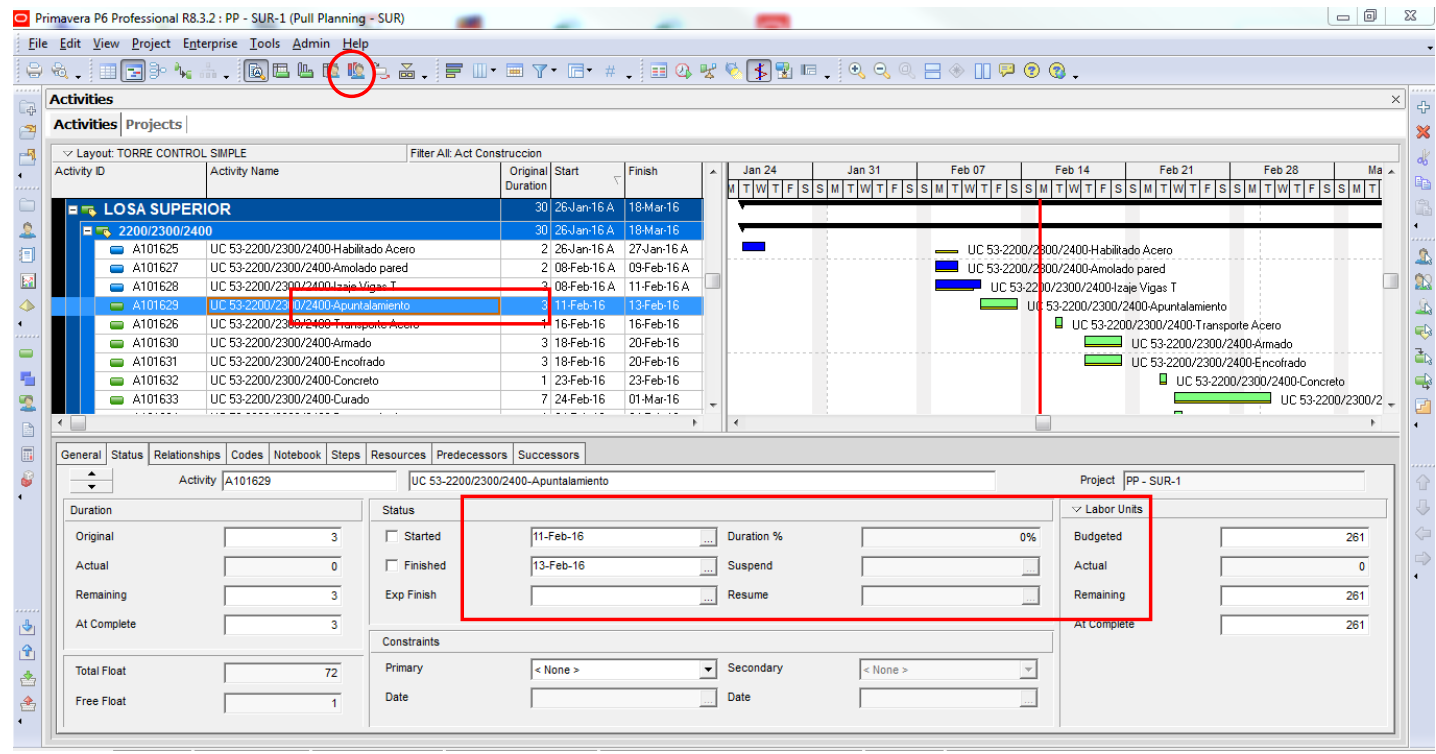

Se debe seguir este mismo proceso para dar avance a todas las actividades realizadas. Una vez que se termine se tiene que actualizar el sistema, para ello en la barra de herramientas buscamos el icono "Schedule" (2), al hacer click sobre este aparece la siguiente ventana.

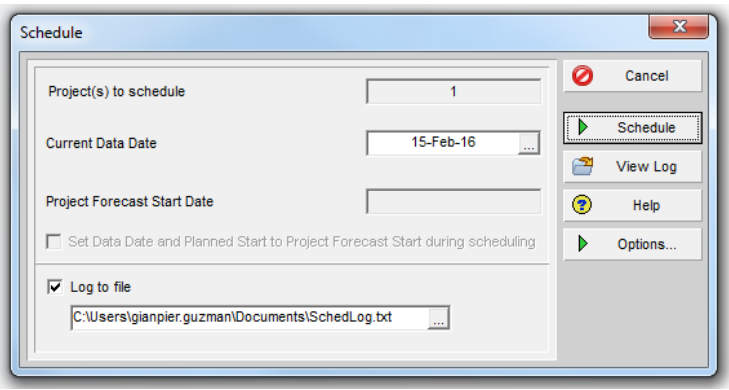


Aquí se debe definir la fecha del "Current Data Date" y hacer click sobre el botón "Schedule" Schedule

"Current Data Date" es la fecha de corte para la actualización, es decir, la fecha hasta la que se reportaron los avances y a partir de la cual se reprogramaran las actividades en proceso y las no iniciadas.

Nota: Esta metodología actualización de avances ayuda también para no programar trabajos ya realizados en la siguiente semana.

Emisión de Reportes de Avance de Producción y Cálculo de PPC

\section{Responsables:}

Ingeniero de Producción

Ingeniero Responsable de Programación

\section{Alcance:}

Una vez que se tiene actualizado los avances de la semana en el Primavera P6 el responsable de la programación emite el reporte de avance semanal de producción y calcula el PPC. Luego de obtener los resultados de la semana estos son revisados y aprobados por el ingeniero de producción.

\section{Descripción del Proceso:}

Paso 1: Una vez actualizado el cronograma en el software Primavera P6, a partir del Layout PPC exportamos a excel las actividades realizadas utilizando el filtro de la semana correspondiente: 


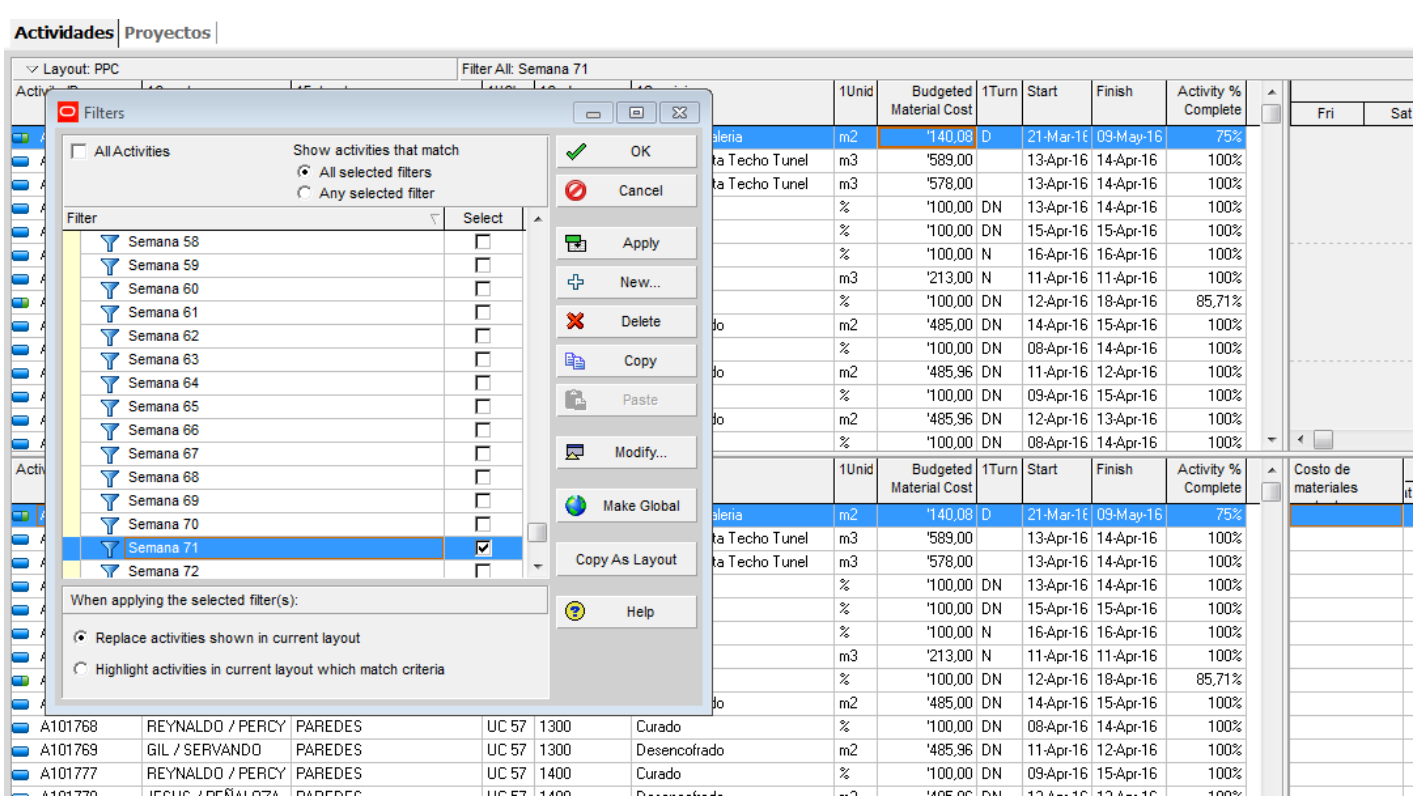

\begin{tabular}{|c|c|c|c|c|c|c|c|c|c|c|c|c|}
\hline 4 & A & B & c & D & E & $\mathrm{F}$ & G & H & 1 & 1 & k & L \\
\hline 1 & ID de activid: : & 3CAPATAZ & 3ESTRUCTURA & 300 & 3ELEMENTO & 3SERVICIO & - 3UNIDA= & Presupue: $\mathrm{V}$ & 3TURN $=$ & Finalización & Inicio & Porcentaje $\mathrm{f}=$ \\
\hline 2 & S100141 & CARLOS MORENO & LOSA DE FONDO & UC 58 & $100 / 200 / 300 / 400 / 50$ & 00 Transporte Acero & Ton & '204,18 & D & 12-Abr-16 18:00 A & $11 / 04 / 201607: 00$ & $100 \%$ \\
\hline 3 & S100144 & RUBIO & LOSA DE FONDO & UC 58 & $100 / 200 / 300 / 400 / 50$ & 00 Nivelado & $\mathrm{m} 2$ & ' $1.866,00$ & D & 11-Abr-16 18:00 A & $11 / 04 / 201607: 00$ & $100 \%$ \\
\hline 4 & $\$ 100145$ & GIL & LOSA DE FONDO & UC 58 & $100 / 200 / 300 / 400 / 50$ & 00 Encofrado lateral & $\mathrm{m} 2$ & '81,90 & D & 11-Abr-16 18:00 A & $11 / 04 / 201607: 00$ & $100 \%$ \\
\hline 5 & S100146 & PIRES & LOSA DE FONDO & UC 58 & $100 / 200 / 300 / 400 / 50$ & $00 \mathrm{Imp}$ losa fondo & $\mathrm{m} 2$ & $1.866,00$ & D & 14-Abr-16 18:00 A & $12 / 04 / 201607: 00$ & $100 \%$ \\
\hline 6 & S100155 & RUBIO & LOSA DE FONDO & UC 59 & $100 / 200 / 300 / 400 / 50$ & 00 Excavacion & $\mathrm{m} 3$ & ' $15.758,00$ & D & 14-Abr-16 18:00 A & 08/04/2016 07:00 & $100 \%$ \\
\hline 7 & S100157 & RUBIO & LOSA DE FONDO & UC 59 & $100 / 200 / 300 / 400 / 50$ & 00 Nivelado & $\mathrm{m} 2$ & ' $1.866,00$ & D & 15-Abr-16 18:00 A & $15 / 04 / 201607: 00$ & $100 \%$ \\
\hline 8 & S100158 & GIL & LOSA DE FONDO & UC 59 & $100 / 200 / 300 / 400 / 50$ & 00 Encofrado lateral & $\mathrm{m} 2$ & ' 81,90 & D & 14-Abr-16 18:00 A & $14 / 04 / 201607: 00$ & $100 \%$ \\
\hline 9 & S100159 & PIRES & LOSA DE FONDO & UC 59 & $100 / 200 / 300 / 400 / 50$ & $00 \mathrm{Imp}$ losa fondo & $\mathrm{m} 2$ & ' $1.866,00$ & D & $19 / 04 / 201618: 00$ & 0 16/04/2016 07:00 & $33.33 \%$ \\
\hline 10 & S100147 & RAFAEL/VALENCIA & LOSA DE FONDO & UC 58 & $100 / 200 / 300 / 400 / 50$ & 00 Proteccion mecanica & m3 & ' 130,62 & $\mathrm{~N}$ & 14-Abr-16 18:00 A & $14 / 04 / 201607: 00$ & $100 \%$ \\
\hline 11 & $S 100148$ & JAICO & LOSA DE FONDO & UC 58 & $100 / 200 / 300 / 400 / 50$ & 00 Armado & Ton & 204,18 & DN & 19/04/2016 18:00 & 0 14/04/201607:00 & $60 \%$ \\
\hline 12 & A101447 & PIRES & PAREDES DE GALERIA & UC 56 & 11 & $00 \mathrm{Imp}$ pared galeria & $\mathrm{m} 2$ & ' 140,08 & D & 21/03/2016 07:00 & $09-m a y-16$ & $75 \%$ \\
\hline 13 & A101525 & APONTE & LOSA SUPERIOR GALERIA & A UC 54 & $2100(1 / 3)$ & Relleno Hasta Techo Tunel & m3 & '589,00 & & $13 / 04 / 201607: 00$ & 0 14-Abr-16 18:00 A & $100 \%$ \\
\hline 14 & A102065 & APONTE & LOSA SUPERIOR GALERIA & A UC 54 & $2500(1 / 3)$ & Relleno Hasta Techo Tunel & m3 & '578,00 & & $13 / 04 / 201607: 00$ & 0 14-Abr-16 18:00 A & $100 \%$ \\
\hline 15 & A102039 & JAICO & PAREDES DE GALERIA & UC 57 & $1100 \mathrm{~F}$ & Armado & $\%$ & ' 100,00 & DN & $13 / 04 / 201607: 00$ & 0 14-Abr-16 18:00 A & $100 \%$ \\
\hline 16 & A102040 & GIL/ SERVANDO & PAREDES DE GALERIA & UC 57 & $1100 \mathrm{~F}$ & Encofrado & $\%$ & ' 100,00 & DN & $15 / 04 / 201607: 00$ & 0 15-Abr-16 18:00 A & $100.00 \%$ \\
\hline 17 & A102041 & RAFAEL/ VALENCIA & A PAREDES DE GALERIA & UC 57 & $1100 \mathrm{~F}$ & Concreto & $\%$ & $' 100,00$ & $\mathrm{~N}$ & $16 / 04 / 201607: 00$ & 0 16-Abr-16 18:00 A & $100 \%$ \\
\hline 18 & A101758 & RAFAEL/ VALENCIA & A PAREDES & UC 57 & 12 & 200 Concreto & $\mathrm{m} 3$ & 213,00 & $\mathrm{~N}$ & $11 / 04 / 201607: 00$ & 0 11-Abr-16 18:00 A & $100 \%$ \\
\hline 19 & A101759 & REYNALDO / PERCY & PAREDES & UC 57 & 12 & 200 Curado & $\%$ & ' 100,00 & DN & 12/04/2016 07:00 & 18 -abr-16 & $86 \%$ \\
\hline 20 & A101760 & GIL/ SERVANDO & PAREDES & UC 57 & & 200 Desencofrado & $\mathrm{m} 2$ & $' 485,00$ & DN & $14 / 04 / 201607: 00$ & 0 15-Abr-16 18:00 A & $100 \%$ \\
\hline 21 & A101768 & REYNALDO / PERCY & PAREDES & UC 57 & 13 & 300 Curado & $\%$ & ' 100,00 & DN & 08/04/2016 07:00 & 0 14-Abr-16 18:00 A & $100 \%$ \\
\hline 22 & A101769 & GIL/ SERVANDO & PAREDES & UC 57 & & 0 Desencofrado & $\mathrm{m} 2$ & $' 485,96$ & DN & $1 / 04 / 201607: 00$ & 0 12-Abr-16 18:00 A & $100 \%$ \\
\hline 23 & A101777 & REYNALDO / PERCY & PAREDES & UC 57 & 14 & 100 Curado & $\%$ & $' 100,00$ & DN & 09/04/2016 07:00 & 0 15-Abr-16 18:00 A & $100 \%$ \\
\hline 24 & A101778 & JESUS / PEÑALOZA & PAREDES & UC 57 & & Desencofrado & $\mathrm{m} 2$ & 485,96 & DN & 4/2016 07: & 13-Abr-16 18:00 A & $100.00 \%$ \\
\hline 25 & A101786 & REYNALDO / PERCY & PAREDES & UC 57 & & Curado & $\%$ & ' 100,00 & DN & 08/04/2016 07: & 0 14-Abr-16 18:00 A & $100 \%$ \\
\hline 26 & A101787 & JESUS / PEÑ́ALOZA & PAREDES & UC 57 & 15 & 500 Desencofrado & $\mathrm{m} 2$ & $' 485,00$ & DN & $11 / 04 / 201607: 00$ & 0 12-Abr-16 18:00 A & $100 \%$ \\
\hline
\end{tabular}

Paso 2: Una vez que tenemos la información en Excel, empleamos una fórmula con la función "=consultav" para buscar mediante el ID de actividad cuales de las actividades programadas para la semana fueron realizadas y en cuanto porcentaje, asimismo se identifican las actividades realizadas fuera de la programación, estas no se consideran en el cálculo del PPC pero si son incluidos en el reporte de avance de producción semanal; seguidamente realizamos la diferencia entre el porcentaje actual acumulado y el porcentaje acumulado de la semana anterior. 


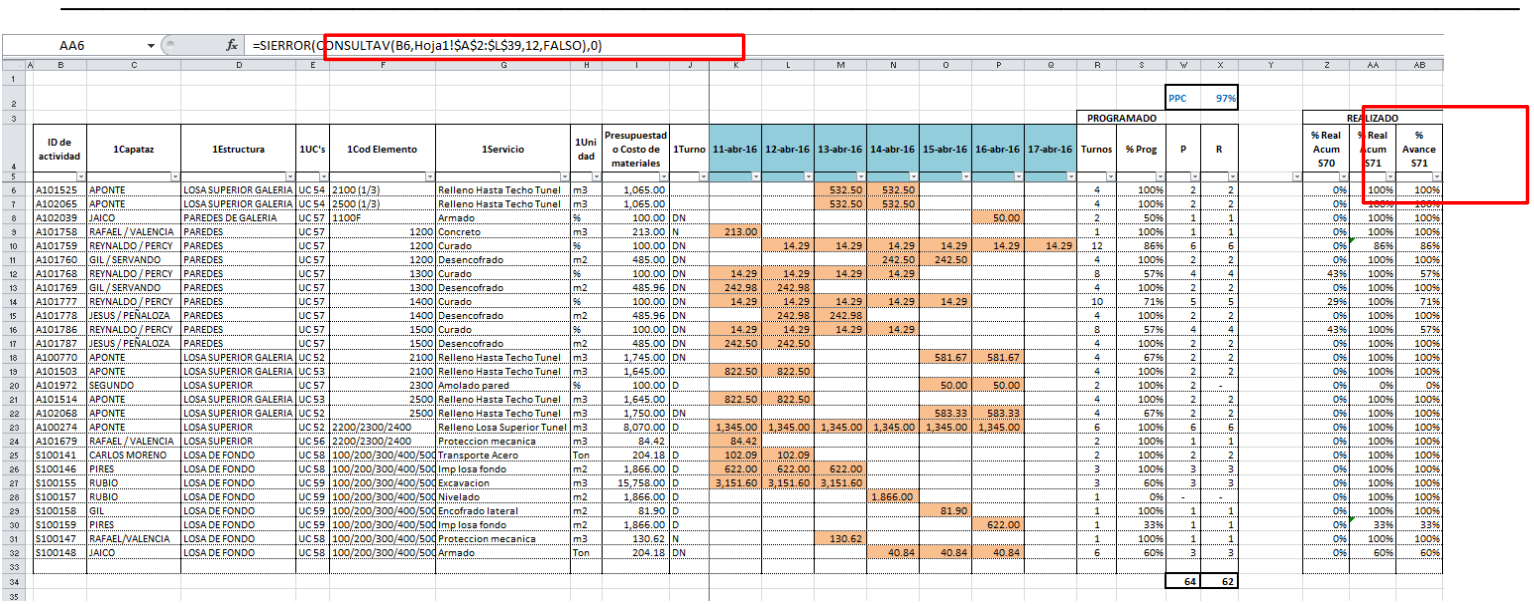

El cálculo de PPC se basa en la relación entre la cantidad de servicios ejecutados y la cantidad de servicios programados durante la semana.

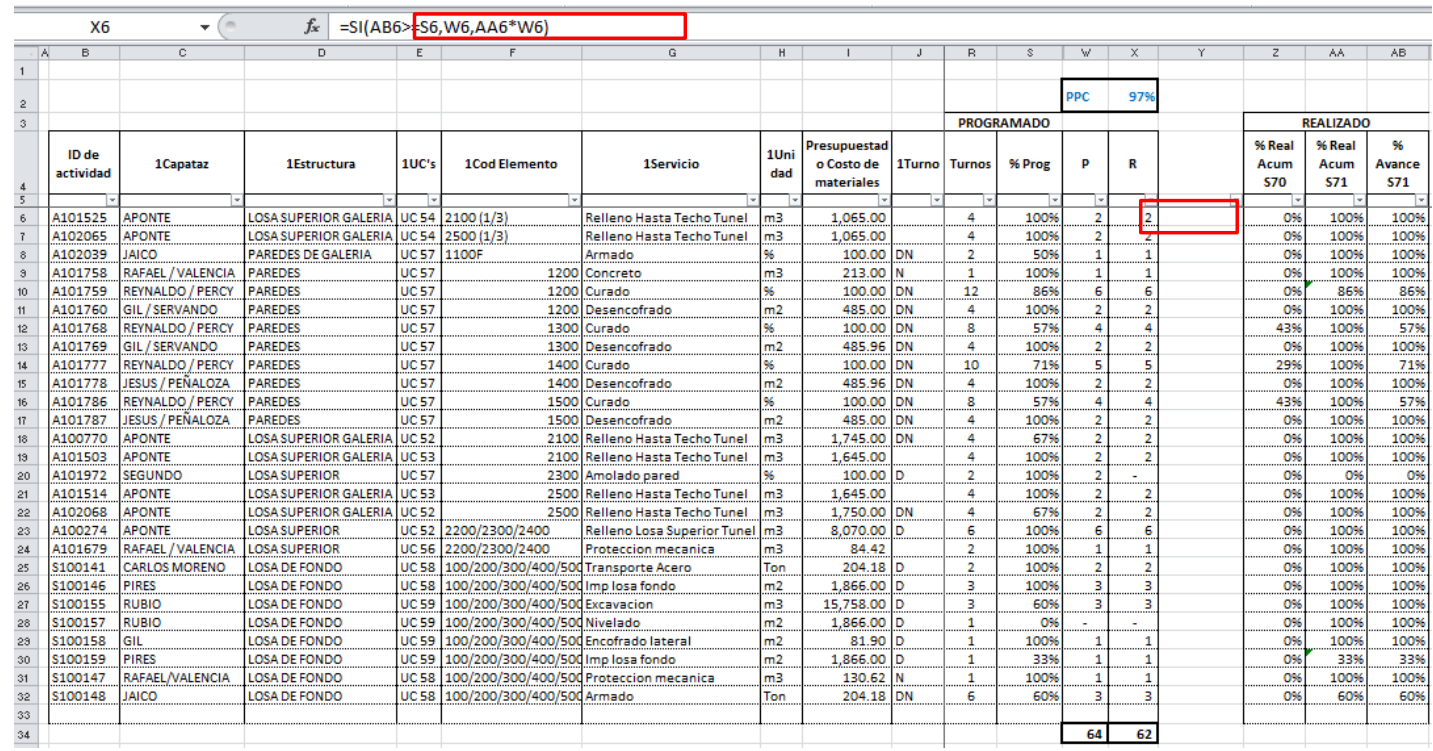

Paso 3: Luego de tener los datos anteriores construimos una tabla dinámica para tener el PPC por capataz y por responsable. 


\section{PPC de Capataces}

\begin{tabular}{|c|c|c|c|}
\hline Etiquetas de fila & - Suma de P & Suma de R & Suma de PPC \\
\hline PIRES & 4 & 4 & 100.0 \\
\hline RAFAEL I VALENCIA & 2 & 2 & 100.0 \\
\hline SEGUNDO & 2 & 0 & - \\
\hline JESUS I PENÁALOZA & 4 & 4 & 100.0 \\
\hline CARLOS MORENO & 2 & 2 & 100.0 \\
\hline JÄICO & 4 & 4 & 100.0 \\
\hline RUBIO & 3 & 3 & 100.0 \\
\hline APONTE & 18 & 18 & 100.0 \\
\hline REYNALDO I PERCY & 19 & 19 & 100.0 \\
\hline TELMO & 41 & 30 & 72 \\
\hline GIL & 1 & 1 & 100.0 \\
\hline GIL I SERVANDO & 4 & 4 & 100.0 \\
\hline RAFAELWALENCIA & 1 & 1 & 100.0 \\
\hline Total general & 105 & 91.594 & 87 \\
\hline
\end{tabular}

\section{PPC de Supervisores}

\begin{tabular}{lrrrr|} 
Etiquetas de fila & $\nabla$ & Suma de $P$ Suma de R & Suma de PPC \\
\hline CHAMORRO & 21 & 21 & 100 \\
PALACIOS & 10 & 10 & 100 \\
PIRES & 4 & 4 & 100 \\
RICHARD & 23 & 21 & 91 \\
JOEL & 2 & 2 & 100 \\
PELAEZ & 41 & 29.594 & 72 \\
JAICO & 4 & 4 & 100 \\
\hline Total general & $\mathbf{1 0 5}$ & $\mathbf{9 1 . 5 9 4}$ & $\mathbf{8 7}$
\end{tabular}

\section{PPC de Encargados de Frentes}

\begin{tabular}{|l|rrr|}
\hline Etiquetas de fila & $\boldsymbol{\nabla}$ & Suma de P Suma de R & Suma de PPC \\
\hline OTAVIO & 84 & 70.594 & 84 \\
CHAMORRO & 21 & 21 & 100 \\
\hline Total general & $\mathbf{1 0 5}$ & $\mathbf{9 1 . 5 9 4}$ & $\mathbf{8 7}$
\end{tabular}

Paso 4: Con los datos obtenidos se construye un cuadro de indicadores en el formato ya establecido. 
UNIVERSIDAD PERUANA DE CIENCIAS APLICADAS

Laureate International Universities ${ }^{\circledR}$

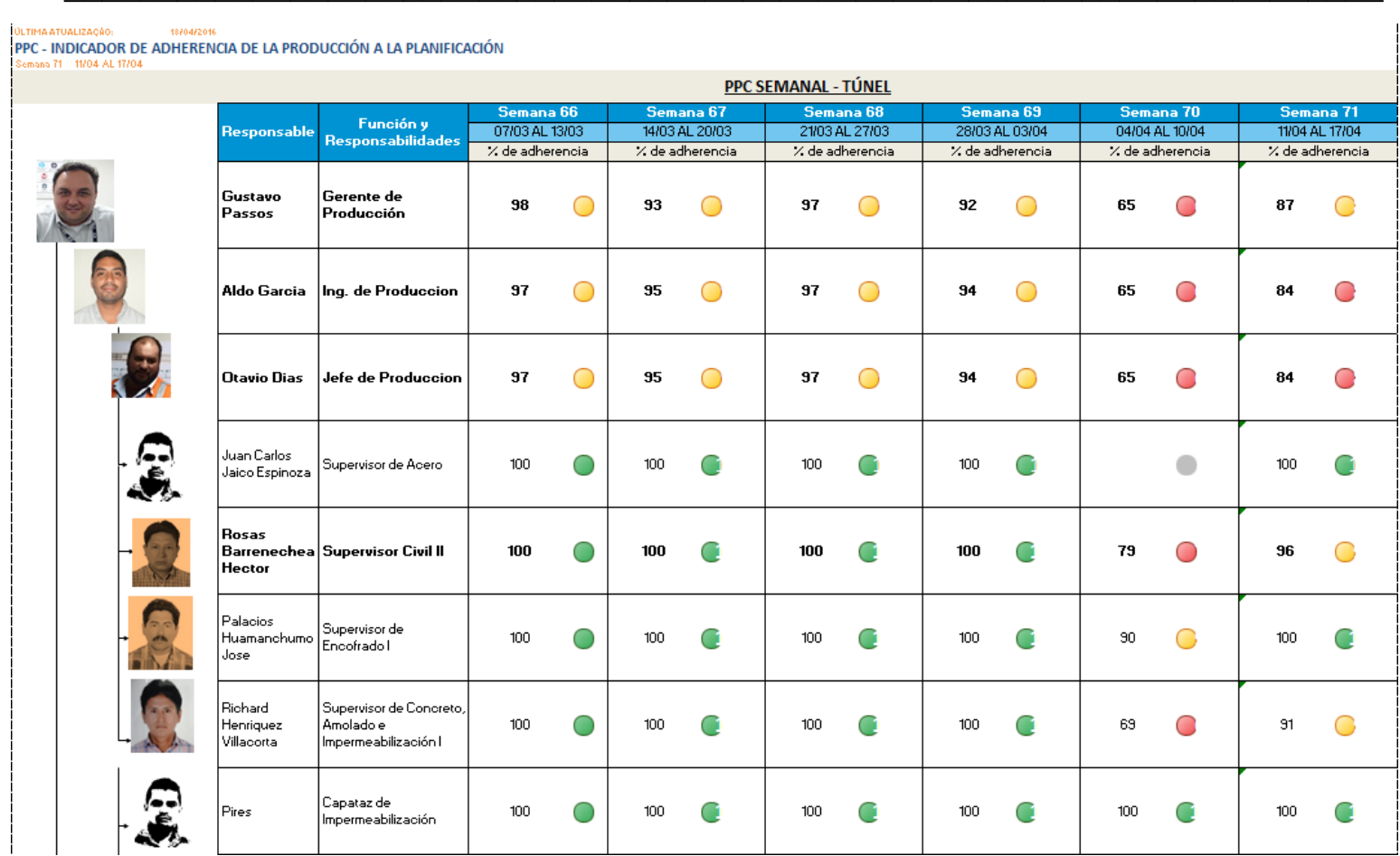

